\title{
'Early' and 'late' class III drugs for the treatment of atrial fibrillation : a pre-clinical study in the goat
}

Citation for published version (APA):

Blaauw, Y. (2005). 'Early' and 'late' class III drugs for the treatment of atrial fibrillation : a pre-clinical study in the goat. [Doctoral Thesis, Maastricht University]. Universitaire Pers Maastricht. https://doi.org/10.26481/dis.20050527yb

Document status and date:

Published: 01/01/2005

DOI:

10.26481/dis.20050527yb

Document Version:

Publisher's PDF, also known as Version of record

\section{Please check the document version of this publication:}

- A submitted manuscript is the version of the article upon submission and before peer-review. There can be important differences between the submitted version and the official published version of record.

People interested in the research are advised to contact the author for the final version of the publication, or visit the DOI to the publisher's website.

- The final author version and the galley proof are versions of the publication after peer review.

- The final published version features the final layout of the paper including the volume, issue and page numbers.

Link to publication

\footnotetext{
General rights rights.

- You may freely distribute the URL identifying the publication in the public portal. please follow below link for the End User Agreement:

www.umlib.nl/taverne-license

Take down policy

If you believe that this document breaches copyright please contact us at:

repository@maastrichtuniversity.nl

providing details and we will investigate your claim.
}

Copyright and moral rights for the publications made accessible in the public portal are retained by the authors and/or other copyright owners and it is a condition of accessing publications that users recognise and abide by the legal requirements associated with these

- Users may download and print one copy of any publication from the public portal for the purpose of private study or research.

- You may not further distribute the material or use it for any profit-making activity or commercial gain

If the publication is distributed under the terms of Article $25 \mathrm{fa}$ of the Dutch Copyright Act, indicated by the "Taverne" license above, 
(i) Yuri Blaouw, Madshicht 2005

ISBN 9052784604

Production by Dotomyse / Uniwersitaire Pers Moostricht 


\title{
'Early' and 'Late' Class III Drugs for the Treatment of Atrial Fibrillation A Pre-clinical Study in the Goat
}

\author{
Proefschrift \\ ter verkrijging van de graad van doctor \\ aan de Universiteit Maastricht \\ op gezag van de Rector Magnificus, Prof. mr. GPMF Mols \\ volgens het besluit van het College van Decanen \\ in het openbaar te verdedigen \\ op vrijdag 27 mei 2005 om 14.00 uur \\ door
}

Yuri Blaauw

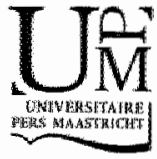




\section{Promotor}

Prof.dr. MA Allessie

\section{Beoordelingscommissie}

Prot.dr. HJGM Crins (voorzitter)

Prof.dr. H Gögelein (Aventis-Sanofi, Frankfurt)

Prol.dr. S Nattel (Montreal Heart Instifuie and University of Montreal, Montreal) Prot.dr. MJ Post

Prof.dr. HAJ Struiker Boudier

The sudies in this thesis were supported by grants 902 -16-097 and $920-033-122$ from the Netharlands Organization bor Scientific Research

Additional Inancial support was granted by: $3 \mathrm{M}$ Phorma Nederland, Boehringer lngellhem, Guidan, Medtronic-Bakken Reseandy Center, Prizer, Sanoli Aventis. Resicar Foundation Maustricht 
Voor Thea en Koen 


\section{Contents}

Prologue

Chapter 1. Pre-Clinical Models of AF: What Lessons have we Learned?

Chapter 2. Inhibitors of the $\mathrm{Na}^{+} / \mathrm{H}^{+}$Exchanger Cannot Prevent Atrial Electrical Remodeling in the Goat

Chapter 3. Consequences of Atrial Electrical Remodeling for the Anti-Arrhythmic Action of Class IC and Class III Drugs

Chapter 4. 'Early' Class III Drugs for the Treatment of Atrial Fibrillation: Efficacy and Atrial Selectivity of AVEO1 18 in Remodeled Atria of the Goat

Chapter 5 . The Combination of $I_{K_{u}} / l_{\mathrm{Ho}^{-}}$and $I_{\mathrm{Kr}_{r}}$-Blockers for Effective Cardioversion of Persistent Atrial Fibrillation in the Goat

Chapter 6. Long-Term Changes in Sequence of Atrial Activation and Refractory Period: No Evidence for 'Atrial Memory' in the Goat

Chapter 7. Preferential Class III Action of Dotetilide on the Bundle of Bachmann. A Critical Determinant for the Initiation of Atrial Fibrillation in the Goat

Future Perspectives

Samenvatting

Dankwoord

Curriculum Vitae 


\section{Prologue}

Atrial fibrillation (AF) is a common arrhythmia that affects about $0.4 \%$ of the general population and its incidence increases with age to $-6 \%$ in patients over the age of 80 years. "Atrial fibrillation is associated with a significant morbidity and mortality. ${ }^{2.4}$ Strategies for the treatment of AF aim at reducing symptoms and improving long-term prognosis. Basically, this can be achieved by slowing down the fast ventricular heart rate during AF ('rate' control) or by restoring the normal sinus thythm and preventing recurrences of AF ("rhythm" control).

The hallmark of the treatment of AF has been the use of anti-arrhythmic drugs. Already back in 1918 Walter Frey described the anti-fibrillatory action of quinidine. ${ }^{5}$ At present, more than 80 years later, several anti-arrhythmic drugs are available for the treatment and prevention of AF. Unfortunately, so far the clinical use of anti-arrhythmic drugs for AF has been far from successful. Most drugs are only moderately effective in restoring sinus rhythm. For example, the commonly used class $1 C$ drug flecainide and the class III drug ibutilide can terminate AF in $\sim 60$ to $80 \%$ of the patients if they are treated within the first 1-3 days after the onset of the arrhyth mia. ${ }^{6.10}$ In contrast, if the arrhythmia is present for a longer period of time, pharmacological cardioversion is only successful in 20 to $30 \%$ of the patients. ${ }^{6,9,11}$ Also, anti-arrhythmic drugs have not been very effective in preventing AF, In a large Canadian trial (CTAF) it was demonstrated that despite 1 year treatment with amiodarone, dl-sotalol or propafenone still respectively 31,61 and $61 \%$ of the patients experienced a recurrence of the arrhythmia. ${ }^{12}$ Besides being only moderately effective, anti-arrhythmic drugs are also poorly tolerated. In the large AFFIRM-trial (Atrial Fibrillation Follow-Investigation of Rhythm Management) it was shown that respectively $12.3,11.1$ and $28.1 \%$ of patients receiving amiodarone, sotalol and class I drugs discontinued their medication because of side effects. ${ }^{13}$ Anti-arrhythmic drugs may cause serious ventricular pro-arrhythmia. Large clinical trials even demonstrated an increased mortality of flecainide or encainide in patients with a previous myocardial infarction. ${ }^{14}$ For these reasons, alternative (non-pharmacological) treaiment strategies have been developed, including catheter ablation, ${ }^{15}$ surgery and pacemakers. ${ }^{13,18}$ However, because of the large number of people with AF, the only way to manage AF in the general population is to use safe anti-arrhythmic drugs.

In the last decade important progress has been made in the understanding of the electrophysiological mechanism of AF. In 1995 Wijffels et al. published a paper in which they showed that 'AF begets. AF' because of AF-induced atrial remodeling. 19 In this experimental study it was demonstrated that repetilive induction of AF by burst pacing, progressively prolonged the duration of AF-episodes until after 1.2 weeks the arrhythmia no langer terminated spontaneously anymore. The underlying 
electrophysiological mechanism proposed was a progressive shortening of the atrial action potential that produced a substrate for AF by decreasing the wavelength of the fibrillation waves. ${ }^{20.21}$ Since then, others have demonstrated electrical atrial remodeling in different species, including man. ${ }^{22,23}$ At a cellular level, several changes have been described and downregulation of the L-type $\mathrm{Ca}^{2+}$ current has been shown to play a central role in the shortening of the atrial action potential. ${ }^{23}$

\section{OBJECTIVES OF THE STUDY}

In my thesis I evaluated the electrophysiological effects of experimentally and clinically available anti-arrhythmic drugs in a goat model of AF. An impontant focus was to investigate the consequences of AF-induced electrical remodeling for the action of anti-arrhythmic drugs. It was hypothesized that due to AF-induced shortening of the action potential, the sensitivity for specific channel blockers may be altered. This hypothesis is supported by the clinical observation that the efficacy of anti-arrhythmic drugs declines when AF persists for a longer period of time.

In Chapter 1 several animal models of AF are compared and their clinical relevance is discussed. In Chapter 2 we evaluated the anti-arrhythmic properties of two $\mathrm{Na}^{\prime} / \mathrm{H}^{*}$ exchanger blockers EMD125021 and EMD87580. The rationale behind this study was the hypothesis that prevention of atrial acidosis during AF by blocking the $\mathrm{Na}^{+} / \mathrm{H}^{*}$ exchanger could prevent or revert AF-induced electrical remodeling. In chapter 3 we describe the effects of AF-induced electrical remodeling on the action of class IC and class III drugs (flecainide, d-sotalol and ibutilide). In chapter 4 we evaluated the anti-arrhythmic properties of a novel drug AVEO 118 that blocks $\left.\right|_{\text {Kur }} I_{\text {to }}$ and $I_{\text {Kach }}$ currents. This drug is believed to have a selective class III action on the atria. In chapter 5 we evaluated the effects of combined administration of AVEO 118 with the currently available $I_{k}$ blockers. We demonstrate in goats with persistent AF that this drug combination could restore sinus rhythm in $100 \%$ of the cases. In Chopter 6 we evaluated whether the spatial distribution of the atrial refractory period and the vulnerability to AF are altered by long-term changes in the sequence of atrial activation. In chapter 7 we explored whether the class III drug dofetilide may facilitate the initiation of AF by increasing atrial refractoriness on Bachmann's bun. dle.

\section{REFERENCES}

1. Kannel WB, Woll PA, Benjamin EJ, Levy D: Prevalence, incidence, prognosis, and predisposing conditions for atrial Hibrillation: population-based estimates. Am J Cardiol 1998;82:2N-9N.

2. Krahn AD, Mantreda J, Tale RB, Mathewson FA, Cuddy TE: The natural history of atriall librillation: incidence, risk foctors, and prognosis in the Manitoba Follow-Up Study. Am I Med $1995 ; 98: 476-484$.

3. Flegel KM, Shipley ML, Rose $G$ : Risk of stroke in non-sheumatic atrial fibrillation. Lancet $1987 ; 1: 526-529$ 
4. Konnel WB, Abbott RD, Savage DD, McNamara PM: Coronony hear disease and atriol librillation: the Framingham Study. Am Hear 1 1983:106:389-396.

5. Frey W: Uber vorhoflimmern bein menschen und seine beseigung durh dhinidin. Bert Klin Wochenschr 1918,55.

6. Vos MA, Golisyn SR, Stangl K, Ruda MY, Van Wijk IV, Harry JD, Perry KT, Touboul P, Steinbeck $G$,

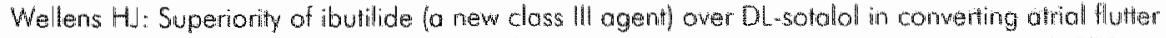
and atrial fibrillation. The Ibutilide/Sotalol Comparator Study Group. Heart 1998,79:568.575.

7. Crijns HJ, van Wijk LM, wan Gilst WH, Kingma JH, wan Gelder KC, Lie KJ: Acute conversion of atrial fibrillation to sinus thythm: dinical efficacy of flecainide acetate. Comparison of two regimens. Eur Hear' $17988 ; 9: 634-638$.

8. Suttorp MJ, Kingma JH, Lie AHL, Masł EG: Intravenous llecainide versus verapamill for acute conversion of paroxysmal atrial fibritlation or flutier io sinus rhythm. Am J Cardiol 1989;63:693-696.

9. Volgman AS, Carberry PA, Stambler B, Lewis. WR, Dunn GH, Perry KT, Vonderlugt IT, Kowey PR: Conversion efficacy and safety of intravenous ibutilide compared with intravenous procainamide in patients with atrial flutter or fibrillation. J Am Coll Cordiol 1998;31:1414-1419.

10. Domanovits $H$, Schillinger $M$, Thoennissen J, Nikfardjam $M$, Janata $K$, Brunner $M$, Laggner $A N$ : Tar. mination of recent-onset atrial fibrillation/flutter in the emergency depatment: a sequential approach with intravenous ibutilide and extemal electrical cardioversion. Resuscitation 2000;45:181-187.

11. Ellenbogen KA, Stambler BS, Wood MA, Sager PT, Wesley RC, Jr., Meissner MC, Zoble RG, Wakefield LK, Perry KT, Vanderllugt JT: Efficacy of intravenous ibutilide for rapid termination of atriall fibrillation and atrial flutter: a dose-response siudy. J Am Coll Cardial 1996;28:130-136.

12. Rioy D, Talaijic M, Dorian P, Connolly S, Eisenberg MJ, Green M, Kus T, Lambert J, Dubuc M, Gagne P. Nattel S. Thibault B: Amiadorone to prevent recurrence of atrial filarillation. Canadian Trial of Atrial Fibrifllation Investigators. IN Engl J Med 2000;342:913-920.

13. Maintenance of sinus rhythm in palients with atrial fibrillation: an AFFIRM substudy of the first antiarrhythmic drug. I Am Coll Cardiol 2003;42:20-29.

14. Echt DS, Liebson PR, Mitchell LB, Pelers RW, Obios-Manno D, Barker A.H, Arensberg D, Baker A,

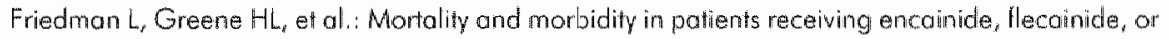
placebo. The Cardiac Arrhythmia Suppression Trial. N Engll J Med 1991,324:781-788.

15. Haissaguerre $M$, Jain $P$, Shah DC, Takahashi $A$, Hocini $M, Q$ Quniou $G$, Garrigue $S$, Le Mouroux $A$, Le

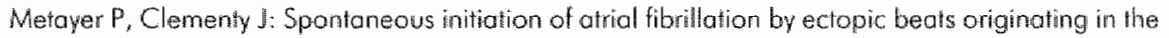
pulmonary veins. N Engl I Med 1998;339:659-666.

16. Cox JL: Cardiac surgery for arrhythmias. J Cardiovasc Electrophysiol 2004; 15:250-262.

17. Friedman PA, Dijkman B, Warman EN, Xia HA, Mehro R, Stonton MS, Hammili SC: Atrial therapies reduce atrial arrhythmic burden in defibrillotor potients. Circulation 2001; 104:1023-1028.

18. Wellens HJ, Lou CP, Luderitz B, Akhtar M, Waldo AL, Camm AJ, Timmemans $C$, Tse HF, Jung W, Jordaens $L$, Ayers $G$ : Arriovertier: an implantable device lor the treatment of arial librillation. Circu. Uotion 1998:98:1651-1650

19. Wiffels MC, Kirchhor C., Dorland R. Allessie MA: Arrial fibrillation begets alrial fibrillation. A sludy in awake chronically instrumented gooss. Circulation 1995;92:1954-1968.

20. Mae GK, Abildskov JA: Atrial fibrillation as a self-sustaining arthythmia independent of focal dis. chorge. Am Heart J 1959:58:59-70.

21. Allersie M, Lammers WJ. Bonke Fl, Hollen J. Experimental evalualion of Moe's multiple wavellet hypothesis of atrial fibriltation. Orlondo: Grune and Sratton; 1985.

22. Fronz MR, Karasik PL, LI C. Moubarak I, Chavez M: Electrical remodeling of the humon atrium: silmilar affects in patients with chronic atrial fibrillation and atrial flutter. J Am Coll Cardiol 1997;30:1785-1792

23. Yue L, Feng J, Gospo R, Li GR, Wang $Z$, Nattel S: Ionic remodeling underlying action potential changes in a canine model of atrial fibrillotion. Circ Res 1997:81:512-525. 
CHAPTER

\section{Pre-Clinical Models of AF: What Lessons Have We Learned ?}

Yuri Blaauw, MD; Ulrich Schotten, MD, PhD; Maurits Allessie, MD, PhD.

Book Chapter in "Atrial Fibrillation". Editors: Peter Kowey, Gerald Naccarelli. December 2004. 


\section{INTRODUCTION}

Atrial fibrillation (AF) is a common arrhythmia responsible for a substantial marbidity' and martality ${ }^{2}$ in the general population. It affects mainly the elderly, with a prevalence of $0.5 \%$ in patients aged 50 to 59 years, incrementing to almost $9 \%$ in men aged over 80 years. ${ }^{3}$ Atrial fibrillotion sometimes occurs in individuals withoul cardiac abnormalities (lone atrial fibrillation). ${ }^{4}$ More often it is associated with an underlying heart disease such as hypertension, walvular disorders, coronary artery disease, and/or congestive heart failure. ${ }^{3}$

In the last century, several animal madels of atrial fibrillation were developed. This has led to a considerable improvement in our understanding of the mechanisms of the arrhythmia. The aim of the current chapter is to review the various animal madels of atrial fibrillation and assess what they have taught us about the treatment of AF.

\section{AF is due to Multiple Mechanisms}

Atrial fibril lation can easily be diagnosed on the basis of the characteristic features of the surface electrocardiogram. However, this does not provide much information on the many possible causes and mechanisms of the arrhythmia in individual patients. Experimental and clinical studies have revealed that AF has several different etiologies and that the mechanisms by which AF sustains itself are diverse. Atrial fibrillation can be perpetuated by either a single source or by multiple sources. In Figure 1, different mechanisms of AF are presented schematically. Some of them are still hypothetical; others have been demonstrated experimentally or clinically.

\section{Single-Source AF}

An important characteristic of AF 'driven' by a single source is that the arrhythmia should terminate after elimination of the rapid source.

Automatic Focus: In this type of AF, an automatic focus is present, which fires so rapidly that the atria cannat follow $1: 1$ (fibrillatary conduction). Clinical studies have shown that the vast majority of these atrial ectopic foci are located in the myocardial 'sleeves" of the pulmonary veins. ${ }^{5}$

Mather Wave: This is a single stable macroreentrant circuit with a short cycle length and a fixed anatomically or functionally defermined pathway. The high frequency of the reentrant circuit leads to fibrillatory conduction in the rest of the atria. Interruption of the circulating mother wave should terminate AF.

Fixed Rotor: AF can also be 'driven' by a stable fixed microreentrant circuit with a high frequency.

Moving Rotor: This is AF driven by a stable microreentrant circuit driffing through the atria. AF results because the rest of the atrium cannot follow the high frequency in a 1: I fashion. Rotors may have preferential locations determined by anatomical and functional properties of the atria. 


\section{Single Source}

Automatic Focus

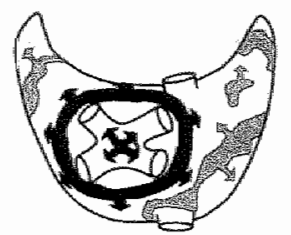

Multiple Foci

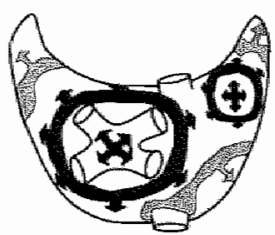

Mother Wave

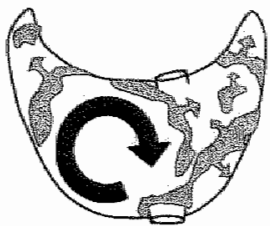

Multiple Sources

Unstable Circuits

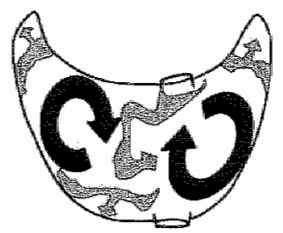

Fixed Rolor

Moving Rotor
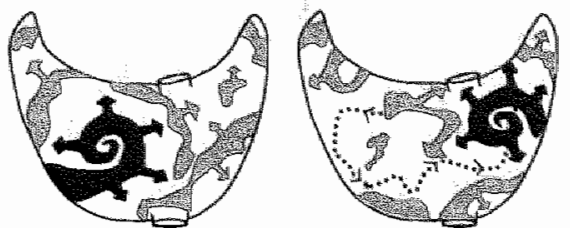

Figure 1: Schemolic representation of the different mechanism that can give rise to atrial fibrillation. See fext for details.

\section{Multiple-Source AF}

Multiple Foci: Foci due to enhanced automaticity can be present at multiple sites. In this case the successful elimination of one of these foci will not restore sinus rhythm.

Multiple Circuits: Multiple reentrant circuils may co-exist in the atria. Their circular pathways can be anatomically or functionally determined. Because they are multiple, the circuits do not have to be stable in order to perpetuate AF.

Multiple Wavelets: The atria are activated with a high frequency by multiple wavelets wandering simultaneausly through the atrial myocardium. The pathways of the wavelets are determined by the anatomical and functional properties of the atrial wall. While traveling through the atria, the wavelets often reenter the tail of refractoriness of other waves (random reentry). Incidentally they can also reenter their own refractory tail. However, stable rotors are not observed during this type of AF. The stability of AF depends on the number of wavelets that 'fit' on the atrial surface. The shorter the wavelength of the atrial impulse, the more wavelets will co-exist and the less likely AF will terminate. Prolongation of the wavelength by class III drugs reduces the number of wavelets and teminates AF.

Facus and Multiple Wavelets: It is not unlikely that different mechanisms of AF can be operative at the same time. If a rapid focus exists together with randomly re- 
entering multiple wavelets, atrial hbrillation will be highly persistent or even permanent.

\section{Aconitine-induced AF}

Already in 1907, Winterberg 6 proposed that AF can originate from a single automatic focus. Experiments by Scherf al al confirmed this hypothesis. Local application of aconitine (a sodium channel apener) on canine atria induced a rapidly firing focus that, depending on the frequency, created either atrial futter or fibrillation. When the facus was eliminated by clamping off the site of aconitine application, the arrhythmic stopped. This is illustrated in Figure 2. In this experiment pertormed by Moe and Abildskow, AF was induced by injecting aconitine in the tip of the atrial appendage. To investigate whether the focal discharge was responsible for perpetuation of $\mathrm{AF}$, the facus was isolated from the rest of the atrium by clamping the atrial appendage. Indeed, ofter electrical is olation of the appendage, the arrhythmia was promptly terminated.

In a recent clinical study, Haissaguerre and co-workers ${ }^{5}$ demonstrated that in pafients with paroxysmal AF, fibrillation was initiated by a rapidly firing focus in the pulmonary veins. Selective ablation of these foci strongly reduced the number of AF episodes; in many patients, anti-arrhythmic drugs could be discontinued. The ionic electrophysiological mechanism underlying the rapid focal activity is not clear. It is also not understood whether these foci act solely as the trigger to start AF or whether they also act as a 'driver' that perpetuates the arrhythmia. So far, only anecdotal reports have shown that chronic AF can be terminated by focal ablation inside the pulmonary veins." Circumferential radiofrequency ablation of the pulmonary weins has been reported to cardiovert long-lasting chronic AF in some patients. 10 However, it is important to note that this rather extensive ablation procedure will not only isolate the trigger within the pulmonary veins but also affects the substrate of AF by markedly reducing the atrial tissue mass of the diseased left atrium (debulking). Although the dinical outcome of pulmonary vein ablation is often beneficial, complete and permanent electrical isolation of the veins is seldom accomplished." This raises the question of whether alternative mechanisms like a reduction of atrial mass, autonomic denervation, or interruption of critical reentry crossroads may explain the clinical efficacy of pulmanary vein ablation.

\section{Vagal AF}

The autonomic nervous system, in particular the vagal nerves, has been recognized to play an importan role in the initiation and perpetuation of atrial fibrillation. Already in 1897, Knol12 observed that AF often occurred during vagal stimulation in rabbits and dogs. In 1915, Rothberger and Winterberg ${ }^{13}$ showed that AF could easily be induced during vagal stimulation in normal canine atria. Figure 2 demonstrates the importance of the vagal nerves for the stability of AF. When the driver of AF (aconitine) was eliminated by clamping the atrial appendage, AF persisted when 
A.
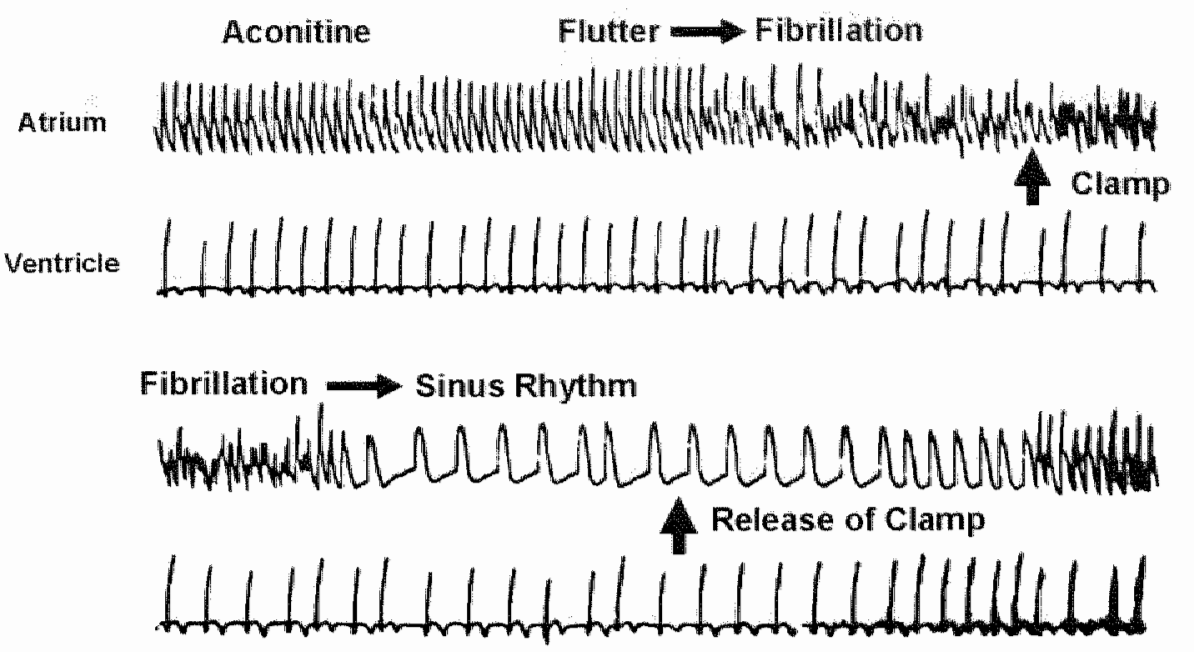

Figure 2A: Demonstration of AF 'driven' by a rapidly firing focus. Shown are electrograms recorded from the right atrium and ventricle. Injection of aconitine into the atrial myocordium resulied in the de. generotion of atrial flutter into fibrillation. Isolation of the site of injection from the rest of the atrium by clamping the atrial appendage caused the arrtythmia to terminate. When the clamp was released, atrial fibrillation restarfed.

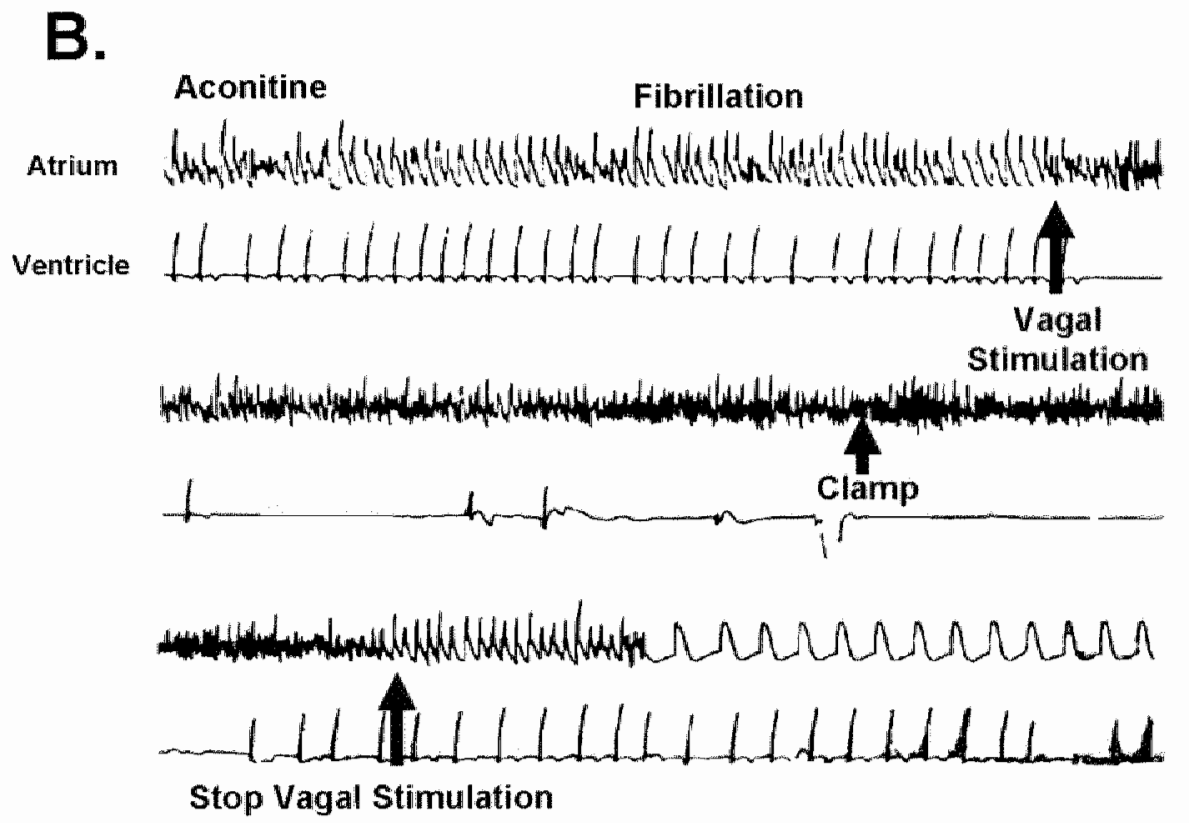

Figure 2B: lllustration of the elfect of wagal simulation on the stability of AF. Shown are the same lracings as in $2 \mathrm{~A}$. Aconitine injection into the right alrial appendage resulted in $A F$. When the vagal nerve wos stimulated, the rate of fibrill ation accelerated. Isalation of the aconitine focus by clamping of this point did not terminate the arrythmia. When vagal stimulatian was stopped, atrial fibrillation slawed down and sirnus thythm resumed. (From Moe and Abillskov") 
the vagal nerves were stimulated. To demonstrate that vagal stimulation was re sponsible for the maintenance of AF, vagal stimulation was stopped (see arrow in Figure 2). This led to prompt termination of $A F$.

Induction of AF by vagal stimulation, either by direct stimulation of the vagal nerve or by intravenous infusion of cholinergic agents, is an estrbblished way to induce AF. The main underlying electrophysiologica mechanism is a shortening of the atrial refractory period and passibly an increase in the spatial dispersion of refractoriness. "When a premature impulse encounters an area of prolonged refractoriness, the wavefrant will be blocked lacally, while in other directions (with shorter retractory periads) it will be propagated. When the time required for the impulse to travel around the area of block exceeds the refractory period of the cells proximal to the area of block, these cells will be re-excited by the returning wavefront and a re-entrant arthythmia will be initiated. Not only the induction but also the persistence of fibrillation is facilitated by vagal stimulation. When the refractory period shortens, the length of the fibrillation waves will decrease and AF may become sustained because more wavelets can now circulate simultaneously in the atria. The multiple wavelet hypothesis of Moe ${ }^{8}$ was experimentally confirmed by Allessie et at. ${ }^{15}$ in isolated canine atria perfused with acetylcholine. Using a multi channel mapping system, they recorded the electrical activity from several hundred atrial sites. It was found that a critical number of four to six wavelets was required to sustain AF. The experiments by Wang et al. " are in line with this observation. In a canine model of vagal AF, they demonstrated that class $I C$ drugs terminated AF by decreasing the number of wavelets. In 1992, Schuessler et al ${ }^{\text {"p }}$ demonstrated that, at high dosages of acetylcholine, a single rotor with a very short cycle length of $\sim 40 \mathrm{~ms}$ caused fibrillatory conduction in the rest of the atria. The small functionally determined reentry circuit was either stationary or drifted slowly through the atrial wall. In addition, these authors demonstrated that in specific regions activation of the epicardium was discordant from the endocardial surface. ${ }^{13}$ The role of anatomical heterogeneities for the pattern of atrial activation during AF was further supported by Wu et al. ${ }^{19}$ In isolated canine atria, they found that pectinate muscles were involved in lines of conduction block, thus allowing stationary reentry. Also, in isolated perfused sheep heart, Skanes et al.20, demonstrated that in the presence of acelylcholine, single sources of micro-reentry of very rapid rates caused loss of $1: 1$ conduction in other parts of the atria. Mandapati et al. ${ }^{21}$ demonstrated that these rotors were predominantly located in the posterior left atrium. However, evidence that such a mechanism is responsible for clinical AF is as yet lacking.

Although the above mentioned experiments have contributed significantly to our understanding of the mechanism of AF, one must be cautious in extrapolating these obsenations to clinical arrhythmias. First of all, it is important to note that contrary to mast clinical cases of AF, no structural abnormalities are present in the atria in most animal studies. It is also questionable whether the extreme shortening of atrial refractoriness by vagal stimulation is encountered in patients. After the first description of vagal AF by Coumel et al., ${ }^{22}$ several studies addressed this issue. In most studies, the neurohumoral activity was evaluated by analysis of heart rate variability. 

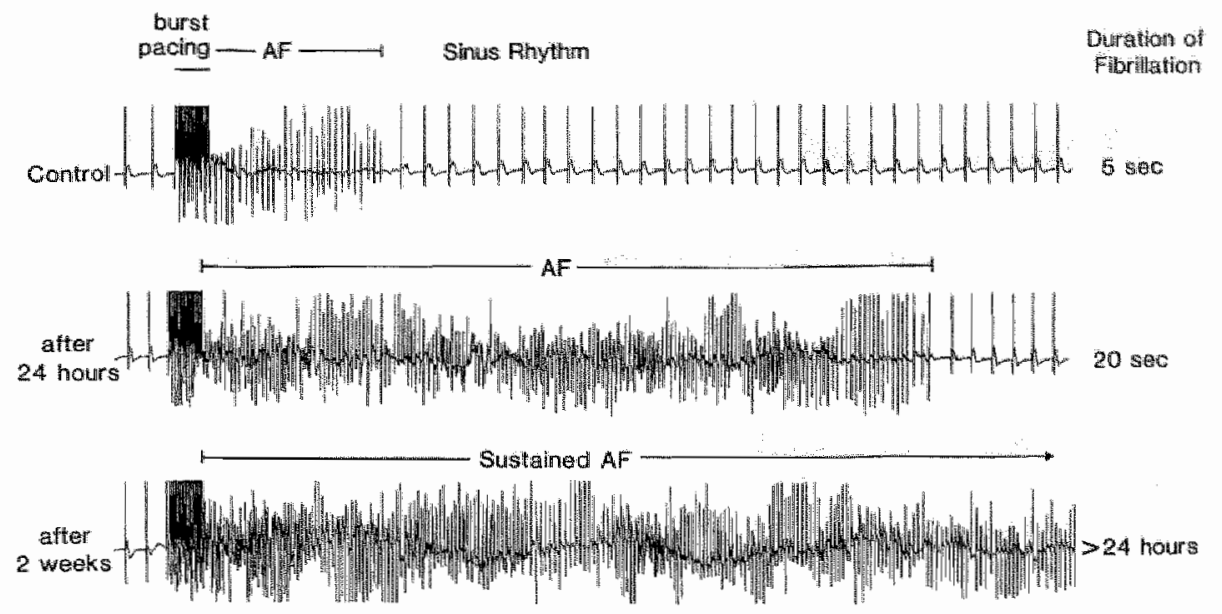

$2 \sec$
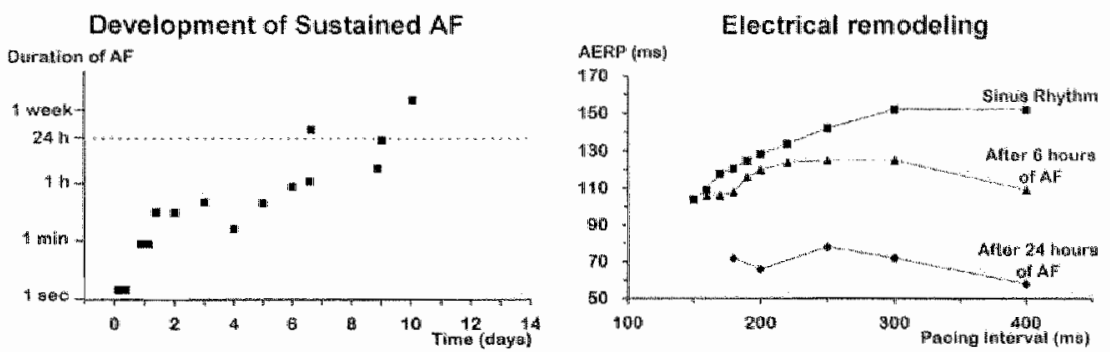

Figure 3: The gool model of AF. Upper ponel: lnductian of AF by burst pacing. An atrial bipalar electrogram was continuously analyzed by a custom-made fibrillation pacemaker. As soon as sinus thythm occurred a burst of stimuli was given to renduce AF. In this way AF could be maintained 24 hr a day, 7 days a week. Heft lower parell: Time course of the development of sustained AF. In the example shown, Af became persistent (>24 hours) after 7 to 10 days of artificially maintained AF. Lower right panel: AF induced of tial electrical remodeling. After 6 so 24 thr of AF, the refraciary period had short ened and the physiological rate adaptation was lost. (from Wiffels et al. ${ }^{58}$ ).

No consistent picture regarding the onset of AF can be derived from these studies. While in some studies vagal tone was found to be increased ${ }^{23.24}$ other studies demonstrated a predominance of sympathetic activity. ${ }^{25.26}$ Also, the circadian pattern of onset of paroxysmal AF does not support the concept of vagally induced AF. Since vagal tone is higher during the night, one would expect most episodes of AF to occur during the night. In contrast, Irwin ef al. ${ }^{27}$ and Kupari et al. ${ }^{28}$ found that most paroxysms of AF actually occurred during the day.

\section{AF-induced Atrial Remodeling}

Clinical studies have shown that atrial fibrillation is progressive in nature. In many patients with paroxysmal AF the arrhythmia tends to become persistent with time. ${ }^{29}$ 

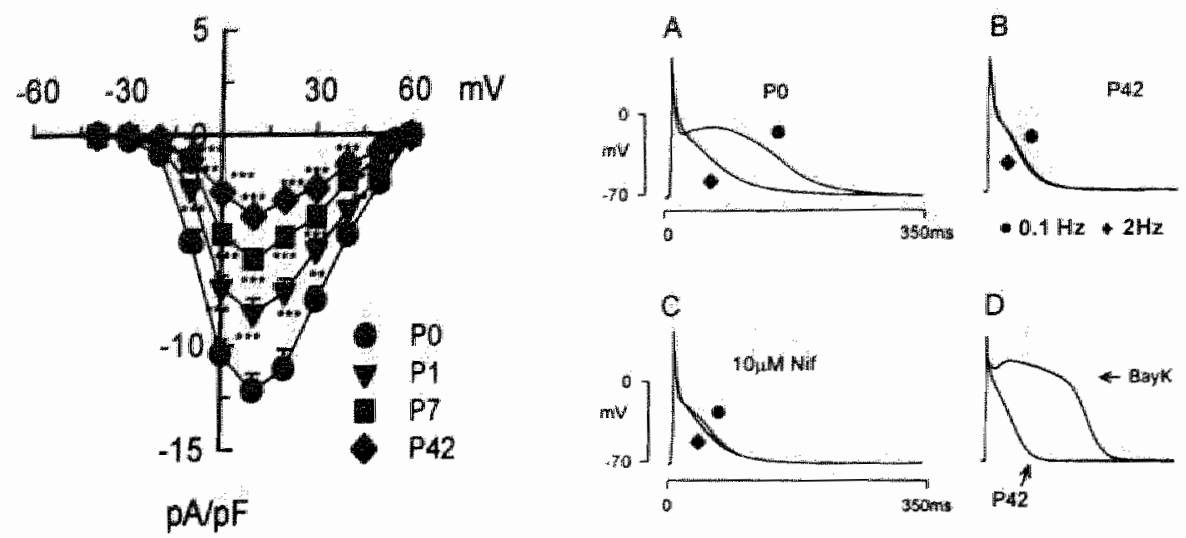

Figure 4: Leff ponel: Woltage current relatianships of $\mathrm{CO}_{\mathrm{C}}$ during control (PO) and ofter 1,7 , and 42 days af rapid afrial pacing in the dog. The density of 1 co wos progressively reduced with the duration of rapid pacing. Right panel: Action potentials recorded a $0.1(\cdot)$ and $2 \mathrm{~Hz}(\bullet)$ in control atrial cells (PO) and of ter 42 days of rapid atrial pacing $(\mathrm{P} 42)$. Addition of nifedipine $(\mathrm{C})$ mimicked the effects of electrical remodeling, whereas the Ca-agonist Bayk 8644 restored the plateau phase of the action potential (D) (From Yue et al ${ }^{33}$ ).

In 1995, wo studies helped to explain these clinical abservations, ${ }^{30,31}$ Morillo ef al. ${ }^{30}$ subjected dogs to 6 weeks of continuous rapid atrial pacing ( $400 \mathrm{bpm}$ ) and observed a shortening of the atrial refractory period by about $15 \%$. In chronically instrumented goats, Wiiffels et al. ${ }^{31}$ maintained AF by a fibrillation pacemaker that automatically delivered bursts of stimuli ( $1 \mathrm{sec}, 50 \mathrm{~Hz}$ ) as soon as sinus rhythm was detected (Figure 3). Using this method, AF could be maintained 24 hr a day, 7 days a week. After 2 to 4 days of AF, the atrial refractory period had shortened from -150 to $-80 \mathrm{~ms}(-45 \%)$. In addition, the normal physiological rate dependency of the refractory period was last. Restoration of sinus rhythm completely restored the normal refractory period within 2 to 3 days ireverse electrical remodelingl. In both sludies, the rapid atrial rate led to a progressive increase in the duration of AF paroxysms. After 6 weeks of rapid atrial pacing in the dog, $82 \%$ of the paroxysms of AF lasted longer than $15 \mathrm{~min}$. In the gaat model, as a result of 2 to 3 weeks of repetitive induction of AF, $90 \%$ of the animals developed persistent AF." Both in the dog model of Morillo et al. ${ }^{30}$ and the goat model of Wiffels et al ${ }^{31}$ it was hypothesized that the mechamism of increased susceptibility for AF was based on a shortening of atrial refractoriness and wavelength. Morillo et al ${ }^{30}$ observed a significantly shorter atrial fibrillation cycle length in the left atrium compared to the right. Cryoablation of the area with the highest dominant frequency terminated AF in 9 of 11 dogs.

The ionic mechanisms underlying AF-induced electrical remodeling have been extensively studied. ${ }^{32}$ Yue et al. ${ }^{33}$ were the first to demonstrate that the L-type $\mathrm{Ca}^{2}$. current $\left(l_{c a}\right)$ was reduced in cardiomycytes of electrically remodeled atria (Figure 4). Inhibition of I cat by nifedipine produced a shortening of the action potential, comparable to the changes caused by prolonged atrial tachycardia. On the other hand, an 
increase of the L-type $\mathrm{Ca}^{2}$ current by BayK8644 could partly reverse the shotening of the action potential by rapid atrial pacing. These data strangly suggest that a reduction of $I_{c a}$ underlies the tachycardia-induced shortening of the refractory period. In additional studies it was shown that $\mathrm{AF}$ also reduces the transient outward current $(1)$ and the ultrarapid delayed rectifier current $\left(l_{k u}\right)^{33,2}$. The ionic remodeling resulting from prolonged thigh atrial rates or atrial fibrill ation are reviewed by Bosch and Nattel. ${ }^{32}$

Electrical remadeling of the atria also occurs in humons. As far back as 1982 Attuel ef al. ${ }^{35}$ observed a shortening and abnormal rate adaptation of atrial refractoriness in patients with AF. In 1986, Boutjidir ef al. ${ }^{36}$ found that atrial action poten. tials were shorter in patients with AF compared to those with normal sinus rhythm. Franz et al ${ }^{37}$ demonstrated that after electrical cardioversion of atrial flutter or fibrillation, the human atrial action potential was shontened. The time course of reverse electrical remadeling was studied by $Y_{u}$ et all. ${ }^{30}$ In 19 patients, the change in atrial refractorimess was monitored dally after electrical cardioversion of chronic AF. Ht was found that the shortening of the refractory period was completely reversible within 3 to 4 days of sinus rhythm.

After the initial description of the AF-induced shortening of atrial refractoriness, several studies have tried to prevent tachycardia-induced electrical remodeling. First, it was reported that administration of the L-type Ca ${ }^{2}$ antagonist verapamil could delay the AF-induced shortening of refractoriness. ${ }^{39.40}$ In other studies, initially a protective effect was described for angiotensin $\mid l$ antagonists, "Na $\mathrm{Na}^{+} / \mathrm{H}^{4}$ exchanger inhibitors, ${ }^{42}$ anti-oxidants (ascorbate), mibefadril (T-type Ca ${ }^{2+2}$ channel blacker) and amiodarone. ${ }^{45}$ However, most of these studies addressed the short-term effects (hours) of atrial tachycardia. When the atria were paced for longer periads of time (days) most drugs failed to prevent electrical remodeling. ${ }^{46,47}$ Only mibefadril ${ }^{44}$ and amiodarone ${ }^{45}$ retained their protective effects during 7 days of rapid pacing and could prevent the development of persistent AF in dogs. Recently it was found that the class III action of $I_{\mathrm{i} r}$-blackers like d-sotalol, ibutilide and doletilide was strongly reduced after 48 hr of AF. ${ }^{48.49}$ In contrast, the class 11 ll effect of AVE 01118, a subw

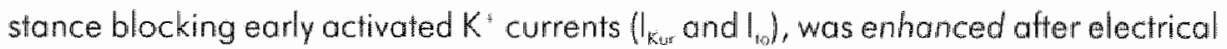
remodeling. If these observations are be reproduced in humans, such 'early' class III drugs may become very useful in the cardioversion and prevention of AF.

From clinical studies, it is known that the atrial contractile function is impaired after successful cardioversion of AF. The degree of contractile dystunction seems to be related to the duration of AF. In patients with lone AF, Sanfillippo et al. si observed an increase in atrial volume of $-40 \%$ after 20.6 months of AF. After restorafion of sinus irhythm atrial cantractile function can recover, although this may take several months. Schotten et al. sas hypothesized that the reduction in $I_{\text {cot }}$ during AF-induced electrical remodeling may also underlie atrial contractile dysfunction. To test this hypothesis, they chronically instrumented goats with pairs of piezoelectric crystals on both atria and a pressure catheter in the cavity of the right atrium (Figure 5). With the atrial volume-pressure loops obtained in this way, the external work pertormed by the right atrium could be meosured chronically. During the first 5 days 

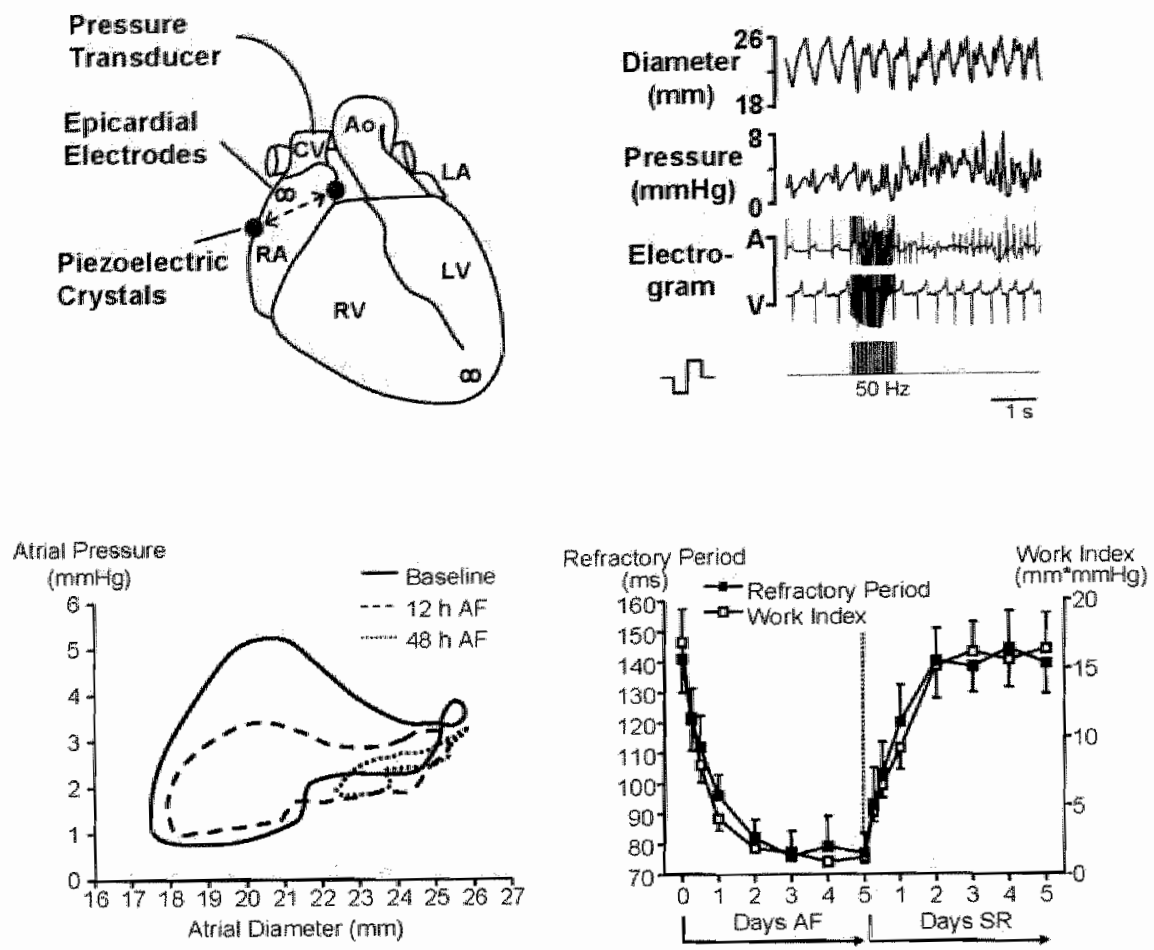

Figure 5: Controctite remodeling during the lirst 5 days of AF. Upper left: A poir of piezoelectric crystals sutured on the right athum. Right atrial pressure was measured by an mplanted pressure tronsducer. LA, left atrium; RA, right atrium; CV, superior covol vein; Ao, Aorth. Upper right: Simuloneous recording of right atrial diometer and pressure. AF was induced by 1 sec $(50 \mathrm{~Hz})$ of bursi pocing. Lower left: Right atrial pressure-volume loops recorded at baseline and after 12 and after 48 h of Af. Lower right: Time course of electrical and comtractile remodeling and their reversibility in seven goots fFrom Scholten. ${ }^{3}$ !

of AF, the strength of the atrial contractions markedly declined. After 2 days the pressure-wolume loop already showed that atrial contractile function was almost completely abolished. The atrial work index decreased from 16 to $2 \mathrm{~mm} \times \mathrm{mmHg}$. The time course of electrical and contractile remodeling was the same. Also, during reverse remodeling, the time courses of restoration of the refractory period and atrial contractile function were the same; after 2 days of sinus rhythm, the pressure-diameter loop returned to control values. These findings indicate that during the first 5 days of AF, electrical and contractile remodeling are closely linked. They are probably both the result of the same mechanisms, i.e., a downregulation of the L-type $\mathrm{Ca}^{2+}$ current.

Apart from inducing electrical and contractile remodeling, AF also changes the structure of the atrium. The first experimental study in which this was demonstrated was done by Morillo et al ${ }^{30}$ Dogs subjected to 6 weeks of rapid atrial pacing revealed a marked disarray of atrial myofilaments, increased number and size of mi- 


\section{Myolysis}

\section{Sinus Rhythm Atrial Fibrillation}
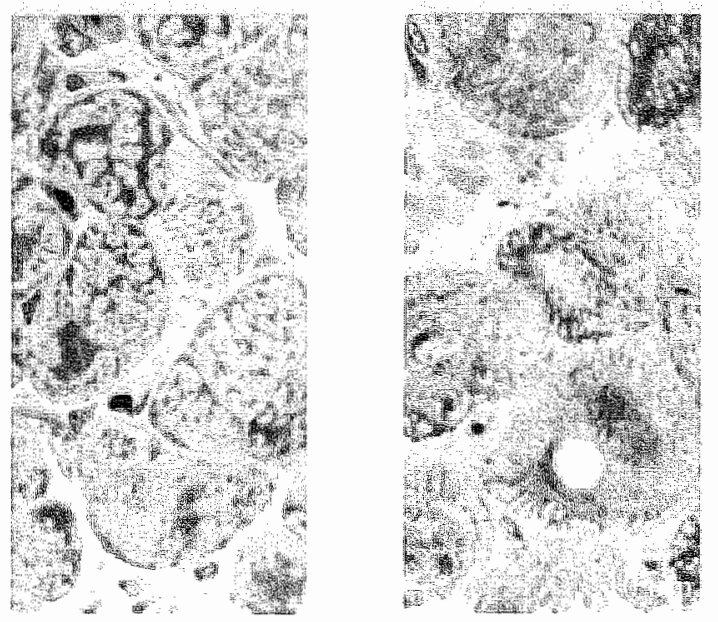

\section{Connexin 40}
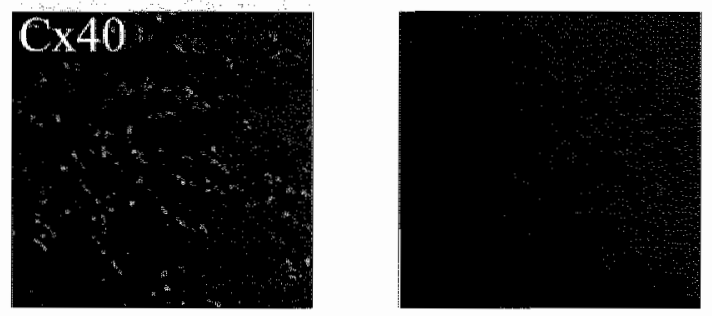

Figure 6 : Structural remodeling of coprime ania by 4 months of AF. Top: Light micioscopy shows enlorged otrial cells with sewere myolysis and accumulation of glycogen. Batiom: Immuna label. ing of $\mathrm{C} \times 40$ showing a clear reduction in Cx40 expression. If rom Ausma ef al. ${ }^{54}$ and van der Velden et al. ${ }^{90}$.

tochondria and disruption of the sarcoplasmic reticulum. Ausma et al found similar changes in the atria of goats in which AF was maintained for 9 to 23 weeks. The atrial myacytes were markedly increased in size, and changes in cellular structure were characterized by loss of myofibrils, accumulation of glycogen, reduction in connexin 40, changes in mitochondrial shape and size, fragmentation of sarcoplasmic reticulum, and dispersion of nuclear chromatin (Figure 6). It was suggested that these ultrastructural alterations closely resembled the changes observed in ventricular myocardium due to low flow ischemia, termed 'hibernation'. Hiber- 
nating atrial myocytes were heterogeneously distributed, with some cells strongly affected and neighbouring cells virtually normal.

In two recent studies, the reversibility of structural atrial remodeling was evaluated. Everett ef al. ${ }^{55}$ found no recovery of structural remodeling 2 weeks after restoration of sinus thythm in dogs subjected to 2 months of AF. Ausma ef al. ${ }^{\text {sto }}$ investigated the reversibility of structural changes in the atria of goats that had been in AF for 4 months. Four months after restaration of sinus thythm structural abnormalities were still present. Although by at that time cell size, connexin 40 , and myocytes with severe myolysis were nomal again, $25 \%$ of atrial myocytes still sthowed a moderate degree of myolysis. Also, the duration of induced AF episodes was still prolonged.

\section{Atrial Dilatation}

The impact of atrial dilatation on the propensity for AF is being studied in several experimental models. In most models the acute effects of atrial dillatation were studied. In the Langendorf perfused rabbit heart, Ravelliet al. "found that acute atrial stretch was associated with a shortening of the atrial action potential and refractory period. In contrast, other studies have reported na change 5.8 or a prolongation of atrial refractoriness ${ }^{59}$ after acute volume overload. In a recent study, Eijsbouts et all. ated the effects of acute atrial dillatation on atrial conduction. As a result of dilatation, atrial conduction slowed and the number of areas with local conduction delays increased significantly. In combination with a short atrial wavelength, such stretch-induced lines of intra-atrial conduction black may serve as sites of wavebreak which can initiate AF.

Although the models of acute dilation have provided important information about the electrophysiological effects of acute atrial stretch, atrial dilatation develops more gradually in patients. As early as 1981 Boyden et al. "l evaluated the effects of chronic atrial dilatation on atrial electrophysiology in dogs. Right atrial dilatation was created by cutting the chordae tendineae of the septal cusps of the tricuspid valves and partly accluding the pulmonary artery. After a mean follow-up of 93 days, the right atrial volume had increased by $39 \%$. The propensity for atrial arrhythmias had clearly increased and the incidence of AF episodes lasting $>10$ min was significanlly higher. However, in vitro recorded atrial action potentials did not differ in duration from action polentials recorded from non-dilated atria. ${ }^{\text {id }}$ An increased trabeculazation of the right atrium was obserwed and atrial histology was characterized by hypertrophy and tibrosis. Cox el al. ${ }^{3}$ developed a canine model of chronic mitral regurgitation by cutting the chordae tendineae of the mitral valve. After 3 months of regurgitation, AF could easily be induced by burst pacing. Multisite mapping revealed multiple activation patterns: ranging from the simplest pattern, in which a single re-entrant circuit was present, to the mast complex cases, in which no consistent pattern of activation could be identified'. Of nate, animals with sustained AF demonstrated the highes degree of dilatation. The most complex AF activation patterns were observed in these animals. Similar observations were made by 
$[0]$

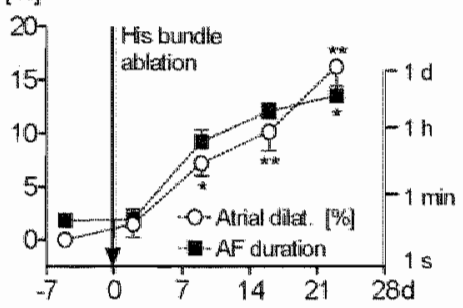

Acute AF

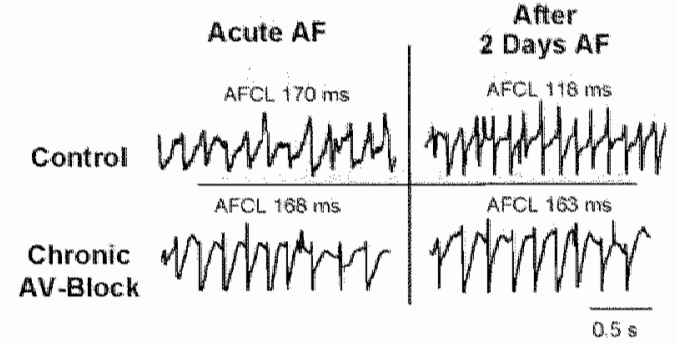

Figure 7: Elfects of atrid dilatation on the electrophysiological properties of the alrio in 6 goots with chronic AV-block. Left: Relative changes in atrial diameter and duration of induced AF episodes during 4 weeks of compleie AV block. Right: Representalive examples of unipolar endocardial arieal electrograms. Under control conditions (upper ponels), the median AF interwal shortened within the first 2 days of AF from 170 to 118 ms. After chronic AV block (lower panels), 2 days of AF sill shortened the AERP (not shown) but no longer shortened the AF cycle length. (From Neuberger at al.

Verheule et al ${ }^{\circ-4}$ In dogs with 1 month of mitral regurgitation, the inducibility of AF was strongly increased. Atrial conduction did not change, but atrial refractory periads in the right and left atria were prolonged. Structural alterations in the atrial myocardium were confined to the left atrium and consisted of increased glycogen accumulation and interstitial fibrosis.

Recently Neuberger et al ${ }^{65}$ investigated the relation between the time course of atrial dilatation and the stability of AF in goats with chronic atrio-ventricular (AV) block. Endocardial screw-in leads with sonomicrometer ultrasound crystals were chronically implanted in the right atrium. In this way, atrial electrophysiology and atrial size could be monitored simultaneously. After His bundle ablation, a progressive increase in atrial size was observed; after 4 weeks, atrial diameter had increased by $12 \%$. Before the creation of this AV-block, episodes of AF induced by burst pacing were generally brief (lasting seconds). After 4 weeks of AV-block, the duration of AF paroxysms gradually increased. In goats with the largest degree of dilatation, AF now lasted longer than 1 hr (Figure 7). As in the study of Boyden ell al. ${ }^{6 ?}$ no changes in atrial refractoriness were observed. Detailed mapping of the right and left atria revealed an increased heterogeneity in concluction. Whereas maintenance of AF still resulted in shortening of the atrial refractory period, the AF cycle length did not shorten accordingly. This suggests that, in this model of atrial dilatation, structural conduction defects are involved in the reentrant process.

Clinical data on the effects of chronic atrial stretch on atrial electrophysiology are scarce. Sparks et al ${ }^{60.6 \%}$ evaluated the effects of chronic W/ and DDD pacing on atrial size and electrophysiology in patients requiring permanent pacing. In this prospective randomized study, it was found that WI pacing increased atrial dimension, and that this was associated with a prolongation of the atrial effective refractory period (AERP). ${ }^{\prime 3}$ No changes, either in atrial size or electrophysiological properties were observed after DDD pacing. Although a prolangation of atrial 
refractoriness can be expected to prevent arhythmias by prolonging the atrial wavelength, Wl pacing clearly increased the propensity for AF compared to DDD pacing. The underlying mechanisms are unknown, but it is likely that changes in atrial conduction due to an increase in connective tissue play a role in the genesis of AF in patients with dilated atrio.

\section{Inflammation}

In 1986, the group of Waldo deweloped a new canine madel of atrial flutter ${ }^{68}$ After a thoracotomy, both atria were dusted with sterile talc and a gauze dressing was left on them. Electrodes were sutured to the atria and the chest was closed. During the first week after surgen, susceptibility for atrial arrhythmias was evaluated daily. In more than $90 \%$ of the animals, atrial flufter could be ind uced by programmed electrical stimulation on at least one of the first four postoperative days. With time, the susceptibility for arrhythmias declined; 1 week after surgery, flutter could be induced in anly one of four animals. The mechanism of this temporarily high atrial wulnerability is still unclear. Atrial refractoriness and conduction welocify were not different in susceptible or non-susceptible dogs. In subsequent studies also atrial fibrillation was induced. Extensive mapping of electrical activation showed that one to four unstable reentrant circuits of short cycle length were responsible for the maintenance of AF. ${ }^{69}$ Reentrant circuits involved the septum, right atrial free wall, pulmonary veins and inferior and superior caval veins. Importantly, Bachmann's bundle was involved in mast of these reentrant circuits. Radiofrequency catheter ablation of this 'critical crossroad" completely abolished AF in this model. It is of interest to note that the time-course of inducibility of atrial flutter and fibrillation observed in the model shows striking similarities with the incidence of post-operative AF in patients. AF/atrial flutter occurs in 70\% of patients during the first 4 doys after surgery. ${ }^{70}$ The canine madel of sterile pericarditis can thus be useful in elucidating the mechanisms of postoperative atrial arrhythmias in humans. In a recent study, Waldo's group evaluated the anti-arrhythmic effects of steroids in the canine model of pericarditis." Administration of oral prednisone completely prevented atrial arrhythmias during the first 4 days after surgery. Histological examination revealed that the degree of inflammation was clearly reduced in steroid-treated animals. In an earlier clinical study, Yared et al. ${ }^{2}$ showed that, in patients undergoing elective coronary or valvular heart surgery, administration of a single dose of dexamethasone reduced the incidence of postoperative AF from 32.3 to 18.9\%. These studies dearly indicate a link between postoperative AF and inflammatory responses.

\section{Congestive Heart Failure}

In clinical practice it is well known that heart failure often leads to AF. ${ }^{3}$ On the other hand, AF can also worsen ventricular function. Not surprisingly, AF and heart failure coexist in many patients. To elucidate how heart failure increases the vulmerability for AF, Nattel and co-workers" subjected dogs to rapid ventricular pacing 1220 to 


\section{Control}

\section{Rapid atrial pacing}
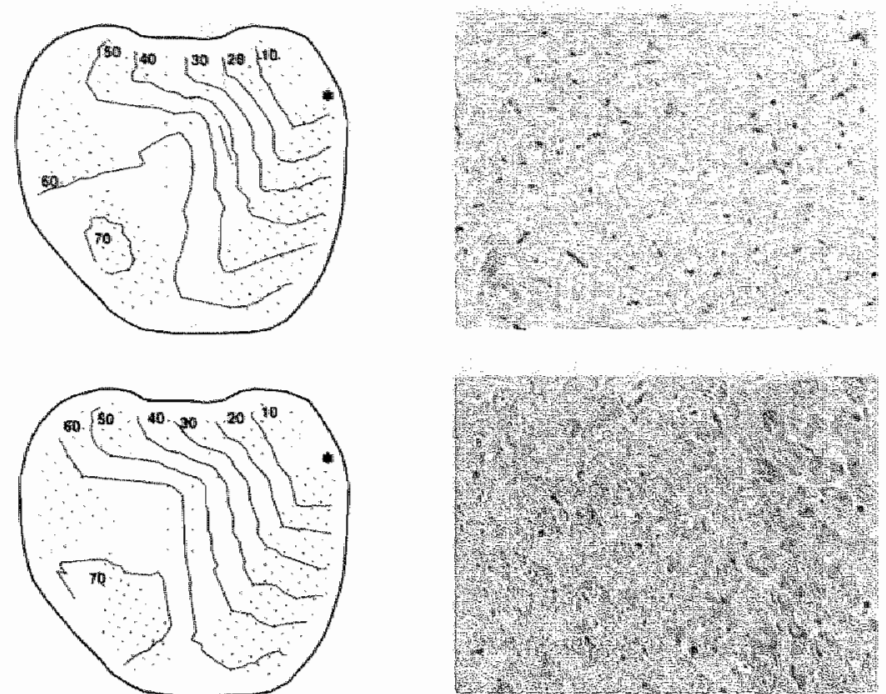

Congestive heart failure
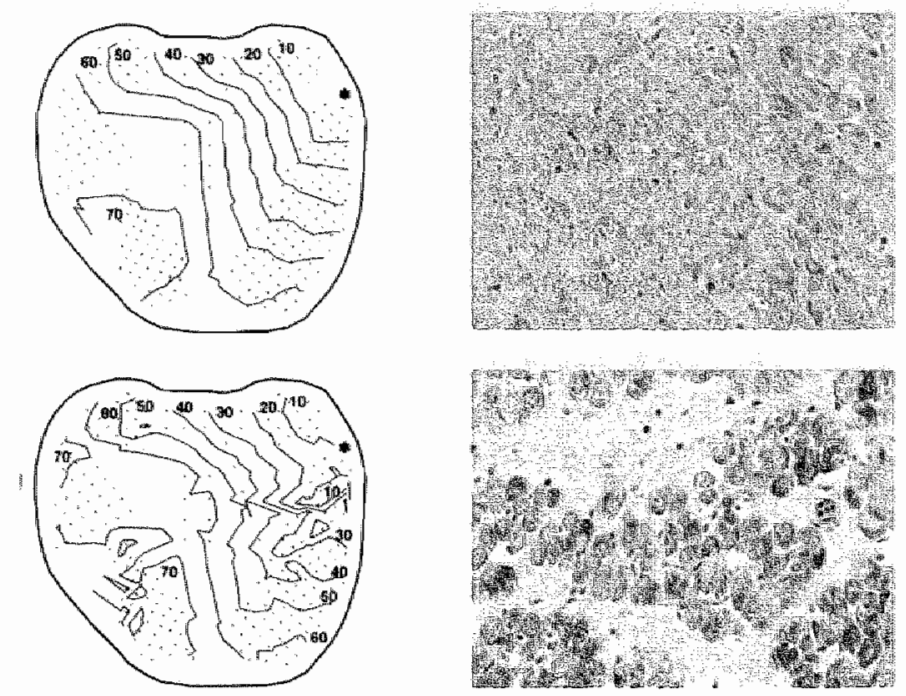

Figure 8: Different kinds of atrial remodeling in canine afria. Leff: crowding of isochrones was observed only in dogs with congestive heart failure, indicating local slowing of conduction. Right: Histological examination revealed severe atrial fibrasis in dogs with congestive heart failure, whereas prolanged rapid atrial pocing had no significant effect on the amount of connective tissue. (Modified from Li et al. ${ }^{71}$ ).

$240 \mathrm{bpm})$ for a period of 3 weeks. The animals progressively developed clinical and hemodynamical signs of heart failure. In 10 of 18 dogs, sustained AF could be induced. AF was characterized by long AF cycle lengths and a relatively low degree of polymorphism of the fibrillation electrograms. Atrial mapping suggested that AF was maintained by a small number of reentrant waves. Unlike the case in the rapid atrial pacing model, the increased stability of AF was nol based on a shortening of the atrial wavelength. No changes in refractoriness, conduction velocity, or wavelength were noted. However, when the local conduction properties were studied in more detail, discrete regions of slow conduction were found. Histological analysis revealed a marked increase in fibrous tissue, which was held responsible for the local disturbances in atrial conduction (Figure 8). Characterization of the cellular electrophysiological changes showed a decrease in $I_{4 a} I_{C o r}$ and $I_{K a}$ and an increase in the $\mathrm{Na}^{+} / \mathrm{Ca}^{2+}$ exchange current. ${ }^{75}$ Thus, in the setting of congestive heart failure $(\mathrm{CHF})$, an increase in atrial fibrasis and tissue anisotropy may promote AF by the fa- 
cilitation of AF by inducing microreentry. Of note, the structural abnomalities showed striking simblarities with the histological findings observed in atrial myocardium of the elderly and in patients with rheumatic heart disease. "7

Sanders ef al. ${ }^{\prime}$ recently inyestigated the atrial electrophysiological propenties in patients with CHF. Using electroanatomic mapping, they found that right airiat conduction velocity was markedly slowed and that the number of electrograms with tractionated potentials was increased. Although no clear differences in the inducibility of AF was observed, the duration of induced Af paraxysms was clearly prolonged.

Since the renin-angiotension system is thought to play a pivotal role in the development of cardicic fibrosis, $L i$ et al ${ }^{73}$ investigated whether the angiotensin converting enzyme (ACE) inhibitor enalapril could prevent AF in the canine CHF model. After 5 weeks of rapid ventricular pacing, drug-treated animals showed a lower level of angiotensin II in the atrial wall. At the same time, the duration of induced AF episodes was significantly shorter than in the placebo group. ACE inhibition attenuated the development of interstitial fibrosis and could partly prevent the development of intra-atrial conduction abnormalities. Recent clinical data suggest that ACE-inhibitors may have beneficial effects in patients with atrial fibrillation. In the TRACE study, it was found that trandolapril reduced the incidence of AF during a 2 to 4 year follow up in patients with reduced left ventricular function. Similar results: were obtained in the SOLVD trial. ${ }^{81}$ Recurrences of atrial fibrillation after ellectrical cardioversion were significantly less in patients treated with amiodarone and irbesartan (an angiotensin I type 1 blocker) vs. patients treated with amiadarone alone." However "it remains to be determined whether the observed anti-arrhythmic action of ACE-inhibition is based on an anti-fibrotic effect. Other effects such as lowering of the atrial pressure might also explain a reduction in susceptibility for AF.

\section{Ischemia}

Myocardial infarction is an independent risk factor for the development of AF." Up to $21 \%$ of patients admitted with an acule myocardial infarction suffer from atrial fibrillation/flutter during their hospital stay. ${ }^{83}$ The pathophysiological mechanisms of ischemia related AF are not well understood. Most of our our knowledge of the arrhythmogenic mechanisms of ischemia has been aquired in the ventricles. Both a marked heterogeneity in refractoriness and areas of slow and discontinuous conduction may lead to a substrate of reentrant arhythmias, If is unclear whether the same electrophysiological effects also occur in ischemic atria. Only recently, the effects of coronary ocdusion on atrial arrhythmias have been studied. In a dog model, Jayachandran et al. ${ }^{22}$ observed an acute shortening of the atrial refractary period atter ocdusion of the proximal right coronary artery. In a study of Sinno et al. ${ }^{\text {at no }}$ effects on atrial refractoriness were observed during the first hours affer ligation of a branch of the right coronary artery (right intermediate atrial artery). In ischemic atrial tissue, the pacing threshold was increased, conduction was slowed, and the duration of induced AF episodes increased significantly. Miyauchi et al. ${ }^{85}$ investigated 

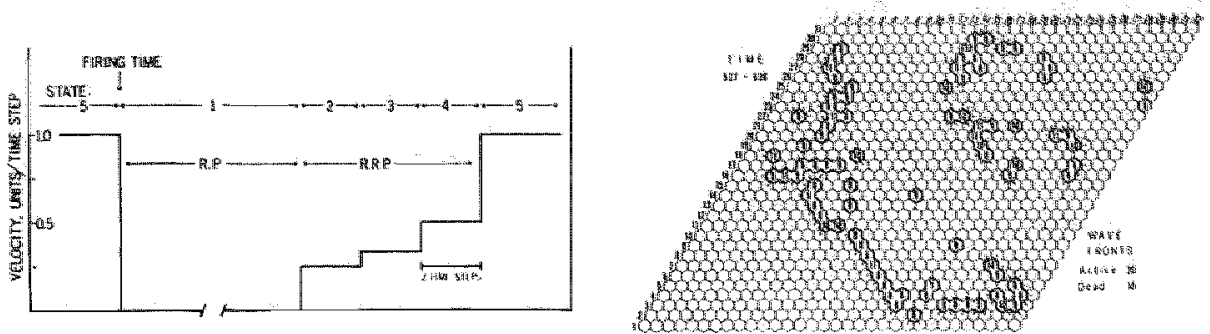

Figure 9: The early compuier model of AF by Moe and Abildskov. Left: Each unit of a 992-unit motrix was assigned one of tive states of excitobility. State 1: absolutely refractory. State 2 to 4 : relotively refractory with decreased conduction velocity in case of activation. Stote 5: fully recowered excitability. Right: Several simultaneously propagating wavefronts differing in size and direction of propagation. $A_{r}$. rows indicate progress of wavefronts. (From Moe et al. ${ }^{87}$ ).

the long-term effects of occlusion of the left descending artery below the first diagonal branch in dogs on the susceptibility of the atria for AF. After 8 weeks occlusion, atrial electrophysiological measurements were performed. Both the inducibility and stability of AF were increased after myocardial infarction; in the control group, the duration of induced AF lasted for only $3 \mathrm{sec}$, after myocardial infarction atrial fibrilllation lasted for an average of $41 \mathrm{sec}$. Mapping of atrial activation during application of premature stimulation showed epicardial wavebreaks degenerating into AF. No differences in the duration of atrial action potentials or refractoriness were found after myocardial infarction. However, at fast pacing rates, a higher spatial dispersion in the duration of monophasic action potentials was found. The slope of the restitution curve was also steeper. Immunocytochemical staining of sympathetic nerves showed an increased density and marked heterogeneities in different parts of the atria. The amount of connexin 40 was reduced and it was also more heterogeneously distributed. ${ }^{\text {No }}$ No signs of atrial ischemia or fibrosis could be found. Thus it appears that ventricular infarction itself leads to the creation of a substrate for AF, possibly due to nerve sprouting, atrial stretch, or modulation of the autonomic nervous system.

\section{Computer models of AF}

In the early 60.s Moe and co-workers ${ }^{87}$ developed the first computer model of AF, consisting of a two-dimensional matrix of 992 units. Each unit could have five different states of excitability, ranging from fully excitable to absolutely refractory (Figure 9, left panell). Spatial dispersion in refractoriness was simulated by varying the duration of the lowest excitable state in different units. The 'turbulent activity' within the matrix was sustained by multiple wandering wavelets varying in both number and size (Figure 9, right panel). When the refractory period was increased or the surface area reduced, the activity was terminated. The creation of internal obstacles resulted in a circus movement flutter. The growing knowledge of cellular electrophysiology 
led to the design of more sophisticated computer models implementing various ionic currents and concentrations, subcellular compartments, membrane capacity, and cell to cell coupling. One example is the model recently developed by Zou et al. ${ }^{38}$ These authors simulated cell grids of varying size in the presence of spatially different acetylcholine concentrations, causing different patterns of spatial dispersion of refractoriness: in almost all cases, AF was sustained by a single spiral wave ratating around am area of low acetylcholine concentration. When the grid became too small, AF was not sustained. Since, above this critical size, the behavior of AF was qualitatively the same in an 11-fold increase in atrial grid size, these authors stated that the emphasis on tissue mass as an important determinant of AF stability may have been overstated. ${ }^{88}$ Virag ef al.$^{89}$ developed a model of AF based on the anatomy of human atria. An ion-based membrane madel was implemented in an anatomical structure derived from segmented magnetic resonance images. However, anisotropy and differences in wall thickness were not implemented in this model, in which burst pacing induced atrial fibrillation even when the membrane properties were uniform. As expected, shortening of the refractory period increased the duration of AF,

\section{REFERENCES}

1. Wolf PA, Abbat RD, Konnel WB: Atrial fibrillation as an independent risk factor for stroke: the Framingham Study. Siroke 1991;22:983-988.

2. Benjomin EJ, Woll PA, DAgostino RB, Silbershatz H, Kannel WB, Levy D: Impact of atrial fibrillation on the risk of death: the Framingham Heort Swdy. Circulation 1998:98:946-952.

3. Benjomin EJ, Lewy D, Vaziri SM, D'Agosfino RB, Belanger AJ, Wolf PA: Independent risk foctors for atrial fibrillation in a population-bosed cohort. The Framingham Hear Study. Jama $1994 ; 27 \|: 840-844$

4. Kopecky SL, Gersh BJ, McGoon MD, Whisnant JP, Holmes DR, In, Ilstrup DM, Frye RH: The notural history of lone atrial fibrillotion. A population-based study over three decodes. N Engl J Med $1987,317: 669-674$.

5. Haissaguerre M, Jais P, Shah DC, Tokahashi A, Hocini M, Quiniov G, Gorrigue S, Le Mouroux A, Le Melayer P. Clemenly J: Spontaneaus intiation af arial fibrillation by ectopic beats originating in the pulnonory weins. NEngl J Med 1998;339:659-666.

6. Winterberg H: Shdien uber harthmmern. 1. Uber die wirkung des N. Vagus und accelerans auf dos fimmern des Herzans. Plingers Arch Physiol 1907,117:223-256.

7. Scherf D: Studies on auricular tachycandia caused by aconitine administration. Proc Soc Exp Biol Med $1947,64: 233$

B. Moe GK, Abildskov JA: Atral librillation as a self-sustaining artythmio independent of local dischorge. Am Heart J 1959:58:59-70.

9. Henweg B. Kowalski M. Steinbarg JS: Termination of persistent atrial hbrillation resistant to carcioversion by a single rodiofrequency opplication. Pacing Clin Electrophysiol 2003,26:1420-1423.

10. Pappone C, Rosanio S, Oreno G, Tocchi M. Gugliatia F, Vicedomini G, Salvati A, Dicondia C. Mazzone P, Santinelli V. Gulletho S. Chierdia S. Circumlerentid radiofrequency ablation of pulmonory vetn ostio: A new anotomic approach lor curing atrial fibrillotion. Circulation $2000 ; 1022019-2628$.

11. Coppoto R. Negroni S, Pecoro D, Bentivegno S. Lupo PP, Carolei A, Esposito C, Furlanello F, De Ambroggi L: Prospectiwe assessment of late conduction recurrence across radiofrequency lesions. producing electrical disconnection at the pulmonary vein ostium in patients with atrial fibritation. Circulation 2003;108:1599.1604. 
12. Knoll P: Ueber die wirkungen des herawgus bei wamblutern. Archiv fur die gesome Physiologie $1897 ; 67: 587-614$.

13. Rothberger C, Winterberg H: Archiv Ges Playsiol 1915;160:42.

14: Alessi R, Nusynowitz M, Abildskov J, Moe G. Nonuniform distribution of vagal eftects on the atriat re. fractory period. Am J Physiol 1958,194:406-410.

15. Allessie M, Lammers WJ, Bonke Fl, Hollen J. Experimental evaluation of Moe's multiple wavelet hypothesis of atrial Mbrillation. Orlando: Grune and Stratton: 1985.

16. Wang Z, Page P, Nattel S: Mechanism of flecainide's ontiarthythmic action in experimental atrial fibrillation. Circ Res 1992;71:271:287.

17. Schuessler RB, Grayson TM, Bromberg B!, Cox JL, Boinedu JP: Chalinergically mediated tadyarthythmias induced by a single extrastimulus in the isolated conine right altium. Circ Res $1992 ; 71: 1254-1267$.

18. Schuessler RB, Kawamoto T, Hand DE, Mitsuno M, Biromberg BI, Cox JL, Boineau JP: Simullaneous epicardial and endocardial octivation sequence mopping in the isolated canine right atrium. Circulation 1993;88:250.263.

19. Wu TJ, Yashima M, Xie F, Alhill CA, Kim YH, Fishbein MC, Qu Z, Gartinkel A, Weiss JN, Karagueuzian HS, Chen P.S. Role of pectinate muscle bundkes in the generation and maintenance of intra-atrial reentry: patential implications for the mechanism of conversion between atrial fibrillation and atrial flutter. Circ Res 1998;83:448-462.

20. Skanes AC, Mandapali R, Berenfeld O. Davidenko JM, Jalife J: Spatiotemporal periodicity during atrial fibrillation in the isolated sheep heart. Circulation 1998;98:1236-1248.

21. Mandapati $R$, Skones $A$, Chen J Berenfeled $O$, Jalife J: Stable microreentrant sources as a mechanism of atrial fibrillation in the isolated sheep heart. Circulation 2000;101:194-199.

22. Coumel P, Attuel P, Lavallee J, Flammang D, Ledercq JF, Slama R: [The atrial arthythmia syndrome of wagal originl. Arch Mal Coeur Vaiss 1978;71:645-656.

23. Herweg B, Dalal P, Nagy B, Schweitzer P: Power spectral analysis of heart period variability of preceding sinus rhythm before initiotion of paroxysmal atrial fibrillation. Am I Cardiol $1998 ; 82: 869-874$.

24. Bettoni M, Zimmermann M: Autonomic fone wariations betore the onsef of paroxysmal atrial fibrillan. tion. Circulation 2002;105:2753-2759.

25. Dimmer C, Tavernier R, Gjorgav N, Van Nooten G, Clement DL, Jordaens L: Variations of aulonomic tone preceding anset of atrial fibrillation after coronary artery bypass grafting. Am 1 Cardiol $1998 ; 82: 22-25$.

26. Wen ZC, Chen SA, Tail CT, Huang JL, Chang MS: Role of autonomic tone in focilitating spontaneous onset of typical atrial flutter. J Am Coll Cardial 1998;31:602-607.

27. Irwin JM, MCCarthy EA, Wilkinson WE, Pritchett EL: Circadian occurrence of symptomatic paroxys. mol supraventricular tochycardic in unirealed palients. Circulation 1988.77:298.300.

28. Kupari M, Koskinen P, Leinonen H: Dauble-peaking circadian variotion in the occurrence of sustained supraventricular tachyarhythmias. Am Heart J 1990;120:1364-136\%.

29. Godthedsen J: Arrial librillation: a rewiew of course and prognosis. In: Kulbertus HE, Olsson 5B, Schlepper M eds. Atrial Fibrillation. Molndal, Sweden: Lindgren and Soner; 1982:134.145.

30. Marillo CA, Klein GJ, Jones DL, Guiraudon CM: Chronic rapid atral pacing. Struciural , functional, and electrophysiological characteristics of a new model of sustained atrial fibriflation. Circuletion 1995:91:1588-1595.

31. Wiiffels MC, Rirchhof CJ, Dorland R, Allessie MA: Atrial fibrillation begets atrial fibrillation. A study in awake chronically instrumented goats. Circulation 1995;92:1954-1968.

32. Bosch RF. Natrel S: Cellular electrophysiology of atrial fibritlation. Cardionasc Res 2002:54:259-269.

33. Yue L, Feng J, Gaspo R, Li GR, Wang Z, Nattel S. lonic remodeling underlying action potential changes in a conine model of atrial fibrillation. Circ Res 1997:81:512.525.

34. Von Wagoner DR, Pond AL, Mc Carthy PM, Trimmer JS, Nerbonne JM: Ouiward K+ curreni densilies and Kv1.5 expression are reduced in chronic human atrial librillation. Curc Res 1997;80:772-787.

35. Attuel P, Childers R, Cauchemez B. Poveda J, Mughica J, Coumel P. Failure in the rale adaplation of the atrial refraciory period: its relolionship to vulnerability. Int $\downarrow$ Cardial $1982 ; 2: 179-197$. 


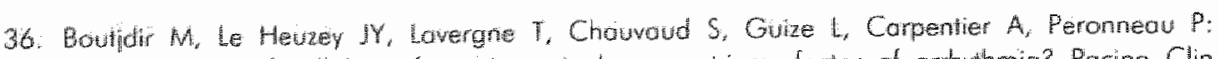

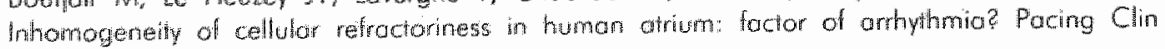
Electrophysiol 1908,9:1095-1100.

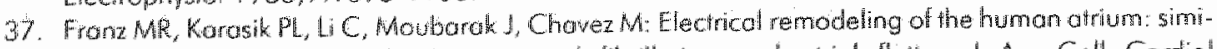
lor ehects in posients with chromic alrol bibrilotion and atrial intuter. I Arn Call Cardiol $1997,30.1705-1792$

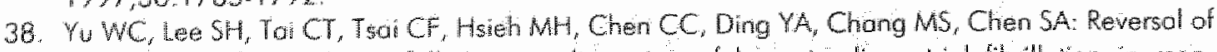

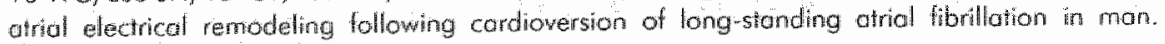
Cordiovasc Res 1999:42:470.476.

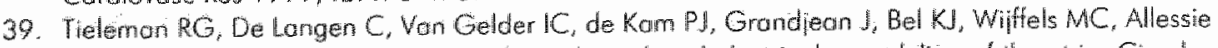
MA, Crins H: Verapamil reduees tochycorda-induced electrical remodeling of the otria. Circulation $1997,95: 1945,1953$

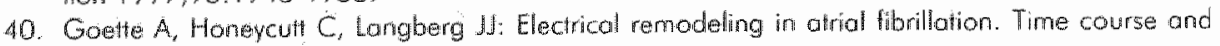
mechonisms. Circulation 1996,94:2968-2974.

41. Nakashimo H, Kumagai K, Urato H, Gondo M, ldeishil M, Arokawa K. Angiotensin ll antogonist prew vents electrical remodeling in atrial fibrilation. Circulation 2000; $101: 2612-2617$.

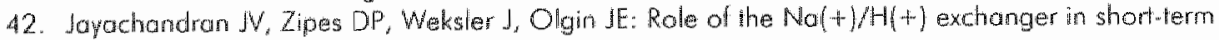
ofrul elechophysialogical remodeling. Circulation 2000; 101:1861-1866.

43. Comes: CA, Chung MK, Nakoyoma T. Nokayama H, Baliga RS, Piaa S, Kanderian A. Pavia 5. Homlin RL, MCCarthy PM. Bouer JA, Van Waganer DR. Ascombate atenuotes airal pacing-induced peroxyilrite lomation and electrical remodeling and dectecsest the incidence of postoperative atriol Vibrillotion. Circ Res 2001,89:E32-38

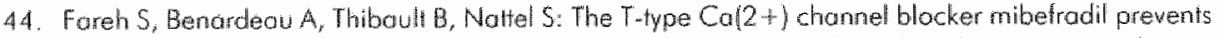
the development of o substrate lor atrol fibrlatom by tachycardia-induced atrial remodeling in dogs. Circulation 1999:100:2191-2197.

45. Shinagowa $K_{*}$ Shiroshito-Tokeshita A Schron $G$, Nottel $S$ : Efects of ontianhythmic drugs on hbriliathon in the remadeled otritum: insights into the mechanism of the superior efficacy of amiodarone. Circulation 2003:107:1440-1446.

46. Lee SH, Yu WC, Cheng IJ, Hung CR, Ding YA, Chang MS, Chen SA: Eflect of werapamil on long-term tochycardianduced atral electrical remodeling. Circulation 2000;101:200-206.

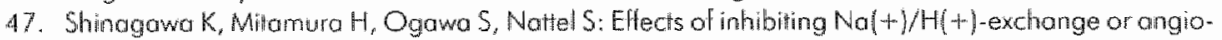
tensin converting enzyme on atrial tachycardia-induced remodeling. Candionose Res $2002,54: 438-446$

48. Duytschaever M. Wijfels, M.C.E.F. Aflessie MA. Eltect of AF induced remodeling an class IC and III drug action: loss of dass lll effect by atral tibrillation. Pacing Clin Electrophysiol 2000,23:564.

49. Bloduw Y, Gogelein H, Tieleman RG, Van Hunnik A, Schoten U, Allessie MA: "Early" Closs HI Drugs Tor the Treatmen of Alrial Fibrillotion. Ellicocy and Afrial Selectivity of AVEOI18 in Remodeled Atria of the Gout. Circulation 2004:110:1717.1724

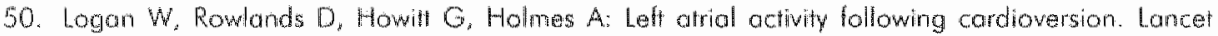
$1965: 2: 471.473$

5. Sanlilippo AJ, Abascol WM, Sheehom M, Oertel LB. Hamgan P. Hughes RA, Weyman AE Atrid en-

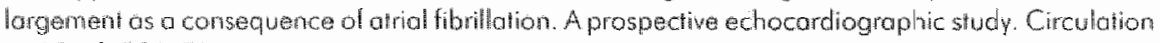
$1990,82,792,797$

52. Manning WH, Stwemon DI. Kotz SE, Riley MF, Doherty RM, Munson 1T, Douglas PS: Temporal dependence of the feturn of atral mechantal function on the mode of cardioversion of atrid fibrillahion to sinus rhylym. An J Cardiol 1995:75:624-626.

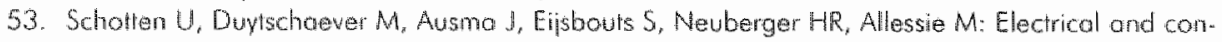
tractile remodeling during the first days of otral fibrillation go hand in hand. Circulation $2003,107: 1433 \cdot 439$

54. Ausma 4. Willels M, Thone F, Woulers L, Allessie M, Bongers M: Structural changes of ofrial myocardinu dve to sustaned atrial Horillation in the goat. Circulotion 1997;96:3157-3163.

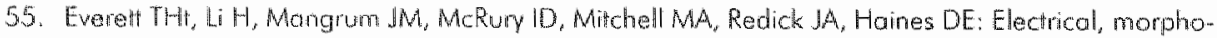
bogical, and ultrostuctural remodeling and rewerse remadeling in a conne model of chronic atrial fibrilletion. Circulation 2000; $102: 1454-1460$. 
56. Ausmo J, van der Velden HM, Lenders MH, wan Ankeren EP, Jongsmo HI, Romoekers FC, Bongers $M$ Allessie MA: Reverse structural and gap-junctional remadeling after prolonged atrial fibrillation in the goat. Circulation 2003;107:2051-2058.

57. Ravelli $F$, Allessie M: Effects of atrial dillotation on refraction period and wulinerability to atrial fibrillia. tion in the isolated Langendorff-perfused rabbit heart. Circulation 1997,96:1686 1695.

58. Wiiffels $M C$, Kirchhof CJ, Dorland R, Power J, Allessie MA: Electrical remodeling due to atrial fibrilliotion in chronically instrumented conscious goats: roles of neurohumaral changes, ischemio, atrici stretch, and high rate of electrical activation. Circulation 1997:96:3710-3720.

59. Satoh T, Zipes DP: Unequal atrial stretch in dogs increases dispersion of refractoriness conducivg to developing atrial fibrillation. J Cardiovase Elecarophysiol 1996;7:833-842.

60. Eijsbouts SC, Majidi M, van Zandwoort M, Allessie MA: Effects of acute atrial dilotion an heterogeneily in conduction in the isolated rabbit heart. 1 Cardiovasc Electrophysiol 2003; 4:269-278.

61. Boyden PA, Hoffman BF: The effects on atrial electrophysiology and structure of surgically induced right cirial enlargement in dogs. Circ Res 1981;49:1319-1331.

62. Boyden PA, Tilley LP, Pham TD, Liu SK, Fenoglic JJ, Jr., Wit AL: Effects of left atrial enlargement on atrial transmembrane potentials and structure in dogs with mittral valve fibrosis. Am $\perp$ Cardiol $1982 ; 49: 1896-1908$.

63. Cox JL, Canavan TE, Schuessler RB, Coin ME, Lindsoy BD, Stone C, Smith PK, Corr PB, Boineou JP: The surgical treatment of atrial fibrillation. II. Introoperative electrophysiologic mapping and description of the electrophysiologic basis of airial flutter and atrial fibrillation. I Thorac Cardiowasc Surg 1991;101:406:426.

64. Verheule S, Wilson E, Everett It. Shanbhag S, Golden C, Olgin J: Alterations in alrial electrophysiology and tissue structure in a camine model of chronic atrial dilatation due to mitral re. gurgitation. Circulation 2003;107:2615-2622

65. Neuberger HR, Schatten U, Ausma J, Blaauw Y, Eijsbouts S, Hunnik van A, Allessie MA: Atrial re. modeling in the groat due to chronic complete atrioventricular block. Eur Heart $\downarrow 2002 ; 23: 813$.

66. Sparks PB, Mond HG, Vohra IK, Yapanis AG, Grigg LE, Kalman JM: Mechanical remodeling af the left atrium alter loss of atrioventricullar synchrony. A long-term study in humans. Circulation 1999;100:1714-1721.

67. Sparks PB, Mond HG, Vohro JK, Jayaprakash S, Kalman JM: Electrical remodeling of the atria following loss of atrioventricular synchrony: a long-term study in humans. Circulation $1999 ; 100: 1894-1900$.

68. Page PL, Plumb VJ, Okumura K, Wallo AL: A new animal model of atriall flutter. I Am Call Cardial $1986 ; 8: 872-879$.

69. Kumagai K, Khrestian C, Waldo AL: Simultaneous multisite mapping studies during induced atrial fibrillation in the sterile pericarditis modell. linsights into the mechanism of its maintenance. Circulation $1997,95: 511-521$.

70. Aronki SF, Show DP, Adams. DH, Rizzo RJ, Couper GS, VanderVliet M, Collins JJ, Jr., Cohn LH, Burstin HR: Predictors of atrial fibrillation ofter coronary artery surgery. Current trends and impact on hospital resources. Circulation 1996,94:390-397.

71. Goldstein RN, Khrestion CM, Ryu K, Von Wogoner DR, Stombier BS, Waldo AL: Prevention of postoperative atrial fibrillation and flutter using steriods. Pacing Clin Electrophysiol 2003,26:1068.

72. Yored JP, Siarr NJ, Tarres FK, Bashour CA, Bourdakos G, Piedmante M. Michener JA, Dowis JA, Rasenberger TE: Effects of single dose, postinduction dexamethasone on recovery after cordiac surgery. Ann Tharac Surg 2000;69:1420-1424

73. Stevenson WG, Stevenson LW: Arral fibrillation in heart foilure. NEngl J Med 1999;34 1:910-911.

7.4. Li D, Fareh 5, Leung TK, Nattel S: Promotion of atrial fibrillation by heart failure in dogs: atriall remodeling of a different sort. Circulation 1999;100:87-95.

75. Li D, Melnyk P. Feng J, Wang $Z_{s}$ Petrecco K, Shrier A, Nottel S: Effects of experimental heon ficilure on atrial cellular and ionic electrophysiology. Circulation 2000;101:2631-2638.

76. Lie JT, Hammond P1: Pathology of the senescent heart: anatomic observalions on 237 outopsy stud. les of patients 90 to 105 years old. Mayo Clin Proc 1988;63.552-564.

77. Pham TD, Fenoglio JJ, Jr: Right atrial ultrashructural in chronic rheumatic heart disease. Int J Cardiol $1982 ; 1: 289-304$ 
79. Sanders P, Morton JE, Davidson NC, Spence, 51, Vohra IK, Sparks PB, Kalman JM: Electrical Remodeling of the Afria in Congestive Hearf Failure. Electrophysiological and Electroanatomic Mapping in Humans. Circulation 2003.

79. Li D, Shinogawa K, Pang L, Leung TK, Cardin S, Wang Z, Natiel S: EHects of angiotensin-converting enzyme inhibition on the development of the atrial fibrillotion substrate in dogs with ventriculor tachpocing-induced congestive heart foilure. Circulation 2001; 104:2608-2614.

80. Pedersen OD, Bagger $H$, Kober $L$. Torp-Pedersen $C$. Trandolapril reduces the incidence of atrial fibrillation after acute mocardial infarction in putients with left ventricullar dystunction. Circulation $1999 ; 100: 376-380$.

81. Vermes E, Tardif JC, Bourassa MG, Racine N, Levesque S, White M, Guerro PG, Ducharme A: Enalopril decreases the incidence of atrial fibrillation in patients with leff ventricular dystunction: insight from the Studies of Left Ventricular Dysfunction (SOLVD) trials. Circulation $2003 ; 107: 2926-293$ !

82. Madrid At4, Bueno MG, Rebollo JM, Marin I, Pena G, Bemal Ex Radriguez A, Cono L Cano JM, Cabeza $P$, Maro $C$ : Use of ibesarton to mointain sinus rhythm in potients with long-lasting persistent atrial fibrillation: a prospective and randomized study. Circulation 2002;106-331-336.

83. Pedersen $O D$, Bagger $H$, Kober $L$, Tarp Pedersen $C$ : The occurrence and prognostic significance of atrial fibrillation/-flutter following acute myocardial infarction. TRACE Study group. TRAndolapril Cardiac Evalution. Eur Heart J1999;20:748-754.

84. Sinno H, Derakhchan $K_{s}$ Libersan D, Merhi Y, Leung TK, Nottel S: Atrial ischemia promotes atrial finbrillation in dogs. Circulation 2003; 107:1930-1936.

85. Miyouchi Y, Zhou S, Okuyama Y, Miyauchi M, Hayashi H, Hamabe A, Fishbein MC. Mandel WJ, Chen LS, Chen PS, Karagueuzian HS: Allered Atrial Electrical Restitution and Heterogeneous Sympo. thetic Hyperimervation in Hearts With Chronic Left Ventricular Myocardial Infarction. Implications for Atrial Fibrillation. Circulation 2003.

86. Ohara K, MiyauchiY, Ohara T, Fishbein MC, Zhou S, Lee MH, Mandel WJ, Chen PS, Karagueuzion HS: Downregullation of immunodetectable atrial connexin 40 in a canine model of chromic left ventricular myocardial infaretion: implications to atrial fibrillation. J Cardiowasc Pharmacol Ther $2002 ; 7: 89-94$.

87. Moe GK, Rheinboldt WC. Abildskov JA: A computer model of atrial fibrillation. Am Heart J $1964: 67: 200-220$.

88. Zou $R$, Kneller $J$, Leon $L$, Nottel S: Development of a computer algorithm for the detection of phase singularities and initial application to andyze simulations of otrial fibrillation. Chaos 2002:12:764-778.

89. Virag $N$, Jacquemet V, Henriquez CS, Zozor S, Blanc O, Vesin JM, Pruvat E, Kappenberger L. Study of atrial arrhythmias in a computer model based on magnetic resonance images of human atria. Choos 2002;12:754.763.

90. van der Velden HM, von Kempen MI, Wiffels MC, won Zijverden M, Groemewegen WA, Allessie MA, Jongsma HJ: Allered pottern of comexin 40 distribution in persistent atrial fibrillation in the goat. If Cardiovasc Electrophysid 1998;9:596-607.

91. Schotien U, Neuberger HR, Allessie MA: The role of atrial dilatation in the domestication of atrial fibrillation. Prog Biophys Mol Biol 2003:82:151 \%,62. 


\section{CHAPTER 2}

\section{Inhibitors of the $\mathrm{Na}^{+} / \mathrm{H}^{+}$Exchanger Cannot Prevent Atrial Electrical Remodeling in the Goat}

Yuri Blaauw, MD; Norbert Beier, PhD; Pepijn van der Voort, MD; Arne van

Hunnink, BS; Ulrich Schotten, MD, PhD; Maurits Allessie, MD, PhD 


\section{ABSTRACT}

Introduction: It has been suggested that blockade of the $\mathrm{Na}^{+} / \mathrm{H}^{+}$exchanger (NHE 1 ) can prevent atrial fibrillation (AF)-induced electrical remodeling and the development of AF.

Methods and Results: AF was maintained by burst pacing in 10 chronically instrumented conscious goats. Intravenous and oral dosages of two NHEI blockers (EMD87580 and EMD125021) resulted in plasma-levels several magnitudes higher than required for effective NHE 1 blockade. Shortening of atrial refractoriness immediately after 5 minutes of AF was not prevented by NHEI blockade. In remodeled atria, increasing dosages of EMD87580 and EMD125021 did not reverse the shortening of the atrial refractory period or reduce the duration of AF episodes. The cycle length during persistent AF was also not affected. Oral pre-treatment with EMD87580 (8 mg/ $\mathrm{kg}$ b.i.d) starting 3 days before AF could not prevent electrical remodeling. After 24 and 48 hours of remodeling, the duration of AF paroxysms was respectively $47 \pm 32$ and $135 \pm 63$ seconds compared to $56 \pm 17$ and $136 \pm$ 52 seconds in placebo treated animais $(p>0.8)$, respectively.

Conclusion: In the goat model of $\mathrm{AF}$, the $\mathrm{Na}^{+} / \mathrm{H}^{+}$exchanger inhibitors EMD87580 and EMD 125021 did not prevent or revert AF-induced electrical remodeling. This indicates that activation of the $\mathrm{Na}^{+} / \mathrm{H}^{+}$exchanger is not involved in the intracellular pathways of electrical remodeling. This does not support the suggestion that blockers of the $\mathrm{Na}^{+} / \mathrm{H}^{*}$ exchanger may be beneficial for prevention and treatment of AF. 


\section{INTRODUCTION}

Atrial fibrillation (AF) induces electrophysiological changes that are characterized by a shortening of the atrial refractory period and a loss of its physiological rate adaptation. This electrical remodeling has been shown to play an important role in the development of persistent AF.' Studies on cellular electrophysiology revealed that the abbreviation of the action potential was mainly due to a reduction of the L-type $\mathrm{Ca}^{2+}$ current $\left(I_{C a . L}\right)^{2}$ Down-regulation of $I_{C a . L}$ is believed to be due to AF-induced $\mathrm{Ca}^{2+}$ overload. One of the factors which may enhance $\mathrm{Ca}^{2+}$ overload is intracellular acidosis. A metabolic mismatch during AF may lead to an accumulation of protons which is known to activate the $\mathrm{Na}^{+} / \mathrm{H}^{+}$exchanger (NHE 1). ${ }^{3}$ Extrusion of $\mathrm{H}^{+}$from the cell increases the intracellular $\mathrm{Na}^{+}$concentration, which may activate the reverse mode of the $\mathrm{Na}^{+} / \mathrm{Ca}^{2+}$ exchanger. This, in its turn, will increase the intracellular $\mathrm{Ca}^{2+}$ concentration of the cell. ${ }^{4}$

Inhibition of the $\mathrm{Na}^{+} / \mathrm{H}^{*}$ exchanger would interrupt this cascade and thus might be able to attenuate AF-induced electrical remodeling. The first studies addressing this possibility have produced inconsistent results. Jayachandran et al. showed that blockade of the NHEl indeed prevented shortening of atrial refractoriness during 5 hours of rapid pacing. ${ }^{5}$ In contrast, Shinagawa et al. showed no effect of NHE1 inhibition after 7 days. ${ }^{6}$ Thus, although blockade of the $\mathrm{Na}^{+} / \mathrm{H}^{+}$exchanger seems to be able to prevent short-term electrical remodeling, this beneficial effect is not maintained. The present study was designed to evaluate the effects of NHEI inhibitors on electrical remodeling in the goat during both short-term and long-term atrial fibrillation. Because NHEI blockers have few side effects, ${ }^{p / 3}$ prevention or reversal of electrical remodeling by these drugs could be of great potential for the treatment of AF.

\section{METHODS}

\section{Goat Model of Atrial Fibrillation}

Ten female goats (weight $54 \pm 4 \mathrm{~kg}$ ) were used for this study. The animals were handled according to the European Directive for Animal Research and the study protocal was approved by the Animal Investigation Committee of the University of Maastricht. During general anaesthesia, the heart was exposed and a double row of electrodes (inter-electrode distance $7 \mathrm{~mm}$ ) was wrapped around the AV groove. An. other band of electrodes (triple row; inter-electrode distance $5 \mathrm{~mm}$ ) was pulled through the space between the aortic root and Bachmann's bundle (Figure I). In addition, a small plaque with 3 electrodes was sutured on the free wall of the left ventricle. A silver plate was implanted subcutaneously to serve as indifferent electrode. The electrode leads were funnelled to the neck and exteriorized by four 30-pole connectors. The experiments were started 3 weeks after surgery. AF was induced by repetitive burst pacing as described by Wijffels et al.' The duration of AF paroxysms progressively increased during the first days, then AF became persistent 

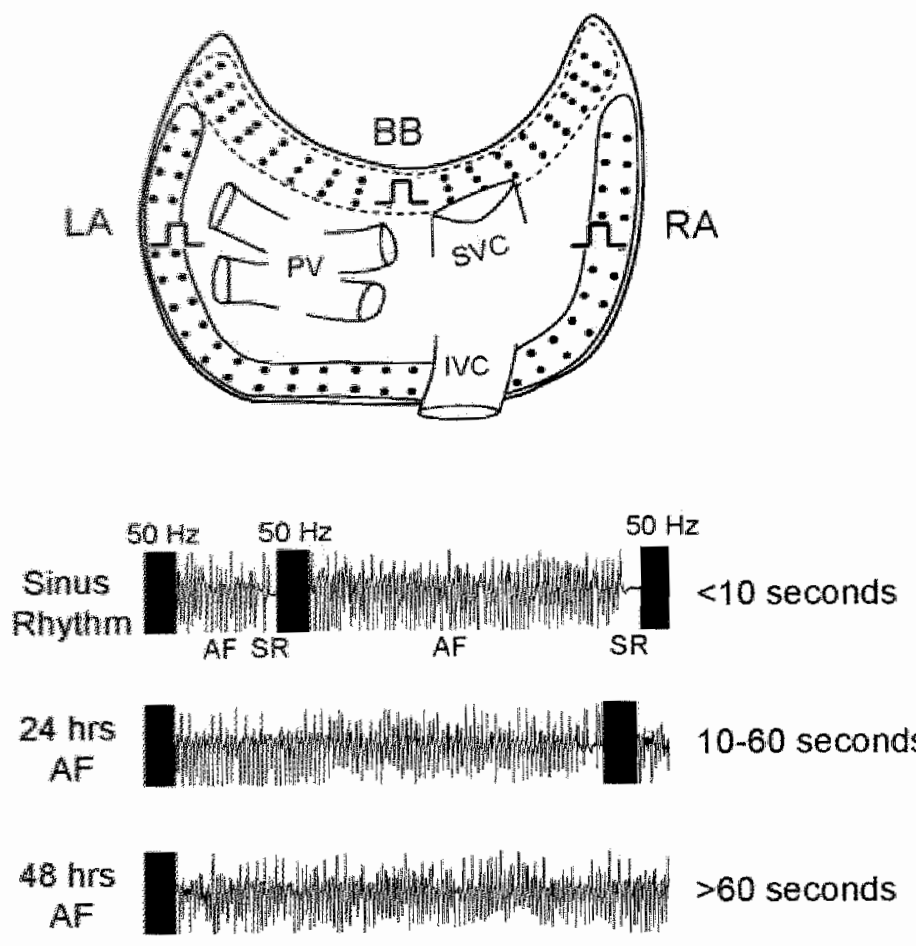

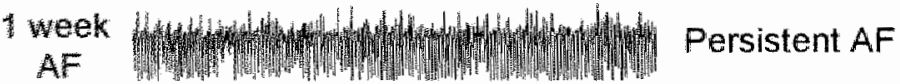

$$
1 \text { sec }
$$

Figure 1 Top: Dingram of the chronically implonted atrial electrodes. A long strip containing a double row of elgerodes was wropped around the atrio-ventricular groove and sutured to the lateral wolls of the righ ond lefi atrich oppendoges. Another strip with three rows of electrodes was positioned along (xuntham 's bundie and sulured to the anterior wall of the atrial appendages. Pairs of electrodes at the right alrium, left atrium and Bcchmann s bundle were used for pacing and measurement of atrial refracloriness. Botlon: induction of AF by burst pacing ( $50 \mathrm{~Hz}$ ). During sinus rhythm the episodes of AF losted * 10 saconds. Continuous re-induction of AF progressively prolonged AF duration until ofter 1 week AF become persistent. $B B=$ Bachmann's bundle, $L A=$ eft atrium, $R A=$ right cotrium, $P V=$ pulmonory vains, IVC = interior coval vein, SWC = superior caval vein.

atter 1.2 weeks (lower panel Figure 1). During AF, an approximately 1.5 fold increase in ventricular rate was observed (from $110 \mathrm{bpm}$ during sinus rhythm to 170 bpm during AF). The condition of the arimals was checked regularly and no noticeable clinical signs of heart failure (shortness of breath, oedema or changes in body weight /were observed. 


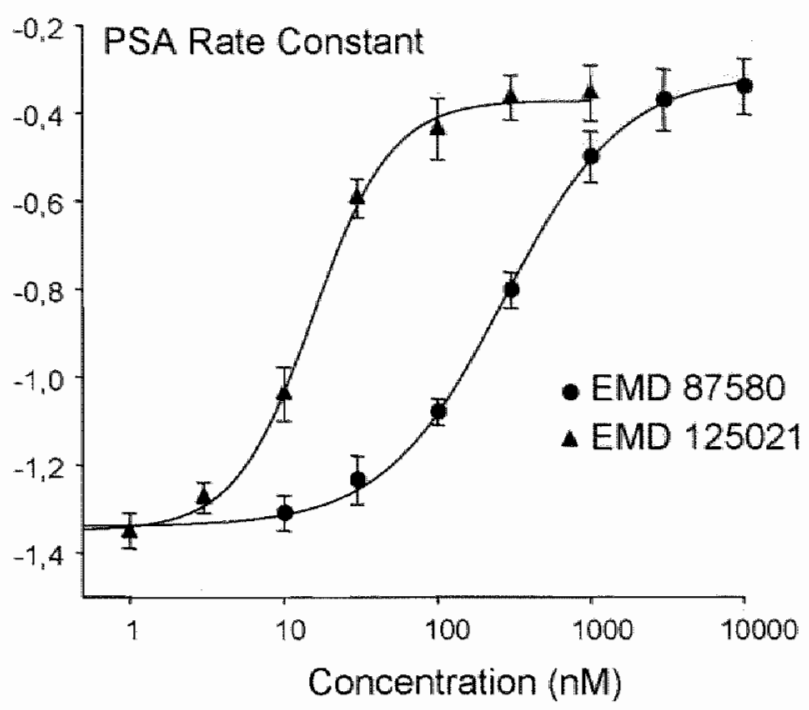

Figure 2: Dase response curves of NHE 1 inhibition by EMD87580 and EMD125021 in the gaat. An in witro platelet swelling was used to measure the activity of the $\mathrm{Na}^{+} / \mathrm{H}^{+*}$ exchanger. The curves show the platielet swelling rate cansiant $(x 0.001 / s)$ att different concentrations for each compound. Dala-points are the average volues of 2 gadts
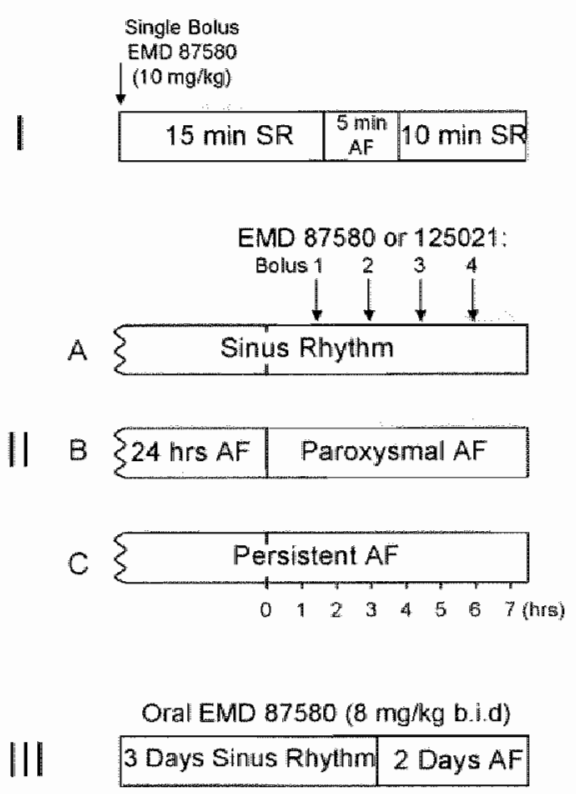

Figure 3: Schematic representation of the three experimental protocols. In protocal I, the effects of EMD87580 $(10 \mathrm{mg} / \mathrm{kg})$ on the changes in atrial refractoriness ofter 5 minutes of AF were studied. Protocol II consisted of three parts, which studied the eftects of cumulative dosages of EMDI25021 and EMD87580 in non-remodeled atria $(A)$, electrically remodeled atria $[B$, and during persistent $A F(C)$. Prolocoll III evalusated the possible preventive effects of oral treatment with EMD87580 on AF.induced electrical remadeling. 


\section{$\mathrm{Na}^{*} / \mathrm{H}$ Exchange Inhibitors (EMD87580 and EMD125021)}

Two selective inhibitors of the isoform 1 of the $\mathrm{Na}^{+} / \mathrm{H}^{*}$ exchanger were used: EMD87580 (N-[2-Methyl-4,5-bis(methylsulfonyl)-benzoyll-guanidine hydrochloride) and EMD125021 (N-[5-Methanesulfonyl-2-methyl-4-trifluoro-methoxy/ benzoyll-guanidine methanesulfate) (Merck KGaA). ${ }^{9}$ To demonstrate effective inhibition of the NHE 1 in the goat, a platelet swelling test was performed. ${ }^{10}$ In this test, propionic acid is added to platelet rich plasma. This leads to acidification of platelets and activation of the $\mathrm{NHE1}$. As a result, intracellular $\mathrm{Na}^{+}$concentration increases, leading to osmotic swelling. The concentration-response curves for EMDI25021 and EMD87580 are shown in Figure 2. The concentrations of EMD 125021 and EMD87580 which produced a 50\% reduction of platelet swell ling were 15 and $269 \mathrm{nM}$, respectively. These values correspond to a mass-concentration of respectively 7 and $105 \mathrm{ng} / \mathrm{ml}$. Because protein binding of EMD87580 has been shown to be very weak, this value can be regarded as the free plasma concentration. A similar situation can be assumed for EMD 125021. The dosages given in the present study produced plasma levels well above these effective dosages.

\section{Experimental Protocol}

Three different protocols were performed (Figure 3). In the first study, the effects of NHEI blackade on the shartening of the atrial refractory period following 5 minutes of AF was evaluated. Atrial refractoriness was measured during sinus rhythm, before and after AF, both during infusion of saline and after intravenous EMD87580 (10 $\mathrm{mg} / \mathrm{kg}$ ). The second protocol assessed the effects of NHE 1 blockade on atrial refractoriness and conduction velocity and consisted of three sub-studies (sinus rhythm, 24 hours AF, persistent AF). Two different NHE1 blockers were administered intravenously in incremental dosages of $1,3,10$ and $30 \mathrm{mg} / \mathrm{kg}$ (EMD87580), and $0.1,0.3,1$ and $3 \mathrm{mg} / \mathrm{kg}$ (EMD 125021) at 90 -minute intervals. The fwo compounds were studied in random order, with a washout period of at least 3 days in between. The third protocol was designed to test the hypothesis that oral administration of NHEI blockers can prevent electrical remodeling. Capsules with EMD87580 $(8 \mathrm{mg} / \mathrm{kg})$ were given twice daily starting three days before the induction of AF. Atrial refractory period, conduction velocity and duration of AF were measured both before and 24 and 48 hours after induction of atrial fibrillation. In each goat this prow tocol was performed with EMD87580 and placebo in random order. A period of at least 7 days was allowed between the experiments.

\section{Electrophysiological Measurements}

Atrial effective refractory periods (AERP) were measured at three sites, during a range of pacing frequencies $\left(S_{1}-S_{1}\right.$ interval $\left.400-200 \mathrm{~ms}\right)$. A single premature stimulus was interpolated at every eight basic interval and, starting well within the refractory period, the coupling interval $\left(S_{1}-S_{2}\right)$ was increased in $2 \mathrm{~ms}$ steps. The longest 


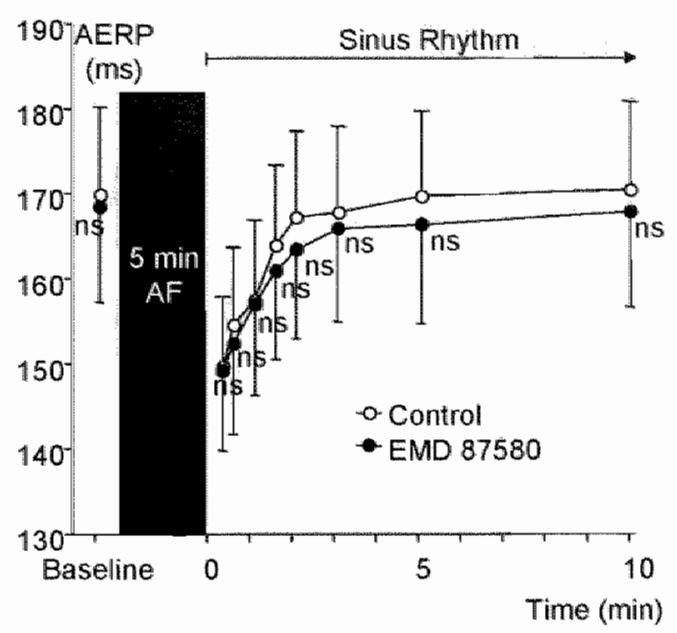

Figure 4: Absence of an effect of EMD87580 $(10 \mathrm{mg} / \mathrm{kg}$ i. . ) on shortening of atrial refractorness by 5 minutes of AF. Dota are mean values \pm SEM of five goats.

$S_{1}-S_{2}$ interval which did not capture the atria was taken as the AERP. The transient change in atrial refractoriness immediately after spontaneous termination of $\mathrm{AF}$ was measured as follows. "Synchronized premature stimuli ( $4 x$ threshold) were delivered at the right atrium after every six sinus beats incrementing the coupling interval in $2 \mathrm{~ms}$ steps. In this manner the AERP could be determined three to five times per minute. To collect sufficient data, these measurements were performed twice.

Atrial conduction velocity was calculated from the conduction times along Bachmann's bundle during pacing from the right atrium at cycle lengths of $400,300,250$ and $200 \mathrm{~ms}$. Conduction parallel to Bachmann's bundle was checked by similar activation times along the three rows of electrodes. The total distance over which the conduction velocity was measured ranged from 6 to $7.5 \mathrm{~cm}$.

The effects of EMD87580 and EMD125021 on the stability of AF were evaluated by measuring the duration of at leas 10 consecutive AF paroxysms. In case of persistent AF, changes in the median AF cycle length (AFCL) were monitored (300-500 consecutive fibrillation intervals). The effects on the ventricles were monitored by measuring the R-R interval, QRS duration and QT time from a left ventricular electrogram.

\section{Statistical Analysis}

Data are given as mean \pm SEM. Differences between graups were evaluated by the paired Student's t-test with the Bonferroni correction for multiple comparisons. Serial measurements of the AERP were analyzed using ANOVA for repeated measures. A p-value of $<0.05$ was considered as statistically significant. 


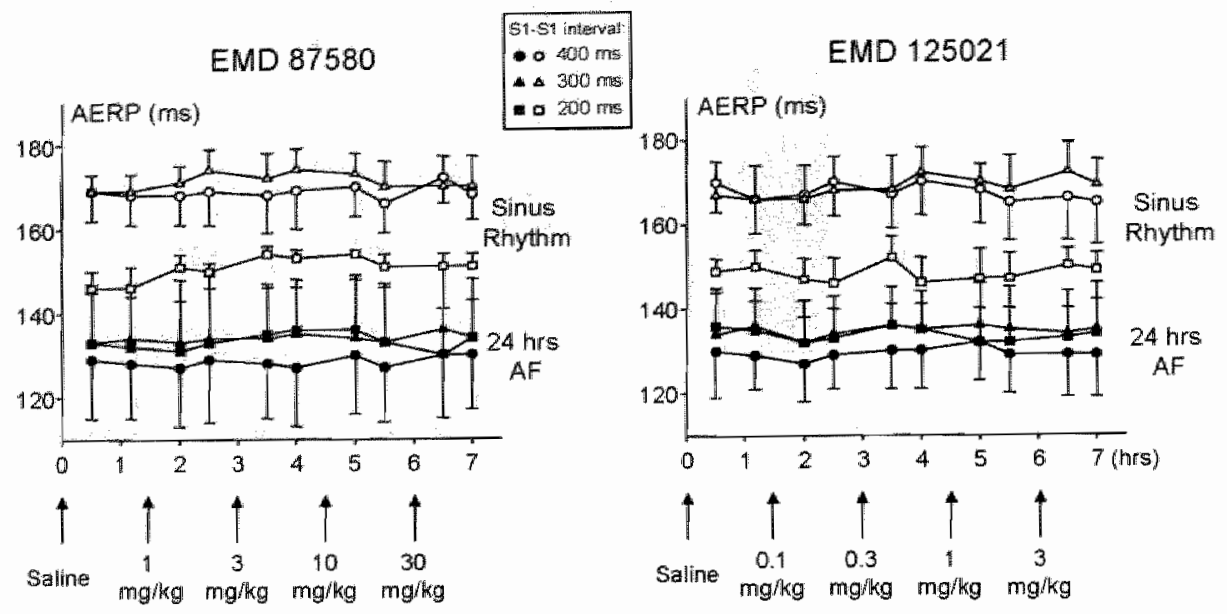

Figure 5: Meosurement of the atrial refractory period during cumulative dosages of EMD87580 and EMD 125021 during normal sinus rhythm and after 24 hours of AF. Three pocing rates were used $\left(S_{1}-S_{1}\right.$ interval: 400,300 and $200 \mathrm{~ms}$ ). Blockade of the $\mathrm{No}^{4} / \mathrm{H}^{+}$exchanger had no effect on AERP in both non-remodeled and electrically remodeled atria. Doto points are mean values ISEM of three airial sites in five goots.

\section{RESULTS}

\section{Short-term Rate Adaptation}

The effect of NHEl inhibition on shortening of the atrial refractory period following 5 minutes of AF was evaluated in 5 goats. The median atrial cycle length during sinus rhythm was $564 \pm 41 \mathrm{~ms}$ whereas during AF the median cycle length was $150 \pm$ $7 \mathrm{~ms}$. Adaptation of the atrial refractory period ofter 5 minutes of AF is shown in Figure 4. Immediately after termination of AF the AERP was shortened from $170 \pm 10$ to $149 \pm 9 \mathrm{~ms}$. NHE 1 blockade by EMD87580 did not affect the transient shortening of atrial refractoriness after termination of short-lasting AF. Both with and without EMD87580 the AERP returned to baseline within less than 2 minutes.

\section{Effects of NHEI Blockade on Atrial Electrophysiology}

Figure 5 shows the effects of EMD87580 and EMD125021 on steady-state atrial refractory periods during pacing at a cycle lengths of 400,300 and $200 \mathrm{~ms}$ both during sinus rhythm and after 24 hours of AF. The data points represent the average AERP at three atrial sites (right and left atrium and Bachmann's bundle) in 5 goats. As expected, AF shortened the AERP at all pacing rates. NHE1 blockers did not affect atrial refractoriness in either non-remodeled and remodeled atria. In addition, no statistically significant effect on atrial conduction velocity was abserved (Table). 

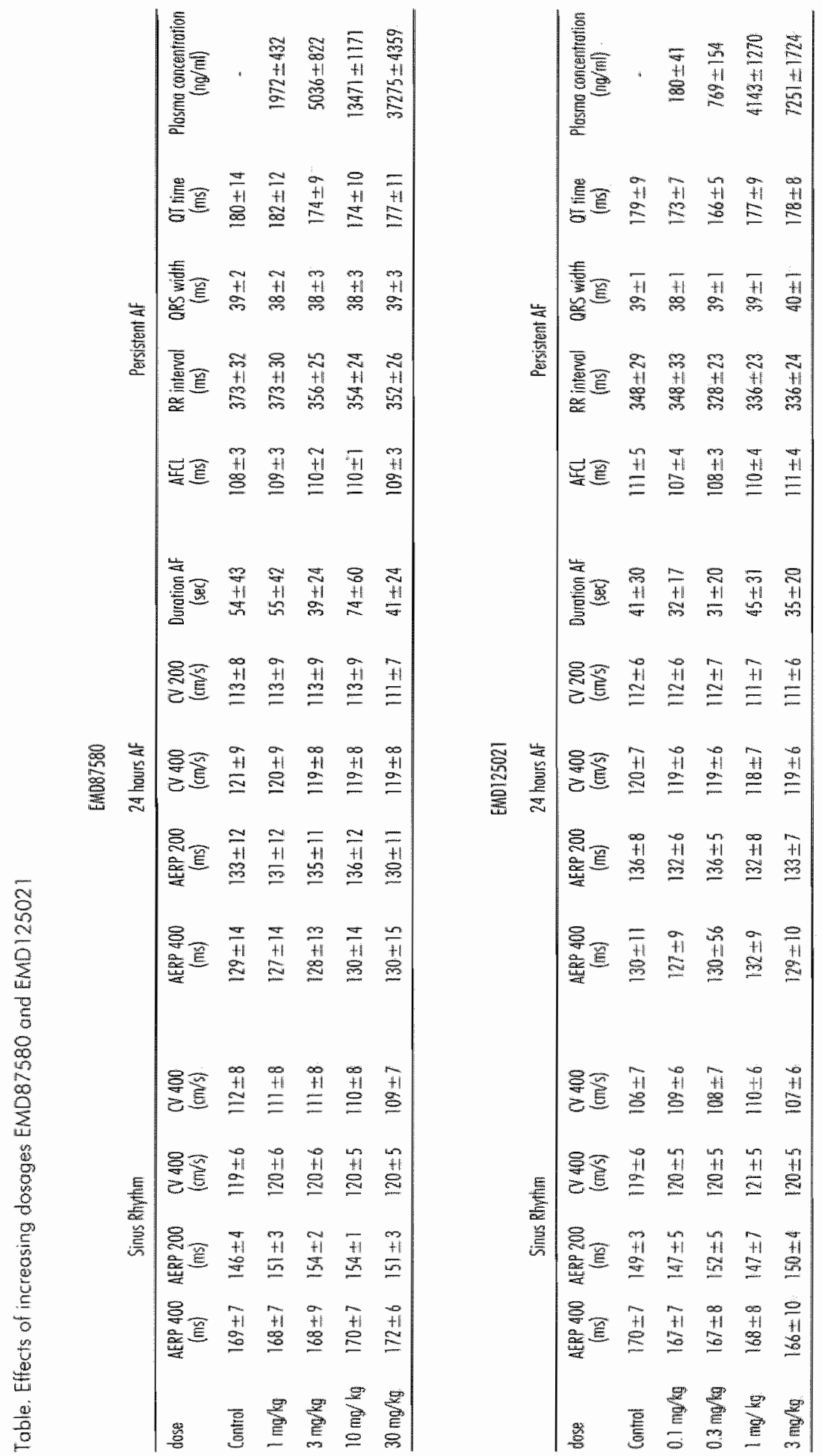

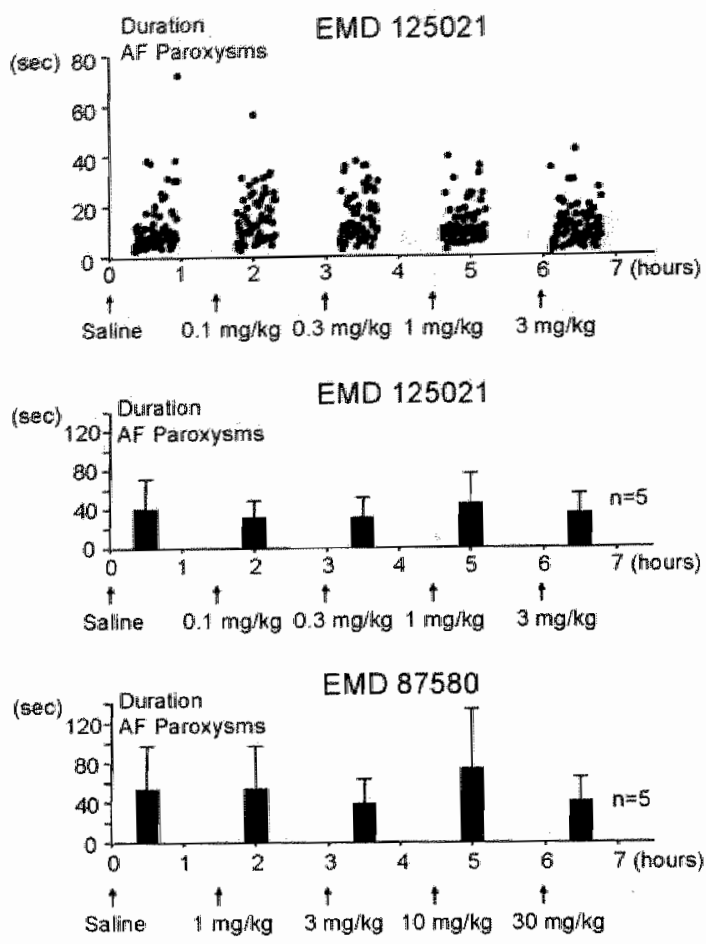

Figure 6: No effect of EMD87580 and EMD 125021 on the duration of AF paraxysms after 24 hours of electrical remodeling. Upper panel: Representative example in which the duration of each conseculive AF paroxysm is plotted individually. Lower panels: Median duralion of AF paroxysms at increosing dosagles of EMD125021 and EMD87580 are plotted for five goats (mean \pm SEM).

\section{Effects of NHEI Blockade on Paroxysmal and Persistent AF}

The effect of EMD87580 and EMD125021 on the duration of AF paroxysm is shown in Figure 6. In the upper panel, an example is shown in which more than 300 episodes of AF were induced consecutively at increasing dosages of EMD 125021. During saline infusion, the duration of AF paroxysms ranged from 3 to 73 seconds (median 9). EMD125021 did not shorten the duration of AF paroxysms. Even at the highest concentration $(3 \mathrm{mg} / \mathrm{kg}$ ) the median AF duration was still 12 seconds (range 2-42). The absence of an effect of EMDI25021 and EMD87580 on duration of AF paroxysms is shown for all goats in the middle and lower panels of Figure 6 and in the Table.

The effect of NHE blockers on persistent AF fduration $35 \pm 10$ days, range $21-70$ ) was evaluated in five goats. A representative example is shown in Figure 7. AFCL was monitored continuously for 7 hours. Every 90 minutes, a bolus of EMD 87580 (dosage increasing from 1 to $30 \mathrm{mg} / \mathrm{kg}$ ) was injected intravenously. No effect on AFCL was observed. In addition, EMD125021 had no effect on AFCL (Ta- 
Persistent AF:
Saline

EMD 87580

(3 $\mathrm{mg} / \mathrm{kg})$
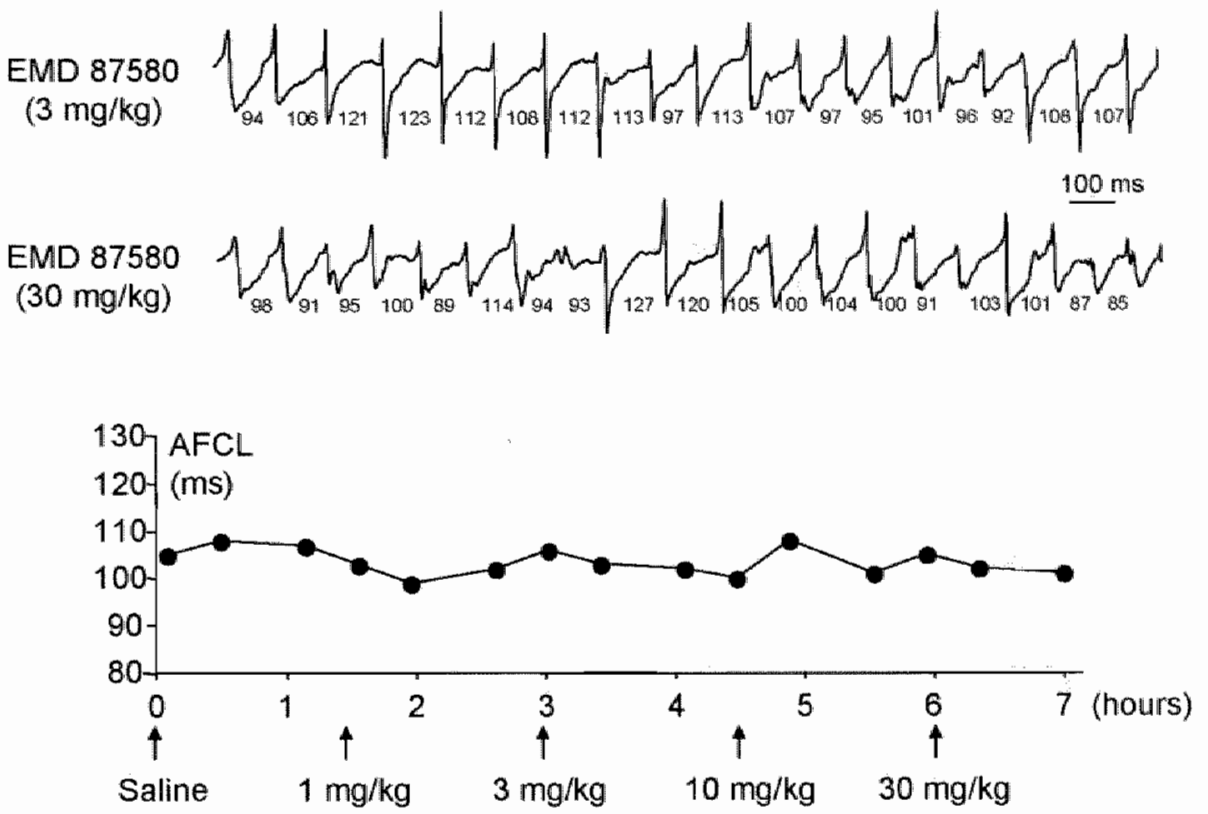

Figure 7: Unipolar atrial electrogram recorded from the right atrium during persistent AF. Infusion of EMD87580 up to a dosage of $30 \mathrm{mg} / \mathrm{kg}$ did not change AFCL. Bottom panel: Median AFCL. in the same goat during the whole experiment of 7 hours.
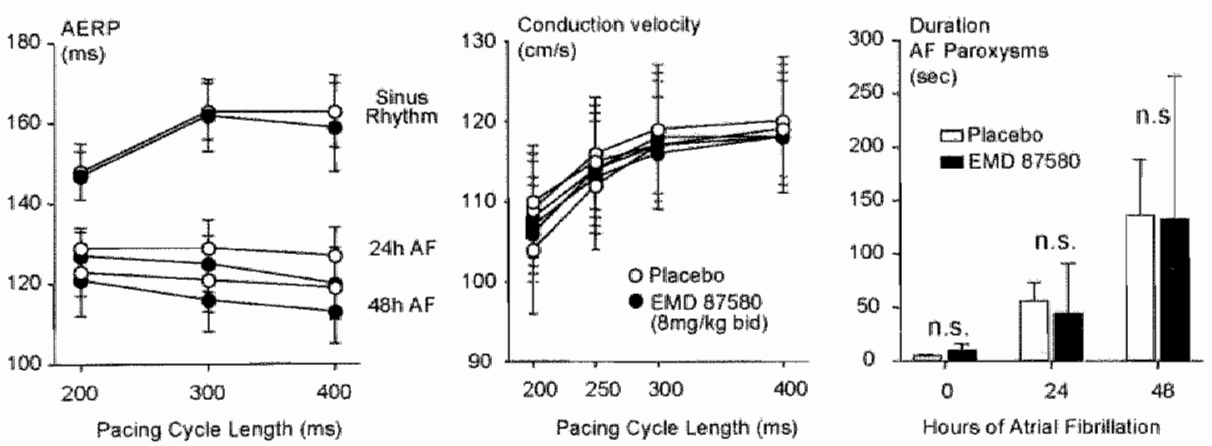

Figure 8 Effects of oral pretreatment with EMD87580 $8 \mathrm{mg} / \mathrm{kg}$ b.i.d.) on AF-induced elecirical remod. eling. Leff: No effect of EMD87580 on AF-induced shortening of AERP. Middle: No effect on conduction velocity (CV). Right: No effect on AF paroxysms. 
ble). None of the drugs converted AF. No statistically significant changes in RR interval, QRS dunation or QT interval were observed during persistent AF (Table).

\section{Prevention of Electricol Remodeling by Oral NHEI Blockade}

Prevention of electrical remodeling by oral treatment with EMD87580 $18 \mathrm{mg} / \mathrm{kg}$ b.f.d.) was studied in five gaats. Oral administration was started 3 days prior to induction of $A F$, resulting in a plasma concentration of $683 \pm 67 \mathrm{ng} / \mathrm{mL}$. The $\mathrm{Na}^{+} / \mathrm{H}^{+}$ exchanger inhibitor completely failed to prevent AF-induced electrical remodeling (Figure 8). Both AERP and conduction velocity did not differ from placebo-freated goats. Not surprisingly, the increase in duration of AF poroxysms due to electrical remodeling was not prevented by EMD87580. After 24 and 48 hours of AF, the duration of $A F$ paroxysms was $47 \pm 32$ and $135 \pm 63$ seconds compared to $56 \pm 17$ and $136 \pm 52$ seconds in placebo treated animals $(p=N S)$. In one additional goat in which AF became persistent already within 48 hours of remodeling, oral treatment with EMD87580 did not prevent early development of persistent AF.

\section{DISCUSSION}

\section{Metabolic Mismatch and Atrial Fibrillation}

An appropriate balance between myacardial axygen demand and coronary perfusion is required for optimal cardiac performance. In case of increased metabolic demand or reduced supply, compensatory mechanisms come into play. The high activation rates during $A F$ increase the metabolic demand of atrial myocytes. White et al. demonstrated that immediately after induction of AF, the myocardial oxygen consumption increased three-fold. ${ }^{12}$ To investigate whether this increased oxygen demand could be met by an increased coronary perfusion, Lau ef al. measured the arteriovenous difference in lactate in patients without ischemic heart disease. ${ }^{13}$ Myocardial lactate extraction did not increase during acutely induced AF. No changes in atrial ATP and lactate were found after 5 minutes of AF in dogs. "In the goat model of $\mathrm{AF}$, a decrease in atrial phosphocreatine occurred, without a concomitant decrease in creatine and ATP. ${ }^{15}$ Goette ef al. ${ }^{16}$ and Wiffels ef al. ${ }^{17}$ evaluated whether the ATP-dependent $K^{*}$ channel is activated during AF. No effect of the ATP-dependent $\mathrm{K}^{+}$channel blocker glibenclamide on AERP could be demonstrated. Thus, at present no clear evidence is available to support the hypothesis that atrial fibrillation leads to ischemia. However, this does not exclude that, in case of a reduced coronary reserve, a mismatch between axygen demand and supply may occur in fibrillating atria. 


\section{The role of Atrial Acidosis in Electrical Remodeling}

A factor that may contribute to atrial electrical remodeling is the development of intracellu ar acidosis during AF. In such a case, the $\mathrm{Na}^{+} / \mathrm{H}^{+}$exchanger will stant to exchange intracellular $\mathrm{H}^{+}$for extracellular $\mathrm{Na}^{*}$ ions. ${ }^{3}$ The resulting increase in intracellular sodium will activate the reverse mode of the $\mathrm{Na}^{4} / \mathrm{Ca}^{2+}$ exchanger which will lead to an increase of intracellular $\mathrm{Ca}^{2+4}$. in a recent study, Myata et al. demonstrated that selective blockade of the reverse mode of the $\mathrm{Na}^{+} / \mathrm{Ca}^{2+}$ exchanger by KB-R7943 indeed prevented electrical remodeling during 90 minutes AF. ${ }^{18}$ However, an increased intracellular $\mathrm{Na}^{*}$ concentration might not only result from an increase in NHEl activity, but may be due to an increased influx through the $\mathrm{Na}^{*}$ channels, the $\mathrm{Na}^{+}-\mathrm{HCO}_{3}$ cotransporter, the $\mathrm{Na}^{+} / \mathrm{K}^{+} / 2 \mathrm{Cl}$ cotransporter or the $\mathrm{Na}^{+4}-\mathrm{Mg}^{2+}$ antiporter. ${ }^{19}$

Inhibition of the NHE ? has been shown to prevent ischemia-induced shortening of the ventricular action potential ${ }^{20}$ and to reduce reperfusion arrhythmias. ${ }^{21}$ Administration of cariporide also led to spontaneous ventricular defibrillation. ${ }^{22}$ Because $\mathrm{Ca}^{2+}$ overload is believed to be involved in the intracellular signaling pathways leading to atrial electrical remodeling, it was hypothesized that blockade of the $\mathrm{NHEl}$ should prevent AF-induced shortering of atrial refractoriness. Jayachandran et al. were the first to evaluate the effects of NHE 1 inhibition on atrial ellectrical remodeling. In dogs subjected to 5 hours of rapid pacing, cariporide completely prevented the shortening of atrial refractoriness. In contrast, Shinagawo et al. found no beneficial effect of cariporide after 7 days of rapid pacing. ${ }^{6}$ In our present study, $\mathrm{NHE} 1$ inhibitors did not prevent shortening of atrial refractoriness after 5 minutes of AF, nor did it prevent electrical remodeling after 48 hours of AF. It is unclear why the results of Jayachandran et al. differ from the results obtained in the present study. However, there were several important differences in experimental conditions. In the study by layachandran et al, experiments were performed in anesthetized dogs under complete autonomic blockade, whereas in the present study awake goats with. out vagal or adrenergic blockade were used. It cannot be excluded that the NHEI plays a different role in AF in different species. The extent to which the heart can meet the higher metabolic demand will not only depend on anesthesia and autonomic blockade but also on the degree by which the coronary blood flow can increase. Since different species show a wide variation in coronary reserve, the degree of intracellular acidosis during AF may vary among different animals. In addition, expression of the NHEI in the heart may be genetically determined. Another explanation for the discrepant results of the different studies is that the compounds (EMD87580 and EMD125021) used in our study were less effective in blocking the $\mathrm{Na}^{+} / \mathrm{H}^{+}$exchanger than cariporide. However, this seems not very likely since cariporide is only about three-fold more potent than EMD87580, but six-fold less potent than EMD125021. In addition, the attained plasma-levels of EMD87580 and EMD125021 in the goat were several magnitudes higher than the concentra* tion required to block platelet swelling. Therefore, one must conclude that in the goat model of AF, activation of the $\mathrm{Na}^{*} / \mathrm{H}^{+}$exchanger plays no role in the process 
of AF-induced electrical remadeling. This does not mean that AF cannot cause a deficit between oxygen demand and supply. Metabolic mismatch can affect ion channels in different ways. Fearon et al. demonstrated that low $\mathrm{O}_{2}$ levels inhibits the cardiac L-type $\mathrm{Ca}^{2+}$ current ${ }^{23}$ whereas prevention of electrical remodeling by the anti-oxidant ascorbate suggests an important role for oxidative stress in $\mathrm{AF}^{2{ }^{24}}$

\section{Prevention of AF-induced Electrical Remodeling}

Atrial electrical remodeling has been shown to occur in different species in response to rapid pacing, atrial flutter or fibrillation. 1,25,26 Several studies pointed to an important role of the L-type $\mathrm{Ca}^{2+}$ current. ${ }^{2,27,28}$ Prevention of tachycardia-induced remodeling has been disappointing. L-type $\mathrm{Ca}^{2+}$ channel-blockers and $\mathrm{ACE}$-inhibitors delayed the time course of remadeling ${ }^{16,29,30}$ but failed to prevent the long-term effect. 43 Our present study shows that also NHEI inhibitors did not prevent or revert long-term electrical remodeling.

\section{Acknowledgements}

The authors gratefully acknowledge the technical support of Jörg Rothenstein for performing the platelet swelling tests.

\section{REFERENCES}

1. Wiffels MC, Kirchhor CJ. Dontand R, Allessie MA: Atriall fibrillation begets atrial fibrillotion. A study in awoke chronically instrumented goats. Circulation 1995;92:1954-1968.

2. Vue L, Feng J, Gaspo R, Li GR, Wang $Z$, Nattel S: llonic remadeling underlying action potential changes in a conine model of atrial fibrillation. Circ Res 1997,81:512-525.

3. Aronson PS: Kinetic properties of the plasma membrane Mat-H+ exthonger. Annu Rev Physiol $1985 ; 47: 545-560$

4. Kimura J, Noma A, Irisowa H: Na.Ca exchange current in mammalian heart cells. Nature $1986,319: 596,597$

5. Jayachandron JV, Zipes DP, Weksler 1 . Olgin JE: Role of the $\mathrm{Na}(+\mathrm{H} / \mathrm{H}(+)$ exchanger in short-tern atrial electrophysiolagical remodeling. Circulation 2000; $101: 1861$ - 1866 .

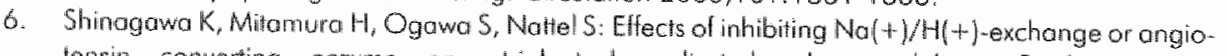
tonsin conwerting anzyme on atrol tochycardic-induced remodeling. Cardiovasc Res $2002,54: 438-4: 16$.

7. Thenaw P, Chatman BR, Danchin N, Erhardt L, Meinent. T, Schroeder JS, Tognoni G, White HD, Willerson JT, Jessel A: Inhibition of the sodium-hydrogen exchonger with coriporide to prewent myocardial inlarction in high-risk ischemic situations. Main resuls of the GUARDIAN trial. Guard during ischemia agoinst necrosis (GUARDIAIN) lnwestigators. Circulation 2000;102:3032-3038.

8. Zeymer U, Sunyopranata H, Monossier JP, Opolski $G$. Dawies J, Rasmonis $G$, Linssen $G$, Tebbe U, Schroder $R$, Tiemonn R, Mochnig T, Neuhous $K$. The $N a(+1 / H(+)$ exchange inhibitor eniporide os an adjunct to early reperfusion therapy for acute myocardial infarction. Resuls of the evaluation of the sallety and cardioprotective effects of eniporide in acule myocardial infarction (ESCAMI) mal. J Am Coll Cardiol 2001;38:1644:1650.

9. Beier N, Brondle $M$, Ehring T, Garicke R, Minck KO, Schelling P: Cardioprotective effects of the NHET-inhibitor EMO 87580. J Mol Cell Curdiol 2001;33:A10. 
10. Rosskopl D, Margenstern E, Scholz W, Osswald U, Siffer W: Rapid determination of the elevaled $\mathrm{Na}(+)-\mathrm{H}+$ exchange in platelets of patients with essential hypertension using an optical swelling as: soy. J Hypertens 1991;9:231-238.

11. Duytschaever M, Danse P, Allessie M: Supenulnerable phase immediately alter termination of atriol fibrillation. J Cardiovasc Electrophysiol 2002;13:267-275.

12. White CW, Kerber RE, Weiss HR, Marcus ML: The effects af atrial fibrillation on atrial pressure-volume and flow relationships. Circ Res 1982,51:205-215.

13. Lau $C P$, Leung $W H$, Wong $C K$, Cheng $C H$ : Haemodynamics of induced atrial fibrillation: a comparative assessment with sinus thythm, atrial and ventricular pacing. Eur Heart J 1990, 11:219-224.

14. Leistad $E_{\text {r }}$ Aksines $G$, Verburg $E$, Christensen $G$ : Atrial contractile dystunction atter short-ferm atrial fibrillation is reduced by verapamil but increased by BAY K8644. Circulation 1996;93:1747-1754.

15. Ausmo J, Coumons WA, Duimel $H$, Van der Vusse GJ, Allessie MA, Borgers. M: Atrial high energy phosphate content and mitochondrial enzyme octivity during chronic atral fibrillation. Cardiovasc Res 2000; $47: 788$-796.

16. Goette A, Honeycutt C, Langberg JI: Electrical remodeling in otrial fibrillation. Time course and mechanisms. Circulation 1996:94:2968-2974.

17. Wijffels MC, Kirchtrof $C J$, Dorland R, Power $J_{2}$ Allessie MA: Elecirical remodeling due to airial fibrillation in chronically instrumented conscious goots: roles of neurchumoral changes, ischernia, atrial stretch, and high rate of electrical activation. Circulation 1997:96:3710-3720.

18. Mirata A, Zipes DP, Hall S, Rubart M: Kb-R7943 prewents acule, atrial fibrillationinduced shortening of atrial refractoriness in anesthelized dogs. Circulation 2002;106:1410-1419.

19. Bers DM, Barry WH, Despa S: Iniracellular $\mathrm{Na}(+)$ regulation in cardiac myacytes. Cardiovasc Res $2003 ; 57: 897-912$.

20. Wirth KJ, Maier T, Busch AE: NHET-inhibitor cariporide prevents the transient reperfusion-induced shortening of the monophasic action potential after coronary ischemia in pigs. Basic Res Cardial 2001:96:192-197.

21. Duan J, Karmazyn M: Protective effects of amiloride on the ischemic reperfused rat heart. Relation to mitochondrial function. Eur I Pharmacol 1992;210:149-157.

22. Gazmuri RJ, Ayout IM, Hoffner E, Kalarowa JD: Successful ventricular defibrillation by the selective sodium-hydragen exchanger isoform-1 inhibitor cariporide. Circulation 2001;104:234-239.

23. Fearon IM, Palmer AC, Balmforth AJ, Ball SG, Mikala G, Schwortz A, Peers C: Hypoxio inhibits the recombinart alpho $1 \mathrm{C}$ subunit of the human cardiac Lutype Ca2+ channel. J Physiol 1997;500 (Pt 3):551-556.

24. Carnes CA. Chung MK, Nakayama I, Nakayama H, Baliga RS, Piao S, Kanderian A, Pavia 5 , Hamlin RL, MicCarthy PM, Baver JA, Van Wagoner DR: Ascorbate altenuates atrial pacing-induced peroxynitrite formotion and electrical remodeling and decreases the incidence of postoperctive atrial fibrillation. Circ Res 2001;89: E32-38.

25. Morillo CA, Klein GJ, Jones DL, Guiraudon CM: Chronic rapid atrial pacing. Structural, functional, and electrophysiological chanacteristics of a new model of sustained atrial fibrillation. Circulation 1995:91: 1588-11595.

26. Franz MR, Karasik PL, Li C. Moubarak, Chavez Ma Electrical remodeling of the hurizan atrium; silmtlar effecis in patients with chronic atrial fibrillation and otrial flutter. I Am Coll Candiol $1997 ; 30: 1785-1792$.

27. Bosch RF, Zeng X, Grammer JB, Popovic Ko Mewis C, Kuhlkamp V: lonic mechanisms of electrical remodeling in humon atrial fibrillation. Cardiovasc Res 1999;4:4:121.131.

28. Vom Wogoner DR, Pond AL, Lomorgese M, Rossie SS, McCarthy PM, Nerbonne JM: Airial L-type $\mathrm{Ca} 2+$ currents and human atrial fibrillation. Circ kes 1999;85:428-436.

29. Nokashima H, Kumagai K, Urata H, Gando N, Ideishi M, Arakawa K. Angiotensin ll antagonist prevents electrical remadeling in afral fibrillation. Circulation 2000,101:2612-2617.

30. Tieleman RG, De Langien C, Van Gelder IC, de Kam PJ, Grandiean J, Bel KJ, Wiffels MC, Allessie

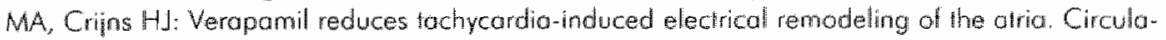
tion 1997,95:1945.1953.

31. Lee SH, Yu WC, Clyeng IJ, Hung CR, Ding YA, Chong MS, Chen SA: Effect of veropomil on long-term tachycardia-induced alrial electrical remodeling. Circulation 2000;101:200-206. 


\section{CHAPTER 3}

\section{Consequences of Atrial Electrical Remodeling for the Anti-Arrhythmic Action of Class IC and Class III Drugs}

Mattias Duytschaever, MD*, PhD; Yuri Blaauw, MD*; Maurits Allessie, MD, PhD

* Both authors contributed equally 


\section{ABSTRACT}

Objective: Atrial fibrillation (AF) induces electrical and ionic remodeling of the atria. We investigated whether AF-induced remodeling alters the electrophysiological and anti-fibrillatory effects of class 1 (flecainide) and class III (d-sotalol, ibutilide) anti-arrhythmic drugs.

Methods: In 9 goats, the effects of flecainide $(6 \mathrm{mg} / \mathrm{kg})$ and d-sotalol $(6 \mathrm{mg} / \mathrm{kg})$ on atrial electrophysiology were measured both before and after 48 hours of electrically induced AF. During a 1 -hour infusion period the atrial effective refractory period (AERP) and conduction velocity (CV) were measured both during slow and rapid pacing (interval 400 and $200 \mathrm{~ms}$ ). $\ln 8$ other goats, the rate-dependent effects of ibutilide $(0.12 \mathrm{mg} / \mathrm{kg})$ on AERP were determined.

Results: The effects of flecainide on atrial conduction and refractoriness were not altered after 48 hours of AF. At a dose of $6 \mathrm{mg} / \mathrm{kg}$ flecainide reduced the CV200 by $19 \pm 5 \%$ in normal atria and by $21 \pm 9 \%$ atter 48 hours of AF $(p=0.20)$. The AERP200 was prolonged by $10 \pm 6 \%$ and $8 \pm 7 \%$ respectively $(p=0.40)$. In contrast, the effect of $d$-sotalol on atrial refractoriness was markedly diminished. During control d-sotalol prolonged the AERP 400 by $17 \pm 6 \%$ compared to only $6 \pm 5 \%$ after 2 days of AF $(p<0.01)$. Also ibutilide lost much of its class Ill effect on the AERP by electrical remodeling (from 15 to $5 \% ; p<0.05$ ). The loss of class III action was less pronounced at rapid heart rates.

Conclusions: AF-induced atrial electrical remodeling in the goat did not modulate the action of flecainide on atrial conduction and refractoriness. In contrast, the class III effects of $d$-sotalol and ibutilide on the atria were strongly reduced after 2 days of AF. The prolongation of QT duration was not affected. 


\section{INTRODUCTION}

Experimental and clinical studies have established that atrial fibrillation (AF) induces a shortening of atrial refractoriness (electrical remadeling) , ${ }^{1,2}$ This AF-induced shortening of the atrial action potential has been shown to be due to downregulation of a number of ionic currents (ionic remodeling). The L-type $\left.\mathrm{Ca}^{2 *}, I_{C_{0} .}\right)$, the transient outward current ( $\left.\|_{\text {ro }}\right)$ and the ultrarapid delayed rectifier current $\left(I_{\text {Kur }}\right)$ become reduced after prolonged rapid atrial pacing or $A F F^{3-5}$ Whereas Lai et al. showed a reduced expression of HERG in humans with longstanding $A F,{ }^{6}$ others found no changes in HERG or $I_{K_{r}}$ current density. ${ }^{3,7}$

It remains unclear whether AF also induces depression of intra-atrial conduction and/or downregulation of $I_{\mathrm{Na}}$ current. In a canine model, rapid atrial pacing was associated with a slowing of intra-atrial conduction and reduction of the rapid $\mathrm{Na}^{*}$ current $\left(\|_{\mathrm{Na}}\right){ }^{8}$ In contrast, in patients with chronic AF, densities and biophysical properties of $\|_{N a}$ were found to be unaltered. "Similarly, in the goat conduction velocity remained unaltered, suggesting no major changes in sodium current. ${ }^{2}$

If the relative contribution of different ionic currents to the atrial action potential changes by electrical remodeling, also the sensitivity for certain specific ion-channel blockers may be altered. This may explain why some antiarrhythmic agents lose their efficacy to cardiovert AF with time. ${ }^{10.12}$

In the present study we evaluated the changes in electrophysiological effects of class IC and class III drugs in the goat model of 'lone' AF. The effects of intravenous infusion of flecainide, $d$-sotalol and ibutilide on atrial refractoriness and conduction were measured both before and after 48 -hours of atrial fibrillation.

\section{METHODS}

\section{The Goat Model of Atrial Fibrillation}

Seventeen goats ( $46 \pm 14 \mathrm{~kg}$ ) were used for this study. The experiments were carried out according to the Guide for the Care and Use of Laboratory Animals published by the US National Institutes of Health (NIH Publication No. 85-23, revised 1996) and approved by the Animal Investigation Committee of the University of Maastricht. Anesthesia was induced by administration of Nesdonal $(15 \mathrm{mg} / \mathrm{kg})$ and maintained by ventilation with halothane $(1-2 \%)$ and a mixture of $\mathrm{O}_{2}$ and $\mathrm{N}_{2} \mathrm{O}$. A thoracotomy was made to expose the heart and a teflon-felt plaque containing 30 electrodes $(3 \times 2.5 \mathrm{~cm}$, inter-electrode distance $4 \mathrm{~mm})$ was sutured on the free wall of each atrium. A $70 \mathrm{~cm}$ lang plaque with three rows of electrodes (54 electrodes; inter-electrode distance $5 \mathrm{~mm}$ ) was implanted on Bachmann's bundle (BB) from the tip of the right to the tip of the left atrial appendage. A small plaque with 3 electrodes was sutured on the left ventricle. Three silver plates were left under the skin of the thorax to record a precordial ECG and to serve as indifferent electrode. The leads were tunneled subcutaneously to the neck and exteriorized by four 30-pole 
connectors. Postoperatively the animais received buprenorfine for $2-4$ days. Experiments were started $3-4$ weeks after surgery. Atrial fibrillation was induced by an automatic fibrillation pacemaker as described previously. ${ }^{2}$ Custom-made sofware continuously anatyzed the atriat rhythm of one of the unipolar atrial electrograms. As soon as sinus rhythm was detected, a 1 second burst of biphasic stimuli (duration $2 \mathrm{~ms}$, interval $20 \mathrm{~ms}$, $4 x$ pacing threshold) was applied by a pacemaker (Medronic SP3084) to reinduce AF. In this way atrial fibrillation could be maintained 24 haurs a day, seven days a week. Prewious experiments have shown that under these conditions atrial electrical remodeling is nearly complete after 48 hours.

\section{Electrophysiological Measurements}

The atria were paced with biphasic stimuli of $2 \mathrm{~ms}$ duration ( $4 x$ threshold) generated by a constant current generator. Atrial effective refractory periods (AERP) were determined at the free wall of the right (RA) and left atrium (LA) during bipolar stimulafion at pacing cycle lengths between 400 and $200 \mathrm{~ms}$. Single interpolated stimuli were applied after every 8 th basic stimulus starting well within the refractory period. The longest S1-S2 interval that failed to capture the atria (increments $2 \mathrm{~ms}$ ) was taken as the AERP. Atrial conduction welocity was measured along $B B$ during right atrial pacing with a cycle length of 400 and $200 \mathrm{~ms}$. Longitudinal conduction along $B B$ was checked by comparing the (similar) activation times of the three parallel rows of electrodes on Bachmann's bundle. Inducibility of AF was measured by applying single early premature stimuli to the free wall of the right or left atrium during regular pacing with a cycle length of $400 \mathrm{~ms}$. AF was considered inducible if a premature stimulus induced a rapid irregular rhythm lasting $>1$ second. This criterion was used to exclude induction of only one or a small number of extra beats. The duration of the QRS complex (QRSD) and the QT interval were determined from a unipalar ventricular electragram during atrial pacing at a cycle length of $400 \mathrm{~ms}$.

\section{Experimental Protocol}

The effects of flecainide and d-sotalol were investigated in 9 goats both before and after electrical remodeling during 48 hours of AF. These experiments were performed in random order and were separated by at least one week of normal sinus rhythm during which the atria completely recovered from an earlier episode of remodeling and drug administration: 13 Before each drug, a baseline study was performed during 30 -minutes of saline infusion. During this baseline period the refractory period of the right $(n=6$ goats) or left atrium ( $n=3$ goats) and the cond $u c$. tion vellocity along Bachmann's bundle were measured every 10 minutes during regular pacing with an interval of 400 and $200 \mathrm{~ms}$. Then flecainide or $d$-satalol were adlministered at a constant infusion rate of $0.1 \mathrm{mg} / \mathrm{kg} / \mathrm{min}$ and the ellectrophysiological measurements were repeated every 10 minutes. After one hour of drug infusion the inducibility of AF was re-evaluated by applying single early premature stimuli at the RA $(n=6)$ or $L A(n=3)$. The electrophysiological action of ibutilide 
was studied in a separate series of 8 goats Ibutilide was infused at a rate of 0.002 $\mathrm{mg} / \mathrm{kg} / \mathrm{min}$ for 1 hour. To evaluate both the rate- and site-dependent action of ibutilide, the refractory period was measured at pacing intervals of $400,350,300$, 250,225 and $200 \mathrm{~ms}$ both at the RA and LA.

The chosen drug dosages were based on previous experiments in the goat. ${ }^{14}$ At the dosages used the drugs were well tolerated and the electrophysiological effects were comparable to the effects of clinically used dosages. Clinically, flecainide (2 $\mathrm{mg} / \mathrm{kg}$ ) prolongs the QRS duration by $18 \%$ whereas $\mathrm{d}$-sotalol $(1.5 \mathrm{mg} / \mathrm{kg})$ and ibutilide $\left(2 \mathrm{mg} / 30 \mathrm{~min}\right.$ ) prolong the QT time by respectively $15 \%$ and $22 \%{ }^{16,17} \mathrm{In}$ our experiments flecainide widened the QRS complex by $15-18 \%$ and $d$-sotalol and ibutilide prolanged the QT time by respectively $19-23 \%$ and $9.11 \%$. Thus, although in the goat the dosages were higher than used clinically, the biological effects of flecainide, $d$-sotalol and ibutilide were comparable.

\section{Statistical analysis}

For the flecainide and $d$-sotalal experiments data of the right $(n=6)$ and left atria $(n=3)$ were pooled. The effects of ibutilide on RA and LA are given separately. Data are given as mean $\pm S D$. Differences between groups were determined by the paired Student's t-test. Serial measurements were analyzed by ANOVA with repeated measures. A p-value of $<0.05$ was considered as statistically significant.

\section{RESULTS}

\section{Flecainide}

The effects of flecainide on atrial conduction before and affer 48 hours of AF are shown in Figure 1. In the example in the left panel, flecainide lowered the conduction velacity along Bachmann's bundle during rapid pacing (interval $200 \mathrm{~ms}$ ) from 121 to $95 \mathrm{~cm} / \mathrm{s}$ in non-remodeled atria $(-21 \%)$ and from 133 to $105 \mathrm{~cm} / \mathrm{s}$ in remodeled atria $(-21 \%)$. In the right panel the effects of flecainide on atrial conduction ( $\$ 1$-S1: $200 \mathrm{~ms}$ ) are plotted for all goats $(n=9)$. Before and after electrical remodeling, conduction velocity along Bachmann's bundle was similar $(124 \pm 12$ versus $125 \pm 14 \mathrm{~cm} / \mathrm{s} ; \mathrm{p}=0.79)$. At a dosage of $6 \mathrm{mg} / \mathrm{kg}$, flecainide depressed atrial conduction in normal atria by $19 \pm 5 \%$ and after 48 hours of AF by $21 \pm 9 \%(p=0.20)$. Also at lower pacing rates the effect of flecainide on atrial conduction and refractoriness was not affected by electrical remodeling (Table 1). During rapid pacing flecainide increased the AERP by $8-10 \%(p=0.4)$ and during slow pacing by $4.7 \%$ $(p=0.53)$. Also the prolongation of the QRS complex by flecainide was not affected by 2 days of AF (15 vs. 18\%; $p=0.72$ ) (Table 1). 
Normal Atria

Baseline

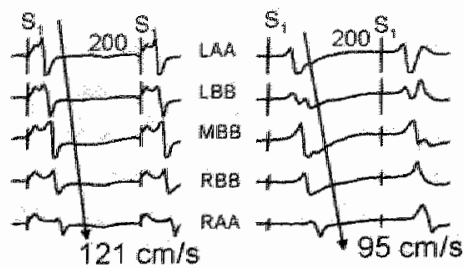

Remodeled Atria (48h AF)

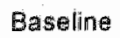

Flecainicle
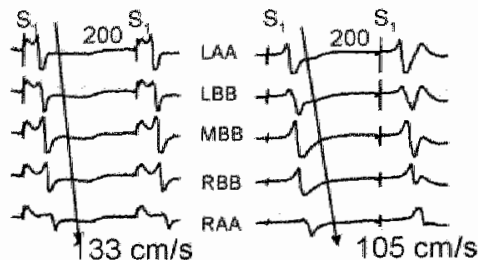

\section{$\mathrm{CV}_{200}(\mathrm{~cm} / \mathrm{s})$}

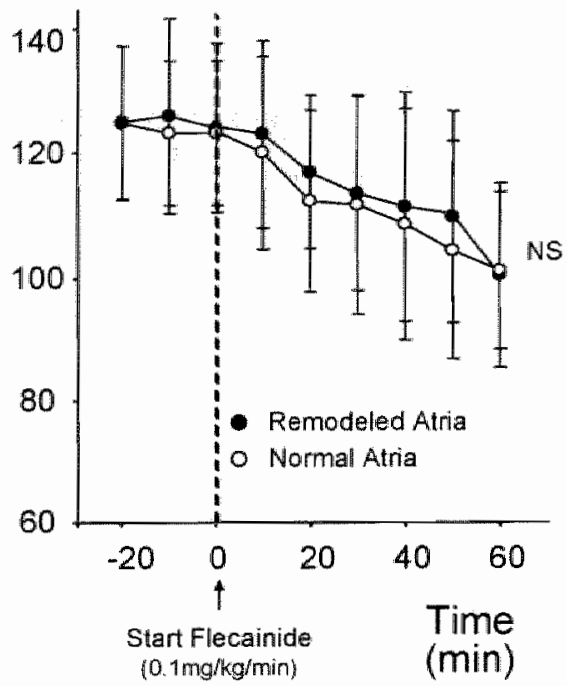

Figure 1: Effects of flecainide on conduction velocity along Bachmann"s bundle during rapid atrial pacing from the left atrial (ree wall ( $\$ 1-\$ 1: 200 \mathrm{~ms}$ ). Left: Electrograms recorded along Bachmonn's bundle. Both before (normal atria) and after $48 \mathrm{~h}$ of remodeling, flecainide $(6 \mathrm{mg} / \mathrm{kg})$ significantly depressed atricl conduction velocity. Right: Equal effects of fleccinide on atrial conduction during a 1 hour infusion $(0.1 \mathrm{mg} / \mathrm{kg} / \mathrm{min}$ ) in 9 goals belore lopen circles) and after remodeling (closed circles). LAA = left atrial appendage, $B$ Bleft = left part of Bochmann's bundle, $B B$ mid = middle part of Bachmonn's bun. dle, $B$ Bright = right part of Bochmonn's bundle, $R A A=$ right atrial oppendage. $N S=$ non-significant
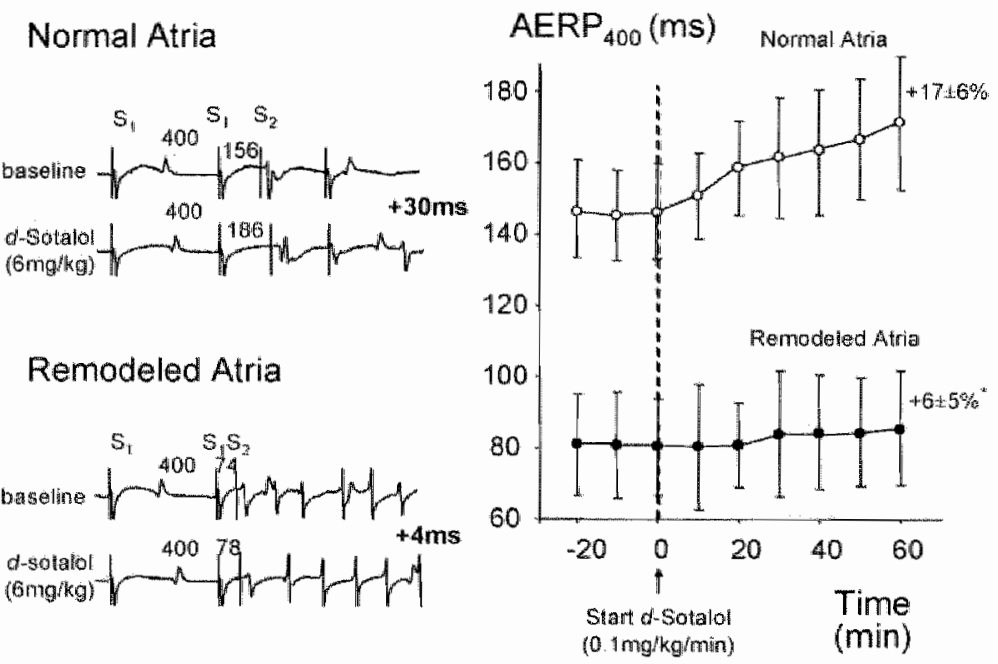

Figure 2: Effects of d.sotalel on atrial refractoriness in normal and remodeled atria (S1.S1:400 ms). Lett: In normal alrio d-sotalol (6mg/ $\mathrm{kg}$ ) pralonged the AERP from 156 to $186(+30 \mathrm{~ms})$, whereas after $48 \mathrm{~h}$ of $\mathrm{AF}$ the AERP lengthened only by $4 \mathrm{~ms}$ (from 74 to $78 \mathrm{~ms}$ ). Incluction of AF was not prevented by the high dosage of d-sotalol. Right: The average effects of $d$-sotalol on the AERP4OD in normol and remodeled atric $[n=9)$. " $p<0.01 ; \Delta \%$ nomal versus remodeled. 


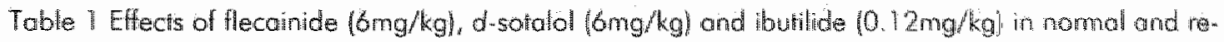
modeled Atria.

\begin{tabular}{|c|c|c|c|c|c|}
\hline & $\begin{array}{c}\text { QRSD or QT } \\
\text { (ms) }\end{array}$ & $\begin{array}{l}\text { AERP4OO } \\
\text { (m)s) }\end{array}$ & $\begin{array}{c}\text { AERP200 } \\
\text { (Ims) }\end{array}$ & $\begin{array}{l}\text { Cv400 } \\
(\mathrm{cm} / \mathrm{s})\end{array}$ & $\begin{array}{r}\mathrm{C} / 200 \\
(\mathrm{~cm} / \mathrm{s})\end{array}$ \\
\hline \multicolumn{6}{|l|}{ Flecainide } \\
\hline Normal & $37 \pm 1$ & 14419 & $138 \pm 6$ & $132 \mathrm{~s}$ & $124 \pm 12$ \\
\hline Flecoinide & $43 \pm 1$ & $149 \pm 10$ & $151 \pm 5$ & $119 \pm 15$ & $101 \pm 13$ \\
\hline$\Delta *$ & $+15 \pm 2 \%$ & $+4 \pm 9 \%$ & $+10+6 \%$ & $-10+8 \%$ & $-19+5{ }^{\circ}$ \\
\hline Remodeled & $37 \pm 5$ & $83 \pm 16$ & $93 \div 20$ & $135 \pm 14$ & 1254 \\
\hline Fleccinide & $43 \pm 4$ & $88 \pm 16$ & $100+20$ & $118 \pm 14$ & $99 \pm 16$ \\
\hline$\Delta \%$ & $+18 \pm 13 \%$ & $+7 \pm 7 \%$ & $+8 \pm 7 \%$ & $-13 \pm 7 \%$ & $-21 \pm 9 \%$ \\
\hline \multicolumn{6}{|l|}{ d-sotalol } \\
\hline Normal & $229 \pm 18$ & $146 \pm 13$ & $142 \pm 7$ & $128 \pm 17$ & $123 \pm 14$ \\
\hline d-sotaloll & $273 \pm 28$ & $171 \pm 19$ & $165 \pm 8$ & $125 \pm 16$ & $117 \pm 14$ \\
\hline$\Delta \%$ & $+23 \pm 7 \%$ & $+17 \pm 6 \%$ & $+17 \pm 5 \%$ & $-2 \pm 4 \%$ & $-5 \pm 10 \%$ \\
\hline Remadeled & $221 \pm 20$ & $81 \pm 14$ & $87 \pm 17$ & $133 \pm 15$ & $128 \pm 12$ \\
\hline d-sotalol & $257 \pm 27$ & $85 \pm 16$ & $99 \pm 19$ & 132415 & $126 \pm 14$ \\
\hline$\Delta \%$ & $+19 \pm 7 \%$ & $+6 \pm 5 \%(* 4)$ & $+13 \pm 5 \%$ & $-1 \pm 1 \%$ & $-2 \pm 4 \%$ \\
\hline \multicolumn{6}{|l|}{ Ibutilide } \\
\hline Normal & $218 \pm 17$ & $158 \pm 16$ & $145 \pm 15$ & $130 \pm 70$ & $118 \pm 2$ \\
\hline Ibutilide & $241 \pm 23$ & $182+23$ & $158+13$ & $128 \pm 11$ & $111 \pm 15$ \\
\hline$\Delta \%$ & $+11 \pm 5 \%$ & $+15 \pm 7 \%$ & $+12 \pm 4 \%$ & $-1 \pm 3 \%$ & $-7 \pm 5 \%$ \\
\hline Remodeled & $213 \pm 17$ & $93 \pm 17$ & $114 \pm 15$ & $127 \pm 17$ & $122 \pm 11$ \\
\hline buttilide & $233 \pm 26$ & $98 \pm 19$ & $126+18$ & 127118 & $115+14$ \\
\hline$\Delta \%$ & $+9 \pm 6 \%$ & $+5 \pm 7 \%(*)$ & $+10 \pm 7 \%$ & $+0 \mathrm{e} 4 \%$ & $-6 \sin 6 \%$ \\
\hline
\end{tabular}

"p<0.05," $p<0.01 ; \triangle \%$ normal versus remodeled, QRSD: duration of the QRS complex

\section{$d$ Sotalol}

The class III effects of $d$-sotalol before and after electrical remodeling are shown in Figure 2 . In non-remodeled atria d-sotalol $(6 \mathrm{mg} / \mathrm{kg}$ ) clearly prolonged the atrial refractory period. In the given example the AERP 400 at the RA prolonged from 156 to $186 \mathrm{~ms}(+30 \mathrm{~ms})$. As expected, after 48 hours of AF atrial refractoriness was abbreviated and the $A E R P_{400}$ had shortened to $74 \mathrm{~ms}$. Single premature stimuli now induced paroxysms of AF. Administration of the same dosage of d-sotalol $(6 \mathrm{mg} / \mathrm{kg})$ prolonged the AERP 400 of the RA by only $4 \mathrm{~ms}$ (from 74 to $78 \mathrm{~ms}$ ) and induction of AF was not prevented. In the right part of figure 2 , the effects of $d$-sotalol on the 


\section{Normal Atria}
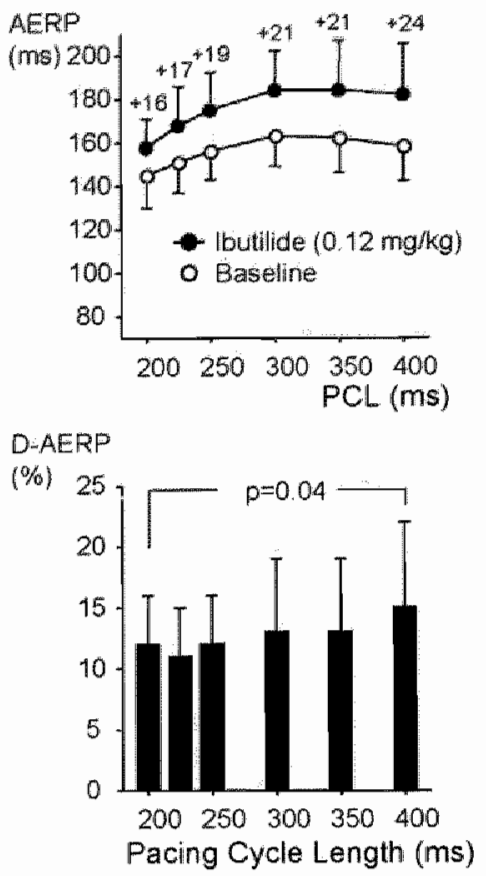

\section{Remodeled Atria}

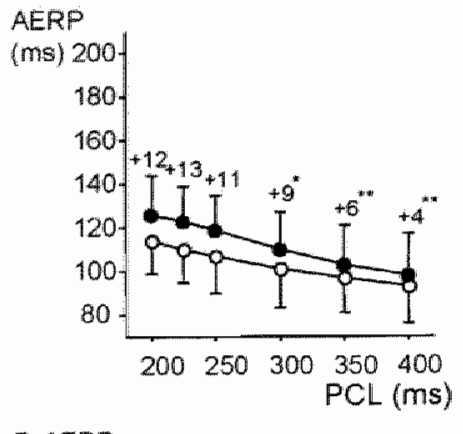

D-AERP

(\%)

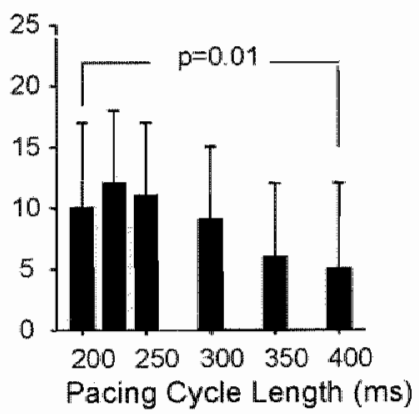

Figure 3: Effects of ibutilide $(0.12 \mathrm{mg} / \mathrm{kg})$ an atrial refractoriness at different heart pates before ond after remodeling $(n=8$; pooled data of right and left atrium). In normal atria (llett) ibutilide prolonged the AERP in a rewerse frequency-dependent way. In remodeled atria (right) the class Itl effect was reduced, especially at slow heart rates. As a result the reverse frequency-dependence of ibutilide was changed into o slight frequency-dependence.
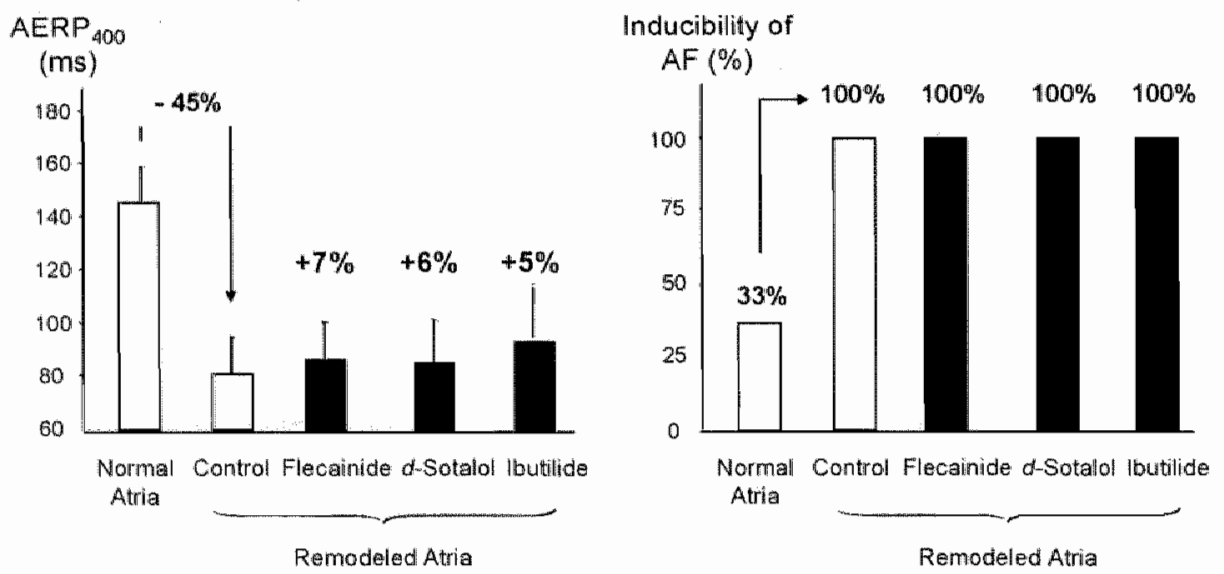

Figure 4: Effects of fleccinide, desotalol and ibutilide on atrial refractoriness and inducibility of AF by single premature stimuli in electrically remodeled atria (48h of AF). Atter $48 \mathrm{~h}$ of AF the atrial refractory period had shortened by $45 \%$ and premature stimuli induced AF in 100\% of the cases. All three drugs prolonged the AERP only slightly $(5-7 \%)$ and none of them could prevent initiation of AF. 
$\mathrm{AERP}_{400}$ are plotted for all 9 goats. At a dosage of $6 \mathrm{mg} / \mathrm{kg}$, d-sotalol prolonged the $\mathrm{AERP}_{400}$ in normal atria by $17 \pm 6 \%$ and by $6 \pm 5 \%$ after 2 days of $A F(p<0.01)$. As shown in Table 1, this loss of class III effect was less at higher pacing rates. During pacing at a cycle length of $200 \mathrm{~ms} d$-sotalol still prolonged the refractory period in remodeled atria by $13 \pm 5 \%$ compared to $17 \pm 5 \%$ during control $(p=0.10)$. The prolongation of the QT time by d-sotalol was the same before and after 48 hours of atrial fibrillation ( $23 \%$ vs $19 \% ; p=0.20)$.

\section{Ibutilide}

In a separate series of 8 goats the site-dependent class III effect of ibutilide was studied before and after 2 days of AF. Whereas in normal atria ibutilide $(0.12 \mathrm{mg} / \mathrm{kg})$ prolonged the AERP 400 of the right and left atrium respectively from $161 \pm 17$ and $1.56 \pm 17 \mathrm{~ms}$ to $186 \pm 25(15 \pm 8 \%)$ and $180 \pm 24 \mathrm{~ms}(16 \pm 9 \%)$, in remodeled atria the class III effect was reduced to $4 \pm 7$ and $6 \pm 8 \%(p<0.05)$. In figure 3 and Table 1 , the average effects on the right and left atrial refractory period are given. The rate-dependence was evaluated by measuring the effects on atrial refractoriness at different cycle lengths between 400 and $200 \mathrm{~ms}$. In non-remodeled atria a normal physiological rate adaptation was present and the AERP shortened from $158 \pm 16$ to $145 \pm 15 \mathrm{~ms}$. Ibutilide $(0.12 \mathrm{mg} / \mathrm{kg}$ ) prolonged the atrial refractory period less at faster than at slower pacing rates (24 $12 \mathrm{vs} .16 \pm 5 \mathrm{~ms}$ al 400 and $200 \mathrm{~ms}$ interval), resulting in a slight increase in the slope of the normal rate-adaptation curve. In electrically remodeled atria the physiological rate adaptation was lost and became slightly inverted (right part figure 3). Note that at low pacing rates the AERP was now shorter ( $93 \pm 17 \mathrm{~ms}$ ) than during rapid pacing (114 $\pm 15 \mathrm{~ms})$. In remodeled atria the class III effect of ibutilide was reduced al all pacing rates. However, since this lass was more marked at slower rates, 2 days of AF converted the normal reverse rate-dependence of ibutilide into a moderate rate-dependent acfion. At a cycle length of $400 \mathrm{~ms}$ the AERP was prolonged by $4 \pm 6 \mathrm{~ms}$ compared to $12 \pm 9$ ms during pacing with a cycle length of $200 \mathrm{~ms}(p<0.05)$.

\section{Effects of Flecainide, d-Sotalol and Ibutilide on Inducibility and Duration of AF}

In figure 4 the effects of flecainide, $d$-sotalol, and ibutilide on the inducibility of AF are given. After 48 hours of atrial electrical remodeling, flecainide, d-sotalol and ibutilide prolonged the AERP by only $5-7 \%$. Compared to normal atria, the class III effect of $d$-sotalol and ibutilide was significantly decreased (Table 1). In non-remodeled atria premature stimuli induced atrial fibrillation in $33 \%$ of the animals. Due to the shortening of atrial refractoriness, in remadeled atria single premature stimuli induced AF in $100 \%$ of the cases. Even at high dosages none of the drugs could prevent the induction of AF (still 100\%). Administration of flecainide, d-sotalol, or ibutilide also did not shorten the median duration of AF paroxysms. With and with. out drugs, paroxysms of AF lasted respectively 4 (range 1-44) and 7 seconds (2-52) 
(Mecainide), $4(1-59)$ and 3 seconds (1-62) (d-solalol) and 4 (2-500) and 3 seconds (1-8) (ibuthide); all $\mathrm{p}=\mathrm{MS}$.

\section{DISCUSSION}

\section{Main findings}

In the present study we evaluated the effects of 2 days of AF-induced electrical remodeling on the electrophysiological action of ane class IC (Necainide) and two class 1 ll agents (d-sotalol and ibutilide). The effect of flecainide an atrial conduction and refractoriness was not changed by electrical remodeling. In contrast, the class IIl effect of $d$-sotalol and ibutilide were strongly reduced. All three drugs failed to prevent induction of atrial fibrillation in electrically remodeled atria by single premature beats.

Importantly, the effects on the QRS complex and QT duration were similar before and after atricl remodeling, suggesting that the biological availibility of the drugs were not different. The effective dosages in our experiments were comparable to the clinically used dosages since the prolongation of the QRS complex and QT interval was similar to the changes observed clinically. ${ }^{15.17}$

\section{Consequences of Electrital Remodeling for the Action of Class IC Drugs}

Class IC anti-arrhythmic agents are often used for termination of atrial fibrillation. However, various clinical studies have shown that the anti-fibrillatory efficacy of class $1 C$ drugs declines when AF persists for a longer period of time. ${ }^{10,11} \mathrm{Crijn}$ et al. showed that thecainide cardioverted AF in $74 \%$ of patients if given less than 24 hours after the start of the arhythmia. In contrast, when AF had persisted for longer than 24 hours, flecainide did not terminate AF in any of the patients."

The failure of flecainide to cardiovert AF of $>24$ hours can be explained either because electrical remadeling makes the fibrillatory process more resistent to class I drugs, ${ }^{18}$ or because it diminishes the class I action of the drug itself. The latter possibility could be excluded in the present study by showing that 48 hours of AF did not alter the electrophysiological action of flecainide an altrial conduction and refracto. riness. This supports the concept that failure of class IC drugs to cardiovert AF must be due to a higher resistance of $A F$, rather than to a lower sensitivity of remodeled atrial myocardium to sodium channell blockers.

Our finding that the effect of fleccinide on atrial conduction was unaltered in remodeled atria is in agreement with other studies. Sato et al. showed that slowing of conduction by the class IC agent pilsicainide was not affected by 14 days of rapid atrial pacing in the dog. Wiffels et al. observed that flecainide still markedly depressed atrial conduction in goats after more than 4 weeks of persistent AF. ${ }^{20}$ Like in our previous studies we observed only a maderate but consistent rate dependent prolongation of the AERP by flecainide. ${ }^{14,20}$ in the present study we observed that this 
prolongation was not affected by electrical remadeling. This moderate prolongation is different from studies by Wang et al. who found that propatenone caused a marked and use-dependent prolongation of refractoriness in canine atria. ${ }^{21}$ In human atria, Le Grand et al. showed that flecainide only increased the action potential duration and effective refractory period if the transmembrane potentials had a long plateau preceded by a notch. ${ }^{22}$

It still remains to be determined whether the presenved electrophysiological effects of flecainide on atrial conduction means that the $I_{\text {No }}$ current is unaltered in remodeled atria. Whereas conduction velocity and $l_{\mathrm{NG}}$ current density were found to be reduced in remodeled canine atria, ${ }^{8,23}$ in the goat, intra-atrial conduction was not altered after several weeks of AF. ${ }^{2}$ Also in patients with chronic AF the density of $I_{\text {Noo }}$ current was not changed. ${ }^{9}$

\section{Consequences of Electrical Remodeling for the Action of Class III Drugs}

Although class III agents are often used to prevent or terminate atrial fibrillation, ${ }^{24}$ several observations suggest that they become less effective in the setting of electrical remodeling. Tieleman et al. showed that class III antiarrhythmic drugs could not prevent early recurrences of AF after successful electrical cardioversion. ${ }^{25}$ Similarly, in the SAFIRE-D study the probability to maintain sinus rhythm for at least 7 days after electrical cardioversion was not different in patients treated with dofetilide or placebo. Only after a follow up of 1 year dofetilide turned out to be slightly superior to placebo in preventing AF recurrences. ${ }^{26}$ The efficacy of class III drugs to terminate AF clearly declines when AF is present for a longer period of time. Whereas ibutilide terminated AF of recent-onset in approximately $70 \%$ of patients, this success rate dropped to $30 \%$ in cases of long-lasting AF. ${ }^{10,12}$

In the present study we tested the hypothesis that AF-induced electrical remodeling reduces the electrophysiological effects of class III drugs. We found that the prolangation of atrial refractoriness was significantly reduced after 2 days of atrial fibrillation. This loss of class Ill action was the same in the right and the leff atrium. Neither d-sotalol or ibutilide could prevent re-induction of AF by single premature beats in remodeled atrio (inducibilify 100\%). These findings imply that class III drugs can not be expected to prevent early recurrences of AF in remodeled atria. It has been shown that most relapses accur during the first days after cardioversion of $A F$ when the atrial refractory period is stitl short. ${ }^{25}$ It may take several days before the atria are recovered from electrical remodeling and the normal electrophysiological action of $I_{k, s}$ blockers is restored.

Our findings are in agreement with other studies. Li et al showed that the ability of dofetilide to prolong atrial refractoriness and to cardiovert AF was lower in dogs subjected to prolonged rapid atrial pacing compared to dogs with congestive heart failure and normal AERPs. ${ }^{27}$ Also in humans there are indications that the action of class III drugs is affected by electrical remodeling. Tse et al. reported a reduced ef. fect of $d$-sotalot on atrial refractoriness in patients with previous episodes of atrial fibriltation. ${ }^{2 B}$ Opposite results were reported by Shiroshila-Takeshita et al. who 
abserved a preserved effect of the $\mathrm{I}_{\mathrm{K}}$ blocker $\mathrm{E} 4031$ and the $\mathrm{I}_{\mathrm{ks}} / \mathrm{I}_{\mathrm{Ks}}$ blocker azimilide in dogs subjected to 14 days of rapid atrial pacing. ${ }^{29}$ However, in the latter study the degree of electrical remodeling was quite moderate and the $\mathrm{AERP}_{400}$ was only shortened by $27 \mathrm{~ms}$ after 14 days of rapid pacing.

The mechanisms responsible for the reduced effect of class III drugs in electrically remodeled atria remain speculative. Both d-sotalol and ibutilide prolong the action potential mainly by blocking the rapid component of the delayed rectifier $\mathrm{K}^{+}$current $\left(I_{k r}\right.$ blockade) ${ }^{30}$ Still only limited information is available regarding the effects of AF on $I_{k e}$. Whereas Lai et al, showed a reduced expression of HERG in humans with longstanding AF, others found no changes in HERG or $I_{k,}$ current density. ${ }^{3,7}$ Theoretically a reduced HERG expression (or $I_{k,}$ current density) would lead to a greater efficacy of $I_{K r}$ blockade. The reduced availability of $I_{k r}$ channels reduces the repolarization reserve and will render the atria more vulnerable to blockade of repolarizing currents. The fact that we observed a lower rather than a higher efficacy of $I_{K r}$ blockers in remodeled atria raises some doubts about the significance of the reported changes in HERG expression. An alternative explanation for the reduced class III effect of $I_{k r}$ blocking agents might simply be that the contribution of this current to atrial repolarization is reduced. When the action potential is shortened by a reduction of the plateau phase due to down-regulation of the $I_{C_{0.1}}$, the membrane will be repolarized by earlier activated potassium currents like $I_{\text {to }} I_{\text {Kach }}$ and $I_{\text {Kur }}$ Because $\|_{K_{r}}$ is activated later during the action potential, the actual contribution of this current may diminish. Under these conditions, blockade of $I_{K r}$ channels obviously will exert less effect. This latter explanation, proposed by the group of Nattel, is based on a mathematical model of the human atrial action potential in which inhibition of the $I_{k s}$ current produced less prolongation of the action potential when the cells were "electrically remodeled'. ${ }^{3 i}$ These investigators stated that: 'because $I_{k r}$ is activated relatively late during the action potential, the inhibition does not disturb the delicate balance of currents during phase 1 repolarization or during the initial phase of the action potential plateau'. These computer simulations were recently supported by experimental evidence from the goat showing that the reduced efficacy of $I_{k r}$ blockers could be immediately and completely restored by restoration of the plateau phase of the remodeled atrial action potentials. ${ }^{32}$

\section{Limitations}

Arr important limitation of the present study is that no in-vitro studies were performed. For this reason, the cellular mechanisms underlying the loss of class III effect of $\mathrm{I}_{\mathrm{kr}}$ blackers remain speculative. Obviously, additional studies will be required to determine the ionic basis of the changed action of class III drugs in electrically remodeled atria.

Although we did not verify plasma concentrations, the effects of flecainide, d'sotallol and ibutilide on QRS and QT duration were the same before and after electrical remodeling. It therefore seems highly unlikely that the reduced class III action was the result of a lower effective dosage. All drugs were infused at a single 
constant rate during 1 hour. Steady state dose-dependent effects were not measured. On the other hand, since the effective dosage during a 1 hour infusion period gradually increases, we can exclude that our abservations are limited to a single or narrow range of dosages.

Extrapolation of experimental results to the human situation should always be done with great caution. Marked differences exist in the distribution of cardiac ionic currents beiween species. In humans the duration of the action potential is longer than in goats and also the degree of AF-induced electrical remodeling is less. "It is therefore quite possible that in humans the reduced class III effect of $I_{k,}$ blockers is less marked than in gaats. In addition, electrophysiological measurements were only performed at the free wall of the right and left atrium. We cannot exclude that in other parts of the atria (especially with longer action potentials) the action of class III drugs is affected differently. Opposite to our findings Li et al. demonstratted marked regional differences in action potential duration between the right and left atrium of the dog. ${ }^{33}$ Differences in species and experimental conditions may explain these discrepancies.

\section{REFERENCES}

1. Franz MR, Karasik PL, Li C, Moubarak J, Chavez M. Electrical remodeling of the human atrium: similor effects in patients with chronic atrial fibrillation and atrial flutter. I Am Coll Cordiol 1997:30:1785-92.

2. Wiffels MC, Kirchhof CJ, Dorland R, Allessie MA. Atrial fibrillation begets atrial fibrillation. A study in awake chronically instrumented goats. Circulation 1995:92:1954-68.

3. Yue L, Feng J, Gaspo R, LI GR, Wang Z, Nottel S. Ionic remodeling underlying adtion polential changes in a canine model of atrial fibrillation. Circ Res 1997;81:512-25.

4. Van Wagoner DR, Pond AL, McCarthy PM, Trimmer JS, Nerbonne JM. Outward K + current densities and Kv1.5 expression are reduced in chranic humon atrial fibrillation. Circ Res 1997;80:772-81.

5. van der Velden HMW, van der Zee L, Wiiffels MC, van Leuven C, Dorland R, Wos MA. Airial fibrillathon in the goat induces changes in manophasic action potential and mRNA expression of ion channels involved in repolarizotion. J Cardiovasc Electrophysiol 2000;11:1262-69.

6. Lai LP. Su MJ, Lin J, Lin FY, Tsai CH, Chen YS. Chonges in the mRNA levels of delayed rectilier potassium channels in human atrial fibrillation. Cardiology 1999:92:248-55.

7. Brundel B., Wan Gelder IC, Henning RH, Tuinenburg AE, Wielses $M$, Grandjean JG, Wilde AA, Van Gillst WH, Crijns HJ. Alterotions in potassium channel gene expression in atria of potients with persis. tent and paroxysmal atrial librillation: differential regulation of protein and mRNA levels for $K+$ chonnels. J Am Coll Cardiol 2001;37:926-32.

8. Gaspo R, Bosch RF, Bou-Abboud E, Nattel S. Tachycardia-induced changes in Nat current in a chronic dog model of atrial fibrillation. Circ Res 1997;81:1045-52.

9. Bosch RF, Zeng X, Grammer JB, Popovic K, Mewis C, Kuhlikamp V. lonic mechanisms ol electrical remodeling in human atrial fibrillation. Cordiovasc Res 1999;44:121-31

10. Reisinger J, Gatterer $E$, Heinze $G$, Wiesinger $K$, Zeindholer $E$, Gattermeier $M$, ef al. Prospective comparison of flecainide versus sotalal for immediate cardioversion of atrial fibrillotion. Am $J$ Cardiol 1998;81:1450-54.

11. Criins HJ, van Wijk LM, wan Gilst WH, Kingma $\Perp_{H}$, wan Gelder IC, Lie KI. Acule conversion of atrial fibrillation to sinus rhythm: clinical efficacy of llecainide acetate. Comparison of two regimens. Eur Heart J 1988;9:634-38. 


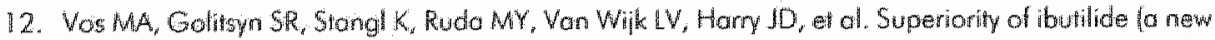
class (II agent) ower DL-sotalol in converting otrial flutter and atrial fibrillotion. The butilitic/Sotalol Comparator Study Group. Heon 1998;79:568-75.

13. Garrat C, Duytschoewer M, Killion M, Dorlond R, Mast F, Allessie MA. Repetitive eleciricol remodeling by poroxysms of atrial tibrillation in the goafi no cumulative effect on inducibility or stobillify of atriol fibrillotion. I Cordiowase Electrophysiol 1999;10:1101-08.

14. Wiffels MC, Darland R, Mast F, Allessie MA. Widening of the excitable gap during pharmacological cardiowersion of atrial fibrillation in the goat: effecis of cibenzaline, hydroquinidine, flecainide, and disotulal. Circulation 2000; 102:260-67.

15. Katritsis D, Rowland E, ONunain S, Shakespeare CF, Poloniecki J, Camm AJ. Effect of flecaimide on atricl and ventricular refracioriness and canduction in patients with narmal left ventricle. Implications. Lor possible antiarthythumic and proarthythmic mechanisms. Eur Heart J 1995; 16:1930-35.

16. Naccarelli GY, Lee KS, Gibson JK, Vanderlugi I. Electrophysiolagy and pharmacology of ibutilide. Am J Cardiol $1996,78: 12-16$.

17. Gottlieb S5, Singh S, Munger M, Eichhorn EJ, Ilgentritz J, Hanyok J. Hemodynamic effects of the class III antiarrlyythmic drug, d-sotalol, in patients with congestive heart foilure. Am I Cardiol 1996:78:1411-15.

18. Allessie M. Ausma J, Schatten U. Electrical, contractile and structural remodeling during atrial fibrilIation. Cardiovesc Res 2002,54:230*46.

19. Sato T, Mitamura H, Kurita Y, Takeshita A, Shinagawa K, Miyoshi S. Electropharmacologic effecis of pilsicainide, a pure sadium channel blocker, on the remadeled atrium subjected to chronic rapid pacing. $J$ Cordiowase Pharmacol 2001;38:812-20.

20. Wiffels MC, Dorland R, Allessie MA. Pharmacologic cardioversion of chronic atrial fibrillotion in the goat by class $|A|$,$C , and III drugs: a comparison between hydroquinidine, cibenzoline, flecainide,$ and d-sotalol. J Cardiovasc Electrophysial 1999;10:178-93.

21. Wang J, Boume GW, Wang Z, villemaire C, Talajic M, Nattel S. Comparative mechanisms of antiorrhythmic drug action in experimental atrial fibrillation. Importance of use-dependent effects on refractoriness. Circullation 1993;88:1030-44.

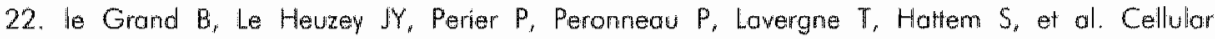
electrophysiological effects of flecainide on human atrial fibres. Cardiovasc Res $1990 ; 24: 232-38$.

23. Gaspo R, Bosch RF, Talajic M, Nattel S. Functional mechanisms underlying tachycardia-induced susiained atrial fibrillation in a chronic dog model. Circulation 1997;96:4027 35.

24. Fuster V, Ryden LE, Asinger RW, Cannom DS, Crijns HJ, Frye RL, er al. ACC/AFHA/ESC guidelines for the management of potients with atrial fibrillation. A repont of the American College of Cardiolagy/Americon Heart Association Task Force on Practice Guidelines and the European Sociely of Cardiology Committee for Practice Guidelines and Policy Conferences ICommitiee to develop guidelines for the management af patients with atrial fibrillation) deweloped in collaboration with the North American Sociey of Pacing and Electrophysiology. Eur Heart J 2001;22:1852-23.

25. Tielenan RG, Van Gelder IC, Crijns HJ, De Kam PJ, Van Den Berg MP, Haaksmo J, at al Early recurrences of atrial fibrillation affer elactrical cardioversion: a result of fibrillation-induced electrical remodeling of the atrie? I An Coll Condiol 1998,31:167-73.

26. Singh $S$, Zoble RG, Yellen L, Brodsky MA, Feld GK, Berk M, et al. Efficacy and safety of oral defefillide in converting to and maintoining sinus whythm in patients with chronic atrial fibrillation or atrial flutter: the symplomatic atriol fibrillation investigative research on dofetilide (SAFRE-DI) study. Circulotion $2000,102: 2385-90$.

27. L. D. Benardeou A, Nattel S. Contrasting efficacy of dofetilide in differing experimental madels of atrial fibrillation. Circulation 2000;102:104-12.

28. Tse HF; Lav CP. Electrophysiologic actions of dl-sotalol in patients with persistent atrial fibrillation. J Am Coll Cordiol 2002:40:2150-55.

29. Shiroshila-Takeshita A, Mitamura H, Sato T, Shinagawa K, Kurita Y, Kanki H, el al. Preserved Effects al Potassium Channel Blockers in the Pocing-Induced Remadeled Canine Atrum: A Comporison between E4031 and Azimilide. \Cardiovasc Phormocol 2003:41:678-85.

30. Singh BN. Current antiarrhythmic drugs: on owerview of mechanisms of action and potential dinical utility. I Cardiowase Electrophysial 1999; 10:283-01. 
31. Courtemanche M, Romirez R, Natel S. Janic targets for drug theropy and otriat fibrillation-induced electrical remodeling: insights from a mahematical model. Cardiowsic Res 1999;42:477,89.

32. Blacuw Y, Goegelein H, Duyischoever $M_{r}$ Tieleman $R G_{H}$ Schotten U, Allessie M. Synergistic dass III

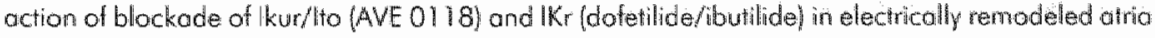
of the goat. Circulation 2003;108:IV84 (Abstract).

33. Li D, Zhang $L$, Kneller S, Nattel S. Potential ionic mechanism for repolarization differences between canine right and left atrium. Circ Res $2001 ; 88: 1168.75$. 


\section{CHAPTER 4}

\section{'Early' Class III Drugs for the Treatment of Atrial Fibrillation: Efficacy and Atrial Selectivity of AVE0118 in Remodeled Atria of the Goat}

Yuri Blaauw, MD; Heinz Gögelein, PhD; Robert Tieleman, MD,PhD; Arne van Hunnik, BS; Ulrich Schotten, MD, PhD; Maurits Allessie, MD, PhD 


\section{ABSTRACT}

Backgrourid: Currently available anti-arrhythmic drugs are only moderately effective against atrial fibrillation (AF) and may cause ventricular pro-arrhythmia. AVEO 118 is a blocker of atrial specific early $\mathrm{K}^{+}$currents $\left(\|_{\text {Xur }} / \mathrm{I}_{\mathrm{io}}\right)$.

Methods and Results: Effects of intravenous AVEO1 18 and dofetilide on atrial effective refractory period (AERP) and inducibility of $A F$ were measured before and afver 48-hours of AF-induced electrical remodeling in the goat. During persistent AF ( $53 \pm 19$ days), the cardioversion efficacy and effects on atrial wavelength of AVEO118, dofetilide, and ibutilide were evaluated. QT durations were measured during atrial pacing and persistent AF. After 48 hours of AF, the effect of dofetilide on AERP was reduced and induction of AF was not prevented. In contrast, the class III action of AVEO1 18 was enhanced and AF inducibility decreased from 100\% to $32 \%(\mathrm{p}<0.001)$. At 1,3 and $10 \mathrm{mg} / \mathrm{kg} / \mathrm{h}$ AVEO 118 terminated persistent AF in respectively $1 / 8,3 / 8$ and $5 / 8$ goats. Dofetilide and ibutilide terminated $A F$ in $1 / 5$ and $2 / 7$ goats. AVE01 $180.5,1.5$, and $5 \mathrm{mg} / \mathrm{kg}$ prolonged the AERP during AF and increased the fibrillation wavelength from $6.7 \pm 0.6$ to $8.5 \pm 0.5,9.7 \pm 0.5$ and $11.2 \pm 0.9 \mathrm{~cm}(\mathrm{p}<0.01)$. Whereas dofetilide and ibutilide prolonged QT duration, AVEO1 18 had no appreciable effect on QT duration.

Conclusions: AVEO118 markedly prolongs the atrial refractory period during AF without affecting QT duration. Cardioversion of AF was due to an almost twofold increase of the wavelength of the fibrillation waves. Atrial selective class III drugs like AVEO 18 may be a promising new option for safe and effective cardioversion of AF. 


\section{INTRODUCTION}

Anti-arrhythmic drugs have been widely used for prevention and termination of atrial fibrillation (AF). Unfortunately, their clinical efficacy has been disappointing and the risk of pro-arrhythmia is a significant concern. "1.2 The antifibrillatory action of commonly used class llli drugs is based on prolongation of the action potential by blockade of the delayed rectifier $K^{+}$current $\left(I_{k}\right)$. Clinical studies have shown that these class III drugs can terminate persistent AF in $-30 \%$ of the cases. ${ }^{3.4}$ Their thera. peutic range is limited because they prolong the $Q T$ duration and induce torsade de pointes arrhythmias. ${ }^{2}$ The development of atrium-specific drugs therefore would be a major step forward.

Nattel and colleagues showed that an early uttra-rapid component of the delayed rectifier (I Kust contributes significantly to repolarization of the human atrial action potential..$^{5}$ Because $l_{K u r}$ is present in atrial but not in ventricular myocytes, they postulated that: "It is a potentially promising target for the development of drugs that prevent atrial reentrant arrhythmias without a risk of ventricular pro-arrhyth. $\mathrm{mia}^{\text {"t. }}$.

Several experimental $\|_{\text {ur }}$ blockers are recently under investigation. " O One of them (AVE0118), which, in addition to $I_{k, w}$ also blocks the $I_{10}$ current, is evaluated in the present study. We hypothesized that in electrically remodeled atria, blockade of the early repolarizing currents restores the plateau of the action potential, thereby exerting an anti-fibrillatory effect. This hypothesis was tested in the goat model of AF in which the electrophysiological and anti-fibrillatory effects of AVEO1 18 were compared with the action of conventional class III drugs (dofetilide and ibutilide).

\section{METHODS}

\section{The Goat Model of Atrial Fibrillation}

Thirteen temale goats weighing $52 \pm 2 \mathrm{~kg}$ were used. The animals were handled according to the European Directive for Animal Research and the study protocol was approved by the local Animal Investigation Committee "Goats were instrumented as described previously, Briefly, during general anesthesia Teflonufelt plaques with multiple electrodes were sutured on the free wall of each atrium, Bachmann's bundle (BB) and the left ventricle. All leads were tunneled subcutaneously to the neck and exteriorized by four 30-pole comnectors. Experiments were started 3 to 4 weeks after surgery. AF was induced by a fibrillation pacemaker as described previously. ${ }^{10}$

\section{Electrophysiological Measurements}

The atria were paced with biphasic stimuli of $2 \mathrm{~ms}$ duration and $4 \mathrm{x}$ threshold. The atrial effective refractory period (AERP) was measured at the free wall of the right and left atrium during regular pacing (interval 400 to $200 \mathrm{~ms}$ ). Single interpolated 
stimuli were applied after 8 basic stimuli, starting within the refractory period. The longest interval that failed to capture the atria ( $2 \mathrm{~ms}$ increments) was taken as the AERP. Atrial conduction velocity was measured along Bachmann"s bundle during right atrial pacing. The distance over which conduction velocity was measured ranged from 3.5 to $5 \mathrm{~cm}$.

The length of the fibrillation waves was determined ot the right atrial free wall by measuring the refractory period $\left(R P_{A A}\right)$ and conduction velocity $\left(C V_{A F}\right)$ during $A F$. RP $P_{A F}$ was measured by slow, fixed-rate pacing $(1 \mathrm{~Hz})$ resulting in a series of single, randomly coupled, premature stimuli." Local capture of AF was evidenced by radial spread of activation from the pacing site and a short delay between stimulus and response. For each coupling interval, the percentage of capture was determined. The shortest interval capturing the atrium $\geq 50 \%$ was taken as the $\mathrm{RP}_{\mathrm{AF}} . \mathrm{CV}_{\mathrm{AF}}$ was determined with a mapping electrode containing $5 \times 6$ electrodes (interelectrode distance, $4 \mathrm{~mm}$ ) from the local conduction vectors within areas of $3 \times 3$ electrodes. At least $50 \mathrm{AF}$ cycles were used to determine the $\mathrm{CV} \mathrm{AF}$.

Inducibility of AF was measured at the right and left atrium by single premature stimuli applied during regular pacing $(400 \mathrm{~ms})$. In case a premature beat induced a rapid irregular rhythm lasting $>1$ second, AF was considered inducible. The AF cycle length (AFCL) was measured automatically by an algorithm detecting the negative intrinsic deflection of the fibrillation electrogram. The median value of 300 consecutive intervals was calculated. QT duration was measured during atrial pacing and persistent AF either from an epicardial electrogram or a precordial electrocardiogram. Since during AF the Bazett's formula cannot be applied, we used another approach to correct the QT duration. In each goat the relationship between the RR-interval and the QT duration was determined during 20 seconds of AF. The $R R$ Q QT relationship after drug administration was compared with the normal RR-QT relation. In some animals, the effects of cllass III drugs during persistent AF was evaluated by recording monophasic action potentials. (MAP) under general anesthesia from the endocardium of the right atrium.

\section{Experimental Protocol}

The electrophysiological effects of AVEO118 ( $n=10$ goats) and dofetilide ( $n=6$ ) were measured before and after 48 hours (11 to 4 days) of AF. In five goats, both drugs were evaluated. Drug effects were studied on separate days with at least 10 plasma halfulives between the experiments. AVEO1 18 and dotetilide were adminisw tered intravenously over 1 hour at $3 \mathrm{mg} / \mathrm{kg} / \mathrm{h}$ and $20 \mu \mathrm{g} / \mathrm{kg} / \mathrm{h}$ respectively. AERP. CV, QT duration and inducibility of AF were measured after 30 minutes of infusion.

In a total of 8 goats the effects of AVEOI $18(n=8)$, dofetilide $(n=5)$ and ibutilide $(n=7)$ were evaluated during persistent AF (53 $m 19$ days). In 6 of these animals, the baseline studies had been pertarmed. AVE0118 was infused in 5 dosages between 0.1 and $10 \mathrm{mg} / \mathrm{kg} / \mathrm{h}$. Dofetilide and ibutilide were given in a dasage of respectively $20 \mu \mathrm{g} / \mathrm{kg} / \mathrm{h}$ and $4 \mathrm{mg} / \mathrm{h}$. Drugs were infused for 1 hour, during which the AFCL was monitored. After 30 minutes of infusion, $R P_{A F}, C V_{A F}$ median 
RR-interval and QT duration were measured. Successful cardioversion was defined as termination of AF within $\leq 1$ hour of drug administration. Plasma-concentrations of AVEO1 18 were determined by Aventis.

\section{Statistical analysis}

Differences between groups were evaluated by the paired Student's t test or by 2-way repeated ANOVA with post-hoc Bonferronit test. McNemar's test was used to compare AF inducibility. Changes in corrected QT duration were evaluated by the 1 -samplet-test (test value 0 ). Differences were considered statistically significant at $p<0.05$. Results are presented as mean \pm SEM.

\section{RESULTS}

\section{Atrial Refractoriness and Conduction Velocity}

Figure 1 shows the effects of dofetilide and AVEO 118 before and after 48 hours of AF. In non-remodeled atria, dofetilide and AVEO1 18 prolonged AERP at all pacing rates. Both drugs showed a smaller class III effect at shorter cycle lengths (reverse frequency-dependence). After AF-induced electrical remodeling the effect of dofetilide was reduced, whereas the action of AVE01 18 was enhanced. In figure 1 (right) the prolongation of atrial refractoriness ( $\triangle$-AERP) is plotted. The normal reverse frequency dependence of dofetilide was changed into a frequency-dependent effect after 48 hours of AF because of a loss of class III action at slow rates. The reverse frequency dependence of AVEO1 18 was reduced. At short cycle lengths (200 ms), the class III effect of AVEO1 18 was almost tripled (2.8), whereas at $400 \mathrm{~ms}$, the prolongation of atrial refractoriness was enhanced by a factor of 1.4.

Before drug infusion a physialogical rate-dependent slowing of conduction along Bachmann's bundle was observed from $125 \pm 4$ to $114 \pm 4 \mathrm{~cm} / \mathrm{s}$ (pacing interval 400 and $200 \mathrm{~ms}$ ). After 48 hours of AF, conduction velocity was not changed. Dofetilide did not affect conduction velocity either before or after electrical remodeling (data not shown). At slow pacing rates ( $400 \mathrm{~ms}$ ), AVEO1 18 had no effect on CV in either normal $(126 \pm 4$ vs. $123 \pm 5 \mathrm{~cm} / \mathrm{s}, \mathrm{p}=\mathrm{NS})$ or remodeled atria $(128 \pm 5$ vs. $126 \pm 5 \mathrm{~cm} / \mathrm{s}, p=N S)$. During rapid pacing $(200 \mathrm{~ms})$ AVEO1 18 slightly slowed conduction from $116 \pm 4$ to $105 \pm 5 \mathrm{~cm} / \mathrm{s}$ in non-remodeled and from $120 \pm 5$ to $113 \pm 6 \mathrm{~cm} / \mathrm{s}$ in remodeled atria (both $p<0.01$ ).

\section{Prevention of AF by Dofetilide and AVEO118}

Figure 2 shows the effects of dofetilide and AVEO1 18 on the inducibility of AF. In non-remodeled atria, single premature stimuli initiated AF in $15 \%$ of the cases $(10$ goats, 3 of 20 sites). After 48 hours of AF, the AERP had shortened from $160 \pm 6$ to $96 \pm 5 \mathrm{~ms}$ and the inducibility of AF was $100 \%$. After electrical remodeling, 


\section{Dofetillide}
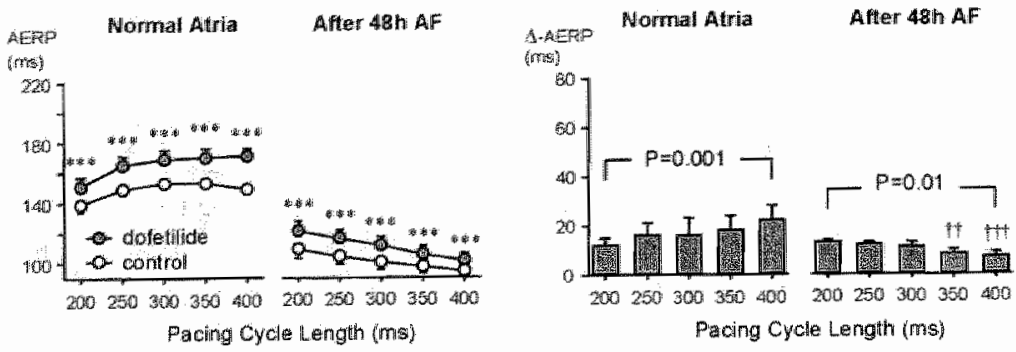

AVE0118
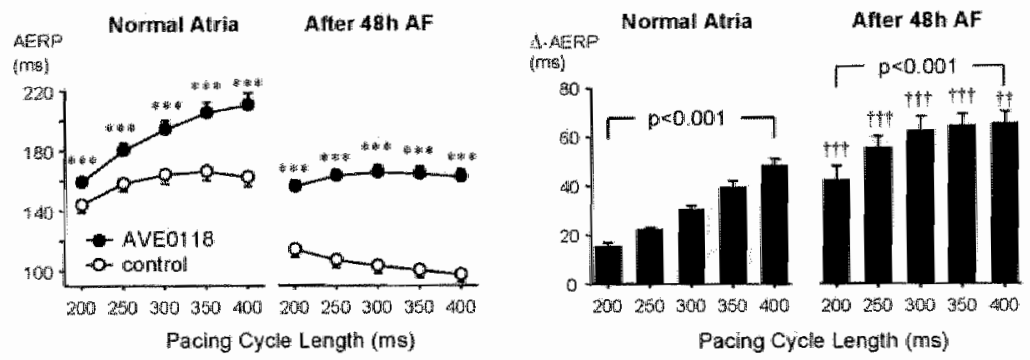

Figure 1: Effects of dolatilide and AVEO 18 on atrial refractoriness at different pacing rates before and ofter 48 hours of AF. In contrast lo dafeilide, the dass lll action of AVEO1 18 was significantly enhanced in remodeled atria. AERP: atrial effective refractory period; ${ }^{* * 2} p<0.001$ vs. no drugs; $+p<0.05_{\text {, }}$ t $p<0.01,+1+p<0.001$ ws. normal otria.

clofetilide prolonged the AERP only by $7 \pm 2 \mathrm{~ms}$ and did not reduce atrial vulnerability (inducibility 100\%; 6 goats, 12 of 12 sites). In addition, the median duration of AF paroxysms remained the same ( 3.5 vs. 2 seconds; $p=0.1)$. In contrast, AVE01 18 prolanged AERP by $65 \pm 5 \mathrm{~ms}$ and exerted a clear preventive effect on AF inducibility $(32 \% ; 10$ goats, 6 of 19 sites; $p<0.001)$. The duration of induced AF episodes ranged between 2 and 1260 seconds (median, 6 seconds) before and 1 to 95 seconds (median, 2 seconds) after administration of AVEO 18.

\section{Cardioversion of Persistent AF by Dofetilide, Ibutilide and AVEO118}

After $53 \pm 19$ days of persistent AF, attempts were made to cardiovert AF pharmacologically. Infusion of saline never terminated AF. Administration of dofetilide (20 $\mu \mathrm{g} / \mathrm{kg} / \mathrm{h}$ ) or ibutilide $(4 \mathrm{mg} / \mathrm{h}$ ) restored sinus rhythm in 1 of 5 and 2 of 7 goots, respectively. The lowest dosage of AVE0 $18(0.1 \mathrm{mg} / \mathrm{kg} / \mathrm{h})$ restored sinus rhythm in 1 of 6 animals. At higher dosages $(1,3$ and $10 \mathrm{mg} / \mathrm{kg} / \mathrm{h})$, the cardioversion efficacy increased and AF was terminated in 1, 3, and 5 of 8 goats, respectively. 
Normal Atria

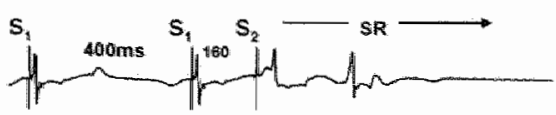

After $48 \mathrm{~h} \mathrm{AF}$

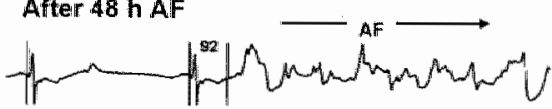

$48 \mathrm{~h} \mathrm{AF}+$ Dofetilinde

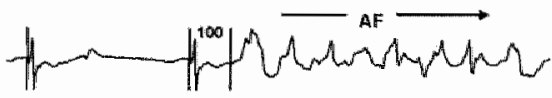

$48 \mathrm{~h}$ AF * AVEOH18

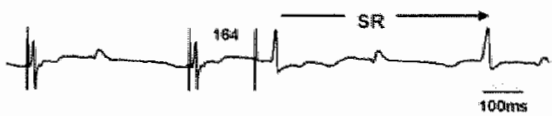

Inducibility of AF

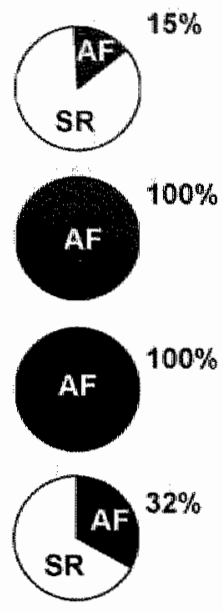

Figure 2: Effects of dofefilide and AVEO 18 on inducibility of AF. Unipolar electrograms recorded from the right atrial free wall during application of single premature stimuli. In remodeled atria, doletilide only slightly prolonged atrial refractoriness with no effect on the inducibility of AF. In contrast, AVEO1 18 morkedly prolonged the atrial refractory period and reduced inducibility of AF.

The effects of dofetilide, ibutilide and AVEO1 18 on AFCL are shown in figure 3. Dofetilide and ibutilide had a moderate effect on $A F C L$, which was prolonged from $105 \pm 5$ and $100 \pm 4(t=0)$ to $121 \pm 5$ and $115 \pm 5 \mathrm{~ms}(t=60 ; p<0.01)$. AVE01 18 exerted a much stronger effect on AFCL. After 60 minutes infusion at 0.1 , $0.3,1,3$ and $10 \mathrm{mg} / \mathrm{kg} / \mathrm{h}$, the AFCL prolonged by respectively $5 \pm 1,16 \pm 2,30$ $\pm 4,52 \pm 4$ and $60 \pm 5 \mathrm{~ms}$ (all $p<0.01$ ).

In 4 goats with persistent $A F, M A P s$ were recorded from the right atrium during administration of dofetilide $(n=1)$, ibutilide $(n=1)$ and AVEO $18(n=2 ; 3 \mathrm{mg} / \mathrm{kg} / \mathrm{h})$. During control, the fibrillation MAPs were characterized by a short duration and an absent plateau. The degree of repolarization showed beat-fo-beat variation, and fractionation occasional ly occurred. Apart from the prolongation in AF cycle-length, dofetilide and ibutilide exerted no clear effects on the duration and shape of the action potentials. AVEO1 18 caused a significant prolongation of AFCL which was associated with restoration of the plateau-phase and increase in duration of the action potential. This demonstrates that the effects of AVEO1 18 on AFCL are primarily due to a prolongation of the atrial action potential.

\section{Effects on Refractory Period and Conduction Velocity during AF}

During cardioversion of persistent $A F, R P_{A F}$ and $C V_{A F}$ were measured after $30 \mathrm{~min}$ utes infusion of dofetilide $(20 \mu \mathrm{g} / \mathrm{kg} / \mathrm{h} ; n=4)$, ibutilide $(4 \mathrm{mg} / \mathrm{h} ; \mathrm{n}=4)$ and AVE0 $118(1,3,10 \mathrm{mg} / \mathrm{kg} / \mathrm{h} ; \mathrm{n}=5)$. Figure 4 shows a representative example of 

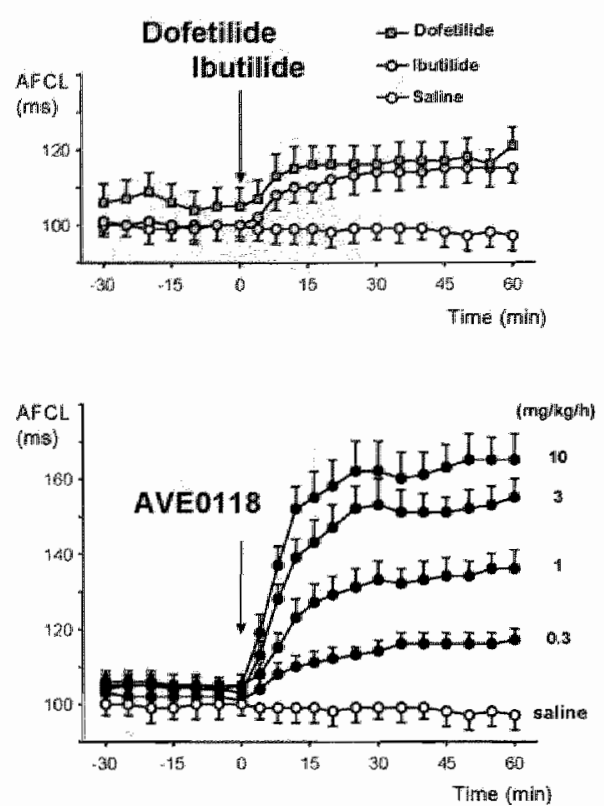

Control DD Dofetilidie $(20 \mu \mathrm{g} / \mathrm{kg})$

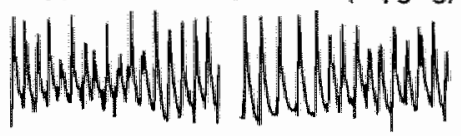

Control $\rightarrow$ Ibutilide $(4 \mathrm{mg})$

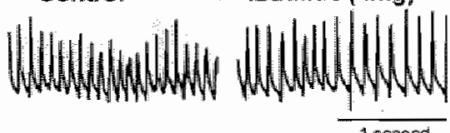

AVE0118:
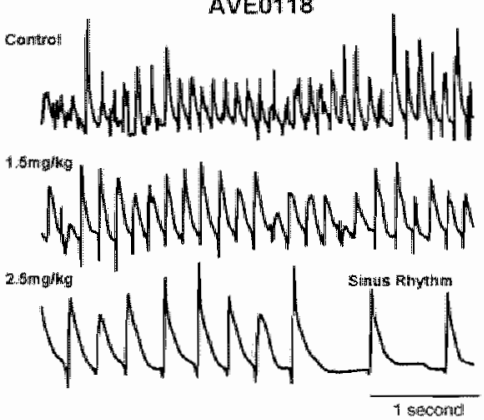

Figure 3 Left: effects of dofetilide $(n=5)$, ibutilide $(n=7)$ and AVEO $18(n=8)$ on AFCLduring 7 -hour infusion. Right: examples of the efflects of dofetilide, ibutilide, and AVEO 118 on atrial MAPs during AF. MAPs were recorded from the right atrial free wall. In contrast to dofetilide and ibutilide. AVEO1 18 markedly prolonged AFCL due to the increase in MAP duration.

the effects of ibutilide and AVEO1 18 on $\mathrm{RP}_{\mathrm{AF}}$. During control, the shortest coupling interval capturing AF in $50 \%$ of the coses was $84 \mathrm{~ms}$. The two tracings show a stimulus with a coupling interval of $84 \mathrm{~ms}$ which in one case captured and in the other case did not capture the fibrillating atria. Ibutilide slightly prolonged the $\mathrm{RP}_{\mathrm{AF}}$ to 95 ms. AVEO 118 exerted a much stronger effect, and $R P_{A F}$ was prolonged to 119 and $150 \mathrm{~ms}$ at dosages of 0.5 and $5 \mathrm{mg} / \mathrm{kg}$. Figure 5 shows the results of all goats. Shown is the percentage of capture of AF at different coupling intervals before and after drug administration. The Sushaped curves indicate that the $\mathrm{RP}_{\mathrm{AF}}$ is probabilistic rather than deterministic. Both dofetilide and ibutilide shift the curves slightly to the right, indicating that they prolonged the $\mathrm{RP}_{\mathrm{AF}}$ only slightly. In contrast, AVEO 118 caused a marked rightward shift of the curve because the $\mathrm{RP}_{\mathrm{AF}}$ was significantly prolonged.

The table gives results for all goats. Dofetilide and ibutilide prolonged the $\mathrm{RP}_{\mathrm{AF}}$ from $88 \pm 3$ and $81 \pm 6 \mathrm{~ms}$ to $95 \pm 6$ and $95 \pm 8 \mathrm{~ms}$ respectively (dofetilide: $p=0.09$; ibutilide: $p<0.05)$. AVE01 18 increased the $R P_{A \pi}$ up to $144 \pm 6 \mathrm{~ms}$ at 5 $\mathrm{mg} / \mathrm{kg}(p<0.001)$. The conduction velocity during AF was measured at the free wall of the right atrium. In figure 6 the histograms of the local conduction velocities are shown during control and after AVEO1 $18(1.5 \mathrm{mg} / \mathrm{kg})$. No effect on atrial conduction was observed. Also at higher dosages AVE01 18 caused no changes in $C V_{A F}$. 


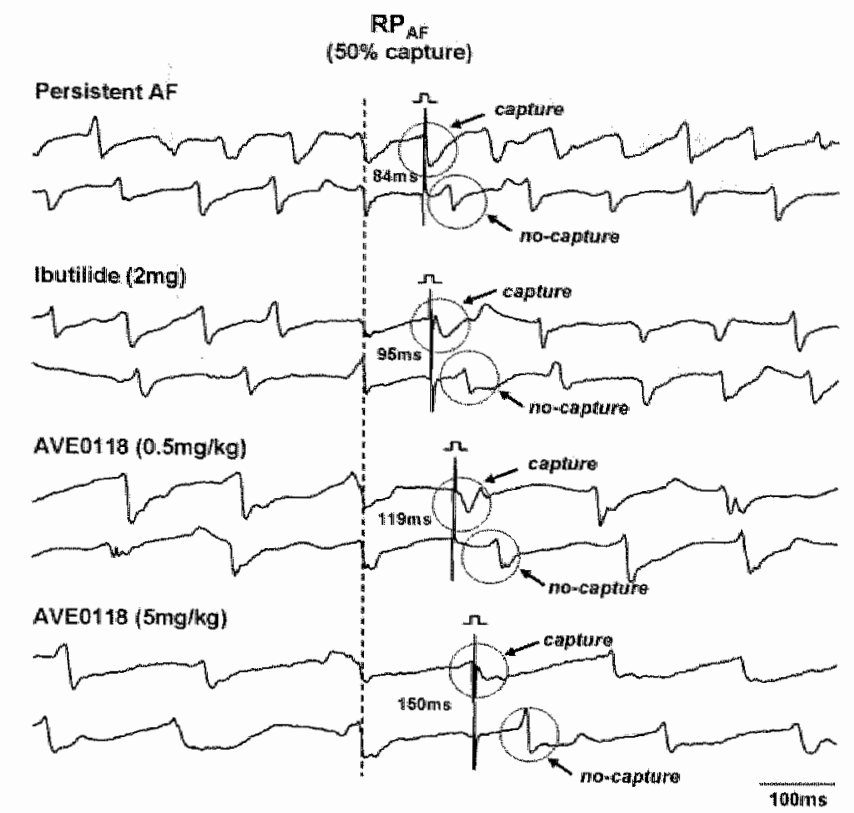

Figure 4: Representative examples of effects of ibutilide $(2 \mathrm{mg})$ and AVEO1 $18\left(0.5\right.$ and $5 \mathrm{mg} / \mathrm{kg}$ ) on $R P_{\text {A. }}$. $\mathrm{RP}_{\mathrm{MF}}$ was deftined as the shortest coupling interwal that captured AF in $50 \%$ of cases. Whereas ibutilide prolonged the RP AF only slightly, AVEO1 18 prollonged RP AF in a dose clependent manner from 84 to 150 ms.

The atrial wavelength during $A F\left(W L_{A F}=R P_{A F} \times C V_{A F}\right.$ ) was increased only slightly by dofetilide or ibutilide. AVEO 18 markedly prolonged the wavelength during AF. At dosages of $0.5,1.5$ and $5 \mathrm{mg} / \mathrm{kg}$, the $W L_{A F}$ increased by $28 \pm 7,53 \pm 10$ and 60 $\pm 7 \%$ respectively $(p<0.01)$. The corresponding plasma-levels of AVEO118 were $0.6 \pm 0.1,1.7 \pm 0.4$ and $4.9 \pm 0.8 \mu \mathrm{g} / \mathrm{ml}$.

\section{Atrial selectivity of AVE0118}

During atrial pacing ( $400 \mathrm{~ms}$ ), dofetilide significantly prolonged the QT duration before and after 48 hours of AF (from $252 \pm 4$ to $266 \pm 3 \mathrm{~ms}$ and from $239 \pm 7$ to $259 \pm 3 \mathrm{~ms}$, respectively; $p<0.05)$. AVE0118 (1.5 mg/kg) did not cause any changes in QT duration ( $259 \pm 7$ vs. $261 \pm 8 \mathrm{~ms}$ and $239 \pm 7$ vs. $246 \pm 5 \mathrm{~ms}$; $p>0.2)$. The class III action on the ventricles was also evaluated during persistent AF. Figure 7 shows a representative example of the effects of ibutilide and AVEO 118 $(1.5$ and $5 \mathrm{mg} / \mathrm{kg}$ ) on the QT duration during AF. Because the ventricular rhythm was irregular, the QT duration showed significant beat-to-beat variations. In general, shorter RR-intervals were followed by a shorter QT duration and longer RR-intervals by a longer QT duration. Infusion of dofetilide prolonged the QT duration more during long RR-intervals (reverse frequency dependence). At a dosage of 1.5 $\mathrm{mg} / \mathrm{kg}$, AVEO 118 had no effect on the median QT duration and RR-interval. In this 

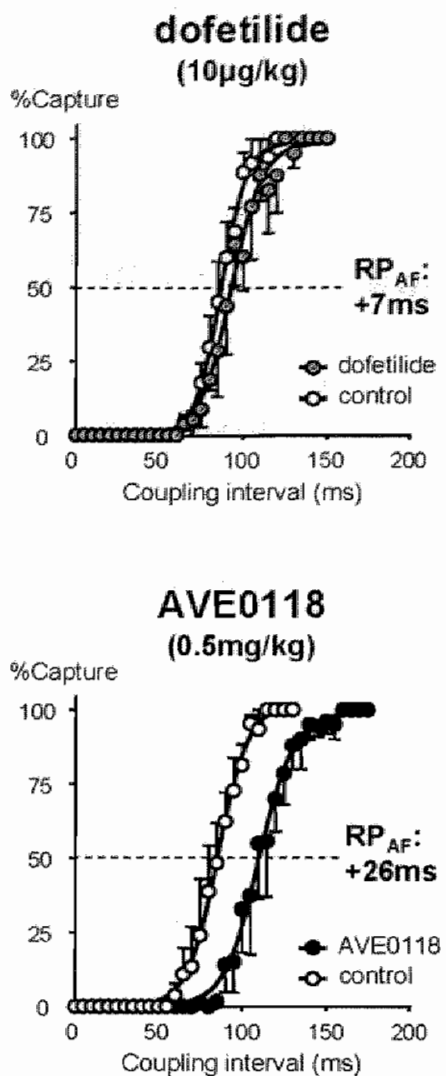
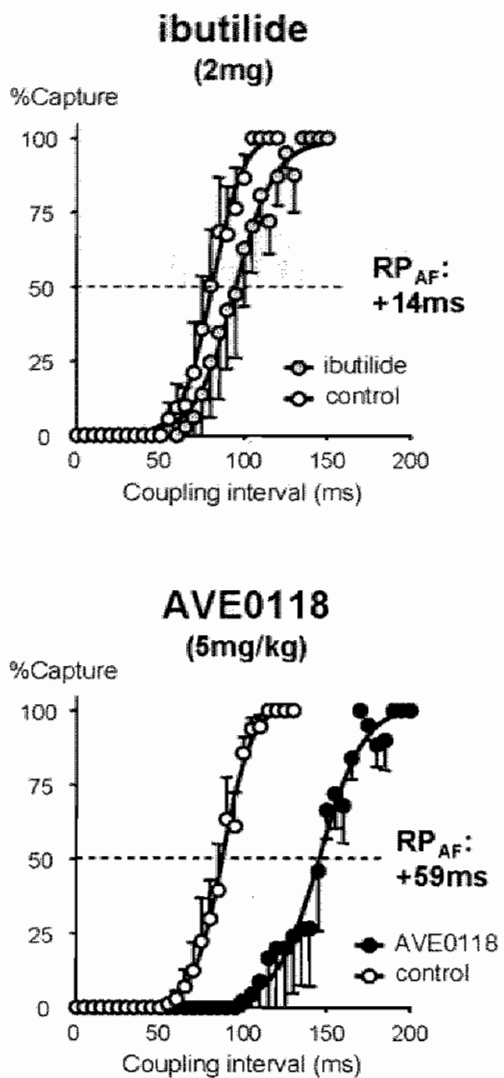

Figure 5: Percentage of capture by premature stimuli of different coupling intervals before and after ad. ministration of dofetilide $(n=4)$, ibutilide $(n=4)$ and AVEO1 $18(0.5$ and $5 \mathrm{mg} / \mathrm{kg} ; \mathrm{n}=5)$. AVEO 18 coused a marked rightward shift of the curve, indicating an increase in refractory period during AF.

\section{Control}

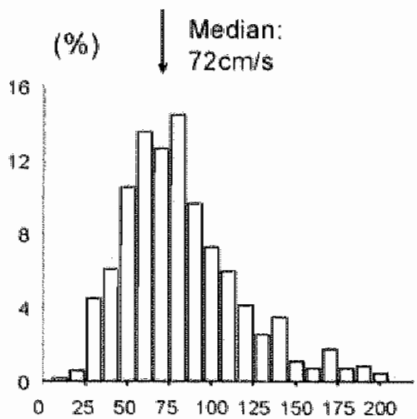

$\mathrm{CV}_{\mathrm{AF}}(\mathrm{cm} / \mathrm{s})$
AVE0118 $(1.5 \mathrm{mg} / \mathrm{kg})$

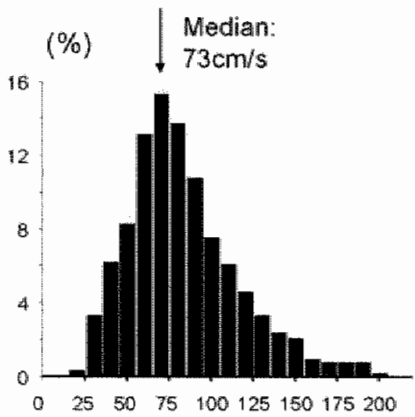

$\mathrm{CV}_{\mathrm{AF}}(\mathrm{cm} / \mathrm{s})$

Figure 6: Histograms of local atrial conduction velacities during AF bellore and aher administration of AVto $118(1.5 \mathrm{mg} / \mathrm{kg})$. No effects on $\mathrm{CV}_{\text {AF }}$ were abserved. 
Ibutilide (2mg)

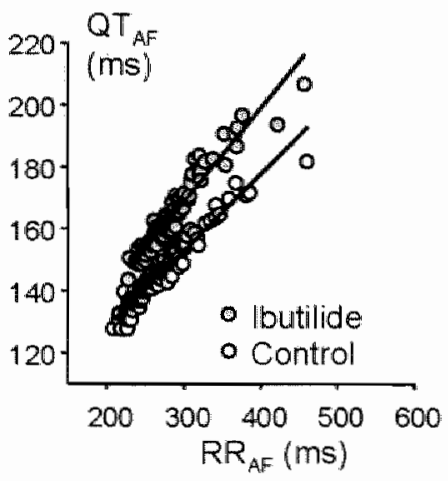

\section{AVE0118 (5mg)}

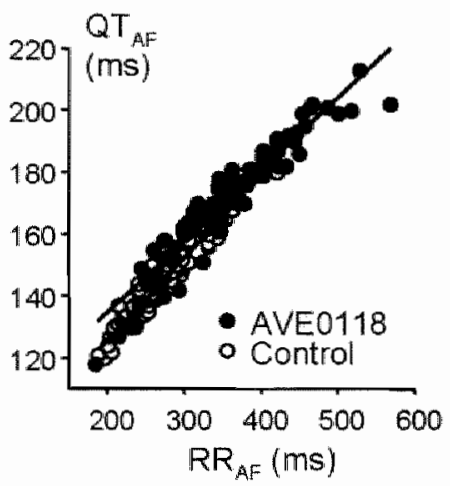

AVE0118 (1.5mg)
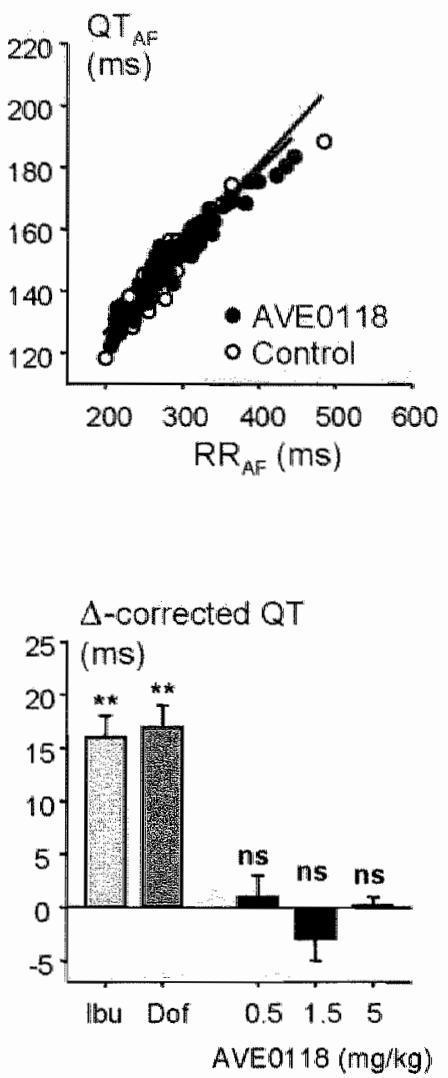

Figure 7: Representative examples of the relation between RR-interval (RRA $\left.R_{A}\right)$ and $Q T$ duration during $A F$

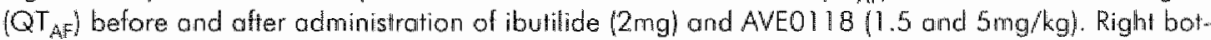
tam: Average changes in corrected QT duration during AF by dofetilide, ibutilide and AVEO118. "* $p<0.01$.

example, $5 \mathrm{mg} / \mathrm{kg}$ AVEO 118 clearly prolonged the median RR-interval from 268 to $357 \mathrm{~ms}$. The QT duration prolonged according to its normal rate adaptation. This finding shows that AVEO1 18 did not cause an independent prolongation of QT duration. In figure 7 (lower right), effects of the different drugs on the corrected QT duration during AF are given for all goats. Dofetilide and ibutilide prolonged the corrected QT duration by $17 \pm 2$ and $18 \pm 2 \mathrm{~ms}(p<0.01)$, whereas AVEO118 did not prolong the corrected $Q T$ duration $(p>0.25)$. 


\section{DISCUSSION}

In the present study, a novel $I_{k, u} / I_{\text {io }}$ blocker (AVE0118) was evaluated in the goat madel of AF. It was found that AVEO1 18 markedly prolonged atrial refractoriness without affecting corrected QT duration. Whereas the class III effect of $I_{k s}$ blockade (dafetilide) was reduced after 48 hours of AF, the action of AVEO 118 was enhanced after atrial electrical remodeling. AVEO118 suppressed the inducibility of AF, whereas dofetilide failed to prevent induction of AF paroxysms. During persistent AF, AVE0 118 prolonged the atrial wavelength in a dose-dependent way. In 5 of 8 goats persistent AF was cardioverted by intravenous administration of AVEO118.

\section{Blockade of lon Channels by AVE0118}

The effects of AVEOT 18 on $I_{K u r}$ and $I_{i \circ}$ have been investigated in CHO-cells expressing hKv1.5 ( $\left.\|_{\text {Kur }}\right)$ and hKv4.3 plus KChIP2S ( $\left.\|_{\text {ro }}\right)$ and in atrial myocytes of the pig. ${ }^{8}$ In $\mathrm{CHO}$-cells, half maximal inhibition of $\mathrm{I}_{\mathrm{Kur}}$ and $\mathrm{I}_{\text {to }}$ occurred in the micromolar range (0.9-3.5 MM). Voltage clamp experiments in pig myocytes revealed a $50 \%$ reduction of $I_{K u r}$ and $I_{i g}$ at comparable concentrations. The $I_{K A c h}$ current was blocked at an $I_{50}$ of $2.6 \mu \mathrm{M} .{ }^{8}$ Additionally, in human atrial myocytes $I_{\text {Kur }}$ and $I_{\text {io }}$ were blocked by low concentrations of AVE0 1 18. "Although these data are still preliminary they indicate that AVEO1 18 is a blocker of $I_{\text {Kurr }} l_{\text {tig }}$ and $I_{\text {Kach. }}$

\section{The Effects of Electrical Remodeling on 'Early' and 'Late' Class III drugs}

It has become clear recently that AF leads to a down-regulation of several ionic currents including $I_{C a, L} I_{K u r}$ and $I_{10}{ }^{12.14}$ lonic remodeling has important implications for the action of anti-fibrillatory drugs. It was recently demonstrated that the action of the $I_{K,}$ blockers $d /$-satalol was reduced in patients with long-lasting AF. ${ }^{15}$ In the present study, a reduced action of dofetilide was found. This suggests that in electrically remodeled atria, the late activated $I_{k_{r}}$ current contributes less to atrial repolarization. In a mathematical model of the human atrial action potential, the effect of $I_{k r}$ blockade on the duration of the action potential was reduced in remodeled atrial cells. ${ }^{16}$ During a short action potential, less $I_{K_{r}}$ was activated; in this setfing, the net prolongation by $I_{k,}$ blockade therefore was minimal. The opposite was true for $I_{K u r}$ blockade, which exerted an enhanced effect in remodeled atria. This finding was rather surprising because this current is down-regulated in remodeled atria. ${ }^{13,14} \mathrm{~A}$ possible explanation for this paradoxical effect is that the $I_{C a, L}$ is reduced to a greaier extent than $I_{\text {Kur }}$ resulting in a larger contribution of $I_{\text {Kur }}$ to atrial repolarization. Wirth et al. ${ }^{17}$ showed that AVEO1 18 prolonged atrial refractioriness more at sites with shorter refractory periods. Nagasawa et al. ${ }^{7}$ reported that the $\|_{\text {Kur }}$ blocker NIP-142 became more effective when the action potential was shortened by vagal stimulation. 
Toble I Effects of dofetilide, ibutilide and AVEO 18 on atrial electrophysiology during atrial fibrillotion

\begin{tabular}{|c|c|c|c|c|c|c|c|c|c|c|}
\hline & \multicolumn{2}{|c|}{$\begin{array}{c}\text { Dadfetitide } \\
(20 i g / \mathrm{kg} / \mathrm{h})\end{array}$} & \multicolumn{2}{|c|}{$\begin{array}{l}\text { thutilide } \\
\text { (4mgh) }\end{array}$} & \multicolumn{2}{|c|}{$\begin{array}{c}\text { Mutolls } \\
(1 \mathrm{mg} / \mathrm{hg} / \mathrm{h})\end{array}$} & \multicolumn{2}{|c|}{$\begin{array}{l}\text { Nonls } \\
\text { (3mo/kghth }\end{array}$} & \multicolumn{2}{|c|}{$\begin{array}{l}\text { Avonis } \\
\text { (10mongefis) }\end{array}$} \\
\hline & Control & $30 \mathrm{~min}$ & Control & 30minn & Control & 30min & Contul & 30 ming & Contrill & Somin \\
\hline $\begin{array}{l}\text { AFCL } \\
\text { (ms) }\end{array}$ & $105=4$ & $117 \pm 6$ & $100 \pm 7$ & $115 \pm 8$ & $107 \pm 6$ & $135 \pm 6$ & $104=3$ & $15 ! \pm 7$ & $106 \pm 3$ & $169+8$ \\
\hline $\begin{array}{l}\text { Refractory Period } \\
\text { (ms) }\end{array}$ & $88+3$ & $95 \pm 6$ & $81 \pm 6$ & $95=8$ & $85 \pm 5$ & $111 \pm 6$ & $82 \pm 4$ & $\sqrt{30}+10 \pm 5$ & $85 \pm 4$ & $144 \pm 6$ \\
\hline $\begin{array}{l}\text { Conduction velocity } \\
(\mathrm{cm} / \mathrm{s})\end{array}$ & $76+2$ & $75 \pm 3$ & $78 \pm 2$ & $79 \pm 2$ & $78 \pm 1$ & $77+3$ & $78 \pm 3$ & $75 \pm 2$ & $82 \pm 3$ & $78 \pm 5$ \\
\hline $\begin{array}{l}\text { Wovelength } \\
(\mathrm{cm})\end{array}$ & $6.6 \pm 0.2$ & $7.1 \pm 0.5$ & $6.3 \pm 0.6$ & $7.5 \pm 0.7$ & $6.7 \pm 0.4$ & $8.5 \pm 0.5$ & $6.4 \pm 0.4$ & $97 \pm 0.5$ & $7.0 \pm 06$ & $11.2 \pm 0.9$ \\
\hline
\end{tabular}

Numbers represent mean 2 SEM. AFCL: atrial fibrillation cycle length. ${ }^{*} p<0.05, * * p<0.01, * * *$ $\mathrm{p}<0.001$ vs. control

\section{Antifibrillatory Action and Atrial Selectivity of AVE0118}

During slow pacing, we measured a prolongation of the atrial refractory period by $70 \%$ in remodeled atria. Also during AF, the refractory period was prolanged, while no changes in conduction velocity were observed. As a result, the wavelength of the fibrillating waves increased from 7 to $11 \mathrm{~cm}$. This prolongation in atrial refractory period and wavelength can adequately explain the antifibrillatory effects of AVE01 118. The increase in size of the intra-atrial reentrant pathways and a consequent reduction in number of fibrillation waves increase the likelihood that the fibrillation waves will die out simultaneously and fibrillation terminates.

Most class III drugs used for the treatment of AF are $I_{K_{r}}$ inhibitors. Unfortunately, blockade of the $\mathrm{I}_{\mathrm{Kr}}$ current alsa prolongs the ventricular action potentials and QT duration. This increases the chance of tarsade de pointes arrhythmias. ${ }^{2}$ Since $I_{K a n t}$ is absent in the ventricles, $1_{\text {ku }}$ blockers may have a selective action on the atria. ${ }^{\circ}$ As shown in the dog by Nattel et al., 4-aminopyridine (a blocker of $I_{K u r}$ and $l_{s a}$ ) increased atrial refractoriness without affecting the ventricular refractory periad. ${ }^{18}$ In the goat, AVEO118 also did not prolong ventricular repolarization while exerting a strong class III effect on the atria. Thus, compared to the $I_{\mathrm{kr}}$ blocker dofetilide, AVE0118 was highly atrial selective. In pigs, no prolongation of ventricular refractoriness and QT duration was found after administration of AVEO 1 18.17

\section{Clinical Implicatians and Limitations}

Despite the development of various ablation techniques for the treatment of AF, the development of a safe and effective drug for prevention and termination of AF would have major impact on the management of AF. Our present study suggests that blockers of early $\mathrm{K}^{+}$currents $\left(\mathrm{l}_{\mathrm{Kur}}\right.$ and $\left.\mathrm{I}_{\mathrm{t}}\right)$ may have a high clinical potential. The strong class 111 effect in remodeled atria, together with the absence of an effect on 
QT duration, offers hope that these drugs can be used effectively without the risk of ventricular arhythmias. However, caution is warranted in extrapolating our results to humans. One important difference is that the atrial action potential is shorter and the degree of electrical remodeling is higher in the goat than in humans. 19 Therefore it is hard to predict whether the beneficial effects of $I_{\text {kur }} / I_{\text {to }}$ blockade, as observed in the goat, will also occur in humans. Another important coveat is that the goat model lacks the pathological changes seen in alria of patients with AF. Hypertension, valvular and coronary artery disease, and heart failure all cause structural changes in the atria such as interstitial fibrosis, apoptosis and dilatation. Therefore, it remains to be seen whether early class III drugs like AVEO1 18 will be safe and effective in humans.

\section{REFERENCES}

1. Walda AL, Camm AJ, deRuyter H, Friedman PL, MacNeil DJ, Pauls JF, Pitt B, Pratt CM, Schwartz PJ, Veltri EP: Effect of d-sotalol on monality in patients with left ventricular dysfunction affer recent and remote myocardial infarction. The SWORD Inwestigators. Survival With Oral d-Soialol. Loncel $1996 ; 348: 7+112$.

2. Tarp-Pedersen C, Maller M, Bloch-Thomsen PE, Kober L, Sandoe E, Egstrup K, Agner E, Carlsen J, Videbaek J, Marchant B, Canm AJ: Doletilide in potsents with congestive heant failure and left ventricular dysfunction. Danish Investiggations of Arrhythmia and Mortality on Dofetilide Study Group. N Engl J Med 1999:341:857-865.

3. Ellenbogen KA, Stambler BS, Wood MA, Siager PT, Wesley RC, Jr., Meissner MC, Zoble RG, Waketield LKK, Perry KT, Vanderlugt JT: Efficacy of intravenous ibutilide for rapid termination of atrial librillation and atrial flutter: o dose-response study. J Am Coll Cardial 1996:28:130-136.

4. Falk RH, Pollok $\mathrm{A}$, Singh SN, Friedrich T: Imiravenous dofetilide, a class lli antiarthythmic agent, for the termination of sustained atrial fibrillation or flutter. Intravenous Dofefilide Investigators. J Am Coll Cordial 1997:29:385-390.

5. Wang Z, Fermini B, Nattel S: Sustained depalarization-induced autward current in human atrial myocytes. Evidence for a novel delayed rectifier $K+$ current similar to $K v 1.5$ cloned channel currents. Circ Res 1993;73:106 1"1076.

6. Li GR, Feng J, Yue L, Carrier M, Nattel S: Evidence for two components of delayed rectifier Kt- current in humon ventricular myocytes. Circ Res 1996:78:689-696.

7. Nagascawa $H$, Fuiki A, Fujikura $N$, Maisuda $T$, Yamashita $T$, Inove $H$ : Effects of a novel class. III antiarrhylamic agent, NIP.142, on canine atrial fibrillation and flutter. Circ J 2002;66:185-191.

8. Goegelein H: Effects of the nowel inhibitor of atrial K chamnels AVEO 118 in anesthetized pigs and on ion chomels. Pacing Clin Electrophysiol 2003;26:1045.

9. Duylschoever M, Mast $F$, Killion M, Bloouw $Y$, Wiffels M, Allessie M: Methods for delermining the refractory period and excitable gap during persistent atrial fibrillation in the goal. Circulation. $2001,104: 957-962$.

10. Wiffels MC, Kirchhof Cl. Dorlland R. Allessie MA: Arrial tibrillation begets atrial fibrillation. A study in awake chronically instrumented goats. Circulation 1995;92:1954-1968.

11. Bosch RF, Lazlo R, Schneck AC, Goegelein H, Bleich M, Mewis C, Kuhikamp V: AVE 0178 , an antiarrhythmic drug with novel mechanism of action - black of lkur and lto polassium currents im human atrial myocytes. Circulation 2002; 106;:1-22.

12. Yue L, Feng J, Gaspo R, Li GR, Wang Z, Nattel S: lonic remodeling underlying action potential changes in a canine model of atrial fibrillation. Circ Res 1997;81:512-525.

13. Van Wagoner DR, Pond AL, MCCarthy PM, Trimmer JS, Nerbonne JM: Outward K+ curren densities and Kv 1.5 expression are reduced in chronic human alrial fibrillation. Circ Res 1997;80:772-781. 
14. Bosch RF, Natel S: Cellular electrophysiology of arial fibrilation. Cordiovosc Res $2002,54: 259-269$

15. Tse HF Lau CP: Electrophysiologic actions of d-sotalol in potients with persistent atrici fibrillotion. I Am Call Cardiol $2002,40: 2150-2155$

16. Courtemanche $M_{2}$ Ramirez RJ. Nottel S: lonic targets for drug theropy and otrial hbrillation-inducad electrical remadeling: insights from a mathematical model. Cardiovase Res 1999:42:477.489.

17. With KJ, Paehler T, Rosenstein B, Knobloch K, Moier T, Frenzel J, Brendel J, Busch AE, Bleich M: Arriol effects of the nowel $k+1$-channel-blocker AVEO 18 in anesthetized pigs. Cordiovosc Res $2003 ; 60: 298-306$

18. Nattel S, Mathews C, De Blasio E, Han W, Li D, Yue L: Dase-dependence of 4-aminopyridine plasma concentrations and electrophysialogical eltects in dogs : potential relevance to lonic mechanisms in viwo. Circulation 2000;101:1179-1184.

19. Fronz MR, Karasik PL, Li C, Mouborak J, Chovez M: Electrical remodeling of the human atrium: simi. lar effects in patients with chronic atrial fibrillation and atrich flutter. I Am Coll Candiol $1997 ; 30: 1785-1792$. 


\section{CHAPTER 5}

\section{The Combination of $\mathrm{I}_{\mathrm{Kur}} / \mathrm{I}_{\mathrm{to}}$ - and $\mathrm{I}_{\mathrm{kr}}$-Blockers for Effective Cardioversion of Persistent Atrial Fibrillation in the Goat}

Yuri Blaauw, MD; Heinz Gögelein, PhD; Arne van Hunnik, BS; Ulrich Schotten, MD, PhD; Maurits Allessie, MD, PhD 


\section{ABSTRACT}

Background: In electrically remodeled atria the class III action of $I_{k,}$ blockers is re-

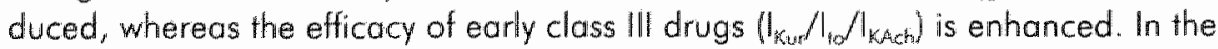
present study we evaluated the antifibrillatory action of the combination of $I_{\text {Kur }} / I_{i o} / I_{\text {Katch }}$ and $I_{k,}$ blackade on persistent atrial fibrillation (AF) in the goat.

Methods and Results: The effects of separate and combined administration of AVE01 18, dofetilide and ibutilide on atrial refractoriness (AERP) and conduction velocity were determined before and after 48 -hours of AF-induced electrical remodeling. The prolongation of AERP $_{400}$ by dofefilide and ibutilide was clearly reduced after 48 hours of AF (from $22 \pm 2$ to $6 \pm 2 \mathrm{~ms}$ and $25 \pm 5$ to $5 \pm 2 \mathrm{~ms}(p<0.01)$. Pretreatment with AVEO 18 restored the narmal prolongation of refractoriness by dofetilide or ibutilide (from $6 \pm 2$ to $20 \pm 3 \mathrm{~ms}$ and $5 \pm 2$ to $25 \pm 2 \mathrm{~ms}$ respectively; $p<0,01)$. This effect was atrial selective since the prolongation of the QT interval was not changed. The anti-fibrillatory effect was evaluated in 10 goats with $46 \pm 17$ days of persistent AF. Infusion of dafetilide $(20 \mu \mathrm{g} / \mathrm{kg} / \mathrm{h})$ or ibutilide $(4 \mathrm{mg} / \mathrm{h})$ alone restored sinus rhythm in $20 \%$ of the animals. In contrast, in combination with AVEa $18(1,3$ and $10 \mathrm{mg} / \mathrm{kg} / \mathrm{h})$, dofetilide or ibutilide terminated AF in respectively $56 \%, 80 \%$ and $100 \%$ of the cases. The effects on AF cycle length were synergistic.

Conclusions: In electrically remodeled caprine atria blockade of $I_{\text {Kua }} / I_{\text {io }} / I_{\text {Kach }}$ restores the class III action of $I_{k,}$ blackade. The efficacy of the combination of AVEO 118 and dofetilide/ibutilide for cardioversion of persistent AF was up to $100 \%$. AVEO118 did not affect the prolongation in QT duration by dofetilide or ibutilide. These findings warrant exploration of a combination therapy of early and late class III drugs in patients with persistent AF. 


\section{INTRODUCTION}

Class III drugs (sotalal, ibutilide, dofetilide) used for the treatment of atrial fibrillation (AF) prolong the atrial action potential mainly by blockade of the rapid component of the delayed rectifier $K^{*}$ current $\left(I_{K_{i}}\right)$. Clinical studies have demonstrated that the success rate of pharmacological cardioversion decreases with the duration of AF. ${ }^{1-3}$ A possible explanation for this observation is that the class III effect of $l_{k_{i}}$ blockade diminishes when the action potential is shortened due to AF-induced electrical remodeling. ${ }^{4,5}$

AVEO1 18 is a novel $I_{\text {Kur }} / I_{\text {io }}$ blacker presently under development for the treatment of AF. ${ }^{6}$ In animal experiments, ${ }^{4,7}$ this drug caused an atrial selective prolongation of the action potential and terminated persistent AF in $70 \%$ of the cases. Interestingly, in remodeled atria the class III action of AVEO 18 was enhanced. ${ }^{4}$ A possible explanation for this observation is that due to abbreviation of the plateav of the action potential (electrical remodeling), the relative contribution of early activated $K^{+}$currents $\left(I_{\text {Ku }} / l_{\mathrm{t} d}\right)$ becomes more important. We hypothesized that under these conditions prolongation of the plateau-phase by $I_{K_{u}} / l_{\text {ta }}$ blockade restores the contribution of the $I_{K_{1}}$ current to atrial repolarization.

The aim of the present study was to evaluate whether in the goat model of AF, $I_{K u r} / I_{t o}$ blockade increases the class III effect of $I_{K r}$ blockade and whether this combination is more effective to cardiovert persistent AF.

\section{METHODS}

\section{The Goat Model of AF}

Thirteen female goats (weight $53 \pm 2 \mathrm{~kg}$ ) were used for the present study. Experiments were performed according to the European Directive for Animal Research and the study protocol was approved by the Animal Investigation Committee of the University of Maastricht. Animals were instrumented as described previously. ${ }^{8}$ During general anesthesia teflon-felt plaques with multiple electrodes were sutured on the free wall of both atria and on Bachmann"s bundle (BB). All leads were tunneled subcutaneously to the neck and exteriorized by 30 -pole connectors. The study protocol was started 3 to 4 weeks after surgery.

\section{Electrophysiological Measurements}

All experiments were performed in conscious animals. The atrial effective refractory period (AERP) was measured at the free wall of the right and left atrium during regular pacing ( $2 \mathrm{~ms}$ pulse duration, $4 \mathrm{x}$ threshold) with intervals ranging between 400 and $200 \mathrm{~ms}$. Single interpolated stimuli were applied after every $8^{\text {th }}$ basic stimuli. The longest coupling interval that failed to capture the atria (increments $2 \mathrm{~ms}$ ) was taken as the AERP. Inducibility of AF was evaluated by single early premature stimuli 
applied to the free wall of the right or leff atrium during regular pacing ( $400 \mathrm{~ms})$. AF was considered inducible if the premature stimulus evoked a rapid irregular atrial thythm lasting $>1$ second.

Atrial conduction velocily was measured allong $B B$ over a distance of ranging from 3.5 to $5 \mathrm{~cm}$ during right atrial pacing at a cycle length of 400 and $250 \mathrm{~ms}$. During persistent AF the median cycle length (AFCL) of 300 consecutive intervals was measured by an algorithm detecting the negative intrinsic deflections of a left or right atrial unipolar fibrillation electrogram. QT duration was measured during atrial pacing (cycle length $400 \mathrm{~ms}$ ) from a precordial electrocardiogram or from a left ventricular unipolar electrogram.

In some animals, during general anesthesia monophasic action potentials were recorded from the high right atrium with a Franz MAP-catheler.

\section{Experimental Protocol}

The electrophysiological effects of dofetilide, ibutilide, AVEO118, and the combination of AVEO1 18 with dofetilide or ibutilide were studied before and after 48 hours of AF (range: 1-4 days) maintained by burst pacing. ${ }^{\$}$. Programmed electrical stimulation was used to measure atrial refractory periods, conduction velocity and inducibility of AF. All drugs were infused intravenously with a rate of respectively 20 $\mu \mathrm{g} / \mathrm{kg}$ (dofetilide), $0.12 \mathrm{mg} / \mathrm{kg}$ (ibutilide) and $3 \mathrm{mg} / \mathrm{kg}$ (AVE0118) per hour. Measurements were performed before and after 30 minutes of infusion. Since previous studies have shown that after 30 minutes of AVEOI 18 infusion the AERP reaches a steady state, the combination of AVEO118 and $I_{k,}$ blockade was studied by infusing dofetilide or ibutilide after 1 hour administration of AVEO 1 18. Measurements were made 30 minutes after AVEO1 18 alone and after 30 minutes of the combination. The drug studies were performed in random order with at least 5 plasma half lives between experiments.

The effects on persistent AF were studied by infusion of dofetilide and ibutilide at a rate of respectively $20 \mu \mathrm{g} / \mathrm{kg} / \mathrm{h}$ and $4 \mathrm{mg} / \mathrm{h}$. AVEO1 18 was administered at different rates of $0.1,0.3,1,3$ and $10 \mathrm{mg} / \mathrm{kg} / \mathrm{h}$. During drug infusion the AFCL was monitored continuously. In case of cardioversion the tolat infusion time and cumulative dosages of the drugs were noted.

\section{Statistical Analysis}

Differences between groups were evaluated by the paired Student's t-test or by 2-way repeated ANOVA with post-hoc Bonferroni t-test. McNemar's test was used to compare AF inducibillity. Differences were considered statistically significant when $p$-value was $<0.05$. Results are presented as mean \pm SEM. 


\section{RESULTS}

\section{Effects of 'Early' and 'Late' Class III Drugs in Remodeled and Non-Remodeled Atria}

Experiments with the combination of AVE0118 and dofetilide were performed in six goats and the combination with ibutilide was tested in seven animals. Figure 1 shows the separate and combined effects of AVEOI 8 and dofetilide or ibutilide on the atrial refractory period before and after 48 hours of AF. In non-remodeled atria AVEO1 18, dofetilide and ibutilide all prolonged the AERP in a reverse frequency-dependent way. At all pacing rates the combination of AVEO 18 with dofetilide or ibutilide exerted an additive effect on the refractory period. Whereas AVEO 18 and dofetilide alone increased the AERP resulted in a prolongation of $75 \pm 6 \mathrm{~ms}$. This was not different from the sum of their separate effects $(73 \pm 7 \mathrm{~ms} ; \mathrm{p}=\mathrm{NS})$. The same was true for the combination of AVEO1 18 and ibutilide.

After 48 hours of AF (lower panels) the AERP was markedly shortened and the physiological rate adaptation was lost (open circles). The class III action of dofetilide and ibutilide was markedly reduced at slower pacing rates $(400,350$ and $300 \mathrm{~ms}$ ). In contrast, the effect of AVEO 18 on AERP (open squares, was entanced at all cycle lengths and the normal rate-adaptation was restored. The combination of AVE0118 and dofetilide or ibutilide had a larger effect on the AERP than the sum of their separate effects (synergism). The combined administration of AVE0118 and dofetilide or ibutilide prolonged the AERP 400 by respectively $92 \pm 6$ and $94 \pm 9$ ms whereas the sum of the separate effects was $78 \pm 5 \mathrm{~ms}(72 \pm 5+6 \pm 2)$ and $68 \pm 8 \mathrm{~ms}(64 \pm$ $5+5 \pm 2$ ) (both $p<0.01$ ).

Figure 2 shows the class III effects of dofetilide and ibutilide, given alone and in the presence of AVEO1 18 (AAERP). In non-remodeled atria dofetilide and ibutilide increased the AERP equally with or without AVEO1 18. However, after $48 \mathrm{~h}$ of AF the effect of $\left.\right|_{k,}$ blockade on the AERP was stronger in the presence of AVEO118. This was especially true at longer cycle lengths when the class $\mid 11$ action of $\left.\right|_{k i}$-blockade was most reduced by electrical remodeling. In fact, pre-treatment with AVEO118 completely restored the normal action of dofetilide and ibutilide as seen in non-remodeled atria.

Dofetilide and ibutilide exerted no effect on intra-atrial conduction velocity both before and after 48 hours AF. In non-remodeled atria AVEO1 18 slowed down atrial conduction al sllow and fast pacing rates (400 and $250 \mathrm{~ms}$ ): respectively $123 \pm 4$ to $120 \pm 5 \mathrm{~cm} / \mathrm{s}$ and $117 \pm 4$ to $110 \pm 4 \mathrm{~cm} / \mathrm{s}, p<0.01)$. In remodeled atria, AVEO 18 slowed down conduction ar fast pacing rates (from $121 \pm 5$ to $115 \pm$ $4 \mathrm{~cm} / \mathrm{s}, p<0.01)$ but not at slow rates $(126 \pm 4$ to $124 \pm 4 \mathrm{~cm} / \mathrm{s}, p=0.15)$. The combination of AVE0 118 and dofetilide did not slow conduction both during slow and fast pacing in normal and remodeled atria. AVEO1 18 and ibufilide did not af fect conduction in non-remodeled aria at slow rate $(123 \pm 7$ to $120 \pm 5 \mathrm{~cm} / \mathrm{s}$ ) but at fast rates conduction slowed from $120 \pm 5$ to $114 \pm 5 \mathrm{~cm} / \mathrm{s}(\mathrm{p}=0.03)$. In remod. 
AVEO118 * Dofettilide
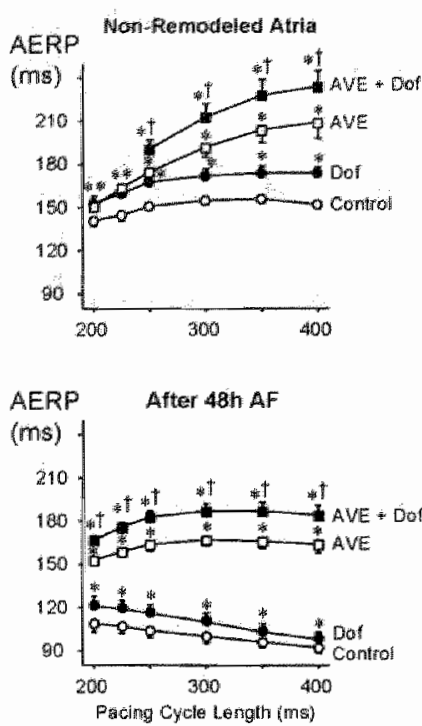

\section{AVE0118 + Ibutillide}
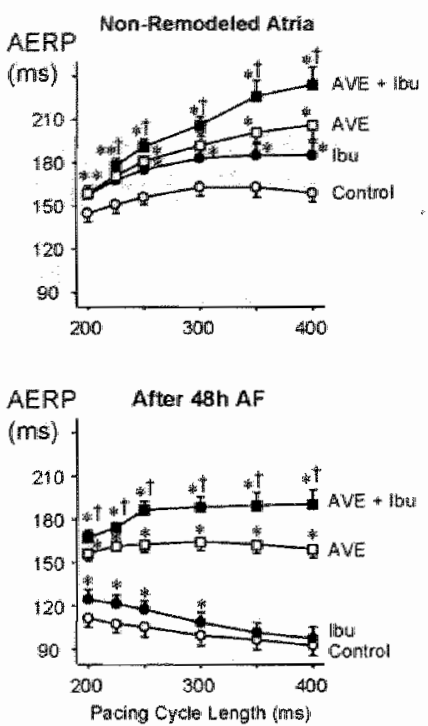

Figure 1: Upper panels: Effects of separate and combined effects of AVEO1 18 and dofefilide (leff) and ibutilide (right) on the atrial refractory period before 48 hours of Af (non-remodeled alria). The datapoints represent the mean AERP of the right and left atrium. Lower panels: AERP affer drug adminisfration in electrically remodeled atria (after 48 hours AF). $p<0.001$ versus contral, $+P<0.001$ versus AVEO1 18.

Dofetilide
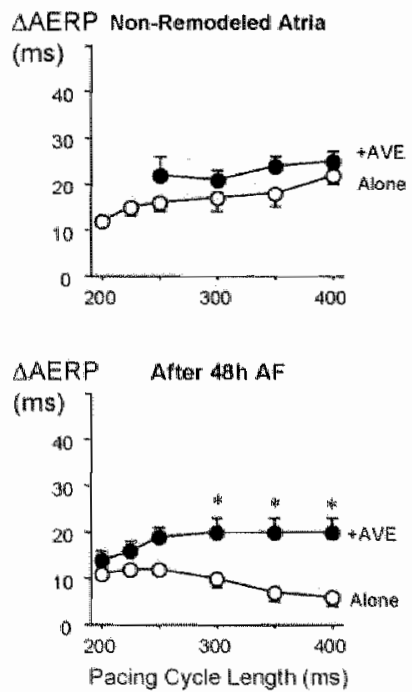

Ibutilide
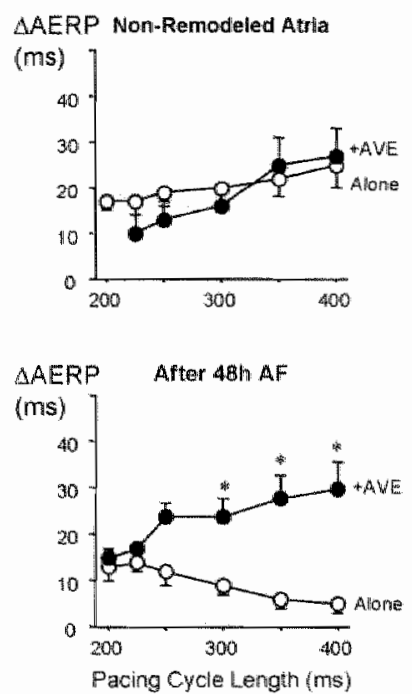

Figure 2: Increase in atrial refroctory period ( $\triangle A E R P$ ) alter administration of dofelilide (left) ond ibutilide (right) either given alone (open dots) or in the presence of AVEO 18 (closed dots). In non-remodeled atrio (upper ponels), no differences were found between the elfects of $\mathbb{K}_{r}$-blockers alone or ofter AVE0118. In electrically remodeled atria, the $\triangle A E R P$ was enhanced in the presence of AVEO118. $* 0<0.001$. 


\section{Control}
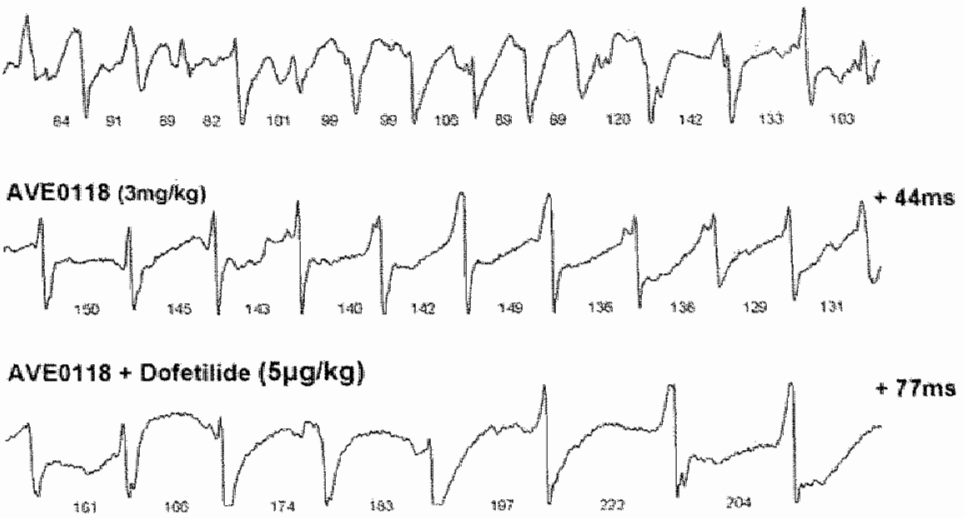

\section{Dofetillide}

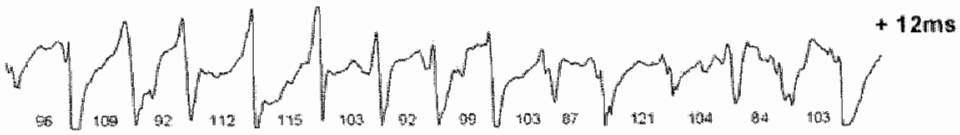

Figure 3: Unipalar right atrial electrograms recarded during separate and cambined infusion of dofetilide and AVE0 18. Dofetilide allone only slightly prolonged the AFCL. AVEO 18 coused a much larger increase in AFCL. When dofetilide were infused in addition to AVEO1 18 the prolongation of the AFCL was much larger than expected fram the effects of the drugs separattely. AFCL: Atrial fibrillotion cy. cle length.
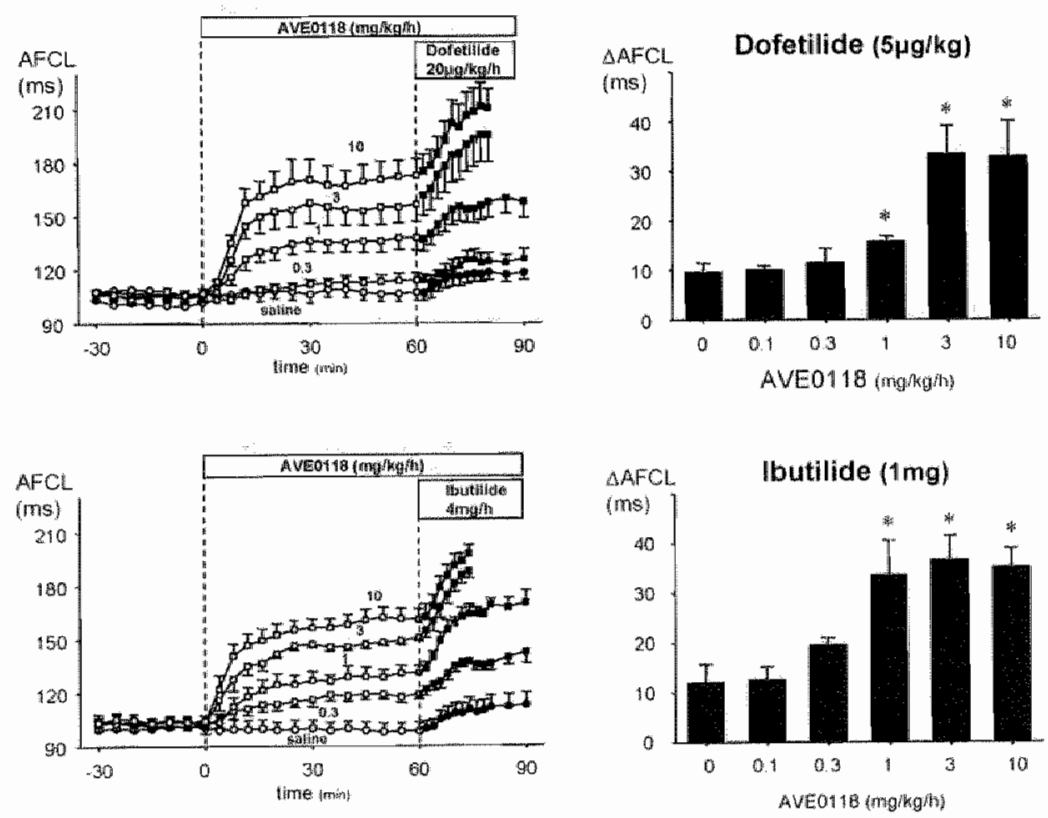

Figure 4 Lefi: Arrial fibrillation cycle length ( $A$.FCL) during 1 haur infusion of $A V E 0118,(0.3,1,3,10$ $\mathrm{mg} / \mathrm{kg} / \mathrm{h})$ followed by additional dotefilide $(20 \mathrm{\mu g} / \mathrm{kg} / \mathrm{h} /$ or ibutilide $(4 \mathrm{mg} / \mathrm{h})$. Increase in afriol tibrillation cycle length ( $\triangle A F C L$ ) atter infusion of doletilide $(5 \mu \mathrm{g} / \mathrm{kg})$ and ibufilide $(1 \mathrm{mg})$ atter pre-treatment with AVEO 18 (different dosages) A synergistic action was observed using AVEO1 18 pre-treatment in dosages of 1,3 and $10 \mathrm{mg} / \mathrm{kg} / \mathrm{h}$. "p<0.05 versus doletilide or ibutilide alone (AVEO1 18:0 $\mathrm{mg} / \mathrm{kg} / \mathrm{h}$ ). 
eled atria, the combination decreased conduction velacity at slow rates from $124 \pm$ $610119 \pm 6$ and from $119 \pm 6$ to $110 \pm 5 \mathrm{~cm} / \mathrm{s}$ af fast pacing rates(both $p<0.01)$.

The inducibility of AF was measured by applying single premature stimuli at the free woll of the right and lett atrium. In non-remodeled atria AF could be induced in $15 \%$ of the cases. After 48 h of electrical remodeling single premature stimuli induced $A F$ in all animals. Whereas administration of dofetilide or ibutilide did not reduce the inducibility of AF in remodeled atria (still 100\%), AVEO118 alone reduced the inducibility to 31 to $33 \%$. The combination and ibutilide or dofetilide caused a further reduction of atrial vulnerability, respectively 23 and $8 \%$.

\section{Effects on AF Cycle Length}

The effects of the separate and combined administration of AVEO1 18 and dofetilide or ibutilide were evaluated in 10 goats with persistent AF of $46 \pm 17$ days (range 5-181). Figure 3 shows an example of fibrillation electrograms recorded during administration of dofefilide and AVEO 118 alone and in combination. In a dosage of 5 $\mu \mathrm{g} / \mathrm{kg}$ dofefilide increased the median AFCL from 98 to $110 \mathrm{~ms}(+12 \mathrm{~ms})$. Administration of $3 \mathrm{mg} / \mathrm{kg}$ AVEO1 18 increased the median AFCL by $44 \mathrm{~ms}$ (from 96 to 140 $\mathrm{ms}$ ). When the drugs were given together the AFCL was prolonged by $77 \mathrm{~ms}$. Thus in the presence of AVEO1 18 the class III effect of dofetilide was markedly stronger than the effect of dofetilide alone (AAFCL: 12 versus $33 \mathrm{~ms}$ ).

In figure 4 the effects of different dosages of AVEO 118 followed by dofetilide or ibutilide are given for all goats. Infusion of AVEO 118 at a rate between 0.3 and 10 $\mathrm{mg} / \mathrm{kg} / \mathrm{h}$ increased the AFCL in a dose dependent way from $103 \pm 3$ (saline) to 167 $\pm 6 \mathrm{~ms}(10 \mathrm{mg} / \mathrm{kg} / \mathrm{h})$. After 60 minutes the infusion of dofetilide or ibutilide was started. The effect of dofetilide and ibutilide on AFCL was clearly dependent on pre-treatment with AVEO1 18. During 30 minutes of dofetilide or ibutilide the slope of the effect on AFCL was steeper at higher concentrations of AVEO1 18. In the right panels the average effects of dofetilide $(5 \mu \mathrm{g} / \mathrm{kg})$ and ibutilide $(1 \mathrm{mg})$ is plotted for all dosages of AVEO1 18. Dofetilide and ibutilide alone (no AVEO118) prolonged the $A F C L$ by $10 \pm 2$ and $12 \pm 4 \mathrm{~ms}$. At increasing dosages the effect of $\mathrm{k}_{\mathrm{k}}$, blockade became progressively enhanced. At $\geq 3 \mathrm{mg} / \mathrm{kg} / \mathrm{h}$ the class lll effect of dofelilide and ibutilide was more than 3 times higher than without AVEO1 18 (respectively $p=0.01$ and $p=0.02$ ).

To elucidate the mechanism of the prolongation of AF cycle length by (the combination of AVE01 18 and $I_{K r}$ blockers we recorded right atrial monophasic action potentials during pharmacological cardioversion. In Figure 5 the effects of AVE01 18 alone and in combination with dofetilide are shown. During control, the fibrillation MAPs were triangular shaped without a plateau phase. In addition, the amplitude and take off potentials of the action potential varied on a beat tio beat basis. The absence of a diastolic boseline potential (phase 4) suggests that no excitable gap was present. Infusion of AVEO 18 proionged the AFCL which was associated with the appearance of a plateaumphase in the action potential. Infusion of additional dofetilide caused a further prolongation of the fibrillation cycle length and a marked 


\section{Monophasic Action Potentials}

\section{Control}
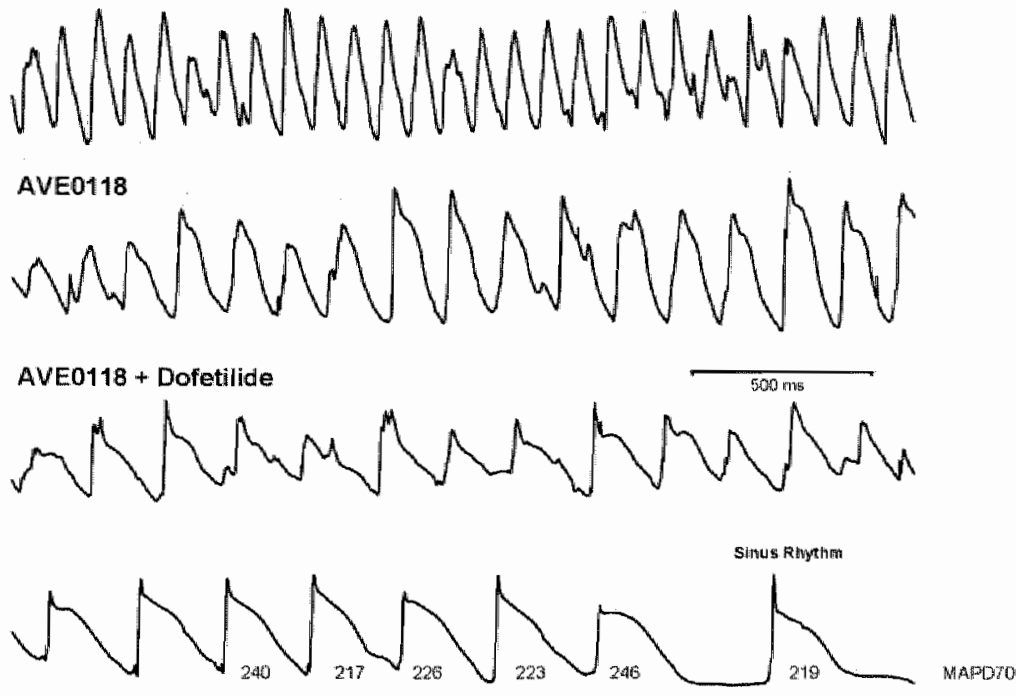

Figure 5: lllustration of the effects of combined administration of AVEO 18 and dofetilide on persistent atrial fibrillation. Monophasic action potentials were recorded from the right atrial free wall during infusion of AVEO 118 followed by additional odministration of dofetilide.

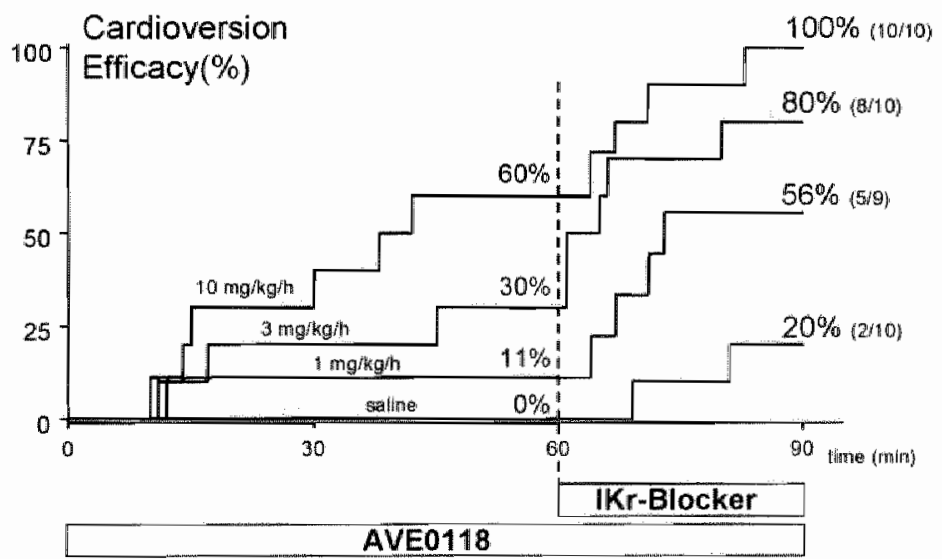

Figure 6: Cumulative cordioversion percentages during infusion of soline and AVEO118 (1, 3 and 10 $\mathrm{mg} / \mathrm{kg} / \mathrm{h} /$ for a 1 -hour period tollowed by additional infusion al $\mathrm{K}_{\mathrm{r}}$.blocker ldotetilide and ibutilide).

prolongation of the action potential was observed, especially during phase lll of the action potential. Shortly before cardioversion the cycle-length had prolonged to $311 \pm 8 \mathrm{~ms}$ and the action potential duration at $70 \%$ repolarization was $227 \pm 5$ ms. This demonstrates that the prolongation of the AFCL by the combination of 

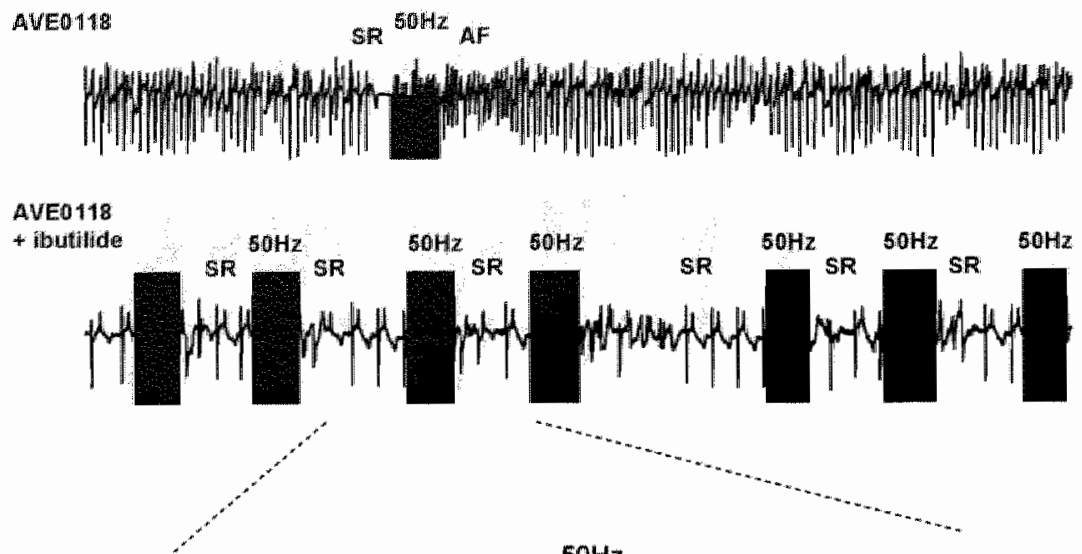

$50 \mathrm{~Hz}$

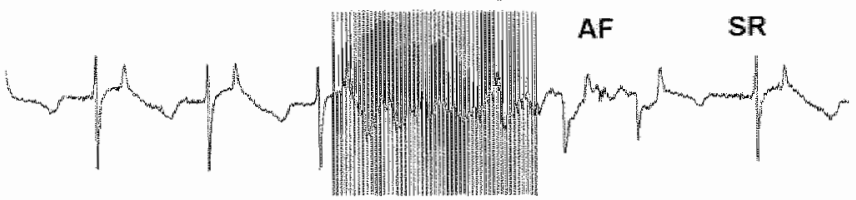

Figure 7: Example of the effects of AVEO 118 and ibutilide on the stability of atrial fibrillotion (A,F). AVEO1 18 (3rig/ $\mathrm{kg} / \mathrm{h})$ could terminate AF, but burst pacing easily reinduced AF paroxysms. Additional infusion of ibutilide resulted in a progressive shartening of the duration af AF-episodes and eventually Aft could not be reinduced.

Dofetilide

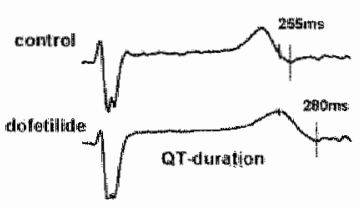

AVE0118 + Dofetilide

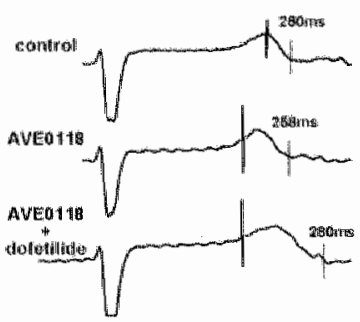

AVE0118 + Dofetilide

Betore 48h AF

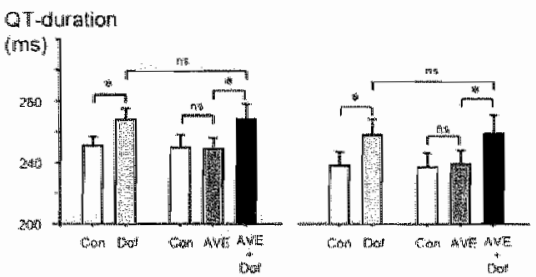

AVE0118 * Ibutlide

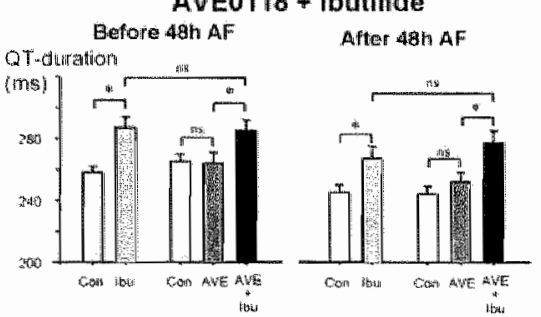

Figure 8 left: Repnesentative examples of electrocardiograms showing the effects of separate ond combined intusion of dotetilide and AVEO 18 on the QT durotion measured during atrial pacing (cycle length 400 ms). When given done, dofettide prolonged the QT duration but AVEOI18 did not. When dotetilide was given in addition to AVEO 18 the increase in QT duration was equal to whem the drug was given alone. The right panels show the data of all goats for combined administration of AVEO 18 and dofetilide (upper ponel) or ibutilide (llower panel). Measurements were pertormed both before and offer 48 hours of AF. ${ }^{*} p<0.01$ versus control. 
AVEO1 18 and $I_{k}$ blockers is primarily due to a prolongation of the atrial action potential.

\section{Success Rate of Cardioversion}

Figure 6 shows the cumulative cardioversion success rates shown for all goats during infusion of AVEO $118(1,3$ and $10 \mathrm{mg} / \mathrm{kg} / \mathrm{h})$ and additional dofetilide $(\mathrm{n}=5)$ or ibutilide $(n=5)(46 \pm 17$ days of persistent AF). AVEO 118 alone terminated AF in a dose dependent manner ranging from $11(1 \mathrm{mg} / \mathrm{kg} / \mathrm{h})$ to $60 \%(10 \mathrm{mg} / \mathrm{kg} / \mathrm{h})$. After 60 minutes infusion, additional dofetilide or ibutilide was administered for another 30 minutes. In the presence of AVEO1 18, the $\mathrm{I}_{\mathrm{K}_{\mathrm{r}}}$ blockers restored sinus rhythm in 56 $(1 \mathrm{mg} / \mathrm{kg} / \mathrm{h})$ and $100 \%(10 \mathrm{mg} / \mathrm{kg} / \mathrm{h})$ of the animals. Of note, both dofetilide and ibutilide alone terminated AF in 1 of 5 goats $(20 \%)$.

Figure 7 shows an example of the effects of separate and combined infusion of ibutilide and AVEO1 18 on the stability of persistent AF. AVEO $118(3 \mathrm{mg} / \mathrm{kg} / \mathrm{h})$ could restore sinus rhythm, but AF was easily reinduced by burst pacing. Combined infusion of AVE01 18 and ibutilide exerted a very strong anti-fibrillatory effect and AF was completely suppressed (lower tracing). The lower tracing shows that during burst pacing an irregular atrial response was provoked, but after resumption of pacing AF could not persist.

\section{Effects on QT duration}

The effects of the separate and combined administration of dofetilide, ibutilide and AVEO 118 on QT duration (atrial pacing at $400 \mathrm{~ms}$ ) were determined before and after 48 hours AF (figure 8 ). As expected, the QT duration increased following infusion of dofetilide $(5 \mu \mathrm{g} / \mathrm{kg})$ and ibutilide $(0.06 \mathrm{mg} / \mathrm{kg})$ whereas AVEO118 $(1.5$ $\mathrm{mg} / \mathrm{kg}$ ) did not change the QT interval. ${ }^{4}$ The combination of AVEO1 18 and dofetilide or ibutilide prolonged QT duration to a similar extent as dofetilide or ibutilide alone. In the right panels the effects on QT duration are shown for all goats. Both before (sinus rhythm) and after 48 hours of AF the prolongation in QT interval by the combination of AVEO 18 and $I_{K,}$ blackade was the same as by dofetilide and ibutilide alone $(p>0.1$. Thus, in contrast to atria, in the ventricles the class III effect of dofetilide and ibutilide were not enhanced by combined administration with AVEO1 18.

\section{DISCUSSION}

\section{Main Findings}

The present study shows that in electrically remodeled atria, prolongation of the refractory period by the $I_{\text {Kur }} I_{\text {to }}$ blocker AVEQ 18 restored the class 11 action of $I_{\mathrm{Kr}}$ blackers. No synergistic prolongation of the QT duration was observed. Intravenous 
administration of the combination of AVEO 118 with dofetilide or lbutilide cardioverted persistent AF of long duration (46 \pm 17 days) in $100 \%$ of the cases.

\section{Modulation of the Effects of Class III drugs by Electrical Remodeling}

It was recently demoinstrated in experimental and clinical studies that the class III action of $\left.\right|_{\text {s. }}$-blockade is reduced by AF-induced electrical remodeling. ${ }^{4,5,10}$ in the goat, the prolongation of left and right atrial refractoriness by $d$-sotalol, dofefilide and ibutilide was reduced by $-75 \%$. ${ }^{410}$ In humans, $d$-sotalol had a reduced effect in patients with long-lasting AF. After internal electrical cardioversion dl-sotalol prolonged the AERP at the distal coronary sinus and high right atrium by $\sim 25 \mathrm{~ms}$ whereas in a matched contral group (no AF) this was $-40 \mathrm{~ms}$. Also the reverse frequency dependence of dl-sotallal was lost in remodeled atria. ${ }^{5}$. These observations suggest that the contribution of the $I_{k r}$ to atrial repolarization is reduced after AF-induced remodeling. Courtemanche et al. " studied the effects of blockade of the various $K^{*-}$ channels in a mathematical model of the human atrial action potential. It was found that in electrically remodeled cells blockade of the $I_{K_{r}}$ caused a smaller prolongation of the action potential than in normal atrial cells. This was explained by the relatively late activation of $\mathrm{K}_{\mathrm{K},}$ during the action potential. Because of this, the contribution of the $\left.\right|_{\mathrm{Kr}}$ current is reduced when the action potential is shorter. Also in ventriculair myocytes the effect of $I_{k r}$ blockade was shown to be dependent on the shape of the action pottential. ${ }^{12}$ Acceleration of the repolarization by constant current injection showed a reduced effect of the $l_{k r}$ blocker E-4031. ${ }^{12}$ In contrast to this reduced effect of $I_{k,}$ blockade, the action of AVE0118 $\left(t_{K u r} / \|_{10}\right)$ was enhanced after electrical remodeling. ${ }^{4}$ This was true despite the fact that the current densities of $\|_{k w}$ and $l_{\text {to }}$ were down-regulated in remadeled atria. ${ }^{13-15}$ However, due to the loss of the plateau-phase, the relative contribution of the early $\left(I_{\text {to }}\right.$ and $\left.I_{k u s}\right)$ may yet be increased.

In the present study we found that the loss of action of $I_{k}$ blockers by ellectrical re. madeling was restored by AVEO1 18. This finding is in agreement with computer modeling showing that the combined inhibition of $I_{k u r}$ and $I_{K_{r}}$ results in a larger prolongation of the APD than expected from the sum of the separate effects. "Blackade of $I_{k u}$ prolonged the plateau of the action potential which in turn increased the contribution of $\mathrm{I}_{k, \mathrm{r}}$ to atrial repolarization. This may explain the synergism between AVEO1 18 and $I_{k}$, blockers.

\section{Effects on QT duration}

In the present study, the combined administration of AVEO118 with dofetilide or ibutilide did not prolong the QT interval to a larger extent than $I_{k,}$ blockers alone. Since the expression of $I_{K_{u F}}$ is large in the atrium and absent in the ventricles, inhibition of $I_{\text {Kur }}$ thus not affect ventricular repolarization. ${ }^{16,37}$ In the ventricles, $\|_{k g}$ is the major repolarizing current and blockade of this channel markedly prolongs the action potential. ${ }^{18}$ The role of $I_{10}$ for the shape of the action potential is less clear and re- 
markable differences between species exist. ${ }^{19}$ in species with short triangular action potentials (mouse and rat) blockade of the current markedly prolongs the action po-

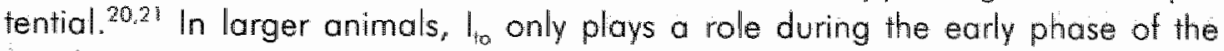
repolarization (phase I). In normal canine ventricle $\left.\right|_{i 0}$ blockade did not affect the duration of the action potential. ${ }^{22}$ Computer modeling showed no effect. ${ }^{23}$ On the other hand, it has been suggested that the prolangation of the ventricular action potentials in failing hearts is due to reductions in $\mathrm{I}_{10}{ }^{24}$ In the present study, the lack of effect on the QT interval suggest that blockade of the $I_{t 0}$ and $I_{\text {Kurr }}$ alone or in combination with $I_{\text {ss }}$ blockade, does not affect the action potential of the goat ventricle.

\section{Possible Clinical Implications}

Currently available anti-arrhythmic drugs are maderately effective in converting persistent AF. Class IC drugs such as flecainide are only effective in cardioverting recent onset AF. In patients in which AF persisted for $>24 \mathrm{~h}$, class I drugs are of no value for pharmacological cardioversion. ${ }^{25,26}$ The cardioversion efficacy of the class III drug ibutilide was only $16 \%$ in of patients with AF of longer than 30 days.' In addition to this low efficacy, also the risk of serious ventricular pro-arrhythmia is a cancern. $^{27,28}$

In the present study we found that the combined administration of AVEO1 18 and dofetilide or ibutilide during persistent $A F$ in the goat caused a marked dose dependent increase in the AF cycle length leading to restoration of sinus rhythm in $100 \%$ of the cases. Ventricular arrhythmias were not observed. Blockade of $I_{\text {Kur }} / I_{\mathrm{s}}$ had no effect on the QT interval whereas the combination of AVEO 118 with dofetilide and ibutilide caused the same (slight) QT prolongation as caused by the $I_{k \text {, }}$ blockers alone. If this combination would yield the same effect in humans then this may have important implications for the management of AF in patients.

Obviously, caution is warranted in extrapolating the results of the present study to humans with AF. Important differences exist in $\mathrm{K}^{+}$currents between species. ${ }^{24,30}$ Therefore, it is possible that the electrophysiological effects of AVEO 1 18, but also of $I_{k}$, blockers may be different in man. In addition, the substrate of AF is very different in patients than in the goat. Patients often have underlying heart diseases that contributes to the persistence of the arrhythmia by changing the electrophysiological, structural and contractile properties of the atrium.

\section{Limitations}

A major limitation of the present study is that the underlying ionic mechanisms of the action of AVEO 18 and dofetilide/ibutilide were not addressed. At the moment anly computer modeling data is available on the effects of combined blockade of $I_{k u} / I_{10}$ and $I_{K_{r}}$ on atrial electrophysiology. It is important that the data of the modeling study of Courtemanche el al." is backed up by additional in vitro experiments. 


\section{REFERENCES}

1. Ellenibogen KA, Stumbler BS. Mood MA, Souger PT, Wesley RC, Jr, Meissner MC, Zoble RG. Wakefield LK, Perry KT, Vanderlugi JT: Efficocy of intravenous ibufilide lor ropid termination of atrial fibrillation and citricil Huiter: a dase-response study. J Am Coll Cardiol 1996,28:130-136.

2. Vos MA, Golisyn SR, Stangl K, Ruda MY, Van Wijk LV, Horry JD, Perry KT, Touboul P, Steinbeck G. Wellens H.J. Superiority of ibutilide (o new closs II agent) over DL-sotalol in converting atrial flutter and atrial fibrillation. The lbutilide/Sotalol Comparator Study Group. Heart 1998;79:568-575.

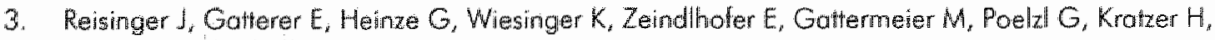
Ebner $A$, Hoherwallner W, Lenz K. Slany J, Kuhn P: Prospective comparison of flecainide wersus sotalal for immediate cardioversion of abral fibrillation. Am J Cardiol 1998;81:1450-1454.

4. Bhouw Y, Gogelein H, Tieleman RG, Van Hunnik A, Schotien U, Allessie MA: "Early" Class III Drugs lor the Trearmem of Afrial Fibrillation. Efficacy and Atrial Selectivity of AVEO118 in Remodeled Atria of the Goot. Circulation 2004; 110:1717-1724.

5. Tse HF, Lau CP. Electrophysiologic attions of di-sotolol in patients with persistent atrial fibrillation. I Arr Coll Cardiol 2002;40:2150-2155.

6. Goegelein H: Effects of the novel inhibitor of afrial K channels AVEOI 8 in anestherized pigs and on Ion chonnels. Pacing Ch Electrophysiol 2003,26:1045.

7. Wirth KJ, Poehler T, Rosenstein B, Knobloch K, Maier T, Frenzel J, Brendel J, Busch AE, Bleich M: Atrial effecis of the novel $\mathrm{K}(+1$-channel-blocker AVEO118 in anesthetized pigs. Cardiovasc Res 2003;60:298-306.

8. Wiffels MC, Dorland R, Mast F, Allessie MA: Widening of the excitable gap during pharmacalogical cardioversion of atrial tibrillation in the goot: effects of cibenzoline, hydroquinidine, flecainide, and d-sotaloll. Circulation 2000;102:260-267.

9. Wiffels MC, Kirchhof CJ, Dorland R, Allessie MA: Alriall fibrillation begets atrial fibrillation. A study in awake chronically instrumented gaats. Circulation 1995;92:1954-1968.

10. Duytschaever $M$, Bloouw $Y$, Allessie MA: Consequences of Atrial Electrical Remodeling for the Anti-Arrhythmic Action of Class IC and Closs. Ill Drugs. Cardiovascullar Research 2005

11. Courtemanche $M$, Ramirez RJ, Nattel S: lonic targets for drug therapy and atrial fibrillation-induced electrical remodeling: insights from a mathematical model. Cardiovasc Res 1999:42:477-489.

12. Rocchetti M, Besano A, Gurrola GB, Possani LD, Zoza A: Rate dependency of delayed rectifier currents during the guinea-pig ventricular action patential. J Physiol 2001;534:721-732.

13. Yue L, Feng J, Gaspo R, Li GR, Wang Z, Nattel S: lonic remodelling underlying action potential changes in a canine model of atrial fibrillation. Circ Res 1997;81:512-525.

14. Van Wagoner DR, Pond AL, McCorthy PM, Trimmer IS, Nerbonne IM: Outward K+ current densities and KvI.5 expression ore reduced in chronic human atrial fibrillofion. Circ Res 1997;30:772.781.

15. Basch RF, Zeng X, Grammer JB, Popovic K, Mewis C, Kuhlkamp V: lonic mechanisms of electrical remodeling in human atrial librillation. Cardiowase Res 1999:44:121-131.

16. Konazewska H, Peeters GA, Sanguineti MC: Repolorizing K t currents in nonfriling human hearis. Similarities between right septah subendocardial and left subepicardial ventricular myocytes. Cinculation $1995,92: 1179-1187$

17. Li GR, Feng J, Yue L, Comier M, Nottel S: Evidence for two components of delayed rectifier KKt current in human ventricular myocytes. Circ Res 1996;78:689-696.

18. Haverkamp W, Breithardt G, Camm AJ, Janse MJ, Rosen MR, Antzelevitch C, Escande D. Franz M, Malik $M$, Moss $A$, Shoh R: The potential for QT prolongation and pro-arhythmia by non-anti-arthythmic drugs: clinical and regulatory implications. Report on a Policy Conference of the European Society of Cardiology. Cardiovasc Res 2000;47:219-233.

19. Nerbonne JM: Molecular basis of functional woltage-gated $K+$ channel diversity in the mammalian myocardium. J Physiol 2000,525 Pt 2:285-298.

20. Wickenden AD, Lee P. Sah R, Huong Q, Fishman Gi, Backx PH: Targeted expression of a dominant-negative $K(v) 4.2 \mathrm{~K}(+)$ dhannel subunit in the mouse heart. Circ Res 1999;85:1067.1076.

21. Fiset C. Clark RB, Larsen TS, Giles WR: A rapidly activating sustained K+ current modulates repolarization and excitation-contraction coupling in adult mouse ventricle. I Physiol 1997:504 (Pf 3):557-563. 
22. Kenyon Jl, Gibbons WR: 4 -Aminapyridine and the eorly outward curtent of sheep cardioc Purkinge firbers. J Gen Physiol 1979:73:139.157.

23. Priebe L. Beuckelmann DI: Simulation study of cellular electric propenties in heat foilure. Circ Res $1998 ; 82: 1206-1223$.

24. Tomaselli GF, Beuckelmann DI, Calkins HG, Berger RD, Kessler PD, Lawrence JH, Kass D, Feldman AM, Marban E: Sudden cardiac death in heart failure. The role of abnomal repolarization. Circulafion 1994; $9022534-2539$.

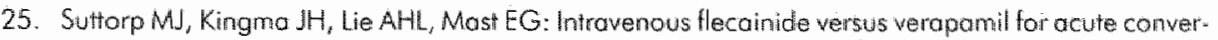
sion of paroxysmal atrial fibrillation or flutter to sines rhythm. Am J Cardiol 1989;63:693-696.

26. Crijns HJ, wan Wijk LM, van Gilst WH, Kingma JH, wan Gelder KC, Lie Kl: Acule conversion of afrial fibrillation to sinus thythm: dinical efficacy of llecainide acetate. Comparison of two regimens. Eur Heari J 1988,9:634-638.

27. Torp-Pedersen C, Maller M, Bloch-Thomsen PE, Kober L, Sandoe E, Egstrup K, Agner E, Carlsen J, Videbaek J, Marchant B, Camm AJ: Dofeilide in patients with congestive heart failure and left ven Aricular dysfunction. Danish Investigations of Arrhythmia andi Mortality on Dofetilide Study Group. N Engl J Med 1999;341:857-865.

28. Waldo AL, Camm Al, deRuyler H, Friedman PL, Mockleil DJ, Pauls JF, Pitt B, Proth CM, Schwortz PJ, Veltri EP. Effect of d-sotalol on mortality in potients with left ventricular dystunction after recent and remate myocardial intarction. The SWORD Investigators. Sunvival With Oral d-Sotalol. Lancet $1996 ; 348: 7-12$.

29. Varra A, Lathrop DA, Hester SB, Nanasi PP, Papp JG: lonic currenis and action polentials in rabbit, rat, and guinea pig ventricular myocytes. Basic Res Cardiol 1993;88:93-102.

30. Zicha S, Moss I, Allen B, Varro A, Popp \, Dumoine R, Antzelevich C, Nattel S: Molecular basis of species-specific expression of repolarizing $K+$ currents in the heart. Am J Physiol Heart Circ Physiol $2003 ; 285: 47641-1649$. 


\section{CHAPTER 6}

\section{Long-Term Changes in Sequence of Atrial Activation and Refractory Period: No Evidence for 'Atrial Memory' in the Goat}

Dirk Vollmann, MD; Yuri Bladuw, MD; Hans-Ruprecht Neuberger, MD; Ulrich Schotten, MD, PhD; Maurits Allessie, MD, PhD 


\section{ABSTRACT}

Objectives: The purpose of this study was to test whether the spatial distribution of the atrial refractory period (AERP) and the vulnerability to atrial fibrillation (AF) are alfered by long-term changes in the sequence of atrial activation.

Background: The spatial distribution of the AERP plays an important role in AF. Changes in the activation sequence have been postulated to modulate atrial repolarization ("atrial memary").

Methods: Six goats were chronically instrumented with epicardial atrial electrodes to determine activation time and AERP at 11 different areas of the right (RA) and left (LA) atrium and the Bachmann's bundle. Activation time and AERP were measured during sinus rhythm and during prolonged RA and LA pacing (1 week RA pacing, 2 weeks LA pacing, 1 week RA pacing; $150 \mathrm{bpm}$ ). Inducibility of AF was determined by the number of atrial sites where single premature stimuli induced AF paroxysms $>1$ second.

Results: During sinus rhythm (106 $\pm 4 \mathrm{bpm}$ ), AERP was longest at the Bachmann's bundle and shortest at the LA free wall (185 $\pm 6 \mathrm{~ms}$ and $141 \pm 5 \mathrm{~ms}, P<$ $.001)$. In five of six goats, an inverse correlation between local activation time and AERP was found during sinus rhythm $(r=-0.53 \pm 0.05 ; P<.05)$. The increase in atrial rate during RA and LA pacing caused an overall shortening of AERP from 167 $\pm 6 \mathrm{~ms}$ to $140 \pm 6 \mathrm{~ms}(P<.001)$. However, a switch between long-term RA and LA pacing did not significantly change AERP at any of the 11 atrial regions and had no significant effect on AF inducibility.

Conclusions: During sinus rhythm, an inverse relationship exists between the sequence of atrial activation and the local refractory period. However, long-term changes in the sequence of atrial activation do not alter the spatial distribution of AERP or the inducibility of AF. 


\section{INTRODUCTION}

Spatial differences in the atrial effective refractory period (AERP) play an important role in the initiation and perpetuation of atrial reentrant arrhythmias. ${ }^{1.3}$ Regional differences in AERP have been attributed to differences in ionic currents and action potential duration (APD). ${ }^{4}$ In isolated canine atria Spach et al. found an inverse relationship between the atrial APD or AERP and the distance from the sinus node. 5.6 Whether this spatial distribution in APD and AERP is the long-term result of the sequence of activation during sinus rhythm or whether it is due to intrinsic electrophysiological differences between atrial myocytes in different parts of the arria is unclear.

Local activation time and APD are inversely related in the ventricles. ${ }^{2}$ A chiange in ventricular activation results in prolongation of the action potential in early activated and a shortening in later activated areas. ${ }^{8}$ Rosenbaum et al. introduced the term 'cardiac memory' to describe this capability of myocardial cells to adjust their repolarization to alterations in sequence of activation. ${ }^{.}$Electrocardiographically, cardiac memory manifests itself as a change in morphology of the T wave, persisting for a considerable time after the normal sequence of activation is restored. Also in the atria, a change in the so-called 'atrial gradient' accurs on the surface ECG after prolonged ectopic atrial activation, indicotive of changes in the atrial $T(a)$-wave ${ }^{10}$ It has beem proposed that the duration of the action potential in the atria, as in the ventricles, is modulated by the sequence of activation ('atrial memory')..$^{10}$ It has also been speculated that tachycardia-induced electrical remodeling may incorporate aspects of cardiac memory. 10,11 However, data on changes in atrial APD and AERP in response to long-term alterations in sequence of activation are sparse and limited to a small number of atrial sites. ${ }^{10,12,13}$

In the present study, we investigated whether long-term changes in atrial activation lead to changes in the spatial distribution of the atrial refractory period. In chronically instrumented goats, AERP was measured at 11 atrial sites (right atrium (RA), left atrium (LA) and Bachmann bundle (BB)) both during sinus thythm and after 1-2 weeks of right and left atrial pacing.

\section{METHODS}

\section{Animal model}

Six goats were used for this study. The investigation conformed with the Guide for the Care and Use of Laboratory Animals published by the US National Institutes of Health (NIH Publication No. 85-23, revised 1996). Anaesthesia was induced with Thiopental $(15 \mathrm{mg} / \mathrm{kg})$ and maintained by ventillation with Isoflurane and a mixture of $\mathrm{O}_{2}$ and $\mathrm{N}_{2} \mathrm{O}$. After left intercostal thoracotomy, the pericardium was opened and a teflon felt strip measuring $10 \times 1.3 \mathrm{~cm}$ and containing 54 electrodes (diameter 2 $\mathrm{mm}$ ) was pulled through the sinus transversus between the atria and the aortic root 

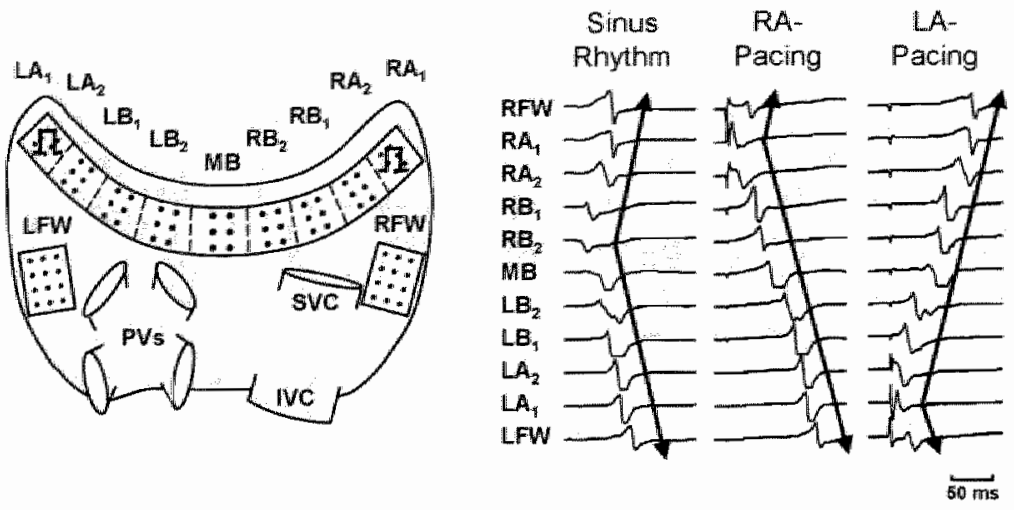

\begin{tabular}{l}
$-90-123 / \mathrm{min}+$ \\
\hline Sinus Rhythm \\
\hline$->1$ year $-1-1$ week -1 Pacing
\end{tabular}

Figure 1: Upper left: Schematic drawing of the chronically implanted epicardial electrodes. Electrophysiological measurements were pertormed at 11 atrial regions. Upper right: Unipolor elecirograms illustrating the change in sequence of activation during pacing from the right $\left(R A_{1}\right.$; RAmpacing) and left atrial appendoge (LA; LA-pacing). Bottom: Experimental protacol. Electrophysiologicol studies were performed during sinus rhythm and were repeated affer 1 hour, 1 day and 1 week of RA-pacing and after 1 hour, 1 day, 1 week and 2 weeks of LA-pacing.

and sutured to the right and left atrial appendage. Two teflon felt plaques of $1 \times 1.5$ $\mathrm{cm}$ (12 electrodes) were sutured on the free wall of the right and left atrium (Fig 1). A subcutaneously implanted silver plate served as indifferent electrode.

All leads were tunneled subcutaneously to the neck and exteriorized by three 30 -pin connectors. Buprenorphin and ampicillin were given pre-operatively and during three days after surgery. The experimental protocol started after 4 weeks when the animals had recovered from the implantation procedure.

All experiments were performed in the fully conscious state. Electrophysiological sludies were performed both during normal sinus rhythm and during 3 consecutive periods of right and left atrial pacing. A conventional pacemaker (Kappa SR703, Medtronic) was used for continous atrial pacing at a rate of $150 / \mathrm{min}$. The external device was connected to a pair of electrodes at the right or left atrial appendage. The pacemaker was programmed in the AAl mode to avoid induction of atrial arrhythmias. Stimulus strength was set at twice threshold at a pulse duration of 1.5 ms. The device counter for sensed and paced atrial beats was used to verify a high percentage of atrial pacing (>99\%). Atrial tachyarrhythmias were automatically detected and stored with an atrial electrogram strip if more than 4 consecutive atrial beats at a rate of $=220 / \mathrm{min}$ occured. Figure 1 illustrates the experimental protocol. After baseline measurements were abtained during sinus rhythm, the right atrial appendage was paced continously for 1 week (RA-pacing). Then the left atrial appendage was paced during 2 weeks (LA-pacing) followed again by 1 week of RA-pacing. 
This protocol was designed to measure changes in AERP (and their reversibility) resulting from long-term changes in sequence of atrial activation without a change in pacing rate.

\section{Electrophysiological Measurements}

Electrophysiological studies were performed during sinus rhythm and after 1 hour, 1 day and 7 days of RA and LA-pacing. In case of LA-pacing measurements were done after 14 days of pacing. The local activation time and refractory period were determined at 11 atrial regions together with the inducibility of AF by single premature stimuli (Figure 1). In each area the average value at three neighboring electrodes was measured. Electrode selection was based on signall quality and stimulation threshold. The local activation time was determined by the steepest negative deflection in the unipolar electrograms. During sinus rhythm the earliest onset of the P-wave in the extremity-leads was defined as the first moment of activation. During pacing the stimulus artefact was taken as time zero. The AERP was measured by single premature stimuli ( $2 \mathrm{~ms}, 2 x$ threshold). An extra-stimulus $\left(S_{2}\right)$ was interpolated at every $8^{\text {th }}$ interval during RA- or LA-pacing $\left(S_{1}-S_{1} 400 \mathrm{~ms}\right)$ synchronized to the local atrial activation $\left(A_{1}\right)$. Starting well within the refractory period, the $A_{1}-S_{2}$ coupling interval was increased in steps of $2 \mathrm{~ms}$. The shortest coupling interval resulting in a propagated response was taken as the AERP. The spatial dispersion in refractory periods was defined as the difference between the longest and shortest refractory period of the 11 regional AERPs. The local atrial recovery time was determined by the sum of the local activation time and the AERP. Atrial vulnerability was measured by the percentage of pacing sites where atrial fibrillation could be induced by administration of single premature stimuli.

\section{Statistical Analysis}

Data are expressed as mean \pm SEM. A one-way repeated-measures ANOVA with a Tukey Kramer post test was used to analyze regional differences in AERP during silnus rhythm and to compare the dispersion in AERP, the dispersion in recovery time and $A F$-inducibility between $R A$ - and LA-pocing. A two-way repeated-measures ANOVA with a Bonferroni post test was used to compare AERPs at different timepoints (sinus rhythm, RA- and LA-pacing). A one sample t-test was used to evaluate whether local changes in AERP during RA- and LA-pacing differed from zero. A $p$-value $<0.05$ was considered to be statistically significant.

The Pearson correlation coefficient was calculated to evaluate the relationship between local activation time and AERP during sinus rhythm. A correlation coefficient of $<-0.50$ or $>0.50$ with a $p$-value of $<0.05$ was considered as statistically significant. 

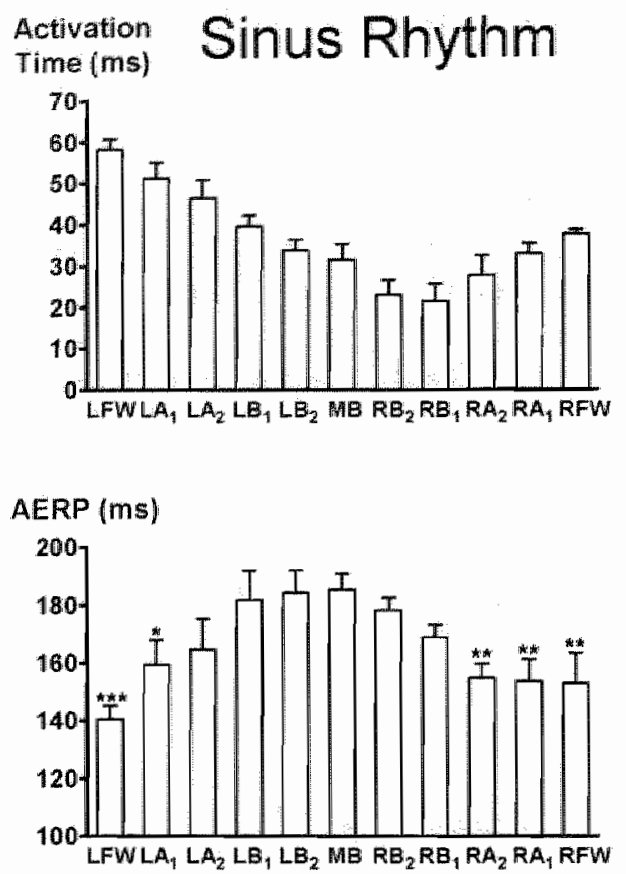

Figure 2: Sequence of activation (top) and spatial distribution of atrial refractory periods (bottom) in 6 goats during normal sinus rhythrm. Re. froclory periads were shorter at late activated regions. "** $p<0.001$;

\section{RESULTS}

\section{Sinus Rhythm}

The sequence of atrial activation and the spatial distribution in refractoriness during normal sinus rhythm are illustrated in Figure 2. Sinus rate ranged between 90 and $123 \mathrm{bpm}$ with an average of $106 \pm 4 \mathrm{bpm}$. In all animals the earliest activation was recorded at $\mathrm{RB}_{1}$ or $\mathrm{RB} \mathrm{B}_{2}$. The latest activation was seen at the free wall of the left atrium (LFW). The AERP was longest at the mid portion of Bachmann's bundle (MB: $185 \pm 6 \mathrm{~ms}$ ) and was significantly shorter of the left and right atrial appendage and tree wall (LA $: 159 \pm 9 \mathrm{~ms}^{2} \mathrm{RA}_{1}$ : $154 \pm 7 \mathrm{~ms}$; LFW: $141 \pm 5 \mathrm{~ms}$; RFW: $153 \pm 10 \mathrm{~ms}$; $p<0.05$ to 0.001 ). Differences between right and left atrial refractory periads were not statistically significant. The AERP values from all atrial sites are given in Table 1 . In 5 of 6 goats an inverse correlation existed between the local activation times and the AERP $(r=-0.53 \pm 0.05 ; p<0.05$ to 0.001$)$. In one goat no correlation was found. 


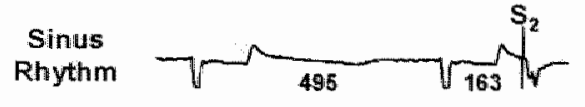

Activation Time (ms)
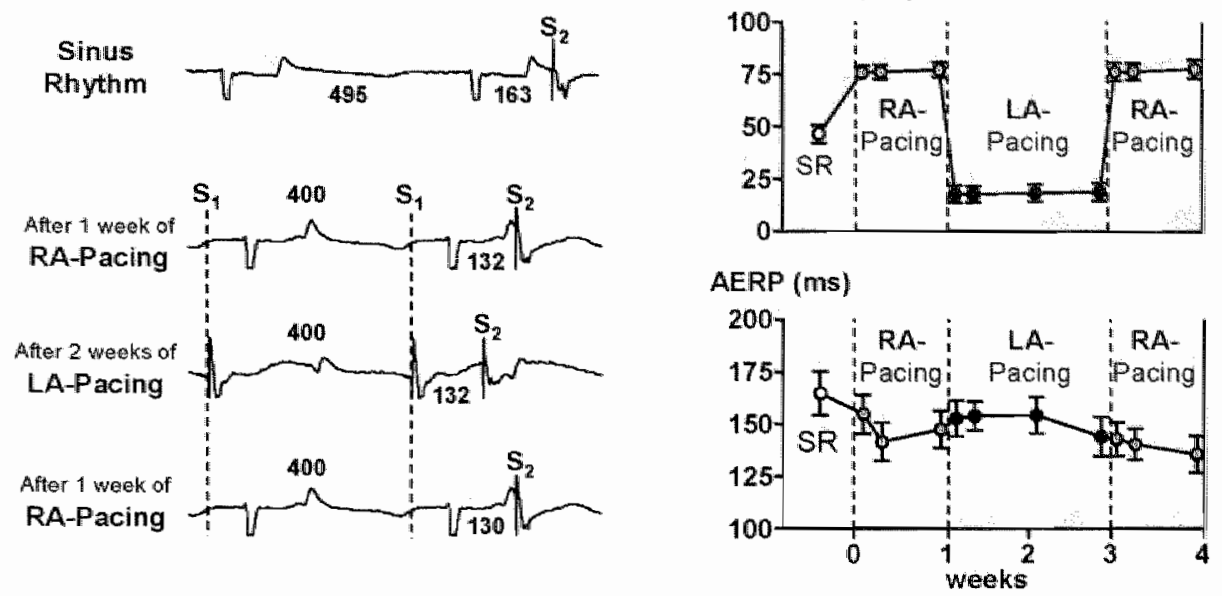

Figure 3: Electrophysiological meastrements at a left atrial site $\left(\mathrm{LA}_{2}\right)$. Left: Electrograms recorded at $\mathrm{LA}_{2}$ during determination of the refractory period in one goat. Right: Local (L $\left.A_{2}\right)$ activation times and refractory periods from 6 goats. The increase in atricl rate during RA- and LA-pocing was associoled with a shortening of the AERP compared to sinus rhythm $(p<0.01)$. A shift in pacing sile from the right to the left atrial appendage and back caused large changes in the relative mament of activation, but had no sig. nificant effect on the AERP.
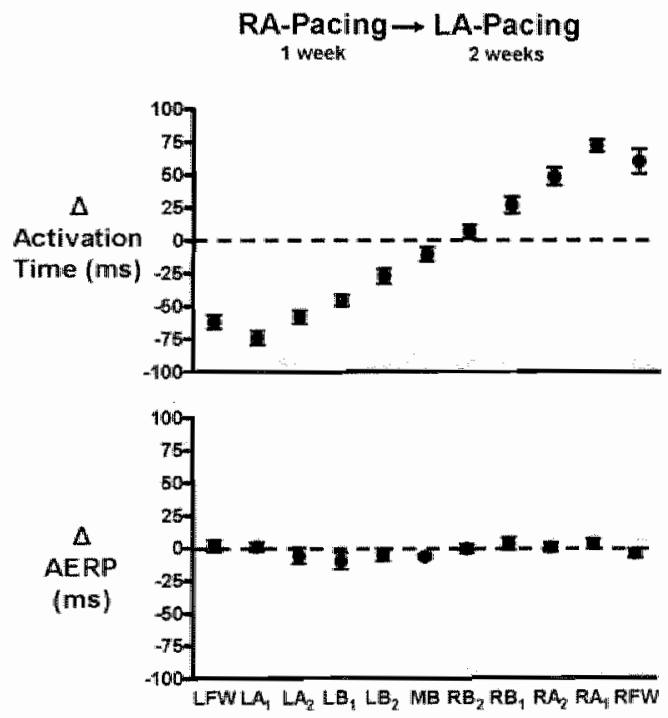
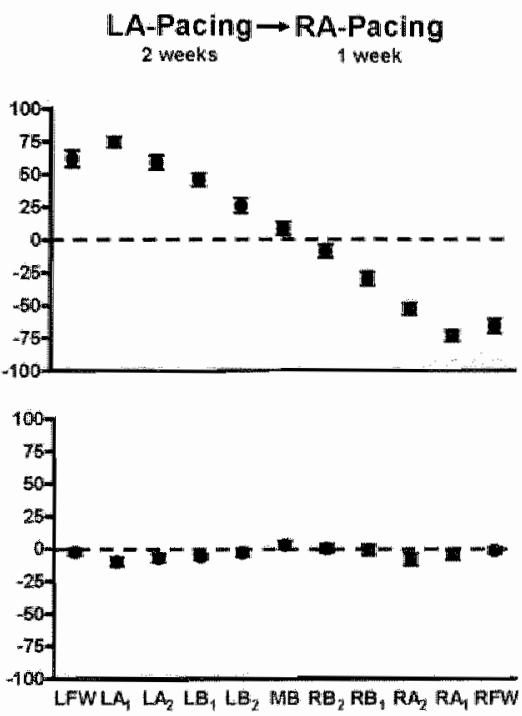

Figure 4: Changes in activation time and refractary period in 11 atrial regions after switching from $R A$. to LA-pacing (left) and bock (righil). A change in pacing site caused large changes in the local activation time (top) but had no significant effect on the AERP in any of the 11 detriol regions (botiom). 
Table I Local activation fime ond AERP during sinus thythm and fiter right atrial (RA-) and left atrial (LA.-) pocing.

\begin{tabular}{|c|c|c|c|c|c|c|c|c|}
\hline \multirow[t]{2}{*}{ Alrial Sile } & \multicolumn{2}{|c|}{ Sinus Rhythm } & \multicolumn{2}{|c|}{$\begin{array}{l}\text { After } 1 \text { week of } \\
\text { RA.Pacing }\end{array}$} & \multicolumn{2}{|c|}{$\begin{array}{c}\text { After } 2 \text { weeks of } \\
\text { LA Pacing }\end{array}$} & \multicolumn{2}{|c|}{$\begin{array}{l}\text { After I week of } \\
\text { RA-Pacing }\end{array}$} \\
\hline & $\begin{array}{l}\text { Activotion } \\
\text { Time (ms) }\end{array}$ & $\begin{array}{c}\text { AERP } \\
(m s)\end{array}$ & & & & & & $\begin{array}{l}\text { AERP } \\
\text { (mis) }\end{array}$ \\
\hline FW & $38+1$ & $153 \pm 10$ & $26 \pm 4$ & $130 \pm 8$ & $86=5$ & $126=9$ & $20 \pm 1$ & $125 \pm 9$ \\
\hline Al & $33 \pm 3$ & $154 \pm 7$ & $9 \pm 1$ & $3 r$ & $81=$ & $136=9$ & $B \pm 2$ & $131 \pm 8$ \\
\hline $\mathrm{A}_{2}$ & $28 \pm 5$ & $155 \pm 5$ & $21=4$ & $129 \pm 7$ & $69 \pm 3$ & $136 \pm 7$ & $16 \div 3$ & $129 \pm 7$ \\
\hline $\mathrm{BI}$ & $21=4$ & $169=4$ & $31 \pm 3$ & $38 \pm 5$ & $58 \pm 4$ & $142 \pm 6$ & $28 \pm 3$ & $140 \pm 5$ \\
\hline 82 & $23=4$ & $178-4$ & $41 \pm 3$ & $144 \pm 5$ & $48 \pm 4$ & $144 \pm 0$ & $39 \pm 3$ & $\| 44 \pm 5$ \\
\hline $\mathrm{BB}$ & $31 \pm 4$ & $185 \pm 6$ & $52 \pm 3$ & $154 \pm 5$ & $42 \pm 4$ & $147 \pm 7$ & $50 \pm 3$ & $1150 \pm$ \\
\hline 82 & $34 \pm 3$ & $184 \pm 8$ & $61 \pm 3$ & $157 \pm 6$ & $34 \pm 4$ & $152=6$ & $60 \pm 4$ & $149 \pm 5$ \\
\hline 31 & $40 \pm 3$ & $182 \pm 10$ & $71 \pm 4$ & $161 \pm 6$ & $25 \pm 3$ & $152 \pm 8$ & $71 \pm 4$ & $145 \pm$ \\
\hline$\angle A 2$ & $47 \pm 4$ & $165 \pm 10$ & $77 \pm 3$ & $148 \pm 8$ & $19 \pm 4$ & $144 \pm 9$ & $78 \pm 4$ & $137 \pm 8$ \\
\hline$\left.\right|_{A} 1$ & $51 \pm 4$ & $159 \pm 9$ & $82 \pm 2$ & $150 \pm 7$ & $8 \pm 3$ & $149 \pm 7$ & $82 \pm 2$ & $141 \pm 6$ \\
\hline LFW & $58 \pm 3$ & $\mid 41 \pm 5$ & $90 \pm 3$ & $123 \pm 4$ & $28 \pm 3$ & $124 \pm 7$ & $90 \pm 8$ & $122 \pm 6$ \\
\hline Average & - & 167 & - & 143 & - & 142 & .. & 140 \\
\hline
\end{tabular}

\section{Right and Left Atrial Pacing}

The increase in atrial rate from $106 \pm 4 \mathrm{bpm}$ during normal sinus rhythm to 150 bpm during atrial pacing was associated with a shortening in the AERP (Table 1). The average AERP shortened from $167 \pm 6$ ms during sinus rhythm to $143 \pm 5 \mathrm{~ms}$ after 1 week of RA-pacing $(p<0.001)$. In contrast, switching from RA- to LA-pacing (and back) did not cause an overall change in the atrial refractory period (1 $42 \pm 7$ ms affer 2 weeks of LA-pacing; $p>0.05$ ).

Figure 3 illustrates local changes $\left(L A_{2}\right)$ in AT and AERP. Whereas the transition from sinus rhythm to atrial pacing was associated with a shorlening in the AERP (due to the higher rate), the switch between long-term RA- and LA-pacing did not cause a change in the local refractory period, despite the large change in the relative moment of activation. The change in local activation time that was caused by switching from right to left atrial pacing was largest at the atrial appendages (Figure 4). The bottom panel demonstrates the absence of any significant effect of the long-term change in sequence of atrial activation on the refractory period at 11 atrial sites.

\section{Atrial Tachyarrhythmias}

No spontaneous atrial arrhythmias were detected by the monitoring function of the pacemaker during the 4 weeks of atrial pacing, nor were they obserwed during the electrophysiological studies. The inducibility of AF by single premature stimuli 

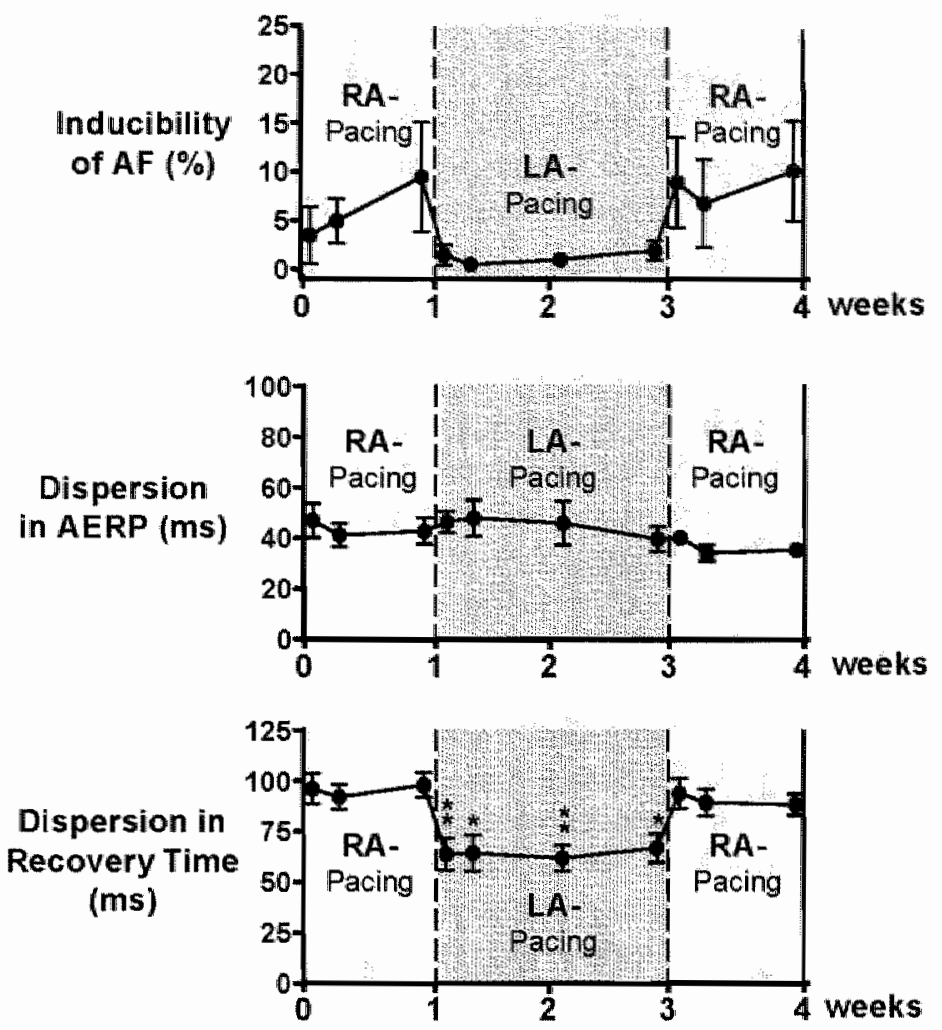

Figure 5: Although not statistically significant, there was a trend that the inducibility of AF was less during left (LA-) compared to right atrial (RA.) pocing. This was associated with a lower spatiol dispersion in lacal recovery times (AT + AERP), while the dispersion in AERP remained the same. "p<0.01; " $p<0.05$ compared to RA-pacing.

tended to be lower during LA- than during RA-pacing. However, due to the high inter-individual variation this difference was not statistically significant. Although the spatial distribution and the dispersion in AERP were not altered by a change in atrial pacing site, the regional differences in repolarization time (AT + AERP) were significantly less during LA- than during RA-pacing (Figure 5). The increased synchronicity in atrial repolarization during left atrial pacing may explain the lower vulnerability for induction of atrial arrhythmias. However, it should be noted that these changes in atrial repolarization occured immediately after a switch in pacing site and were not the result of "atrial memory'. Long-term atrial pacing had no further effect on differences in repolarization or inducibility of AF. 


\section{DISCUSSION}

\section{Spatial Distribution of Atrial Refractoriness}

During sinus rhythm, the AERP was longest at the mid portion of Bachmann's bundle and became shorter towards the tip of the right and left atrial appendage. Also at the right and left free wall the AERP was shorter than at BB. In general the shortest AERPs were measured at the lefi atrial free wall, but the differences in AERP between right and left atrium were variable and not statistically significant. Also in the dog the longest AERP was found at Bachmann's bundle, ${ }^{14}$ whereas the AERP in the left atrial woll was reporied to be shorter than in the right atrium. ${ }^{4,14}$ tt has been suggested that the shorter refractory period in the left atrium contributes to the preferential role of the left atrium in perpetuation of AF.,15 In humans, Chen et al measured the AERP at 16 atrial sites in a control group and in patients with paroxysmal AF. ${ }^{10}$ Again the AERP was longest in Bachmann's bundle. The shortest refractory periods were found distal in the pumonary veins and in the inferior right atrium. There was a considerable spatial variation in AERP in each atrium with no averall difference between right and left atrial refractoriness.

Spach et al. mapped the local refractory periods in isolated canine right atria. The longest refractory periods were found close to the sinus node. At increasing distances from the sinus node the refractory periad became shorter. ${ }^{6}$ In our present study we also observed an inverse relationship between local AERP and activation time during sinus rhythm. However, the spatial distribution of refractory periods was not an exact mirror image of the sequence of activation. Although the AERP was shortest at the latest activated atrial site (LFW), differences in activation time within the right atrium or between the right and left atrium did not correlate with differences in AERP. In addition, the earliest point of activation was measured at the right part of Bachmann's bundle, whereas the longest AERP was measured at the mid-portion of BB. Consequently, the inverse correlation between AT and AERP during sinus rhythm, although statistically significant in 5 of 6 goats, was rather weak $\mathrm{r}=$ $-0.53 \pm 0.05$ ). In ancesthetized pigs, no consistent relationship was found in the right atrium between the relative time of activation during sinus rhythm and the duration of the monophasic action potentiall. Only in 2 of 10 animals a statistically significant (inverse) correlation was present."

\section{Definition of Cardiac Memory}

The term 'cardiac memary' was introduced in 1982 by Rosenbaum and collegues." They described persistent T-wave changes after a transient alteration in the sequence of ventricular activation. Changes in T-wave morphology started to appear after 10-15 minutes and reached a plateau within several days to weeks. After the normal sequence of activation was restored, the changes in T-wave morphology could persist for weeks. Based on these findings it was hypothesized that ventricular myocytes were able to adapt the duration of their action potential to changes in the 
relative moment of activation. Because the effecis were long-lasting, the ventricular cells were said to possess a 'memory' of the prevailing sequence of activation. Later experimental studies by the group of Rosen confirmed that the T-wave changes induced by right ventricular pacing resulted exclusively from an altered sequence of activation and were not due to changes in rate, hemodynamic load, or ventricular ischemia ${ }^{18}$ It was also demonstrated that a change in sequence of ventricular activation modulates the duration of the ventricular action potential and refractory period. ${ }^{8,18-20}$ Costard-Jäckle et al. were the first to record monophasic action potentials at multiple ventricular sites during normal ventricular activation (atrial pacing) and during a transient period of right ventricular pacing. ${ }^{8}$ During the normal sequence of ventricular activation, local activation times and action potential duration were inversely related. At the onset of ventricular pacing this relationship was abruptly lost. However, during 2 hours of ventricular pacing the action potential gradually prolonged at early activated sites and became shorter at later activated regions. As a result, the spatial distribution of the action potential durations changed and the inverse relationship between moment of activation and action potential duration was re-established. Cardiac memory has been interpreted as a specialized form of electrical remadeling, not due to prolonged tachycardia but exclusively resulting from a change in sequence of activation. 11,21

The ionic mechanisms underlying cardiac memory are not precisely understood. Experimental studies point to a role of the transient outward current $\left(I_{10}\right)$ and the L-type calcium current $\left(\mathrm{I}_{\mathrm{Ca}, 1}\right)^{22.24}$ In dogs, pacing-induced changes in the ventricular activation sequence have been shown to reduce the densily of $I_{\text {to }}$ and alter the kinetics of $I_{t o}$ and $l_{C_{0.1} .}{ }^{23,24}$ Blockade of these currents prevented the induction of cardiac memory. ${ }^{22.24}$ However, little is known about the involved intra-cellular signalling pathways. There are some indications that alterations in the myocardial stress-strain relationship and production of angiotensin $\|$ are involved. ${ }^{25}$

\section{Do the Atria Also Have a 'Memory'?}

So far only three studies have evaluated the possible existence of an "atrial memory". Wood et al. investigated the effects of pacing at different atrial sites on the duration of the atrial action potential in the rabbit. ${ }^{12}$ No consistent relationship was found between local activation fime and action polential duration after 3 hours of pacing. The group of Rosen measured changes in the atrial electrocardiogram and refractory periods in chronically instrumented dogs with total AV-block, ${ }^{10,13}$ In their first study, a shortening in right atrial refractory periods was reported after 2 hours of left atrial pacing. ${ }^{10}$ In contrast, in a more recent investigation no changes in right or leff atrial refractory periods ( 3 sites) were observed after prolonged right or left atrial pacing ( 4 weeks). ${ }^{3}$ However, still changes in the so-called spatial 'atrial gradient' (ratio between $P$ and $T(a)$ iso-areas in the $X, Y$, and $Z$ axis) were observed, indicating that the sequence of atrial repolarization might have been changed. 10,13

In the present study we evaluated the long-term effects of right and left atrial pacing ( $1-2$ weeks) in the goat. The AERP was measured in 11 atrial regions (free wall of 
right and left atrum, right and left atrial appendages, Bachmann's bundle). No effect of long-term changes in atrial activation on the distribution of the AERP could be established. If we consider local changes in duration of the action potential or refractory periad-induced exclusively by a change in sequence of activation- as the expression of cardiac memory, then no evidence for 'atrial memory' could be found. Our observations do aiso not suppont the concept that a change in atrial activation sequence contributes to atrial electrical remodeling by prolonged rapid atrial pacing or atrial fibrillation.

\section{The Spatial Atrial Grodient}

Compared to the ventricles, repolarization of the atria is more difficult to study from the surface electrocardiogram. Not only that the atrial T-wave is much smaller than its ventricular counterpart, but it is also superimposed by the end of the P-wave and the beginning of the ensuing QRS complex. Therefore, the Ta-wave can only be measured in the surface electrocardiogram during AV-block. To detect primary changes in the process of atrial repolarization, $P$ and $T a$ voltage-time integrals (arithmetic sum of $P$ and Ta isoareas) have been measured in the $X, Y$ and $Z$ plane using dogs with total AV-block, and the 'spatial atriall gradient' has been defined as the root-mean-square of the three P.Ta voltage time integrals. $10,13,26$ In the study by Herweg ef al., the spatial atrial gradient was shown to increase after 1 hour of left atrial pacing. Changes were more marked at rapid pacing rates and showed accumulation by repeated episodes of left atrial pacing. ${ }^{10}$ Similar as in our experiments, Chandra et al. could not find changes in atrial refractory period during 4 weeks of left atrial pacing. Also the spatial atrial gradient did nat change during prolonged left atrial pacing. The sole indication of 'atrial memory' was a decrease in the spatial atrial gradient occuring 2-3 weeks after cessation of atrial pacing. ${ }^{13}$

How should we interpret a change in the "spatial atrial gradient' in the surface electrocardiogram without a measurable change in atrial action potential or refractory period? On the one hand, one may argue that the atrial gradient is a more sensitive parameter. The action potential and refractory period can not be measured at all atrial sites, whereas the spatial atrial gradient does represent the whole atrium. On the other hand, it is also possible that the atrial gradient is a less specific marker for atrial memory than direct evaluation of atrial repolarization and refractoriness. The fact that in the recent study by Chandra et al. ". the spatial atrial gradient did not change during the 4 weeks of lett atriall pacing but only 2-3 weeks atter restoration of the normal sequence of activation suggests that other factors (related to chronic AV-block and ventricular pacing) may have led to the observed changes in atrial gradient. Since measurement of the spatial atrial gradient was not possible in our study (no total AV-block), we could not compare the absence of changes in refractory period in the majority of the atria (right and left atrial free wall, right and leff atrial appendages, Bachmann's bundle) with changes in the spatial atrial gradient. 


\section{Implications For Atrial Tachyarrhythmias}

Spatial heterogeneity in atrial repolarization is an important determinant of reentrant arrhythmias. ${ }^{1,27}$ Animal and clinical studies have shown that an increased spatial dispersion in atrial refractoriness is associated with an increased vulnerability for AF, 2,3,28 In our study, long-term changes in the sequence of atrial activation did not alter the spatial distribution and dispersion in AERP. Apart from spatial differences in AERP, also differences in local AT will determine the degree of synchronicity in repolarization. Several studies have shown that the dispersion in atrial recovery time (activation time + AERP or APD) and the inducibility of atrial tachyarrhythmias are lower during left atrial pocing. ${ }^{12,29,30}$ Also in the present study the dispersion in atrial recovery time and the inducibility of AF were lower during LA-pacing as compared to RA-pacing. However, since changes in atrial recovery time and AF vulnerability occured immediately after the shift in pacing site, they are not related to 'atrial memory".

\section{REFERENCES}

1. Allessie MA, Bonke FI, Schopman FJ. Circus movement in rabbit atrial muscle as a mechanism of tachycardia. Il. The rale of nonuniform recovery of excitability in the occurrence of unidirectional block, as studied with multiple microelectrodes. Circ Res $1976 ; 39: 168-77$.

2. Wang J, Liu L, Feng J, Nattel S. Regional and functional factors determining induction and maintenance of atrial fibrillation in dogs. Am J Physiol 1996;271:HI 48-58.

3. Ramanna $\mathrm{H}$, Houer RN, Wittkampf FH, de Bakker IM, Wever EF, Elvan A, Robles, De Medina EO. Identification of the substrate of atrial vulnerability in patients with idiopathic atrial fibrillation. CircuIction 2000;101:995-1001.

4. Li D, Zhang L, Kneller J, Nattel S. Potential ionic mechanism for repolarization differences between canine right and left atrium. Circ Res 2001;88:1168-75.

5. Spach MS, Do ber PC, Anderson PA. Multiple regional differences in cellular properties that regulate repolarization and contraction in the right atrium of adult and newborn dogs. Circ Res. $1989: 65: 1594.611$.

6. Spach MS, Dolber PC. Heidloge JF, Interaction of inhomogeneities of repalarizalion with anisotropic propagation in dog atria. A mechanism for both preventing and intiating reentry. Cinc Res $1989 ; 65: 1612-31$.

7. Franz MR, Borgheer K, Rafflenbeul W, Hawerich A, Lichllen PR. Monophasic action potential mapping in human subjects with nonnal electrocardiograms: direct evidence for the genesis of the $T$ mave. Circulation 1987,75:379-86.

8. Costard-Jackle $A_{n}$ Goelsch $B$. Aniz M, Fronz MR. Slow and long-lasting modulation al myocardial repalarization praduced by ectopic activation in isolated rabbit hearts. Evidence lor cardiac "memory". Circulation 1989;80:1412-20.

9. Rosenbaum MB, Blanco HH, Elizari MV, Lazzari JO, Davidenko JM. Electrotonic modulation of the T wave and cardiar memory. Am J Cardial 1982,50:213-22.

10. Herweg B, Chang F. Chandra P, Danilo P, Jr, Rosen MR. Cardiac memory in conine atrium : identification and implications. Circulation 2001:103:455-61

11. Rosen MR. What is cardiac memory? I Cardiovasc Elecirophysial 2000; 1 1:1289-93.

12. Wood MA, Mangano RA, Schieken RM, Baumgarten CM, Simpson PM, Elienbogen KA. Modutation of atrial repolarization by site of pacing in the isolated nabbit heart. Circulation 1996;94:1465-70.

13. Chandra P, Rasen TS, Herweg B, Danilo P, Jr., Rosen MR. Leff atrial pocing induces memory and is assaciated with airial tachyarthythmias. Cardiavasc Res 2003;60:307. 14. 
14. Lee SH, Lin FY, Yu WC, Cheng JJ, Kuan P, Hung CR, Chang MS, Chen SA. Regionol differences in the recovery course of lachycordia-induced changes of otrial elecirophysiological properties. CircuIation 1999,99:1255.64.

15. Jolile J, Berenfeld O. Mansour M. Mother rotors and fibrillatory conduction: a mechanism of ariol fibrillution, Cardiowdse Res 2002,54:204-16.

16. Chen $5 A_{3}$, Hsieh MH, Tai CT, Tsai CF, Prakash VS, Yu WC, Hsu TL, Ding YA, Chang MS. Intitiotion of atrial fibrillation by ectopic beats originoting from the pulmonary weins: electrophysialogical charac. renistics, phormacological responses, and effects of radiofrequency ablation. Circulation $1999,100: 7879.86$

17. Li Z, Hertervig E, Kongsiad O, Hollm M, Grins E, Olsson SB, Yuan S. Global repalarization sequence of the right atrum: monphasic action polential mapping in heath pigs. Pacing Clin Electrophysiol $2003 ; 26: 1803.8$.

18. Shvilkin A, Donilo P, Jr. Wang J, Burkhoff D, Anyukhowsky EP, Sosunow EA, Hara M, Rosen MR. Evolution and resalution of long-term cardiac menory. Circulation 1998;97:1810-7.

19. ibbus I, Rosenboum DS. Transmurd action potential changes underlying wentrieular electrical remadeling. J Cardiovasc Electrophysiol 2003; 14:394-402.

20. Planikow AN, Shvikin A, Xiong W, de Groot JR, Rosenshtraukh L, Feinmark, S, Gainullin R, Danilo P, Rosen MR. Interoctions between antiarthythmic drugs and cardiac memory. Cardiovasc Res $2001,50: 335-44$.

21. Libbus I, Rosenbaum DS. Remodeling of cardiac repolarization: mechanisms and implications of memory. Card Electrophysiol Rev 2002;6:302-10.

22. del Bolzo U, Rosen MR. T wave chonges persisting afier ventricular pacing in conine heart are altered by 4 aminopyridine but nat by fidocaine. Implications with respect to phenomenon of cardiac 'memory. Circulation 1992;85:1464-72.

23. YuH, Mckinnon D, Dixon JE, Gao J, Wymare R, Cohen IS, Danilo P, Jr., Shwilkin A, Anyukhovsky EP, Sosunov EA, Hara M, Roser MR. Trainsient outward current, liol, is aliered in cordiac memary. Cir. culation 1999,99:1898-905.

24. Plotnikov AN, YuH, Geller JC, Gainullin RZ, Chandra P, Fatberg KW, Friezema S, Danilo P, Ir., Cohen IS, Feinmark SJ, Rosen MR. Role of L-type calcium channels in pocing induced shorttterm and long-term cardiac memory in canine heart. Circulation 2003;107:2844-9.

25. Patberg KW, Rosen MR. Mollecular determinants of cordiac memory and their regulation. I Mol Cell Cordiol 2004;36:195-204.

26. Hayashi H, Okailima M, Yamada K. AtrialT (Ta) loop in dogis with or without alrial injury. Am Heart J 1976:91:607-17.

27. Moe GK, Rheinboldt WC, Abildskov JA. A Computer Madel of Atrial Fibrillation. Am Heart J $1964: 67: 200-20$

28. Fareh 5 , Villemaire $C$. Nolttel 5 . Importance of reflractoriness heterogeneity in the enhanced vulnerability to atrial fibriflation induction coused by techycardia-induced atrial electrical remodeling. Cir. culation 1998,98:2202-9.

29. Ogawa M, Kumagai K, Gondo N, Matsumoto N, Suyama K, Saku K. Novel electrophysiologic parameter of dispersion of atrial repolarization: comparison of different atrial pacing methods. I Cardionase Electrophysiol 2002;13:110.7.

30. Papageorgiou P. Anselme F, Kirchhof CJ, Monahon K, Rasmussen CA Epsteir LM, Josephson ME. Coronory sinus pacing prevents induction of alrial fibrillation. Circulation 1997;96:1893 8 . 
CHAPTER 7

\section{Preferential Class III Action of Dofetilide on the Bundle of Bachmann. A Critical Determinant for the Initiation of Atrial Fibrillation in the Goat}

Yuri Blaauw, MD; Mattias Duytschaever, MD, PhD; Arne van Hunnik, BS; Ulrich Schotten, MD, PhD; Maurits Allessie, MD, PhD 


\section{INTRODUCTION}

Spatial heterogeneities in repolarization play an important role in the initiation and perpetuation of reentrant arthythmias. ${ }^{1.3}$ It is well known that marked heterogeneities in action potential duration and refractoriness are present in the heart 4 in a recent study, Duytschaever et al. showed that the distribution of the refractory period in the caprine atrium showed a consistent pattern characterized by significantly longer refractory periods at Bachmann's bundle than at the right and left atrial free wall. "This spatial dispersion of refractoriness was associated with the initiation of atrial fibrillation (AF). Whereas premature stimuli delivered at the left or right atrial free wall induced AF, early stimuli at Bachmann's bundle never caused AF.

Recently it was demonstrated that the class III effect of blockers of the delayed rectifier current $\left(I_{k i}\right)$ on atrial refractoriness was reduced by AF-induced electrical remodeling. 9.10 We hypothesized that the contribution of $I_{k r}$ to atrial repolarization decreased when the action potential is shortened due to AF. These observations are in agreement with recent findings in a computer model of the human atrial action potential in which it was shown that the class III effects of $1_{k,}$ blockade was much stronger in rectangular than triangular shaped action potentials." Based on these abservations, we postulated that blackers of the $\mathrm{I}_{k,}$ current may exert a preferential effect at atrial sites with a long refractory period. If this is the case, $\left.\right|_{\mathbb{R}}$, blockers will increase the dispersion of refractoriness. In the present study we evaluated the effects of the $\|_{k,}$ blocker dofetilide on the atrial refractory period at multiple atrial sites in the goat model of AF. We showed that dofetilide increased the spatial dispersion of refractoriness because it exerted a preferential class III effect on Bachmann's bundle. In electrically remodeled atria this caused a widening of the window of inducibility of atrial fibrillation.

\section{METHODS}

\section{The Goat Model of Atrial Fibrillation}

Nine female goats were used for this study. The animals were handled according to the European Directive for Animal Research and the study protocol was approved by the Animall Investigation Committee of the University of Maastricht. During general anesthesia (halothane $1-2 \%$ and a mixture of $\mathrm{O}_{2}$ and $\mathrm{N}_{2} \mathrm{O}$ ) the heart was exposed through a thoracotomy and a teflon-felt plaque containing 30 electrodes $3 \mathrm{x}$ $2.5 \mathrm{~cm}$, inter-electrode distance $4 \mathrm{~mm}$ ) was sutured on the free wall of each atrium. A $10 \mathrm{~cm}$ long plaque of three rows of electrodes $(54$ electrodes, inter-electrode distance $5 \mathrm{~mm}$ ) was implanted an Bachimann's bundle between the tips of the right and left appendages (figure 1). Three silwer plates were left under the skin of the thonax to serve as indifferent electrode. The leads were tunneled subcutaneously to the neck and exteriorized by four 30-pole connectors. Experiments were started 3-4 weeks after surgery. Details of the goat model have been described ellsewhere. ${ }^{12}$ 

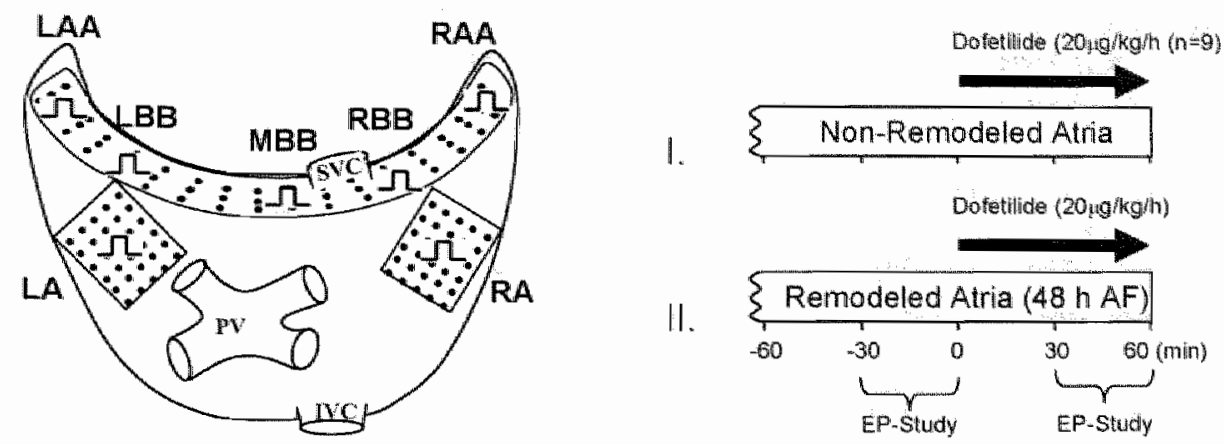

Figure 1: Left: Epicardial instrumentation. Atrial refractory periods were measured at 7 atrial sites at the left and right atrial free wall (LA and RA), left and right atrial appendage (LAA and RAAl and the left, right and middle portion of Bachmonn's bundle (LBB, RBB and MBB). Right: The study protocol. Electrophysiological measurements included determination of the atrial refraction period, windaw of inducibility and duration of AF.

\section{Electrophysiological Measurements}

The atria were paced with biphasic stimuli of $2 \mathrm{~ms}$ duration ( $4 x$ threshold) generated by a constant current generator (Medtronic SP3111). The atrial effective refractory period (AERP) was measured at multiple atrial sites (right and left atrial free wall (RA and $L A)$, right and left atrial appendage (RAA and LAA) and right, middle and left part of Bachmann's bundle (RBB, MBB and LBB)) during regular bipolar pacing with a cycle length ranging between 400 and $200 \mathrm{~ms}$ (Figure 1). Single interpolated stimuli were applied after each $8^{\text {th }}$ basic stimulus starting well within the refractory period. The longest $S_{1}-S_{2}$ interval that failed to capture the atria (increments 2 ms) was taken as the AERP.

The window of inducibility was determined at 3 atrial sites (RA, MBB, RA). During regular pacing ( $400 \mathrm{~ms}$ ) a single premature stimulus, starting at a coupling interval of $250 \mathrm{~ms}$, was given after a drive train of 30 beats. In case a premature stimulus evoked a rapid irregular atrial rhythm (cycle length $\leq 150 \mathrm{~ms}$ ) lasting $\geq 1$ second, AF was considered to be inducible. Each coupling interval was repeated 3 times and then decremented in steps of $5 \mathrm{~ms}$. The upper and lower limit of inducibility were defined as respectively the longest and shortest coupling interval that induced AF in at least 2 of 3 attempts. The window of inducibility was defined as the difference between the upper and the lower limit of inducibility.

The effect of dofetilide on the stability of AF was evaluated by measuring the duration of at least 10 consecutive AF paroxysms induced by atrial burst pacing.

Conduction through Bachmann's bundle was delermined during application of premature stimuli. During decremental pacing from either the right or the left atrial 
tree wall the $A_{1} A_{2}$ interval was determined at the right and left portion of Bachmann's bundle. The coupling interval that resulted in an $A_{1} A_{2}$ interval that was $>10$ ms longer than the $S_{1} S_{2}$ interval was taken as the upper limit for conduction deloy in $B B$.

\section{Experimental Protocol}

The electrophysiological effects of dofefilide were measured before and after 48 hours of AF. Afrial fibrillation was induced by a fibrillation pacemaker as described previously. ${ }^{12,13}$ Measurements of atrial refractoriness, the window of inducibility and the duration of AF were performed before and after 30 minutes of infusion of dofetilide at a rate of $20 \mu \mathrm{g} / \mathrm{kg} / \mathrm{h}$ (figure 1).

\section{Statistical analysis}

Results are presented as mean \pm SEM. Differences between groups were evaluated by the paired Student's tmtest. Differences between groups were determined by the paired Student's t-test. Serial measurements were analyzed by ANOVA with repeated measures. Differences were considered statistically significant when $P<0.05$.

\section{RESUILTS}

\section{Regional Effects of Dofetilide on Atrial Refractoriness}

The effect of dofetilide on the atrial refractory period was measured at 7 atrial sites both before and after 48 hours of AF-induced electrical remodeling. As shown previously, the distribution of refractoriness was characterized by a long AERP at the mid portion of Bachmann's bundle and shorter AERP's at the right and left atrial free wall (figure 2: open circles)." After 48 hours of AF this particular distribution was still present. The shortening of atrial retractoriness by AF-induced electrical remodeling was significantly larger at RA and LA than at MBB (respectively $-64 \pm 5,-55 \pm 5$ and $-34 \pm 7 \mathrm{~ms}, p<0.05$ ). Dispersion of refractoriness, defined as the difference between the longest and shortest atrial refractory period increased from $44 \pm 6$ during control to $74 \pm 9$ uns after $48 \mathrm{~h}$ of $\mathrm{AF}(\mathrm{p}<0.001)$.

Administration of dofetilide prolonged the AERP at all atrial sites both in non-remodeled and after 48 hours of AF (solid circles). However marked differences were abserved at different atrial sites. In the lower panels of figure 2 the prolongation of atrial refractoriness ( $\triangle A E R P$ ) are given at 7 atrial sites. In non-remodeled atria the degree of prolongation was most pronounced at Bachmann's bundle $(+26 \pm 2$ ms). This effect was statistically different from the effect at $L A(+19 \pm 2$ ms, $p<0.05)$ but not from $R A\left(+21=3 \mathrm{~ms}_{,} p=0.08\right)$. Because of the stronger prolongation of the AERP at MBB, the spatial dispersion of refractoriness increased from $44 \pm 6$ to $55 \pm 9 \mathrm{~ms}(p<0.001)$. After 48 hours of AF the measurements were repeated and 
Normal Atria
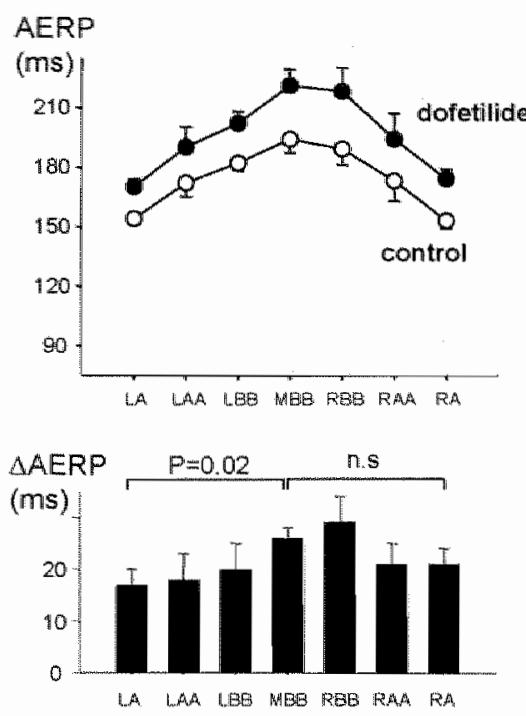

After $48 \mathrm{~h} \mathrm{AF}$
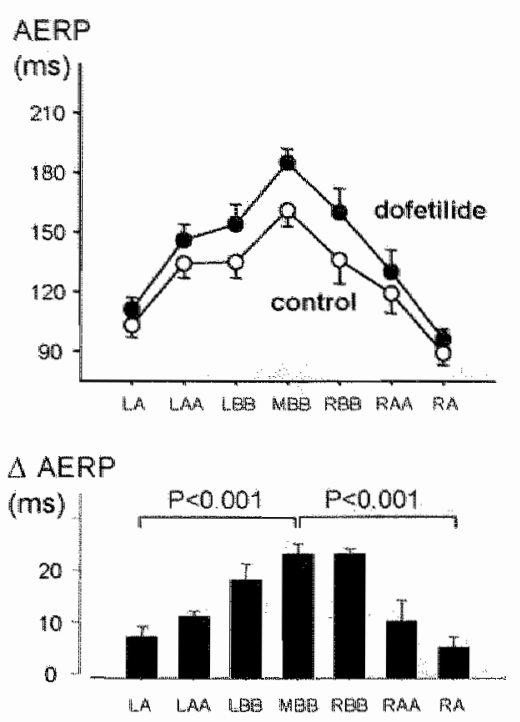

Figure 2: Upper panels: Arrial refractary periods measured of 7 alrial in both nomal (left) and remodeled atria (right), before (open dots) and after infusion of dotetilide (closed dots). In both normal and remodeled atria dafetilide increased the dispersion of refractoriness, due to a stronger prolongation of the AERP at the middle portion of Bachmann's bundle than at the atrial free walls (lower panels).

the prolongation of the AERP was again markedly stronger at MBB than at RA and $L A$ ( $24 \pm 2$ compared to $6 \pm 2$ and $8 \pm 2 \mathrm{~ms}$, both $p<0.01)$. Because of this preferential action of dofetilide at $M B B$, the spatial dispersion of refractoriness increased from $74 \pm 9$ to $92 \pm 8 \mathrm{~ms}(p<0.001)$. When the effect of dofetilide on remodeled atria was compared to its effect in normal atria, the $\triangle A E R P$ was reduced at the right and left atrial free wall but not at Bachmann's bundle.

To test the hypothesis that the contribution of $I_{K}$, to atrial repolarization depends on the duration of the action potential, we determined the correlation between the AERP and the class III effect of dofetilide. In figure 3 the class III effect of dafetilide is plotted against the mean AERP at 7 atrial sites both in non-remodeled (open circles) and remodeled atria (closed circles). A strong positive linear relationship was found between the duration of the refractory period and the degree of AERP prolongation $(R=0.85, p<0.0011)$.

\section{Rate Dependent Action of Dofetilide at RA, LA and MBB}

It is well known that the class 11 effect of $I_{k r}$ blockers is more pronounced at slower than at fast pacing rates. However, in electrically remodeled RA and LA this so called reverse frequency-dependency was not preserved and turned into frequency-dependency or a flat frequency effect. 910 To evaluate whether this was also the case in 
Bachmann's bundle, the class III action of dofetilide was determined during pacing at cycle lengths between 400 and $200 \mathrm{~ms}$. Figure 4 shows the rate-dependent effects of dofefilide on the AERP at RA, LA and MBB both in normal and remodeled atria. In non-remodeled atria, at all sites the prolangation of AERP was stronger at pacing cycle lengths of 400 than at $200 \mathrm{~ms}$. After 48 hours of AF this reverse-frequency dependence was no longer present at RA and LA due to a lass of class III effect at slow pacing rates. In contrast, at BB the AERP still prolonged in a reverse-frequency dependent manner.

Figure 5 shows the effects of dofetilide on the rate-dependent dispersion of refractoriness in normal and electrically remodeled atria. Dispersion of refractoriness was clearly dependent on the pacing rate, i.e. the largest dispersion was observed at the slowest pacing rates. In normal as well as remodeled atria, the spatial dispersion in AERP increased after infusion of dofetilide at pacing rates $>300 \mathrm{~ms}$. At shorter pacing intervals, no changes were observed.

\section{Conduction of Premature Beats along Bachmann's Bundle}

Since the AERP was longest at the mid part of Bachmann's bundle it can be expected that early premature beats will have difficulty to conduct through Bachmann's bundle in addition, since dofetilide preferentially prolongs the AERP' at MBB, this drug may further increase conduction delay at $\mathrm{BB}$. To evaluate this, we measured the conduction of premature beats from RA and LA through Bachmann's bundle before and after infusion of dofetilide ( $n=5$ goats). Shown in figure 6 are unipolar electrograms recorded from the right, left and mid portion of Bachmann's bundle during application of premature stimuli at the RA. Before drug administration, premature stimuli with a coupling interval $>180 \mathrm{~ms}$ propagated along Bachmann's bundle without conduction delay, i.e. the $A_{1} A_{2}$ interval at $R B B$ was equal to $A_{1} A_{2}$ at LBB. The electrograms at RBB, LBB and MBB showed steep biphasic deflections without fractionation. Shortening of the $S_{1} S_{2}$ coupling interval progressively prolonged the $A_{1} A_{2}$ interval at LBB but not at RBB. This was associated with an increased fractionation at MBB but not at RBB and $\angle B B$. This indicates that conduction was preferentially impaired at MBB. The upper limit of conduction delay at $B B$, defined as the longest $S, S$ interval resulting in $\geq 10 \mathrm{~ms} A_{1} A_{2}$ interval was $165 \mathrm{~ms}$. After infusion of dofetilide, fractionation of the electrogram of MBB alleady accurred at coupling intervals $\leq 220 \mathrm{~ms}$. The upper limit of conduction delay was increased to 200 mis. On average, dofetilide increased the upper limit of conduction delay during right and left atrial pacing from $171 \pm 7$ and $168 \pm 6$ to respectively $199 \pm 6 \mathrm{~ms}$ and $197 \pm 5 \mathrm{~ms}$ (both $p<0.001$ ).

\section{Effects of Dofetilide on the Window of Inducibility}

The window of inducibility was measured in 5 goats at 3 atrial sites (RA, LA and BB) both in non-remodeled and remodeled atria ( 48 hours of AF). A representative example of the measurements (and the effects of dofetilide) is given in figure 7 . Shown 


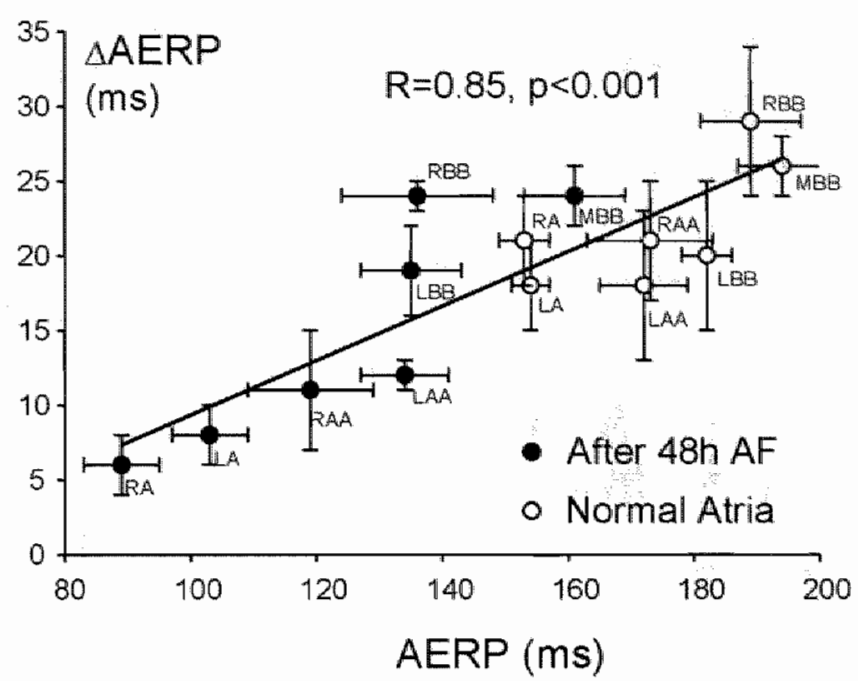

Figure 3: Relation between the atriat refractory periad (AERP) measured at different atrial siles in nomal (open dots) and remodeled atria (closed dots) and the increase in atrial refractory periad by dofetilide

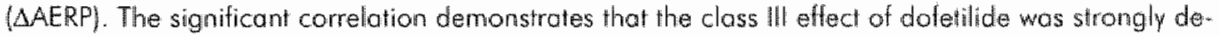
pendent on the AERP, i.e. the longer the AERP, the stronger the ettect.

\section{Left \\ Atrium}

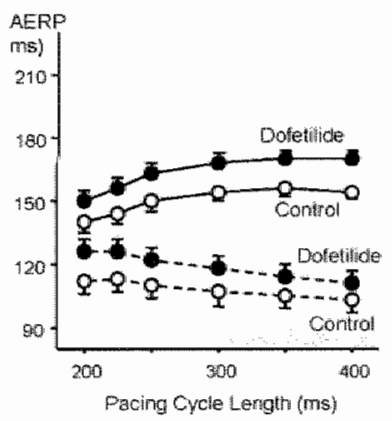

Bachmann's Bundle

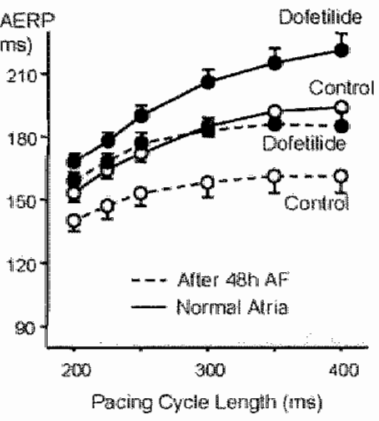

Right Atrium

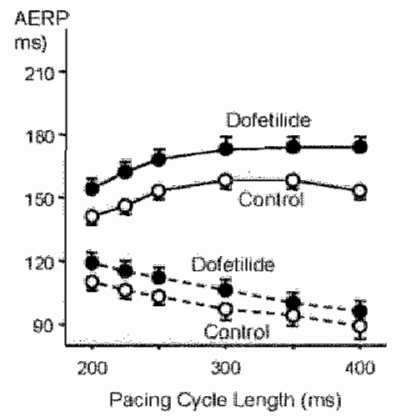

Figure 4: Ellects of doletilide on the rate adaptation of the atrial relractory period (AERP) af the right and left ctrial free wall (RA and LA) and the mid portion of Bachmann's bundle (MBB). Measurements were: performed in normal (solid line) and remodeled atria (dotted lines). In nomal atrio, the prolongation of the AERP by dofetilide was most pronounced at slaw pacing rates freverse-frequency dependencel at all sites. After 48 hours of induced electrical remodeling, the normal rate adaptation was lost at the RA and LA but not at MBB. The action of dofetilide on RA and LA was now no longer reverse frequency depend. ent. In contrast, at MBB the prolongation was still strongest al slaw pacing rates. 
Normal Atria

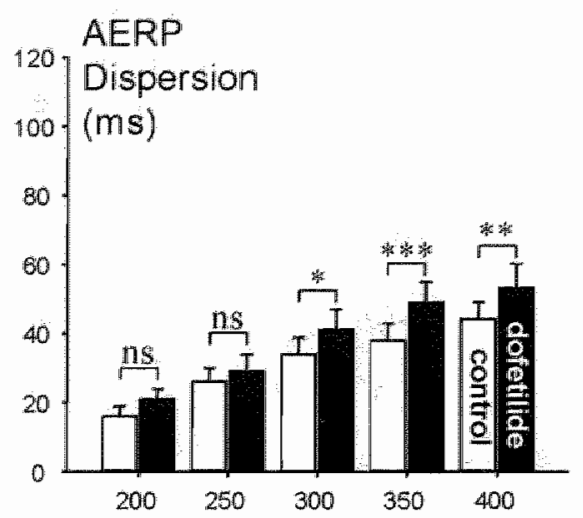

Pacing Cycle Length (ms)
After $48 \mathrm{~h}$ AF

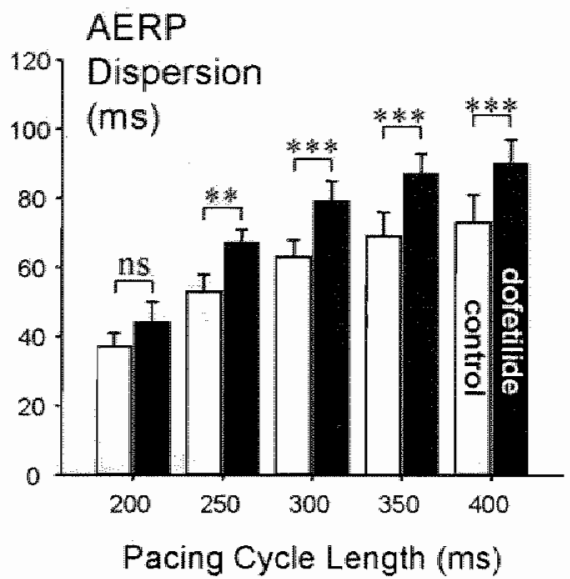

Figure 5: Effects of dofetilide on the rate dependent dispersion of refractoriness in normal (left) and remodeled atria (right). Dispersion was colculated as the difference between the longest and shortest AERP at the right and left atrial free wall and the mid portion of Bochmonn's bundle.

\section{Control}

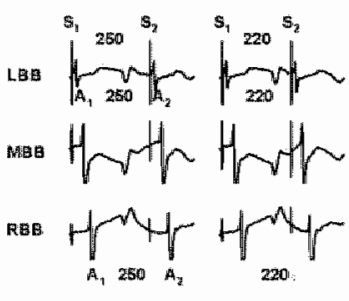

Dofetilide

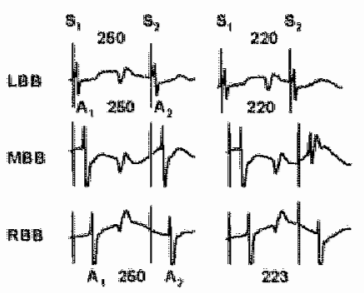

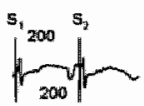

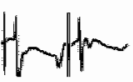<smiles>CCC(C)NC(C)C</smiles>

200

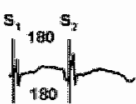

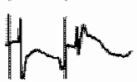

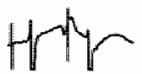
180
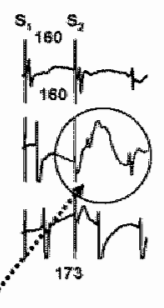

Fractionation
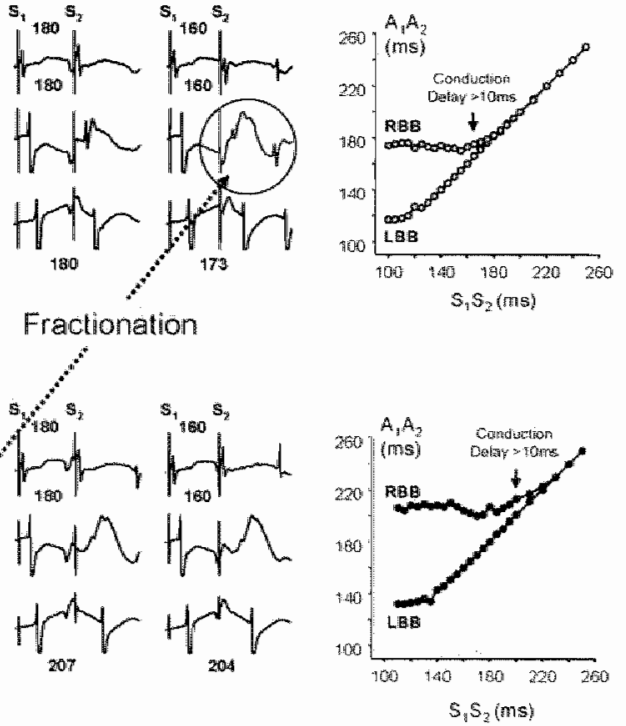

Figure 6: Upper panels: Unipolar electrograms recorded at right, middle and left portion of Bachmonn's bundle $(R B B, M B B$ and $\angle B B$ during application of premalure stimuli from the left atrial free wall. Right panell shows the A1A2 interval at RBB and LBB for different 5152 intervals. Lower ponels: Identical measurement after infuston of dotethide. Alter drug administration, fragmentation in the $M B B$ electrogram occurred at longer coupling intervals and the S1S2 interval that resulfed in a conduction delay $>10 \mathrm{~ms}$ increased from 165 to $200 \mathrm{~ms}$. 
Control
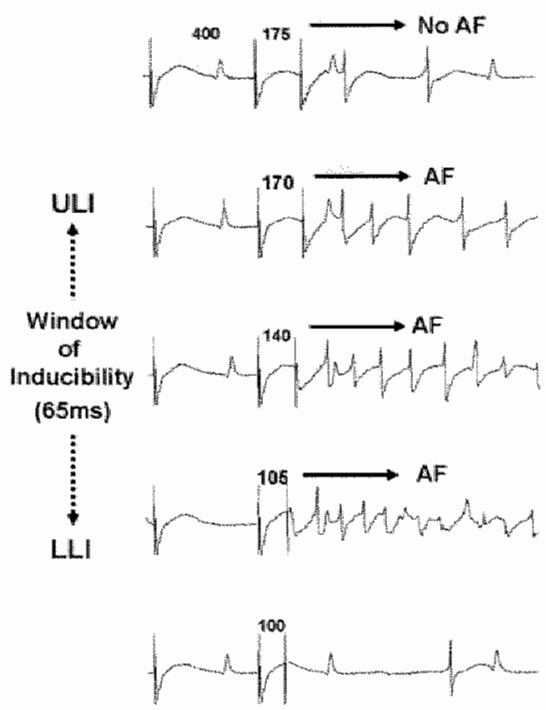

\section{Dofetilide}
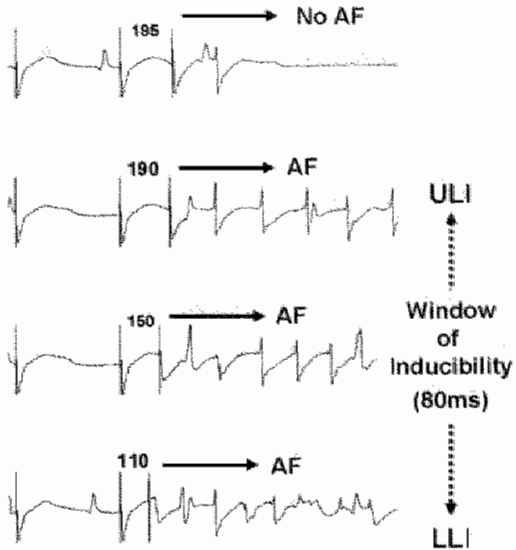

bontis

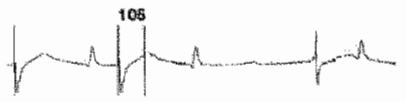

Figure 7: Measurement of the window of AF-inducibility, before (left) and after (right) inlusion of dofetilide. Dofelilide increased the window of inducibility from $65 \mathrm{~ms} 10.80 \mathrm{~ms}$. This was due to a stronger prolangation of the upper limit of inducibility (ULL) than the lower limill of inducibility (LLI), respeclively +20 and $+5 \mathrm{~ms}$.

is a unipolar electrogram recorded from the right atrial free wall during application of premature stimuli at RA. During control, coupling intervalls $\geq 175 \mathrm{~ms}$ coptured the atrium, but did not induce AF. However, at a coupling interval of $170 \mathrm{~ms}$ AF was induced (=upper limit of inducibility). Subsequently, the coupling interval was decremented in steps of $5 \mathrm{~ms}$ until the AERP was reached $(100 \mathrm{~ms})$. The shortest coupling that induced AF was 105 ms and was defined as the lower limit of inducibilitity. The window of inducibility was defined as the difference between the upper and lower limit of inducibility ( $=65 \mathrm{~ms}$ ). In the right part of figure 7 the same measurements are shown after administration of dofetilide. Dofetilide caused a stronger in. crease in the upper than the lower limit of inducibility. As a result, the window of inducibility increased to $80 \mathrm{~ms}$. In non-remodeled atria, AF was hardly inducible and in only 1 goat the window of inducibility could be determined at the right atrium $(15 \mathrm{~ms})$. After infusion of dofetilide, the window of inducibility was $5 \mathrm{~ms}$. In electrically remodeled atria, the inducibility of AF had increased markedly and premature stimuli evoked AF in 100\% of the cases (at both RA and LA). At MBB, AF was never induced. No differences were observed in the window of inducibility at the RA and $L A(68 \pm 5$ and $61 \pm 9 \mathrm{~ms}, p=0.5)$. Infusion of dofetilide increased the window of inducibility at both RA and LA to respectively $80 \pm 4(p<0.01)$ and $78 \pm 9 \mathrm{~ms}$ $(p<0.05)$. This was due to a larger prolongation of the upper limit of inducibility than the lower limit of inducibility. Dofetilide increased the upper limit, at respec- 


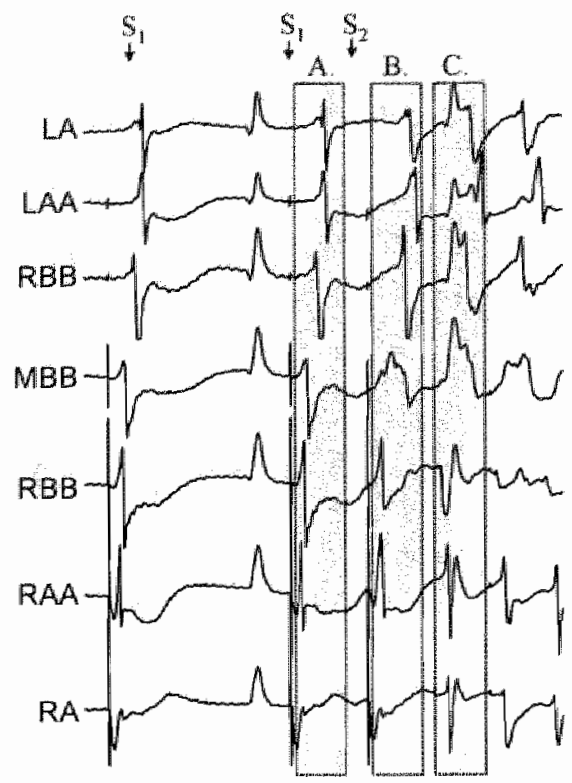

A
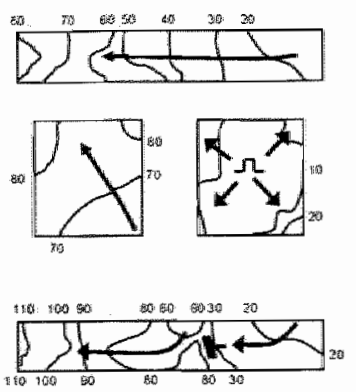

B.

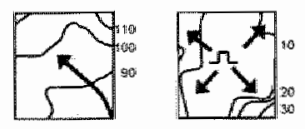

C.
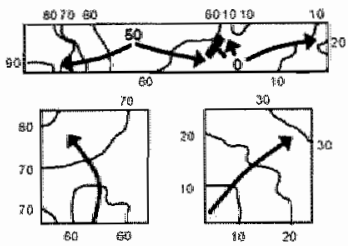

Figure 8: Unipolar electrograms and mapping during initiation of AF by a premature stimulus from the right otrium. See text for explanation.
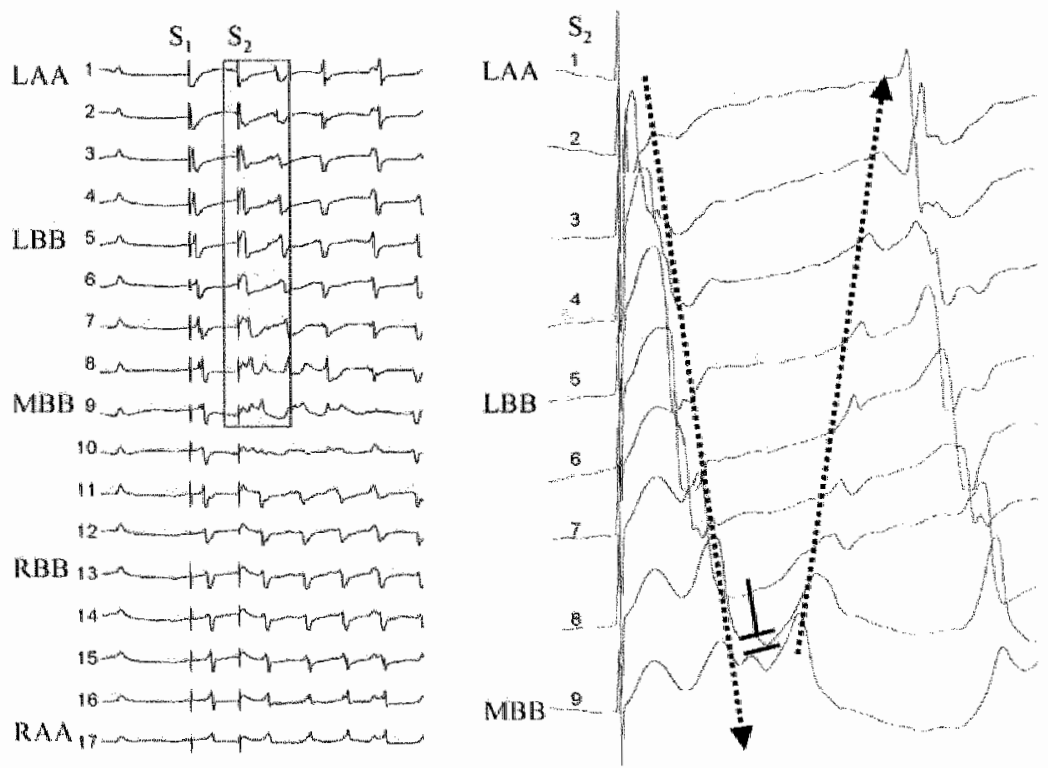

Figure 9 Left: Unipolar electrograms recorded along Bachmann"s bundle (BB) showing initiation of AF. Application of a premature beat from the left atrium was assaciated with impaired conduction and fragmented electrograms at the mid portion of BB (electrode 8.10). The first spontaneous beat of AF was seen in electrode 1 , suggesting that AF originated in that areo. However, after amplification of the signals (right panell) small biphasic deflections could be abserved in electrode 3.8. Mapping of the activation pattern was suggestave of an excitation wavefront traveling from MBB to the LAA (arrow). 
fively the RA and LA, by $18 \pm 2$ and $24 \pm 3 \mathrm{~ms}$ whereas the lower limil increased by only $6 \pm 1$ and $8 \pm 3 \mathrm{~ms}$ (both $p<0.05$ ).

\section{Effects of Dofetilide on the Stability of Atrial Fibrillation}

The effect of dofetilide on the stability of AF was evaluated by measuring the median duration of at least 10 AF-episodes induced by burst pacing. In non-remodeled atria, AF was short-lasting with a median duration of 8 seconds (range 3 to 26). Infusion of dofetilide shortened the duration of AF to a median duration of 3 seconds (range 2 to 13) $(p=0.04)$. After 48 hours of AF the duration of AF episodes was increased significantly to 32 seconds (range 3 to 136$)(P<0.01)$. In this situation, dofetilide infusion shartened the median duration of $A F$ to 11 seconds (2.5 to 54) $(p=0.01)$.

\section{Mapping of Initiation of AF}

The epicardially implanted electrodes were used to map the activation pattern during induction of AF. In figure 8 an example is shown of the initiation of AF by a single premature stimulus delivered at the RA. In the left panel electrograms are shown recorded from RA, RAA, RBB, MBB, LBB, LAA and LA. The right panels show the corresponding activation maps during pacing with $400 \mathrm{~ms}$, application of the premature beat and, the first beat of AF. During regular pacing the wavefront propagated along Bachmann's bundle without conduction delay. Application of a premature stimulus unmasked fractionation at the $M B B$ recording site. The activation map demonstrated a marked local conduction delay $(>30 \mathrm{~ms})$ at the mid portion of $\mathrm{BB}$. Mapping of initiation of AF demonstrated that the earliest excitation originaled from the RBB area, just proximal to the area of local conduction delay. The combination of local conduction delay and early excitation of the area proximal to the site of block suggests that the bundle of Bachmann played a critical role in the initiation of AF.

\section{Initiation of AF by Bachmann's Bundle Reentry}

In two goats we could demonstrate that the initiation of AF was due to reentry within $B B$. Shown in the left panel of figure 9 are electrograms recorded along Bachmann's bundle during pacing from the LA. Application of a premature stimulus resulted in fragmented potentials in electrodes 9 and 10 , indicative of local conduction block at the mid portion of Bachmann's bundle. In this case the earliest activation of the first AF beat was seen at LAA (electrode 1), suggesting that AF originated close to the pacing site and far from BB. However, when electrograms from $B B$ are magnified (right panel) small but distinct biphasic deflections can be seen in the $M B B, L B B$ and $L A A$ electrograms. The sequence of the small potentials showed that the pacemaker impulse actually traveled back from MBB to LAA (arrow). AF thus did not originate at the LAA area, but from the mid portion of Bachmann's bundle. Obviously, during propagation of the premature beat, a small muscle bundle in the left 
part of BB was not activated (longitudinal dissociation) and was available as a retum pathway to the site of stimulation. The fact that so far this phenomenon was observed in only 2 goats does not imply that it is a rare phenomenon. Given the low amplitude of the potentials and the various return pathways, it is quite likely that, due to the low spatial resolution of the implanted electrodes reentry in $B B$ was not detected in the other animals.

\section{DISCUSSION}

\section{Main Findings}

In the present study we evaluated the effects of the $I_{K_{r}}$ blocker dofetilide on atrial refractoriness at multiple atrial sites in non-remodeled atria and after 48 hours of AF. It was demonstrated that the class IIl action of dofetilide was stronger at areas with a longer refractory period. As a result, the spatial dispersion of refractoriness increased due to preferential prolangation of the AERP at Bachmann's bundle. In remodeled atria this caused a widening of the window of ind ucibility, which was due to a stronger prolongation of the upper than the lower limit of inducibility. Premature beats were associated with local conduction delays at the mid portion of Bachmann's bundle. After infusion of dofetilide these critical conduction delay already occurred at longer coupling intervals, because of the prolonged refractory periods at Bachmann's bundle. Mapping of initiation of AF suggested that longitudinal dissociation in Bachmann's bundle was the mechanism of initiation of AF.

\section{Action Potential Dependence of Dofetilide}

Recently we demonstrated that AF-induced electrical remodeling alters the atrial sensitivity for $\mathrm{K}^{+}$channel blockers. Wijffels et al. were the first to show that after cardioversion of persistent AF in the goat, $d$-sotalol failed to prolong the atrial refractory period. ${ }^{14}$ More recently it was established that this loss of efficacy was lost in remodeled atria. 9101 In addition, the well known reverse frequency dependent action of $I_{k r}$ blockers was lost in remodeled atria. Tse et al. showed that this also occurs in humans. ${ }^{15} \mathrm{D} /$-sotalol prolonged atrial refractoriness less after electrical cardioversion in patients compared to in normal sinus rhythm. Also the reverse-frequency dependency of $\mathrm{dl}$-sotalol was lost in AF-patients.

These observations can be explained by the hypothesis that the action of $I_{k \text {. }}$ blockers is dependent on the duration of the action potential. In the present study we evaluated this hypothesis by measuring the effects of dofetilide on the atrial refractory period at multiple atriall sites, before and after electrical remodeling. In agreement with the hypothesis we observed that the prolongation of the AERP by dofetilide was stronger at sites with long AERPs (mid Bachmann's bundle). Also the reverse frequency dependence of dofetilide was preserved at BB but not at RA or LA. This may 
be explained by the fact that, contrary to RA and $L A$, in remodeled atria the refractory period was at Bachmann's bundle still longer at slow than at fast pacing rates.

The ionic mechanisms of these obsenations are not completely understood. In a mathematical model of the human atrial action potential it was demonstrated that inhibition of $I_{k r}$ caused a smaller prolongation of the remodeled action potential than the normal action potential (+105 versus $32 \mathrm{~ms}$ ). "Interestingly, it was also shown that the net effect of $I_{k}$, blockade was dependent on the shape of the action potential. In spike-and-dome like action potentials, blockade of $I_{k r}$ caused a much stronger prolongation of the action potential duration than in triangular action potentials."

Only a few studies have looked at regional effects of $\mathrm{I}_{\mathrm{k}, \mathrm{s}}$ blockers (or other drugs) in the atria. Li et al. showed that in the dog dofetilide caused a larger increase in ERP in the left than in the right atrium. ${ }^{16}$ This was believed to be due to a larger $\|_{K_{r}}$ current in left atrial cells. In the present study we did not observe differences in class III effect in the right or left atrium. The reason for this discrepancy is unclear but may be due to important differences in $\mathrm{K}^{+}$currents between species. ${ }^{17,18}$ In contrast to the dog, ${ }^{16}$ in the goat also the refractory period in the left and right atrium are not different.

\section{Arrhythmogenic Properties of Bachmann's Bundle}

The present study revealed some interesting aspects of Bachmann's bundle. First of all, again we demonstrated that the caprine atria exhibit a distinct regional distribution of refractoriness, characterized by short refractory periods at the right and left atrial free walls and a longer refractory period at the mid-portion of $B B .{ }^{4}$ This was true both in non-remodeled as well as remodeled atria (after 48 hour of AF). Also in other species this has been described. Hara et al. showed that in the dog the action potential recorded from Bachmann's bundle had a longer duration than in cells of right atrial trabecular cells. ${ }^{19}$ Whereas right atrial trabecular action potentials were triangular in shape, at Bachmann's bundle typical spike-and-dome potentials were seen. Also in humans, Chen et al. found the longest AERP af Bachmann's bundle. ${ }^{20}$

We observed that the degree of AF-induced shortening of atrial refractoriness was significantly less at Bachmann's bundle than in the right or left atrial free wall. At Bachmann's bundle the normal rate adaptation of the refractory period was maintainedl after 48 hours of AF. This is in agreement with the study of Fareh et al. who found less electrical remodelling at Bachmann's bundle in the dog. ${ }^{21}$ It is not clear why AF-induced electrical remodeling is different at BB. One explanation could be that the ionic remodeling (downregulation of $\mathrm{I}_{C_{0,1}}{ }^{22}$ ) is less. It is also possible that the long AERP at Bachmann's bundle causes some degree of entrance block of fibrillation waves entering from the right or left atrial free walls. Because of this, the rate of fibrillation at BB may be lower than at of the right or left free wall.

Bachmann's bundle has also unique structural properties. Besides, getting inputs from the right and left atrium and the atrial septum, it exhibits a high degree of tissue anisotropy. ${ }^{23}$ It can be postulated that the fractionation of the electrograms recorded from Bachmann's bundle during premature beats, is caused by electrical 
dissociation of the parallel ariented muscle bundles. Dolber and Spach showed that in contrast to longitudinal conduction allong Bachmann's bundle which was associated with smooth biphasic extracellular potentials, during transverse conduction polyphasic potentials with multiple small peaks and troughs were recorded. ${ }^{23}$

The combination of a long refractory period together with a high degree of tissue anisotropy make Bachmann's bundle a potentially important factor in the initiation and perpetuation of AF. With regard to the initiation of AF, we found that premature stimuli were associated with critical conduction at Bachmann"s bundle and initiation of AF. When the AERP at Bachmann's bundle was prolonged by dofetilide, the upper limit of inducibility increased accordingly. The role of Bachmann"s bundle in the perpetuation of AF is still less clear. However, in a recent study we observed that cardioversion of persistent AF by the class IC drugs was associated with a reduction in the degree of fragmentation at Bachmann's bundle." It was hypothesized that slowing of the rate of fibrillation (without affecting refractoriness) increases the chance that parts of the atria with longer refractory period can also follow the fibrillation frequency in a $1: 1$ fashion. When this occurs, AF may convert either to sinus rhythm or to atrial flutter. The observation in the present study that dofetilide shortened the duration of AF, despite preferential prolongation of the AERP at Bachmann's bundle, appears to contradict this hypothesis. However, at the higher pacing rates (200 ms) the degree of AERP prolongation was not different at the RA, LA or BB. Thus at the pacing cycle length closest to the rate of AF, dofetilide did not increase the dispersion of refractoriness.

\section{Limitations}

An important limitation of the present study is that we did not record the electrical activity of the atrial septum. Therefore activation maps during initiation of AF do nat allow distinction between macro-reentry involving the atrial septum or micro-reentry within Bachmann's bundle.

We would like to emphasize that the findings cannot be directly translated to the human situation. There are impartant differences in atrial electrophysiology beIween the gaat and humans. In humans the action pottential is longer than in the goat and also the degree of electrical remodeling is less. ${ }^{12,25}$ "This may be explained by the different distribution of cardiac ion channel between species. 17,18 Therefore it is quile likely that the observed drug effects may be different in man than in the goat.

\section{REFERENCES}

1. Allessie MA. Bonke Fl, Schopman FJ: Circus movement in rabbit atrial muscle os a mechanism of lachycardia. II. The role of nonuniform recovery of excitability in the occurrence of unidirectional block, as studied with multiple microelectrodes. Circ Res 1976;39:168.177.

2. Moe GK, Rheinbold. WC, Abildskow JA: A computer madel of atrial fibrillotion. Am Heart J $1964 ; 67: 200-220$.

3. Wong J, Liu L. Feng ل, el al.: Regional and functional foctors determining induction and maintenance of atrial fibrillation in dogs. Am J Physiol 1996,271:H148-158. 
4. Duyschaever M, Danse P, Eysbouts $S_{\text {, el a }}$ : Is there an optimel pocing site lo prevent arial fibrilla. tion?: on experimental study in the chronicolly instumented goot. I Condiovose Electrophwsiol $2002 ; 13: 1264: 1271$.

5. Feng J, Yue L. Wang Z, ef al.: Ionic mechonisms of regionat action potentid haterogeneity in the canine right atrum. Circ Res 1998,83:54:55!.

6. Spach MS, Dolber PC, Heidlage JF: Interoction of inhomogeneities of tepolanizaton with antsotropic propogation in dag atria. A mechonism for both preventing and initioting reentry. Circ Res $1989 ; 65: 1612-1631$

7. Spach MS, Dolber PC, Anderson PA: Multiple regional differences in cellular properties that regulate repolorization and contraction in the right atrium of odult and newborn dogs. Cinc Res $1989,65: 1594-1611$.

8. Wang 2, Fermin: B, Nottel S: Delayed rectifier outward current and repolarization in human atrial myocytes. Circ Res 1993;73:276-285.

9. Bloouw $Y$, Goegelem H, Tieleman RG, et al. Early class lll drugs for the treatment of atrial tibrillafion. Efficacy and otral selectiwity of AVEO 18 in remodeled atria of the goat. Circulation 2004 ; $110: 1717-1724$

10. Duytschoever M, Blacuw Y, Allessie MA: Consequencas of Atrid Electricol Remodeling for the Antim. Arthythmic Action of Class IC and Class 111 Drugs. Cordiovasicular Res 2005.

11. Courtemanche M, Ramirez RJ, Natel S: Ionic tangets for drug therapy and atrial fibrillation induced electrical remodeling: insights from a mothemotical model. Cardiowasc Res 1999;42:477-489.

12. Wiffels MC, Kirchan of CJ, Dorland R, et al.: Atrial fibrillation begets atrial fibrillation. A study in awake chronically instrumented goats. Circulation 1995;92:1954-1968.

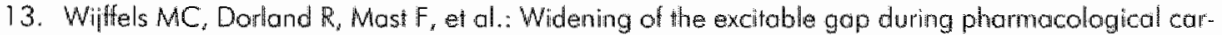
droversion of atrial fibrillation in the gaat: effects of cibenzoline, hydroquinidine, flecainide, and d-sitalol. Circulation 2000;102:260-267.

14. Wiffels MC, Dorland R, Allessie MA: Phomacologic cardioversion of chronic atrial fibrillation in the goat by closs IA, IC, and III drugs: a comparison between hydroquinidine, cibenzoline, flecoinide, and d-sotalol. Cardiovasic Electrophysiol 1999,10:178-193.

15. Tse HF, Lou CP. Electrophysiologic actions of dl-sotalal in patients with persistanl atrial fibrillation. I Am Coll Cardiol 2002; 40:2150-2155.

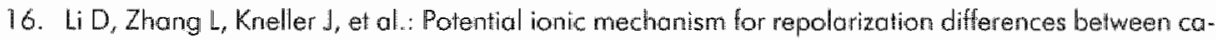
nine right and left atrium. Circ Res 2001;88:1168-1175.

17. Varro A, Lathrap DA, Hester SB, ei all, Ionic currents and action potentials in rabbit, ral, and guinea pig ventricular myocytes. Basic Res Cardial 1993;88:93-1102

18. Zicha $S$, Moss , Allen $B$, et al.: Molecular basis of species-specific expression of repolarizing $K+c u r$ rents in the heart. Am I Physiol Heart Circ Physiol 2003,285:H1641-1649

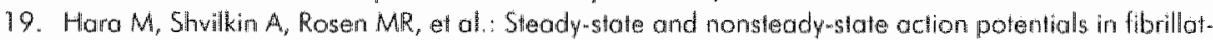
irg conine atrim: abnormal rate odaptation and is possible mechanisns. Cardiovasc Res $1999 \cdot 42: 455-469$

20. Chen SA, Hsieh MH, Tai CT, et al, initiation of atrial fibrillation by ectopic beats originating from the pulmonary veins: electrophysiological characteristics, pharmacological responses, and eflects of radiofrequency ablitation. Circulation 1999;100:1879-1886.

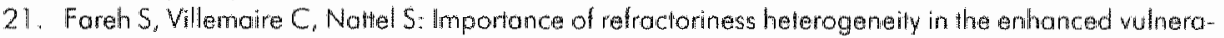
bility to atrial fibrillation induction caused by tochycardia-induced atrial electrical ramodaling. Cir. culation $1998,982202-2209$.

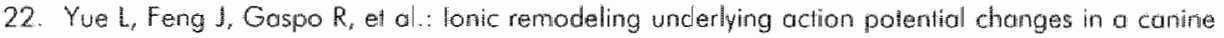
model of atrial fibrillation. Circ Res 1997,81:512-525.

23. Dolber PC, Spach MS: Siruclure of canine Bachmonn's bundle related to propagalion of excitation Am I Physiol 1989:257:H1446-1457.

24. Shan $Z$, Von Der Voor PH, Blaouw $Y$, et al: Fractionation of Electrograms and Linking of Actiwation During Phomacologic Cardioversion of Persistent Ainicl Fibrillation in the Goot. I Cardiovasc Electrophysiol 2004; 15:572-580.

25. Frana MR, Karasik PL, LiC, ef al.: Electrical remodeling of the human otrium: similor effects in patients with chronic atrial fibrillation and atrid ttutter. I Am Coll Cordial 1997;30:1785-1792. 


\section{CHAPTER 8}

\section{Future Perspectives}

\section{WHY RHYTHM CONTROL?}

In 2002, the results of two large randomized clinical trials were published in which two treatment strategies for AF were compared. ${ }^{1,2}$ One strategy was aimed at restoring and maintaining sinus rhythm (rhythm control). In the other, the goal was to reduce symptoms by lowering the ventricular heart rate during AF (rate-control). In both the North American AFFIRM-Study (Atrial Fibrillation Follow-Investigation of Rhythm Management) ' and the Dutch RACE- (RAte Control versus Electrical cardioversion) ${ }^{2}$ it was demonstrated that the overall morlality was not different between rate and rhythm control. In the AFFIRM-trial there was a trend towards increcised mortality in the rhythm control arm. The results of these studies showed that at present, rate control is (at least) equally effective in treating AF as rhythm control. In a recent guideline of the American Academy of Family Physicians and the American College of Physicians published in the Annals of Internal Medicine it was stated that "Rate control with chronic anticoagulation is the recommended strategy for the majority of patients with atrial fibrillation. ${ }^{3}$ As a result, the number of patients referred for pharmacological cardioversion of AF has clearly decreased. This is illustrated in figure 1. Shown is the number of patients referred for chemical cardioversion between 2001 and august 2003 in a phase III study which evaluated the prophylactic efficacy of a new anti arrhythmic drug. After the simultaneous publication of the RACE and AFFIRM studies (arrow) there was a drop in the number of patients referred for cardioversion.

However in the aftermath of these trials several important issues have been raised. In both the RACE and AFFIRM trial it became clear that the current treatment strategies for maintaining sinus rhythm are far from optimal. In RACE, despite the use of anti-arrhythmic drugs, the prevalence of sinus rhythm was only $39 \%$ after 2.3 years of follow up. Anti-arrhythmic drugs were also often assaciated with adverse effects, causing drug discontinuation. In a sub-study from the AFFIRM-study it was found that after one year treatment $12 \%$ of patients on amiodarone, $11 \%$ on sotalol and $28 \%$ of patients using class I drugs stopped taking their drugs due to side effects. ${ }^{4}$ In light of these findings it seems reasonable to raise the question whether the results of the AFFIRM and RACE could have yielded different results with a safer and 


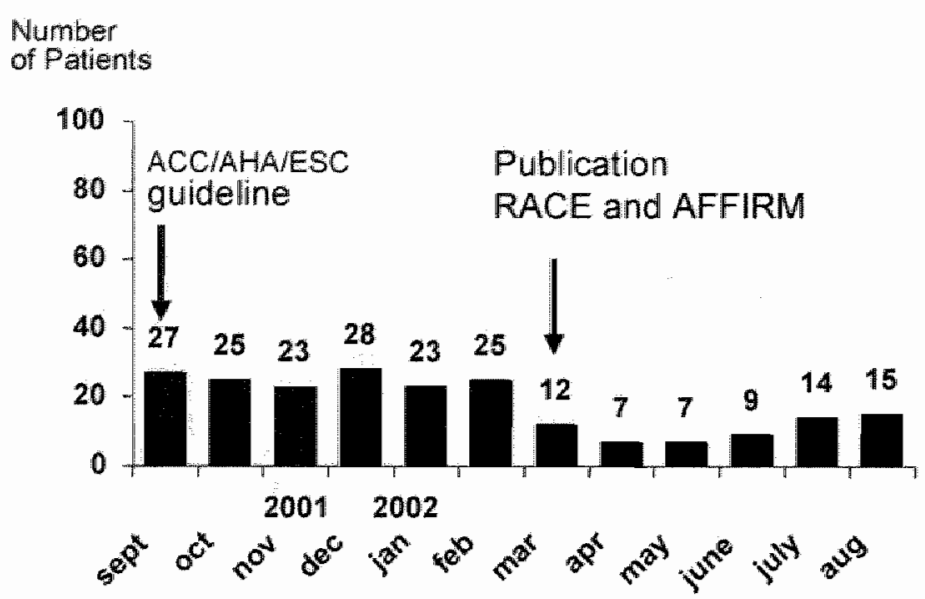

Number of patients referred for phormacologicol cardioversion of AF. Between 2001 and february 2002 approximately 25 patients undenwent a pharmacologicall cardioversion each month. After the publication of RACE and AFFIRM (arrow) the number of patienls decreased markedly. (Courtesy H Crijns)

more effective rhythm control strategy. It is interesting to note that in patients in whom sinus rhythm could be effectively restored and maintained, quality of life improved and long term survival was actually better. ${ }^{15,6}$ In a non-randomized retrospective analysis, Pappone et al. showed that patients who underwent successful catheter ablation of AF by circumferential isolation of the pulmonary veins had a lower rate of cardiovascular death when compared to patients receiving anti-arrhythmic drugs. "Thus, although the RACE and AFFIRM study have clearly shown that at this point in time, rhythm control is not superior, this should not discourage the development of better drugs for rhythm control. The AFFIRM investigators concluded that 'if an effective method for maintaining sinus rhythm with fewer side effects were available, this might improve survival'. ${ }^{6}$

\section{Clinical Implications of Atrial Selective Drugs}

In 1996, Li et al. from the group of Nattel investigated the expression of $\mathbb{K}^{+}$currents in human explanted hearts. ${ }^{3}$ They demonstrated that the ultra-rapid delayed rectifier current $\left(\left.\right|_{K_{u} u}\right)$ was present in the atrium, but absent in the ventricle. The possible clinical relevance was stressed by the statement: "Since $I_{\text {Kur }}$ plays an important role in human atrial repolarization and is absent in human ventricle, it is a potentially promising target for the development of drugs that prevent reentrant atrial arrhythmias without a risk of ventricular proarrhythmia", 8

At present, several pharmaceutical companies are developing compounds that block the $I_{\text {Kur }}$ current. ${ }^{9-11}$ Of note, none of these compounds is a pure $\|_{k u r}$ blocker, other $\mathrm{K}^{4}$ currents are affected as well. In the present thesis we describe the pre-clinical results of AVEO1 18 in the goat model of AF. This drug was synthesized by Aventis 
pharma Germany and in-vitro siudies demonstrated a selectivity for the repolarizing currents $I_{\text {Kurm }} I_{\text {io }}$ and $I_{\text {Kach }} .10$ In the beginning of 2002 the first experiments with AVEO1 18 were performed in a chronic goat model of persistent AF. Infusion of AVEO1 18 caused a marked prolongation of the atrial fibrillation cycle length, the arrhythmia terminated and the drug was well iolerated. In subsequent experiments we observed the following: first of all, AVEO 118 has an atrial selective action, in the atrium the refractary period was markedly prolonged, in the ventricle the QT interval was not changed. Secondly, AVEO1 18 exerted an enhanced action in remodeled atria (Chapter 3). This was rather surprising, since we previously demonstrated that $d$-sotalol and ibutilide, blockers of the 'late' activated $I_{k r}$ current, actually had a reduced effect after AF (Chapter 2). Thirdly, in goats with persistent AF lasting for more than 1 month, AVEO 18 still exerted a strong class III effect and AF was terminated in up to $70 \%$ of the animals. Finally, we showed that combined administration of AVEO1 18 could restore the action of $I_{\mathrm{Kr}}$ blockers in electrically remodeled atria and in goats with persistent AF, the arrhythmia was easily terminated (Chapter 4).

Altogether these properties make AVEO 18 a very promising drug for the treatment of atrial fibrillation. In may 2004 the first clinical phase II study with AVEO 18 has been started. In this multi-center trial (principal investigator Harry Crijins) the safety and cardioversion efficacy of AVEO 18 is evaluated.

Although the pre-clinical results in the goat (Chapter 3 ) and in the pig ${ }^{12}$ suggest that AVEO1 18 may be a very potent anti-arrhythmic agent, there are several reasons why the efficacy may be different in man. First of all, important differences exist in atrial electrophysiology between the goat and man. For example, the right atrial refractory period in man is $\sim 250 \mathrm{~ms}^{13,14}$ whereas in the goat it is only $150 \mathrm{~ms}$. After AF-induced electrical remodeling, AERP shortens to $\sim 200 \mathrm{~ms}^{13,14}$ in man whereas in the caprine atria the AERP will become as short as $100 \mathrm{~ms}$. Since we observed the strongest effects of AVEO 18 at short AERPs, it is uncertain whether the same effects will be seen in patients with long AERPS. Another important difference is that the substrate of atrial fibrillation is very dissimilar in man than in goats. In the present study we used healthy goats without underlying pathology. Of note, contrary to the human situation, in none of these animals spontaneous episodes of Af occurred. Only after a prolonged period of repetitive burst pacing, the animalls developed persistent AF. This is very different from the human situation where atrial fibrillation is often seen in patient with concomitant underlying heart disease. The atria of these patients are very prone to AF, and the first episode may already cause persistent AF. In this respect, the results of the clinical trial will also tell us something about the value of the goat model of 'lane' AF for evaluating the clinical efficacy of novel anti-arrhythmic drugs.

Pending the results of the clinical trial we can only speculate on the possible clinical implications of these novel atrial selective anti-arrhythmic agents. However, if we assume the best case scenario that also in humans. AVEO1 18 is safe and at least equally effective as currently available drugs, this may have important consequences. First of all, atrial selective drugs will become the first therapy of choice for pharmacological cardioversion of atrial fibrillation. In addition to that, it may be 
possible to enhance the cardioversion efficacy of these drugs by additional infusion of a low dosage of $\mathrm{I}_{\mathrm{ks}}$ blocker such as $\mathrm{d} /$-sotalol, ibutilide or dofetilide. Off course, before using such a strategy, additional studies are required to evaluate safety. However in the preclinical model this combination of AVEO1 18 and $I_{K,}$ blockers was such a potent chemical defibrillator, that it is tempting to speculate that it may be an altemative for DC cardioversion of persistent AF. Another important indication would be the prevention of AF recurrences by oral administration of atrial selective drugs. In case this strategy fails it may even be possible to co-administer a small dosage of orall d/-sotalol or dofetilide. Using this drug-regime it may be possible to prolong the AERP to such an extent that premature bests will not be able to initiate AF, In addition, if AF occurs, the potent combination of 'early' and 'late' class III agents may prevent the development of persistent AF.

\section{REFERENCES}

1. Wyse DG, Waldo AL, DiMarca JP, Domanski MJ, Rosenberg Y, Schiron EB, Kellen JC, Greene HL, Mickel MC, Dalquist JE, Corley SD: A comparison of rote control and thythm control in patients with atrial fibrillation. N Engl J Med 2002;347:1825-1833.

2. Van Gelder IC, Hagens VE, Basker HA, Kingma JH, Kaimp O, Kingmo T, Said SA, Dormanata JI, Timmermons A. Tijssen JG, Crijns HJ: $\mathbb{A}$ comparison of rote control and rhythm control in patienis with recurrent persistent atrial fibrillation. N Engl J Med 2002;347:1834-1840.

3. Snow V, Weiss KBB, LeFevre M, McNamara R, Bass E, Green LA, MichkK, Owens DK, Susman J, Allen DI, Moltur-Pilson C: Management of newly detected atrial fibrillation: a clinical practice guideline from the American Academy of Family Physicians and the American College of Physicians. Ann Imw tern Med 2003; 139:1009-1017

4. Maintenance of sinus rhythm in patients with atrial fibrillation: an AFFlRM substudy of the first antiarrinythmic drug. I Am Coll Cardiol 2003;42:20-29.

5. Hagens VE, Ranchor AV, Van Sonderen E, Bosker HA, Kamp O, Tijssen JG, Kingma JH, Crijps HJ, Van Gelder IC: Effect of rate or rhythm control on quality ol life in persistent atrial librillation. Results From the Rate Control Versus Electrical Cardiowersion (RACE) Study. J Am Coll Cardiol $2004: 43: 241-247$.

6. Corley SO, Epsiein AE, DiMarco.JP, Domanski MJ, Geller N, Greene HL, Josephson RA, Kellen JC, Klein RC, Krohn AD. Mickel M, Mitchell LB, Nelson JD, Rosenberg Y, Schron E, Shemanski L, Woldo AL. Wyse DG: Relationships between sinus thythm, trealment, and survizal in the Atrial Fibrillation Follow-Up Investigation of Rhythm Monagement (AFFIRM) Study. Circulation 2004;109:1509:1513.

7. Pappone C, Rosanio S, Augello G, Gallus G, Vicedomini G, Mazzone P, Gulletta S, Guglionta F, Pappone A, Santinelli V, Tortoriello V, Sala S, Zangrillo A, Crescenzi G, Benussi S, Alfieri O: Mortalily, marbidily, and quality of life after circumferential pulmonary vein ablation for atrial fibrillation: outcomes trom a control led nonrandomized long-term study. J Am Coll Cardiol 2003;42: 185-197.

8. Li GR, Feng J, Yue L, Carrier M, Natte S: Ewidence for two components of delayed rectifier Kt- current in human ventricular myocytes. Circ Res 1996,78:689-696.

9. Billman GE; RSD 1235. Cardiome. Curr Opin Investig Drugs 2003;4:352-354.

10. Goegelein $\mathrm{H}$ : Effects of the novel inhibitor of atrial K channel's AVEO1 18 in anesthetized pigs and on ion channels. Pocing Clin Electrophysiol 2003;26:1045.

11. Małsuda T, Mosumiya H, Tanako N, Yamashita T, Tsuruzoe N, Tanaka Y, Tanaka H, Shigenoba K: Unhitition by a novel anti-arrhythmic agent, NIP-142, of cloned human cardiac K+ channel Kr 1.5 current. Life Sci $2001 ; 68: 2017-2024$. 
12. Wirth KJ, Paehler T, Rosenstein B, Knobloch K, Maier T, Frenzel J, Brendel J, Busch AE, Bleich M: Arrial effects of the novel $K(+)$-channel-blocker AVEO 18 in anesthetized pigs. Cardiovasc Res 2003;60:298-306

13. Attuel P, Childers R, Couchemez B, Poveda J, Mugicas. Coumel P: Follure in the rate oddtaptation of the atrial refractory period: its relationship to whinerobility. In J Cordid 1982;2:179-197.

14. Franz MR, Karasik PL, Li C, Moubarak J, Chavez M. Electricol renodeling of the human atrium: similor effects in potients with chronic atrial fibrillation and atrial flutter. I Am Coll Cordiol $1997 ; 30: 1785-1792$. 


\section{Samenvatting}

Boezemfibrilleren (ook wel atriumfibrilleren genoemd) is een hartritmestoornis die bij weel mensen voorkomt. Met name bij patiënten met een hoge bloeddruk, een lekkende hartklep of een doorgemaakt hartinfarct komt boezemfibrilleren frequent voor. De incidentie van boezemfibrilleren neemt toe met de leeftijd. Bij mensen van 60 jaar heeft $4 \%$ van de bevolking de ritmestoornis, bij een leeftijd ouder dan 80 jaar is dit $10 \%$. Door de toenemende vergrijzing van de bevalking zal boezemfibrilleren in de toekomst een steeds belangriiker medisch, maar ook - gezien de kosten van de behandeling - economisch probleem worden.

Tijdens boezemfibrilleren worden de boezems met een zeer hoge frequentie (tot wel 600 slagen per minuut) geactiveerd. Het merendeel van deze electrische impulsen wordt gelukkig niet voortgeleid naar de kamers, maar wordt grotendeels tegengehouden door de atrioventriculare knoop (de verbinding tussen de boezems en de kamers). Toch zal de hartfrequentie bii een patiënt met boezemfibrilleren veel hoger ziịn dan die bij een patiënt met een normaal hartritme (sinus ritme). Atriumfibrilleren veroorzaakt klachten als hartkloppingen, vermoeidheid en kortademigheid. De belangriikste complicatie van boezemfibrilleren is echter het optreden van beroertes. Dit wordt veroorzaakt doordat er een verhoogde neiging betaat tot stolselvorming in de boezems. Wanneer deze stolsels stoomafwarts naar de hersenen doorschieten veroorzaakt dit een CVA.

Het belangrijkste doel van de behandeling van boezemfibrilleren is het verhelpen van de klachten en het voorkomen van CVA's. Dit kan op verschillende wijzen worden bereikt. Ten eerste kunnen de klachten verdwijnen door het normale hartritme (sinus ritme) to herstellen met behulp van mediciinen of een electrische schock. Deze behandelingsstrategie wordt ook wel 'ritme-controle' genoemd. Een andere behandelingsoptie is de snelle ventrikelfrequentie te vertragen door mediciinen ('frequentie-controle"). In dat geval bliff het atriumfibrilleren echter bestaon. Thrombo-embolische complicaties kunnen grotendeels worden voorkomen door gebruik van bloedverdunners.

Het laatste decennium zijn er talloze niet-medicamenteuze therapieën ontwikkeld die erop gericht zijn om boezemfibrilleren te bestrijden. Op dit moment lijkt echter alleen ablatie van de longvenen een belangriike plaats te verwerven in het huidig arsenaal aan behandelingsmogelijkheden. Dit is echter een zeer tijidrovende procedure en gezien het grote aantal patiënten met boezemfibrilleren is deze behandeling voorlopig niet voor iedereen weggelegd. De hoeksteen van de behandeling van boezemfibrilleren bliff derhalve het gebruik van medicijnen. Het grote voordeel van medicijnen is dat ze makkelijk te gebruiken zijn en bovendien zijn ze voor veel patiënten toegankelijk. Op dit moment zijn er diverse van deze zogenaamde anti-aritmica beschikbaar. Het werkingsmechanisme waarmee deze middelen sinus 
ritme kumnen herstellen is echter zeer verschillend. Zo zijn er zogenaamde klasse IC anti-aritmica die met name de geleidingsnelheid in het atrium vertragen door blokkade van het natriumkanaal. Andere mediciinen blakkeren kalium kanalen $\left(l_{k_{s}}\right)$ en kunnen boezemfibrilleren opheffen door een verlenging van de atrial refractaire periode (klasse 3 effect). Helaas kleven er een aantal belangriike nadelen aan de huidig beschikbare medicijnen. Zo is in verschillende klinische studies gebleken dat anti-aritmica hun effectiviteit verliezen als de ritmestoornis langer dan een aantal dagen bestaat. Bovendien kan het gebruik van anti-aritmica in sommige patiënten leiden tot ernstige ritmestoornissen van de kamers. Het is dus van groot belang voor de behandeling van boezemfibrilleren dat er nieuwe medicijnen worden ontwikkeld die nog effectief zijn als de ritmestoornis lang bestaat en die bovendien veiliger zijn. In dit proefschrift hebben wij in een diermodel van boezemfibrilleren onderzocht wat de effecten zijn van het langdurig bestaan van boezemfibrilleren op de effecten van diverse anti-aritmica. Wii hebben niet alleen gekeken naar bestaande medicijnen, ook hebben wil een aantal nieuwe experimentele mediciinen getest.

$\mathrm{Bij}$ experimenteel onderzoek naar boezemfibrilleren wordt veel gebruik gemaakt van proefdieren waarbij de ritmestoornis kunstmatig wordt opgewekt. In hoofdstuk $I$ wordt een overzicht gegeven van de verschillende diermodellen. Al gan het eindle van de $19^{\circ}$ eeuw was bekend dat het mogelijk was om boezemfibrilleren op te wekken door een geringe hoeveelheid electrische stroom toe te dienen op de boezems. In de loop der tijd zijn er diverse modellen ontwikkeld die hebben bijgedragen aan een beter begrip van de onderliggende mechanismen van boezemfibrilleren. Alle experimenten die in dit proefschrift worden beschreven zijn uitgevoerd in geiten met boezemfibrilleren. Tijdens een open-hartoperatie werden electrodes aangebracht op de linker en rechter boezem en op de inter-atriale spier (Bachmann's bundel). Met gebruik van een versterker en een computergestuurde stimulator was het mogelijk om op elke electrode de electrische activiteit af te leiden, en electrische stoompjes toe te dienen. Nadat de borstkas weer was gesloten, en er adequate pijnstilling was toegediend, konden de geiten gedurende 3 tot 4 weken herstellen in de stal. Vervolgens werd boezemfibrilleren apgewekt met een fibrillatie pacemaker. Deze pacemaker kan boezemfibrilleren induceren door de atria gedurende 1 seconde te stimuleren met een frequentie van 3000 slagen per minuut. Op deze manier was het mogelijk om gedurende 24 uur per dag, 7 dagen per week boezemfibrilleren te induceren en te onderhouden. Het gevolg hiervan was dat de ritmestoomis in het begin nog kortdurend was (enkele seconden), maar na enkele dagen duurden de episoden steeds langer en uiteindelijk (na ongeveer 2 weken) stopte de ritmestoornis niet meer vanzelf (persistent boezemfibrilleren). Het mechanisme dat hieraan ten grondslag ligt is een verkorting van de atriale refractaire periode (repolarisatie-tiid). Dit fenomeen wordt wel electrische remodelering genoemd. De atriale refractaire periode representeert de tijd dat een cel niet meer prikkelbaar is madat hii kort tevoren is geactiveerd. Des te korter de retractaire periode, des te vaker kan een hartcel worden geactiveerd en des te kleiner is de kans dat de ritmestoornis spontaran stopt. 
In hoofdstuk 2 hebben wij onderzocht of het mogelijk is om electrische remodelering te voorkomen, of teniet te doen, door de geneesmiddelen EMD87505 en EMD12502 1 toe te dienen. Deze mediciinen zilin remmers van de natrium-waterstof vitwisselaar. Het anderzoek toonde aan dat de mediciinen de verkorting van de atriale refractaire periode niet konden beïnvloeden. Het maakte geen verschil of de medicinnen werden toegediend tijdens, of na het proces van electrische remodelering. De conclusie van dit onderzoek is dat de natrium-waterstof uitwisselaar waarschiinlijk geen belangrijke rol speelt bii de verkorting van de atriale refractaire periode die optreedt tiidens boezemfibrilleren. In hoofdstuk 3 wordt beschreven wat de effecten ziin van electrische remodelering op de werking van het klasse $1 \mathrm{C}$ medicijn flecaïnide en de klasse 3 anti-aritmica d-sotalol en ibutilide. Deze medicijnen worden in de dagelijkse klinische praktijk veel gebruikt om boezemfibrilleren op te heffen. De resultaten van het onderzoek lieten zien dat het werkzame effect van flecaïnide bleef bestaan na 2 dagen boezemfibrilleren. Daarentegen, de effecten van $d$-sotalol en ibutilide waren afgenomen. In normale atria werd -zoals verwacht-een duidelijke verlenging van de refractaire periode waargenomen. Na slechts 2 dagen atriumfibrilleren was dit effect echter nagenoeg verdwenen. De verlenging van de ventriculaire repolarisatie was onveranderd. Dit impliceert dat atriale electrische remodelering de klasse 3 effecten van $l_{k r}$ blokkers sterk doet afnemen. Dit is een mogelijke verklaring voor het verlies van effectiviteit van deze medicinen zoals in de klinische praktiik wordt waargenomen.

Hoofdstuk 4 beschrifft de electrofysiologische effecten van een nieuw experimenteel klasse 3 medicijn (AVEO 18). Dit mediciin heeft een ander aangrijpingspunt dan de huidig beschikbare klasse 3 anti-aritmica. Het blokkeert kalium kanalen zoals $I_{\text {Kurr }} I_{\text {to }}$ en $I_{\text {Kachi }}$. Deze kanalen worden vroegtijdig tijdens de repolarisatie geactiveerd en zijn zeer belangrijk in de atria en in mindere mate in de ventrikels. De verwachting is dan ook dat deze middelen een selectieve anti-aritmogene werking kunnen uitoefenen op de atria. De experimenten lieten zien dat het mogelijk was om de atriale refractaire periode te verlengen zonder de ventriculaire repolarisatie (de QT tijd) te beïnwloeden. Bovendien was de verlenging van de atriale refractaire periode toegenomen in electrisch geremodeleerde atria. Het effect was zo sterk, dat de verkorting van de refractaire periode zoals die werd gezien na 48 uur atriumfibrilleren, volledig ongedaan was gemaakt. Verder bleek het magelijk om in het merendeel van de geiten met persistent boezemfibrilleren de ritmestoornis te beëindigen. In Hoofdstuk 5 hebben wij getest of gelijktijdige toediening van conventionele klasse 3 anti-aritmica (dofetilide en ibutilide) en AVEO1 18 een sterkere verlenging van de refractaire periode geeft dan de som van de separate effecten. De achtergrond van deze hypothese was de bevinding in hoofdstuk 3 dat de werking van 'late' kalium kanaal blokkers afneemt als de refractaire periode was verkort door electrische remodelering. Wii postuleerden dat als de retractaire periode verlengt na toediening van AVE01 18 (hoofdstuk 4), dan neemt de werkzaamheid van de 'late' klasse 3 anti-aritmica weer toe. Gelijktijdige toediening van dotetillide of ibutilide en AVEO 118 zou derhalve een sterkere verlenging van de refractaire periode bewerk- 
stelligen in geremadeleerde atria. De resultaten toonden dat de combinatie van 'vroege' en 'late' klasse 3 anti-aritmica inderdaad een synergetisch effect had in electrisch geremodeleerde boezems. Daarentegen, in normale boezems werd een addifieve verlenging gezien. Vervolgens hebben wil gekeken of de combinatie van vroege en late klasse 3 anti-aritmica ook kan worden gebruikt om langdurig boezemfibrilleren te termineren. Gebruikmakend van de hoogste dosering van AVE01 18 en dofetilide of ibutilide was het mogelijk om in alle geiten het boezemfibrilleren op te heffen. Dit ging gepaard met een synergetische verlenging van de fibrillatie cycluslengte. Concluderend kan worden gesteld dat de combinatie van een vroege en late klasse 3 medicatie een zeer sterk anti-aritmogeen effect bezit. Dit kan van groot bellang zijn voor de medicamenteuze behandeling van boezemfibrilleren. In hoofdstuk 6 onderzoeken wij of de regionale distributie van de atriale refractaire periode kan worden beïnvloed door de activatie-sequentie te veranderen. Het fenomeen dat de atriale repolarisatie athankelijk is van de activatie-sequentie wordt ook wel 'atriaal geheugen' genoemd. In zes geiten, waarbij verschillende electrodes op verschillende plaatsen in het atrium waren aangebracht, werd de atriale activatietiid en refractaire periode bepaald na een periode van langdurig atriaal pacen (150bpm) op het rechter en linker atrium. De resultaten lieten zien dat tijdens normaal sinus ritme er een inverse relatie bestond tussen de activatietijd en de refractaire periode. Met andere woorden, des te eerder een plaats geactiveerd werd, des te langer de refractaire periode. Daarentegen, als de activatie-sequentie werd veranderd door het atrium te activeren vanuit de rechter- of linker-boezem, dan leidde dat niet tot een verandering van de distributie van de refractaire periode. Dit suggereerl dat het atrium geen 'atriaal geheugen' heeft. In Hoofdstuk 7 onderzoeken wiil of de $\mathrm{I}_{\mathrm{kr}}$-blokker dofetilide een preferentiële verlenging van de atriale refractaire periode geeft op de bundel van Bachmann. De achtergrond van deze hypothese was de abservatie in hoofdstuk 3 dat $I_{k r}$ blokkers minder effect hebben als de refractaire periode is verkort door atriale electrische remodelering. Vice versa, op plaatsen met een lange refractaire period (zoals bijwoorbeeld Bachmann's bundel), zou dofetilide dan juist een toegenomen werking moeten hebben. In negen geiten hebben we de effecten gemeten van dofetilide op de atriale refractaire periode op 7 verschillende plaatsen, zowel voor als na een periode van 48 uur boezemfibrilleren. Het klasse 3 effect van dofetilide was inderdaad het grootst op plaatsen met de langste refractaire periode (op dle bundel van Bachman). Daarentegen, op plaatsen met een korte refractaire periode was het effect van dofetilide slechts zeer gering. Hierdoor ontstonden er toegenomen regionale verschillen in refractaire periode. Dit bleek ook geassocieerd te zijn met een verhoogde vatbaarheid voor atriumfibrilleren. Mapping toonde longitudinale dissociatie in Bachmann's bundel tijdens initiatie van atriumfibrilleren. Concluderend, in dit hoofdstuk wordt aangetoond dat verlenging van de refractaire periode door klasse 3 anti-aritmica ook een paradoxaal pro-aritmogeen effect kan hebben door een preferentiële verlenging van de atriale refractaire period op de bundel van Bachmann. 


\section{IMPLICATIES VAN HET ONDERZOEK}

De laatste jaren ziin er verschillende klinische studies gepubliceerd die suggereren dat bij de behandeling van atriumfibrilleren het geen verschil maakt of een patiënt behandeld wordt met een 'ritme-' of 'frequentie-controle' strategie. De mensen zullen evenlang leven en ook de klachten van patiënten zijn gelijk in beide groepen. Echter de meeste huidig beschikbare medicamenten die worden gebruikt voor 'ritme-controle' zijn weinig effectief en bovendien hebben zij soms vervelende bijwerkingen. Het is derhalve van groot belang dat er nieuwe effectieve en veilige medicijnen worden ontwikkeld waormee boezemfibrilleren kan worden bestreden. In dit proefschrift hebben wil gekeken naar de werking van 'nieuwe' en 'oude' anti-aritmica in een pre-klinisch geitenmodel van boezemfibrilleren. Het onderzoek in dit proefschrift geeft inzicht in de werking van anti-aritmica in geremodeleerde atria. De experimentele bevindingen met nieuwe atrium specifieke medicijnen suggereren dat deze groep mediciinen ook van waarde kan ziin bij de farmacologische behandeling van boezemfibrilleren. Uiteraard zal dit nog in een klinische studie onderzocht moeten worden. 


\section{Dankwoord}

Dit proefschrift is tot stand gekomen met de hu p van welen. Op deze plek wil ik proberen iedereen te bedanken. Allereerst mijn promotor prof. dr. Maurits. Allessie. Beste Maurits, ik ervaar het als een voorrecht om één van jouw promovendi te zijn geweest. Ik wil je bedanken voor alle tijd die je hebt gestoken in mijn opleiding tot onderzoeker. De tal rijke electrofysiologische en electrofilosofische discussies heb ik als zeer inspirerend en motiverend ervaren. Jij hebt mii geleerd dat het alleen mogelijk is om het beste resultaat te krijgen door je in iets vast te bijten en eindeloos door te gaan -en vack opnieuw te beginnen-tot er een ware diamant is geslepen (en eigenlijk kan het dan nog mooier).

Prof. dr. Harry Crijns. Beste Harry, het is een eer voor mij dat iij de voorzitter bent van de leescommissie. Jouw ECG-besprekingen op het ochtendrapport in Groningen hebben mij enthousiast gemaakt voor de cardiologie. Ik bewonder jouw vermogen om bij klinische problemen de onderliggende mechanismen te betrekken. Ik ben zeer blij dat ik daar nu dagelijks van kan profiteren en bij jou word opgeleid toi cardioloog in Maastricht.

Prof. Gögelein. An important part of this thesis was the result of a fruifful cooperation between the department of physiology and AVENTIS. It was a great experience to witness the pre-clinical development of a new drug. Dear Heinz, I would like to thank you for the help and advice you gave the last couple of years.

Dear professor Nattel, it's a great honour for me that you are willing to participate in the reading committee of my thesis. I admire the comprehensiveness of your work. The papers you published were of great help for this thesis.

De overige leden van de beoordelingscommissie, prof. dr. Post en prof. dr. Struijker-Boudier dank ik hartelijk voor het kritisch doornemen van het manuscipt en het willen opponeren tijdens de verdediging.

Miin paranimfen en goede vrienden Robert Tieleman en Niels Patberg. Robert, ik weet nog goed dat jii twee studenten zocht die de nachtelijke metingen (wie bedenkt er nou zo'n protocoll) bii jouw promotieonderzoek wilden doen. Door jouw aanstekelijke enthousiasme werd het echter al snel meer dan een bijbaantie en het resultaat ligt nu voor ons. Naast de interesse voor boezemfibrilleren houden we beiden van een stukje koersen op de fiets. Eerst in het platte Groningen, nu in de mooie heuvels van Limburg. Ik hoop dat we dat nog vaak samen zullen doen. Niels, ondanks dat iii de afgelopen vier jaar in New York was voor jouw promotie-onderzoek is onze vriendschap in stand gebleven. Dankzij Microsofts Messenger Service had- 
den we bijna dagelijks contact en konden we onze frustraties en belevenissen acn elkaar kwijt. Nadal je in Groningen eerst roei- en studie-genoot wos, ben ik blii dal je nu in Maastricht collega bent geworden.

Het werken op de afdeling fysiologie heb ik mede door de prettige omgang met alle collega's als zeer plezierig ervaren. Een groot aantal mensen zijn voor langere of kortere tijd op het lab geweest. Een aantal mensen wil ik met name noemen. Sabine Eijsbouts, iil was al die jaren de sociale spil van het lab. Succes met je eigen proefschrift en opleiding. Hans-Ruprecht Neuberger, bedankt voor de prettige samenwerking en veel succes met het afronden van je thesis in Homburg. Mattias Duytschaever, bedankt voor het inwerken en de goede samenwerking aan hoofdstuk 3. Ulli Schotten, ondanks dat je het erg druk had met ondenwijstaken en het opstarten van je eigen laboratorium stand iij altijd klaar voor nuttige adviezen en brainstormsessies. Natasja de Groot, wij zijn ongeveer tegelijkertijd begonnen op het lab. Jouw gedrevenheid heeft nu data opgeleverd voor wel 3 proefschriften. Succes met de afronding van jouw thesis. Ook alle andere collega's van het lab bedank ik voor de gezelligheid en collegialiteit.

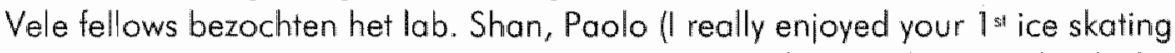
experience!), Ching Tai Tai, Pepijn and Vida thanks for all your help. Dirk, thanks for the cooperation on Chapter 6 and all the hel pful suggestions on young fatherhood.

De collega's van de experimentele cardiologie onder leiding van van prof.dr. Marc Vos wil ik bedanken voor de zeer nuttige en leerzame werkbesprekingen.

Onmisbaar waren de mensen die het onderzoek ondersteunen. De hulp en adviezen van met name Arne van Hunnik en Jan Hollen waren van groot bellang. Zonder hen zou er geen proefschrift zijn. Ook Theo van der Nagel en Marion wil ik hartelijk bedanken voor het kundig implanteren van elektrodes in de geiten. De medewerkers van het CPV dank ik voor de goede verzorging van de geiten. Jos, Claire en Vivian, bedankt voor de secretariële ondersteuning.

Mijn familie en schoonfamilie waren altijd geïnteresseerd in de vorderingen en inhoud van het proefschrift. Papa en mama, ik dank jullie voor de mogelijkheden die jullie Sander en mij hebben gegeven.

Tot slot. Thea jii was degene die meer dan 8 jaar lang geitenstank heeft moeten verdragen. Jij bent meegekomen naar het zuiden, ondanks dat we op ons eerste weekendje Maastricht midden in de carnaval terechtkwamen. Lieve Thea, ik dank je voor je onvoonwaardeliike steun. 


\section{Curriculum Vitae}

Yuri Blacuww werd geboren op 7 november 1972 in Lelystad. In 1992 behaalde hii het eindexamen atheneum aan de Scholengemeenschap Lelystad. Van 1992 tot 1993 studeerde hij geschiedenis aan de Rijksuniversiteit Groningen. In 1993 startte hij de studie geneeskunde aan dezelfde universiteit. Na een keuze-coschap cardiologie in het St. Georges Hospital Medical School te Londen (prof. A Camm) werd het artsexamen in 2000 behaald. Tijdens zijn studie was de auteur betrokken bij experimenteel anderzoek naar de mechanismen van boezemfibrilleren. Dit onderzoek werd verricht onder leiding van dr. RG Tieleman en prof. dr. HJGM Crijns. Tevens was hii lid van de eerste redactie van de studenten-editie van het Nederlands Tijdschrift voor Geneeskunde. In 2000 verkreeg de auteur een Zon-MW AGIKO-stipendium. In hef kader hiervan werd in juni 2000 gestart met experimenteel onderzoek bij de vakgroep fysiologie aan de Universiteit Maastricht in het laboratorium van prof. dr. MA Allessie. In juni 2004 werd begonnen met het klinische deel van de opleiding cardiologie in het academisch ziekenhuis Maastricht bij opleider prof. dr. HJGM Crijns. 


\section{Publications}

\section{JOURNAL ARTICLES}

1. RG Tieleman, $Y$ Blaauw, IC van Gelder, CDJ de Langen, PJ de Kam, JG Grandjean, KW Patberg, KJ Bel, MA Allessie, HJGM Crijns: Digoxin delays the recovery from tachycardia induced electrical remodeling of the atria. Circulation 1999;100:1836-1842

2. Y Blaauw, RG Tieleman, MP van den Berg, PJ de Kam, CDJ de Langen, I Haaksma, JG Grandjean, KW Patberg, IC van Gelder, HJGM Criins: Tachycardia induced electrical remodeling of the atria and the autonomic nervous system in goats. Pacing and Clinical Electrophysiology 1999; 22:1656-1667

3. Y Blaauw, HJGM Crijns: De MUST-Trial: reductie in plotselinge hartdood door implantatie van interne cardiale defibrillator. Nederlands Tijdschrift voor Geneeskunde 2000 (referaat)

4. Y Blaauw, JP Foran, IC van Gelder, HJGM Criipns, AJ Camm: Focal origin of atrial fibrillation and treatment with radiofrequency ablation. Cardiologie $2001 ; 8: 73-78$

5. M Duytschaever, FMast, M Killian, Y Blaauw, M Wiffels. MA Allessie: Measurement of the refractory period during atrial fibrillation. Circulation. $2001 ; 104: 957-62$

6. Y Blaauw, IC Van Gelder, HJGM Crijns: Treatment of atrial fibril lation. Heart. 2002;88:432-7

7. Y Blacuw, N Beier, P van der Voort, A van Hunnik, MA Allessie: Inhibitors of the $\mathrm{Na} / \mathrm{H}$-exchanger cannot prevent atrial electrical remodeling in the goat. It Cardiovasc Electrophysiol. 2004 Apr; 15(4):440-6.

8. Z Shan, PH Van Der Voort, Y Blaauw, M Duytschaever, MA Allessie: Fractionation of electrograms and linking of activation during pharmacologic cardioversion of persistent atrial fibrillation in the goat. J Cardiovasc Electrophysiol. 2004 Apr; $15(4): 440-6$ 
9. U Schotten, S de Haan, HR Neuberger, S Eijsbouts, Y Blaauw, RG Tieleman, MA Allessie: Loss of atrial contractility is primary cause of atrial dilatation during first days of atrial fibrillation. Am J Physiol Heart Circ Physiol. 2004 Nov; $287(5): H 2324-31$

10. Y Blaauw, H Goegelein, RG Tieleman, A van Hunnik, U Schotten, and MA Allessie: Early' Class lil Drugs for the Treatment of Atrial Fibrillation: Efficacy and Atrial Selectivity of AVE0118 in Remodeled Atria of the Goat. Circulation. 2004 Sep 28;110(13):1717-24

11.S Eijsbouts, R Houben, Y Blaauw, U Schotten MA Allessie: Synergistic Action of Atrial Dilatation and Flecainide on Conduction in Rabbit Atria. J Cardiovase Electrophysiol. 2004 Dec;15(12):1453-61.

12. HR Neuberger, U Schotten, S Eiisbouts, Y Blaauw, A van Hunnik, MA. Allessie: Development of a Substrate of Atrial Fibrillation during Chronic Atrial Dilatation in the Goat. Circulation. 2005 Jan 4;111(1):30-7.

13. D Vollmann, Y Blaauw, HR Neuberger, U Schotten, M Allessie: Long-Term Changes in Sequence of Atrial Activation and Refractory Period: No Evidence for 'Atrial Memory' in the Goat. Heart Rhythm. 2005; 2: 155-161

14. M Duytschaever, Y Blaauw, MA Allessie: Consequences of Atrial Electrical Remodeling for the Action of Class IC and Class III Drugs. Cardiovascular Research 2005

\section{BOOK CHAPTERS}

1. YBlaauw, U Schotten, MA Allessie. Animal models of atrial fibrillation: what clinical lessons have we learned? In: Naccarelli and Kowey (eds): Atrial fibrillation. Marcel Dekker, NY, 2004

2. U Schotten, Y Blaauw, MA Allessie. In-Vivo Models of Atrial Fibrillation. In: S Dhein, FW Mohr, M Delmar (eds): Practical Methods in Cardiovascular Research. Springer-Verlag, Berlin Heidelberg, 2005 